\title{
IUCN
}

Conserving wild plants in the south and east Mediterranean region 


\section{Conserving wild plants in the south and east Mediterranean region}

Editors: Marcos Valderrábano, Teresa Gil, Vernon Heywood and Bertrand de Montmollin 
The designation of geographical entities in this book, and the presentation of the material, do not imply the expression of any opinion whatsoever on the part of IUCN concerning the legal status of any country, territory, or area, or of its authorities, or concerning the delimitation of its frontiers or boundaries.

The views expressed in this publication do not necessarily reflect those of IUCN.

This publication has been made possible in part by funding from MAVA Foundation.

Published by: $\quad$ IUCN, Gland, Switzerland, and IUCN Centre for Mediterranean Cooperation, Málaga, Spain

Copyright: $\quad$ @ 2018 IUCN, International Union for Conservation of Nature and Natural Resources

Reproduction of this publication for educational or other noncommercial purposes is authorised without prior written permission from the copyright holder provided the source is fully acknowledged.

Reproduction of this publication for resale or other commercial purposes is prohibited without prior written permission of the copyright holder.

Citation: Valderrábano, M., Gil, T., Heywood, V., and de Montmollin, B. (eds.) (2018). Conserving wild plants in the south and east Mediterranean region. Gland, Switzerland and Málaga, Spain: IUCN. xiii +146 pp.

ISBN: $\quad$ 978-2-8317-1942-9 (PDF)

978-2-8317-1943-6 (print)

DOI: $\quad$ https://doi.org/10.2305/IUCN.CH.2018.21.en

Cover photo: $\quad$ Tulipa sylvestris subsp. australis (c) Khellaf Rebbas

Layout by: $\quad$ Factor $\tilde{\mathrm{N}}$

Proofreading by: Christopher Tribe

Printed by: $\quad$ Solprint

Available from: $\quad$ Centre for Mediterranean Cooperation of IUCN

c/Marie Curie 22

29590 Campanillas

Malaga, Spain

www.iucn.org/mediterranean

www.iucn.org/resources/publications

The text of this book is printed on Cycle Paper 100/300 gsm made from

FSC Recycled Certified paper (wood fibre from well-managed forests certified in accordance with the rules of the Forest Stewardship Council (FSC)). 


\section{Contents}

Contributors

Foreword vii

Executive summary ix

Chapter structure $\quad x i$

Concluding messages xii

Clarifications xiii

1. State of knowledge of the south and east Mediterranean flora 1

1.1 Introduction 2

1.2. Floras of the south and east Mediterranean 2

1.3. State of knowledge and main gaps by country 6

Morocco 6

$\begin{array}{ll}\text { Algeria } & 8\end{array}$

Tunisia 11

Libya $\quad 12$

Egypt 13

Palestine 15

Lebanon 16

Syria 18

1.4. Conclusions and recommendations 20

2. Status of threatened flora 21

2.1 Introduction $\quad 22$

2.2. IUCN Red List of threatened plant species 23

2.3 Red Lists and threats by country 24

Morocco $\quad 24$

$\begin{array}{ll}\text { Algeria } & 25\end{array}$

Tunisia $\quad 28$

Libya $\quad 29$

$\begin{array}{ll}\text { Egypt } & 30\end{array}$

Palestine $\quad 32$

Lebanon $\quad 33$

Syria $\quad 35$

2.4 State of knowledge of the extinction risk for plant species 37

2.5. Main threats to plants in the south and east Mediterranean 38

2.6. Conclusions and recommendations 38 
3. Key Biodiversity Areas (KBAs) for plants

in the Mediterranean region 39

3.1 Introduction 40

3.2 KBAs for plants in the south and east Mediterranean 43

3.3 KBAs for plants by country 45

Morocco $\quad 45$

Algeria $\quad 53$

$\begin{array}{ll}\text { Tunisia } & 61\end{array}$

Libya $\quad 65$

$\begin{array}{ll}\text { Egypt } & 67\end{array}$

$\begin{array}{ll}\text { Palestine } & 73\end{array}$

$\begin{array}{ll}\text { Lebanon } & 77\end{array}$

Syria $\quad 85$

3.4 Conclusions and recommendations 92

4. Approaches to plant conservation in the south

and east Mediterranean 93

4.1. Introduction 94

4.2 Policy guidance $\quad 98$

4.3. In situ conservation at habitat level $\quad 100$

4.3.1. Protected areas $\quad 100$

4.3.2 Plant micro-reserves in the Mediterranean area $\quad 106$

4.4 In situ conservation at species/population level 108

4.5. Species reintroduction programmes 112

4.6 Genetic conservation of crop wild relatives 113

4.7 Ex situ conservation of Mediterranean vascular flora 115

4.8 Ancillary botanic garden $\quad 119$

4.9 Community and participatory approaches $\quad 120$

Participatory mapping of Lebanon $\quad 121$

Studying ecosystems with the involvement of local communities: A conservation programme case study in Morocco 122

Traditional protected patches of Mediterranean forests 123

4.10 Habitat restoration 123

4.11 Conclusions and recommendations 126

$\begin{array}{ll}\text { Way forward } & 127\end{array}$

Recommendations 128

Annexes 131

Annex 1: References 132

Annex 2: KBA criteria and thresholds $\quad 146$ 


\section{Contributors}

\section{Editors}

Valderrábano, M. (IUCN Centre for Mediterranean Cooperation), Gil, T. (IUCN Centre for Mediterranean Cooperation), Heywood, V. (University of Reading, International Association of Botanic Gardens and formerly IUCN), and Montmollin, B. de. (Mediterranean Plant Specialist Group - Species Survival Commission of IUCN).

\section{Authors (in alphabetical order):}

Abi Kheir, S., Abunnasr, Y., Al-Sheikh, B., Al-Zein, M., Bacchetta, G., Baydoun, S., Benhouhou, S., Bou Dagher, M., Bou Fakhreddine, S., Carruso, E., Chalak, L., Charbel, R., Cogoni, D., d'Ambrossio, U., Daoud-Bouattour, A., El Zein, H., Fenu, G., Fois, M., Forrest, A., Ghrabi, Z., Gil, T., Heywood, V., Itani, M., Kays, W., Kell, S., Laguna, E., Machaka-Houri, N., Magos, J., Malti, R., Martin, G., Marzo, A., Maxted, N., Miller, T., Montmollin, B. de., Omar, K., Perez, A., Porceddu, M., Rankou, H., Samaha, L., Sattout, E., Semaan, M., Shaltout, K., Stephan, J., Tahiqui, L., Talhouk, S., Tawk, L. Y., Valderrabano, M., Vela, E., Yahi, N., Yazbek, M., Youssef, S.

Suggested citation for specific sections, for example subsection 4.3.2:

Laguna, E. (2018). 'Plant micro reserves' In: M. Valderrábano, T. Gil, V. Heywood and B. de Montmollin (eds.) Conserving wild plants in the south and east Mediterranean region, pp. XX-YY. Gland, Switzerland: IUCN.

\section{Acknowledgements}

This publication has been made possible thanks to the financial support of the MAVA Foundation and the commitment of IUCN through its Species Survival Commission (Mediterranean Plant Specialist Group) and its Centre for Mediterranean Cooperation.

It could not have been produced without the dedication of more than 50 authors and dozens of other contributors. We thank all of them for their support.

This publication has been peer reviewed by Jesus Charco and Christopher Tracey. We are grateful to them and to the Publication Committee of IUCN for their suggestions and recommendations. 


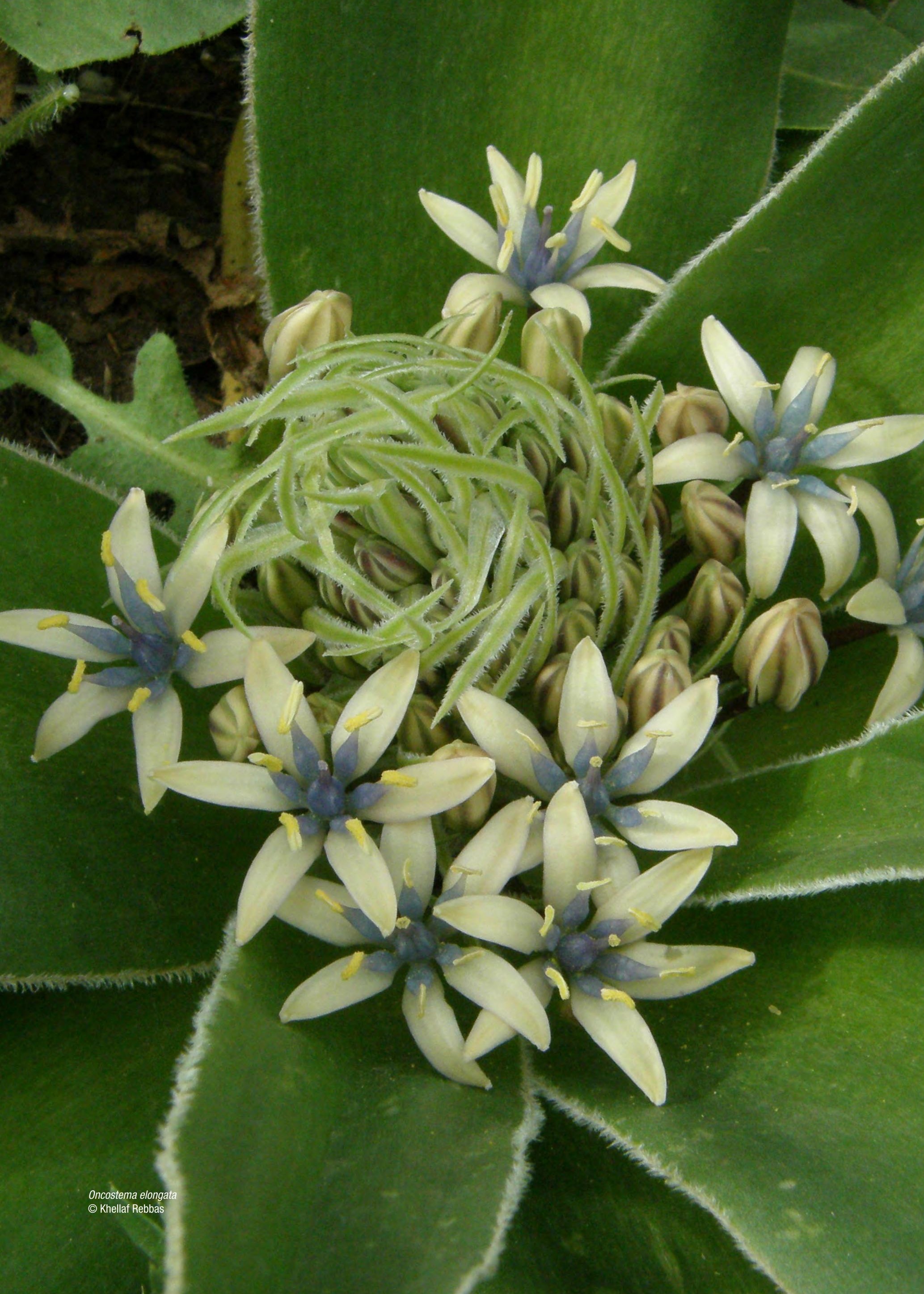


Foreword

The Mediterranean is a top global tourism destination that receives more than $\mathbf{3 0 0}$ million visitors per year. In contrast to the multiple attractions of the region, plant diversity is virtually unknown to the majority of tourist. This, despite that the Mediterranean is a hotspot for biodiversity primarily due to its remarkable botanical richness.

Plant conservation is often overlooked in conservation priorities, where the focus is frequently on more "iconic" organisms, such as birds, mammals or reptiles. As a consequence, dialogue between plant scientist, site managers, communities and civil society organizations in the Mediterranean tends to be fragmented. Furthermore, the lack of a consistent regulatory framework enhances the magnitude of the challenge. As the environmental agenda during the next decade will inevitably be linked to climate change impacts on species and habitats, there is a clear opportunity to integrate plant conservation into climate change policies through the Nationally Determined Contributions for the United Nations Framework Convention on Climate Change.

This publication is the first to gather existing scientific knowledge, practical examples and lessons learned for effective regional plant conservation. It would not have been possible without the collective effort of more than 50 authors, including botanist and conservation practitioners. This is a good example of the convening role of IUCN and its capacity to mobilize national experts, the IUCN secretariat and members of the Species Survival Commission.
The recommendations included here enable decision makers to integrate plant conservation priorities into broader conservation actions or initiatives. This will contribute, in turn, to meet national reporting needs and global commitments to the UN Sustainable Development Goals and the Aichi Targets of the Convention on Biological Diversity.

The identification of effective conservation priorities is critical when resources are limited. Integration of IUCN knowledge products offer a cost-effective and efficient opportunity to strengthen regional biodiversity spatial planning portfolios. Information from the IUCN Red List of Threatened Species and the World Database on Key Biodiversity Areas, was used in this publication to deliver critical analyses and guide the work of decision makers on behalf of Mediterranean plan conservation.

Botanical diversity not only sustains human wellbeing, but is also the foundation for the rest of biodiversity.

\section{Antonio Troya}

Director IUCN Centre for Mediterranean

Cooperation

\section{Jon Paul Rodriguez}

Chair of the IUCN Species Survival Commission 


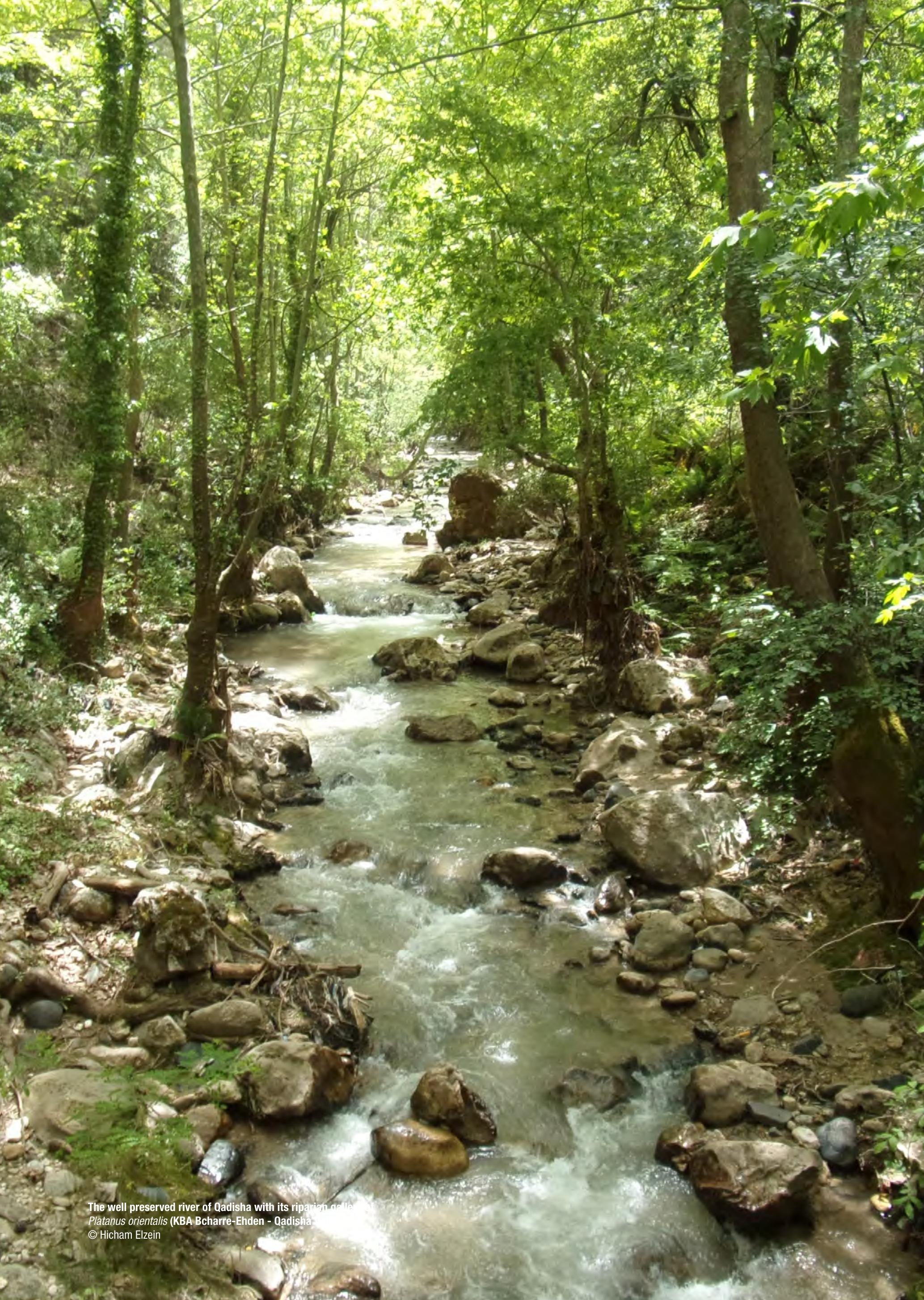




\section{Executive summary}

The Mediterranean region is one of the world's great centres of plant diversity and its benign climates have attracted successive waves of civilisations, which have largely shaped our attitudes and ethics to the present day. Despite the effects of grazing, agriculture, deforestation, pollution, urbanisation and tourism, it has developed a wide array of plant landscapes. It is also one of the cradles of agriculture and a centre of origin and diversification of many of our crop species. Nowhere else on this planet has humankind been so closely and intimately linked to the environment.

Plant diversity is essential for human survival and is the basis of all life on Earth. Through their unique ability to convert the sun's energy into a useable form, plants provide us with food, fuel, fibre, oil, herbs and medicines, as well as fodder for domestic animals. Plants also provide the background structure of most of our terrestrial ecosystems and habitats for animals and fungi. They also play a key role in providing ecosystem services, such as climate moderation, maintenance of the ozone layer, carbon storage, watershed protection and stabilisation of slopes against erosion.

Despite the undisputed importance of plantlife, conservation policies often neglect plant diversity in priority setting, and concrete strategies to ensure plant conservation are still insufficient to face the growing pressures. The reasons for this situation are complex, including not only sociological and political factors but also scientific and technical ones. Globally, most conservation biology research is undertaken on animal groups - notably birds and mammals - and ignores plants, and the same applies to conservation actions. Information on plants is often dispersed and fragmented, thus impeding rational decision making and priority setting.
The aim of this publication is to provide a snapshot of existing knowledge of plant diversity in the south and east Mediterranean, and to propose strategies and actions that can be taken to enhance plant conservation in the region.

Thanks to the joint efforts of more than 40 authors and dozens of contributors, it brings together in a single document an overview of existing knowledge on plant diversity, and provides concrete strategies for plant conservation, with local examples, that are applicable in the south and east Mediterranean region. It is aimed at helping conservation policy makers and a wide range of practitioners (such as land managers, non-governmental organisations, local communities and conservation agencies) to implement plant conservation programmes and initiatives in the region. It will also provide botanists, academics and amateurs with a rapid overview of plant knowledge in the area, as well as information on key resources and where to find them.

The publication also highlights gaps in current policies and action plans and makes recommendations for remedying these deficiencies.

\section{Context}

The Mediterranean Region hosts some 25,000 vascular plant species, half of which are endemic to the region (not found anywhere else in the world), which means that $6-7 \%$ of the world's higher plants can be found in an area equivalent to $1.6 \%$ of the Earth's surface. This high plant diversity has led to the recognition of the Mediterranean as a global hotspot for plant (and animal) diversity.

In the last two to three decades there has been a growing recognition of the importance of plant conservation. Global initiatives in this period include 


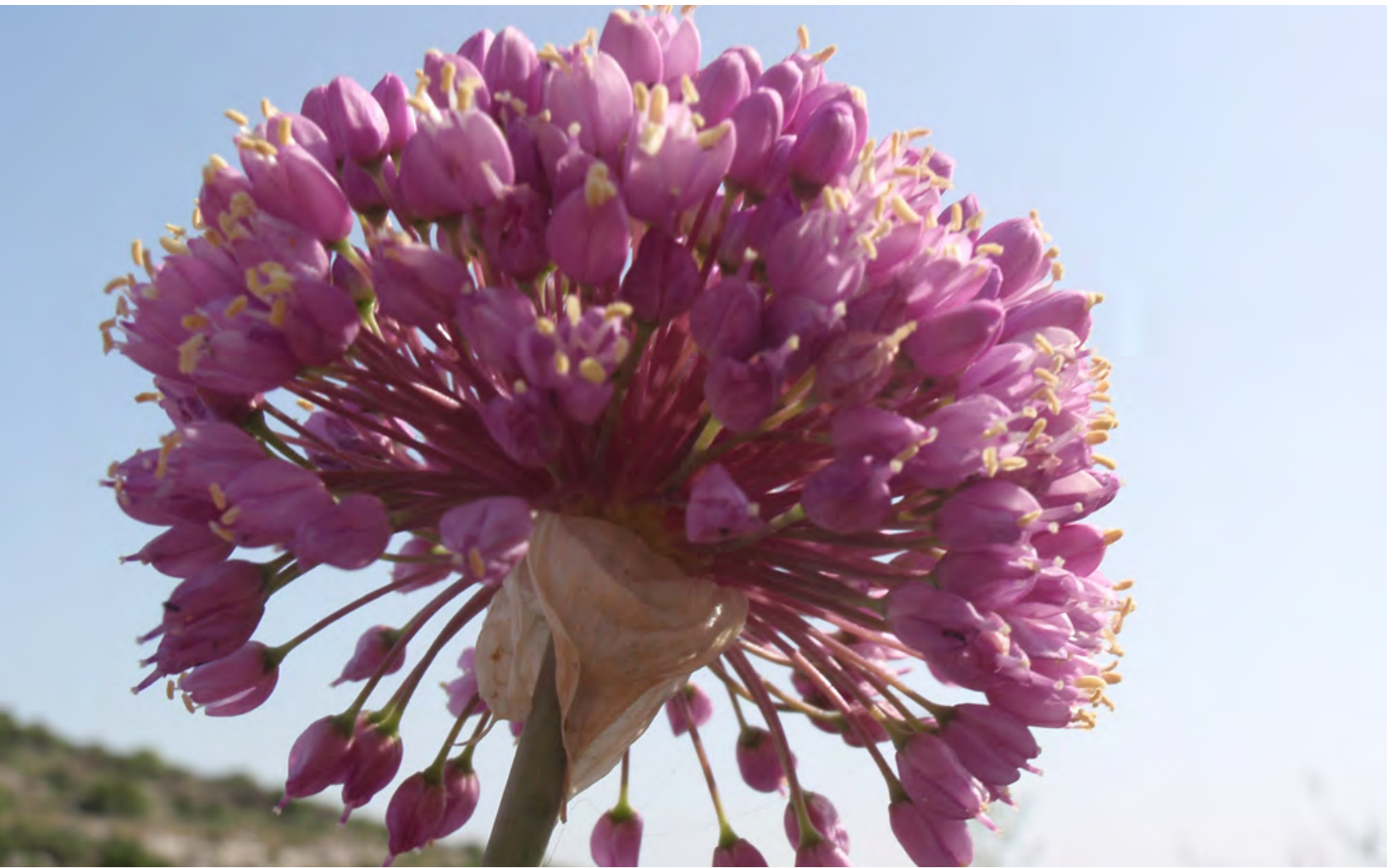

$\Delta$

Allium carmeli

Palestine

(c) Banan Al Sheikh

the development of intergovernmental agreements such as the CBD's Global Strategy for Plant Conservation, the International Plant Protection Convention (IPPC), and the FAO's Global Plan of Action for the Conservation and Sustainable Utilization of Plant Genetic Resources for Food and Agriculture; the recognition of the environmental impacts caused by Invasive Alien Species (IAS); the establishment of the IUCN Botanic Gardens Conservation Secretariat (later Botanic Gardens Conservation International); the identification of Centres of Plant Diversity and Global Hotspots; and the production of the State of the World's Plant Genetic Resources for Food and Agriculture, the Chiang Mai International Consultation and Declaration on medicinal plants (with the WHO) and the WHO, IUCN and WWF Guidelines on the Conservation of Medicinal Plants. In the Mediterranean area, plant conservation has also received growing attention in recent years from the United Nations, inter-governmental agencies and non-governmental organisations.

Despite the growing awareness and this array of international treaties and agreements, habitats continue to be lost or degraded and the risk of species extinction continues to grow. The human footprint on the environment is increasing and we are observing increasingly anthropised landscapes.
Within the Mediterranean region, the southern and eastern sectors face considerable challenges: the growing demands of very dynamic societies are changing the landscape at an unprecedented rate. The current status of many plant species remains largely unknown, and information is often fragmented across different national sources. In addition, conservation infrastructure and resources in the south and east lag behind those of the European part of the Mediterranean. The following questions therefore arise:

Where are endemic plant species located? What do we already know about plant species, their distribution, demography, genetic variation, threats and conservation status? And (perhaps more importantly) what actions or strategies are effective in achieving plant conservation? Are there any successful examples in the Mediterranean region?

A growing number of promising initiatives are in progress, among them, for example, the IPAMed project "Conserving Wild Plants and Habitats for People in the south and east Mediterranean", financed by the MAVA Foundation, which has provided several inspiring examples of plant conservation across the Mediterranean region that are referred to in various sections of this publication. Similar initiatives need to be introduced more widely across the region if sufficient progress is to be made in tackling the challenges of conserving such a rich and diverse flora and vegetation. 


\section{Chapter structure}

Chapter 1 comprises an assessment of what we know of wild plants in the south and east Mediterranean region; for each country or territory it describes the current state of botanical knowledge, identifies gaps that need to be addressed and highlights the actors or institutions involved.

Existing botanical knowledge is often ignored as a basis for developing conservation priorities and strategies, and so placing knowledge at the centre of planning remains a challenge.

The traditional conservation approach has been structured around two pillars: protected area networks and threatened species policies. This has been refined both by methodologies that support conservation planning, including gap analysis, identifcation of priority sites such as centres of diversity, hotspots and Key Biodiversity Areas, and national and global red listing to support species conservation priorities; and by the development of practical conservation methods such as species recovery, reintroduction and ecological restoration.

The IUCN Red List of Threatened Species is the most complete global inventory of species risk assessments. It uses a series of objective criteria to evaluate their risk of extinction. Together with national red lists, it is explored in depth in Chapter 2. The information contained in both the global and the national red lists of threatened species is a valuable resource for determining the main threats facing many Mediterranean plant species. It should be noted, however, that for successful species conservation and recovery a more detailed threat assessment is normally needed.

Key Biodiversity Areas (KBAs) are sites that contribute to the persistence of globally important biodiversity. Objective criteria are used to identify sites of global importance for multiple taxa. Chapter 3 compiles the latest information on the subset of KBAs that have been identified for plants.

Chapter 4 explores concrete examples of conservation actions designed to address the threats described in chapters 2 and 3 . This final chapter provides an account of proven approaches to plant conservation at different levels, including

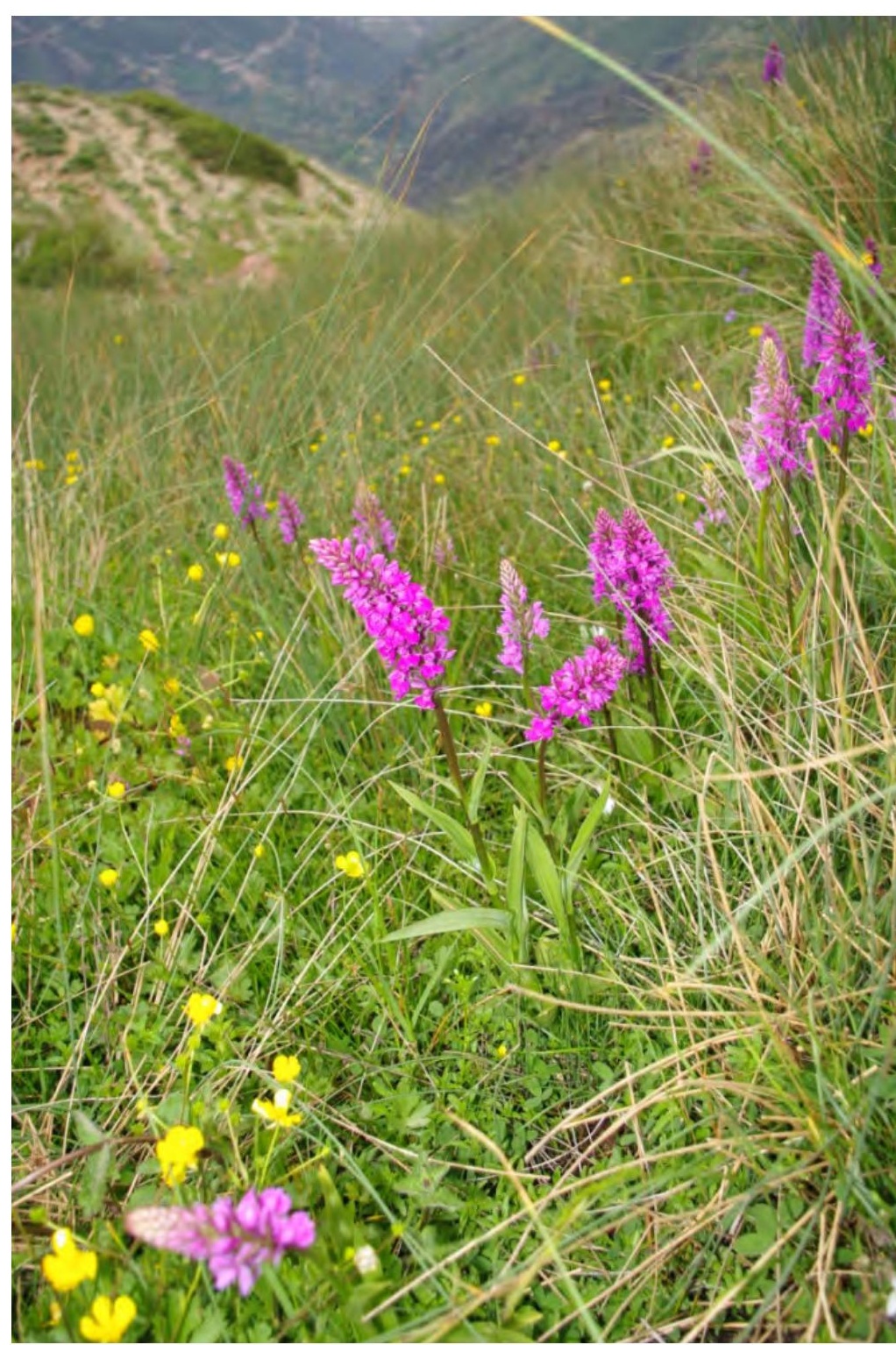

$\Delta$

Dactylorhiza battandieri Djurdjura KBA, Algeria (c) Khellaf Rebbas

strategies and policies, illustrated with specific cases from the region.

The objective of this publication is by no means to be exhaustive, but rather to provide a useful framework. Persons or institutions willing to get involved in plant conservation in the south and east Mediterranean region will find numerous links and references to more detailed sources of information and other resources. 


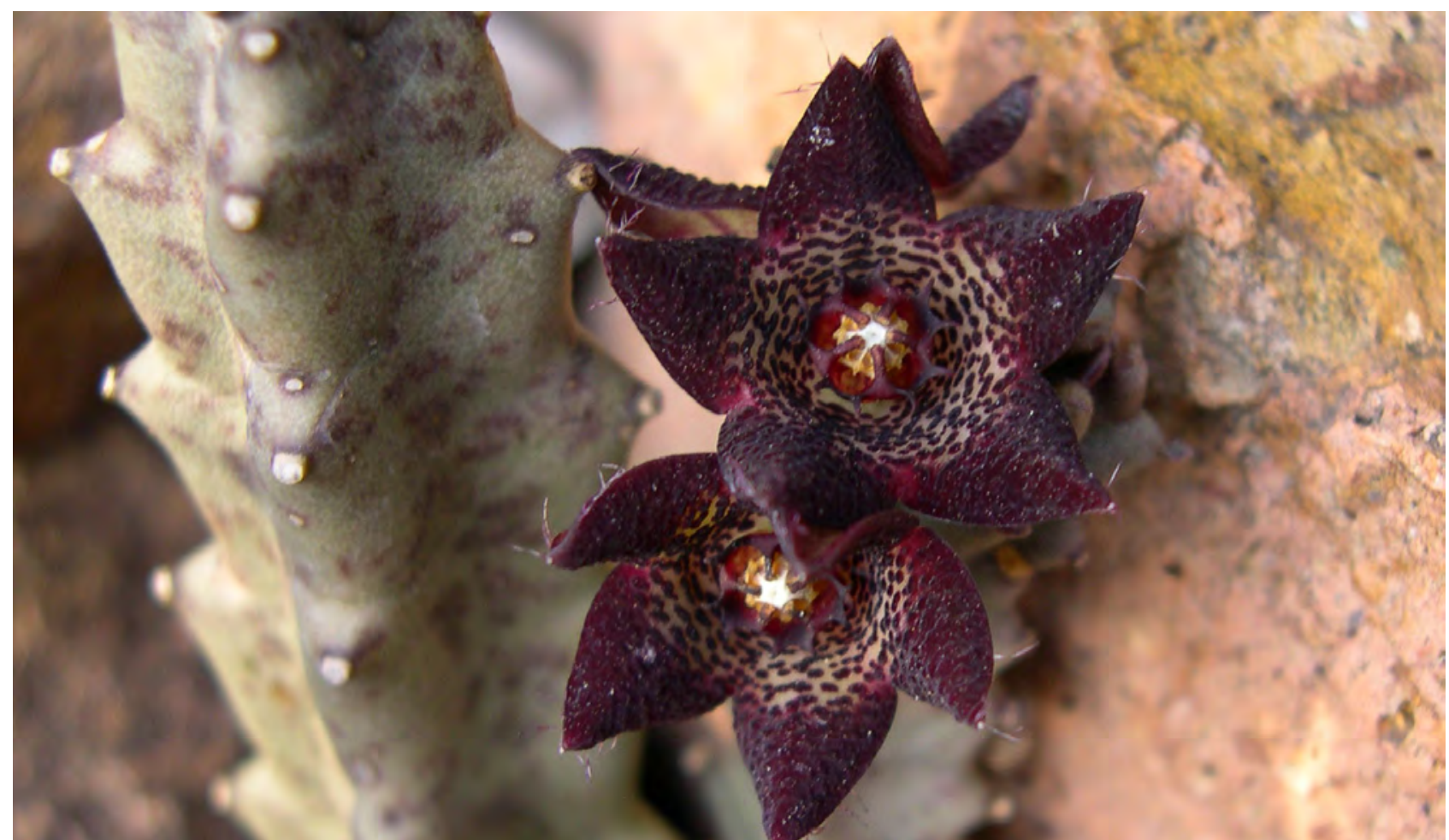

\section{$\Delta$}

Apteranthes joannis. Morocco.

(c) Sébastien Sant / www.teline.fr

\section{Concluding messages}

1. In order to halt and reverse the continuous decline of plant diversity, specific action plans and programmes addressing particular plant conservation challenges must be incorporated in regional and national conservation programmes and strategies.

2. Enhanced cooperation between botanists, practitioners and communities is essential for effective and successful plant conservation programmes.

3. The Red List of Threatened Species and Key Biodiversity Areas are useful sources of information for global, regional and national priority setting, and need to be regularly added to and updated.

4. Despite advances in planning, action on the ground is still too limited to be effective in slowing the rate of loss of threatened species and habitats; it is therefore urgent to move on from the planning phase to the implementation phase.

5. Suggested actions to achieve conservation implementation are:

- Reinforce national Protected Area systems, ensure their effective management and include the conservation of threatened plant diversity in their management plans.

- Explore and apply, where feasible, the various schemes for the conservation of species that occur outside protected areas, such as conservation easements and plant microreserves.

- Recognise the importance of other areabased conservation measures (OECMs), and community/participatory conservation.

- Encourage community involvement and participatory approaches as essential factors in successful plant conservation.

- Devise national ecological habitat restoration programmes that combine restoration techniques with the integration of human activities within the landscape.

- Recognise the importance of conserving genetic diversity as a key element in species conservation, recovery and reintroduction programmes. Ensure the genetic conservation of species of economic importance - notably wild crop relatives and medicinal and aromatic plants - by a diversity of means, including ex situ conservation in gene banks, botanic gardens, ancillary botanic gardens and targeted in situ approaches. 


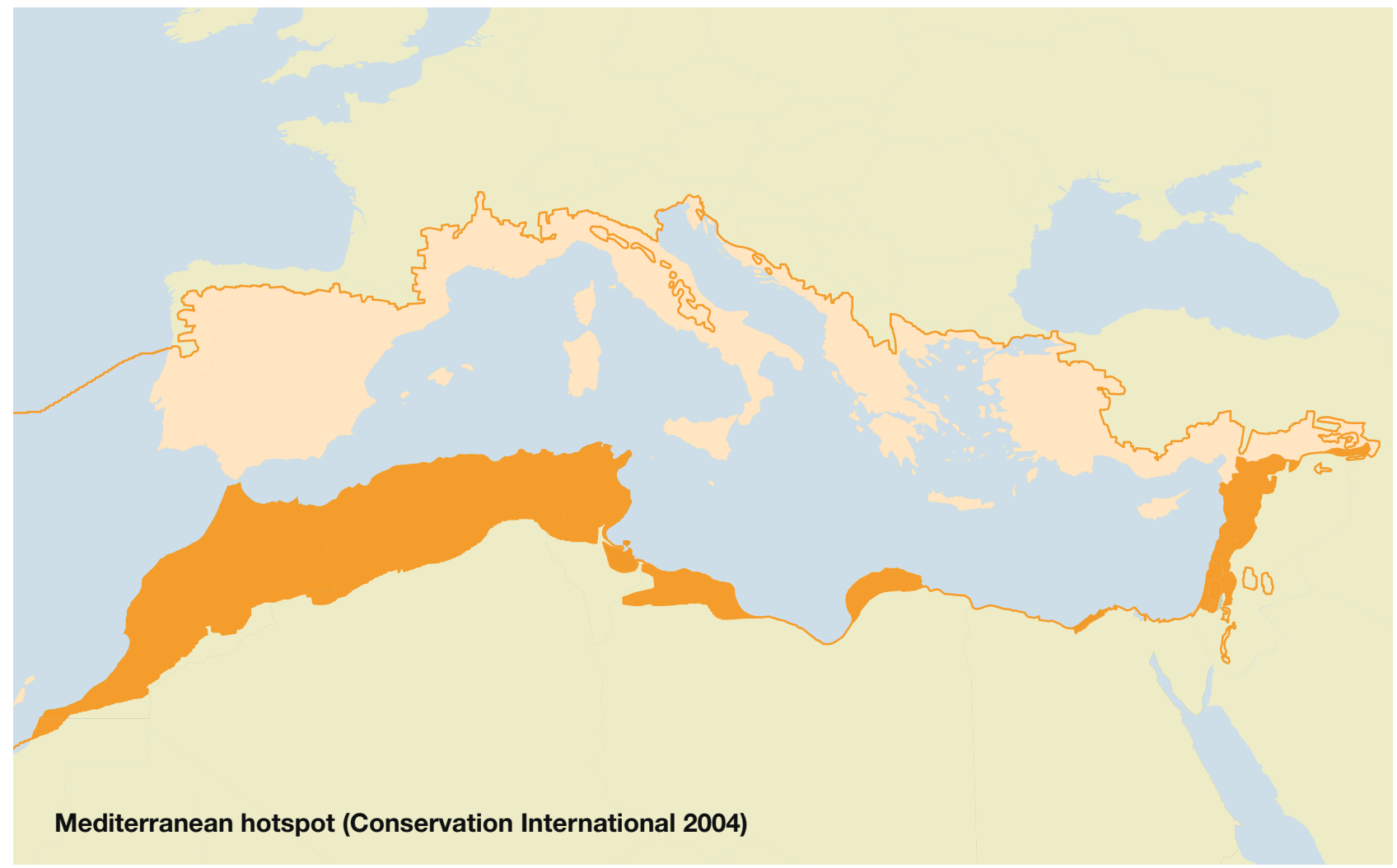

\section{Clarifications}

Taxonomy and nomenclature are often a minefield. In this publication we have used The Plant List as our main taxonomic and nomenclatural reference except where better information is available. For ease of reading, the authors of scientific names have been omitted in the main text but are given in the tables.

The territorial scope of this publication is limited to the Mediterranean area of target countries or territories, using the definition of 'Mediterranean' proposed by the Conservation International Foundation (Mittermeier et al., 2004). A few countries and territories in the eastern Mediterranean are excluded from this analysis, namely Jordan, Israel and Turkey. Thus the countries and territories included are Morocco, Algeria, Tunisia, Libya, Egypt, Palestine, Lebanon and Syria.

The designation of geographical entities in this book, and the presentation of the material, do not imply the expression of any opinion whatsoever on the part of IUCN concerning the legal status of any country, territory, or area, or of its authorities, or concerning the delimitation of its frontiers or boundaries.

For simplicity, the Occupied Palestinian Territories are referred to in the text as Palestine. 


\subsection{Introduction}

Implementing conservation actions requires an in-depth understanding of the flora - not only its taxonomy and phylogenetics, but also its historical and current distribution in the region in question, as well as its ecology, genetic variation and demography. All this data is essential for determining the degree of threat faced by each taxon and thus establishing priorities for conservation (see Chapter 2: Status of endangered flora).

The objective of this chapter is to review the current state of knowledge of the flora, country by country, and to offer suggestions for improving and updating this knowledge.

\subsection{Floras of the south and east Mediterranean}

\section{The flora of the Mediterranean}

With close to 25,000 species of vascular plants, half of which are not found anywhere else in the world (Quézel \& Médail, 1995; Heywood, 1998; Greuter, 1991), the Mediterranean Basin is one of the world's top 35 biodiversity hotspots. It is actually the third most important hotspot for floristic diversity and endemism (Mittermeier et al., 2004; Blondel et al., 2010; Heywood, 2002) and the leading hotspot for agrobiodiversity of traditional crop varieties and crop wild relatives. Of the 234 global sites recognised in the WWF/IUCN Centres of Plant Diversity (Davis et al., 1994), 20 occur in the Mediterranean region. Also of the global centres of crop diversity recognized by Vavilov (1926), two abutting centres the Mediterranean and Asia Minor centres are located in the south and east Mediterranean. On a slightly different scale, an analysis by Médail and Quézel (1997, 1999) identifies 10 sectors or 'red alert' areas in the Mediterranean and Macaronesia, including the High and Middle Atlas Mountains, the Baetic-Rifan

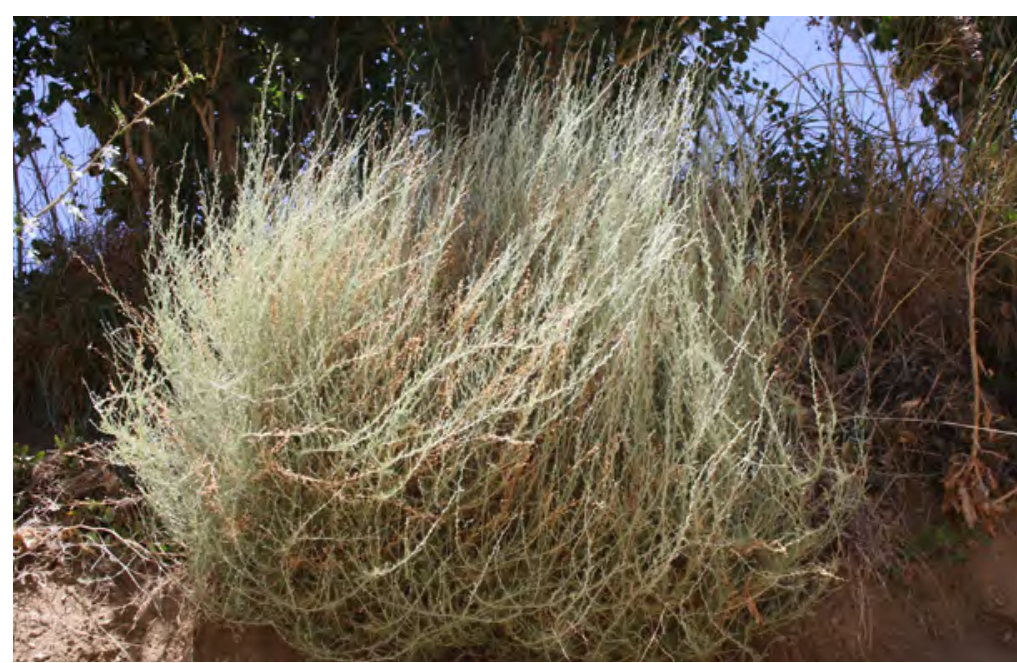

\section{$\Delta$}

Artemisia negre

Eastern High Atlas National Park and KBA

(C) Mohamed Sghir Taleb

complex, Anatolia and Cyprus, the Syria-LebanonIsrael area, and the Cyrenaican Mediterranean.

The Mediterranean is one of the regions that has been most thoroughly explored and described by botanists for hundreds of years, or even thousands if we count Theophrastus, who is regarded as the first Mediterranean botanist, or at least the first to appear in written records (Amigues, 2010).

No Flora Mediterranea - i.e. an exhaustive record of the flora of the Mediterranean region, with identification keys and distribution maps for taxahas yet been produced or is in preparation.

The only modern work that covers the whole of the Mediterranean region is the Med-Checklist (Greuter et al., 1984-2008), which is a synonymic catalogue of vascular plants occurring naturally in the countries bordering the Mediterranean Sea. However, it does not include identification keys for taxa and only four of the planned six volumes have been published. 


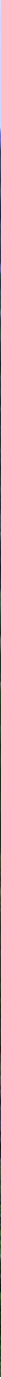

$\Delta$

Forest of Pinus pinaster with Taxus baccata (c) Emilio Laguna

The majority of the information in the Med-Checklist, as well as that in the Flora Europaea (which covers the European part of the Mediterranean) can be consulted online via the Euro+Med PlantBase which has now been completed and includes a comprehensive listing of the flora of the whole Mediterraanean region (www.emplantbase.org).

Online databases (The Plant List - www.theplantlist. org) and networks of observers that share information (Tela Botanica - www.tela-botanica.org) are commonly used methods to keep information up to date.

\section{The flora of North Africa}

A single Flora covering all of North Africa has been published, namely the Flore de l'Afrique du Nord by René Maire, which covers the area from Morocco to Libya (Maire, 1952-1987), with 16 of the 20 planned volumes having been published.
A complete taxonomy reference for all of North Africa has recently been published, entitled Index synonymique de la flore d'Afrique du Nord (Dobignard \& Chatelain, 2010-2013).

A review of all the trees and shrubs of North Africa, updated in 2018, is available at www. northafricatrees.org This online database is based on Guía de los árboles y arbustos del Norte de África (Charco, 2001).

\section{The flora of the Middle East}

The progress of taxonomic and biogeographic knowledge of the Near East flora is currently slow on the one hand because of a lack of interest and resources for taxonomy and on the other hand because of political instability and conflict in the region.

The most complete studies for most of the countries date from 1930-1980, starting with Flora of Syria by Post (1932-1933), then with Flora Palaestina (Zohary, 1966 - 1986) and the Nouvelle flore $d u$ Liban et de la Syrie (Mouterde, 1966 - 1983), but significant additions have been made more 

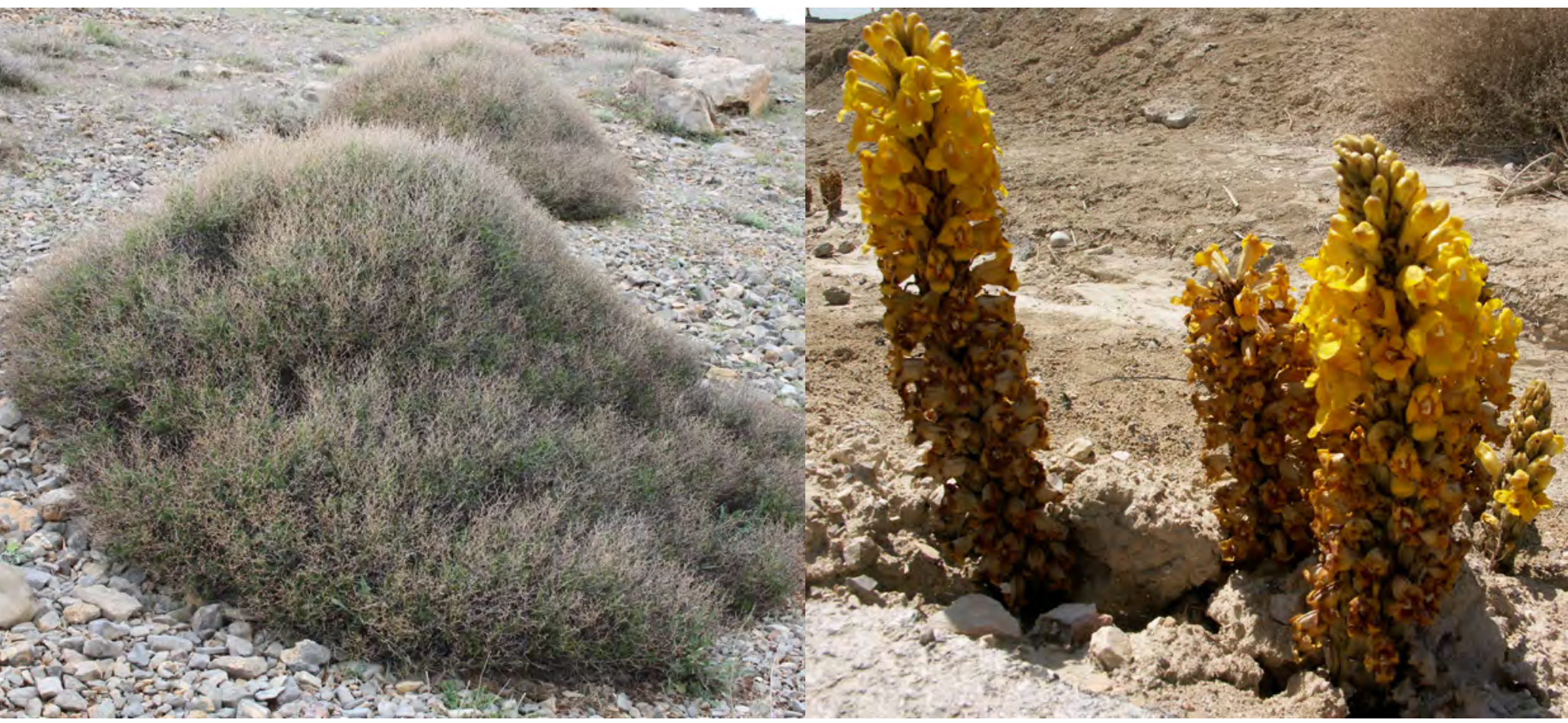

$\Delta$

Artemisia flahaultii

Endemic plant species of in Bou Naceur KBA (C) Mohamed Sghir Taleb

recently, particularly in Egypt and Lebanon. Turkey is fortunate to have attracted extensive recent taxonomic studies that complement Davis's Flora of Turkey (Davis, 1965-1988) such as the supplementary volume of the Flora, the Check Lists of the Flora of Turkey (Türkiye Bitkileri Listesi) (Güner et al., 2012; Erdağ \& Kürschner, 2017) and the new Illustrated Flora of Turkey Resimli Türkiye Florasi (Güner, 2014, 2018).

Lebanese botanists have been particularly active in publishing taxonomic reviews of the flora of their country. An online database http://www.lebanon-flora.org gathering the efforts of a participatory approach to screen plants is developed and updated regularly.

\section{The Fertile Crescent}

Within the south and east Mediterranean region, the Fertile Crescent is the area globally that has made the largest contribution to agricultural development and which today still underpins global food security and human well-being. The Fertile Crescent is a crescent-shaped region of comparatively moist and fertile, mountainous land with major rivers (i.e. Tigris and Euphrates) and marshland that loops around the west, north and east of the Syrian desert (Breasted, 1916). The precise extent of the Fertile Crescent appears ill-defined but most authors favour a more restricted region of an arc of agricultural diversity that encompasses parts of
Cistanche tubulosa

(c) Banan Al Sheikh

Northern Jordan and Palestine, Lebanon, West Syria, south east Turkey, Caucasus and North West Iraq and West Iran.

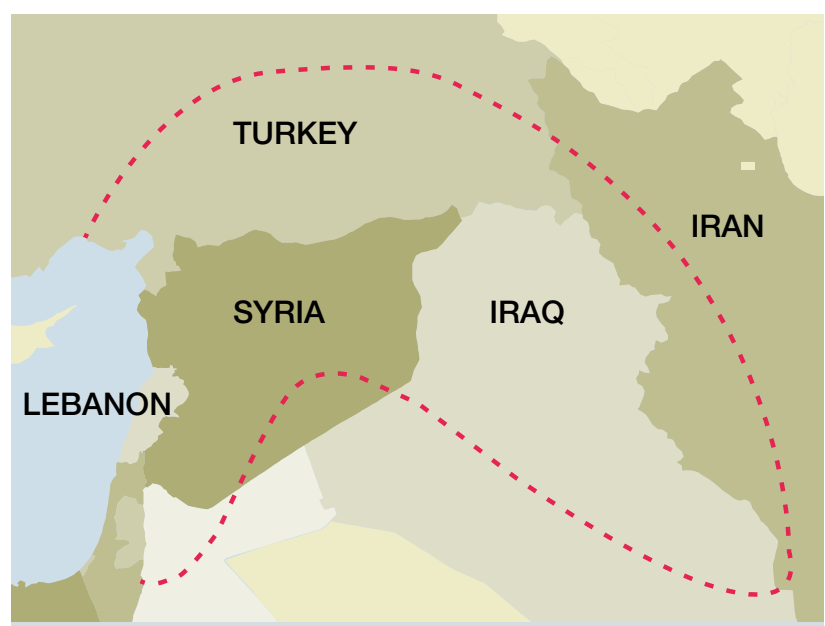

Mediterranean

Wheat, oat, grasspea, lupine, clover, flax, brassicas, olive, beet, lettuce, asparagus, faba bean, celery, parsnip, thyme, sage, hop, etc.

Asian Minor

Wheat, barley, oat, chickpea, lentil, lupine, alfalfa, clover, vetch, fig, pomegranate, apple, pear, etc.

\section{$\Delta$}

Map showing the location of the Fertile Crescent; and examples of crop diversity in the Mediterranean and Asian Minor Vavilov centres of crop origin (adapted from Magos Brehm et al., 2016) 


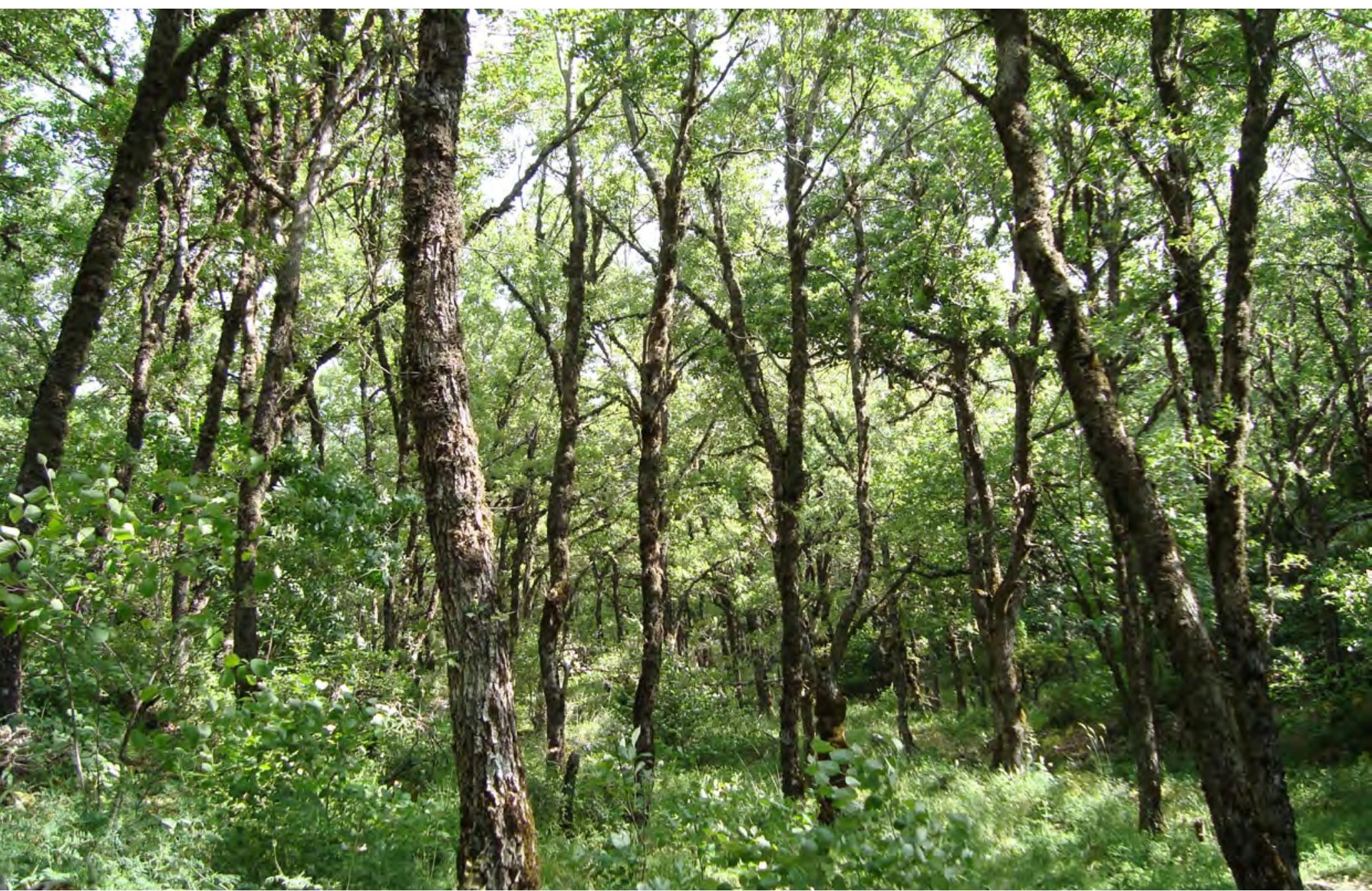

$\Delta$

Quercus cerris pseudocerris in Abu-Qbeis KBA

(c) Aroub Almasri

The Fertile Crescent is well established as the cradle of agriculture origin, both being a historic centre of agricultural development and a current centre of crop and crop wild relative (CWR) diversity. The Near East centre was the earliest centre of plant domestication and generated the largest and most economically important group of crop plants (Harlan, 1998).

The Fertile Crescent is also the region where two Vavilov centres of crop origin abut (Vavilov 1926). The Asia Minor Centre includes the Transcaucasia, Iran and Turkmenistan and is rich in crop gene pool diversity of: wheats (Triticum monococcum, T. durum, T. turgidum and T. aestivum), rye (Secale cereale and S. montanum), oat (Avena byzantina and $A$. sativa), chickpea (Cicer arietinum), lentil (Lens culinaris and L. orientalis), bitter vetch (Vicia ervilia), pea (Pisum sativum), and various forages (Medicago sativa, Trifolium resupinatum, Trigonella foenum-graecum, Onobrychis spp., Lathyrus cicera, and several Vicia spp.), oil-producing plants (Sesamum, Linum, Brassica, Camelina, Eruca spp.), melons (various Cucumis and Cucurbita spp.), vegetables (Lepidium, Brassica, Daucus, Eruca, Allium, Petroselinum, Lactuca, and Portulaca spp.), fruit crops (Malus, Pyrus, Punica, Ficus, Cydonia, Cerasus, Amygdalus, Vitis, Pistacia) and dye plants (Crocus sativus and Rubia tinctorum). While the Mediterranean Centre of Origin stretches around the Mediterranean Sea and also contains some of the crop gene pools of Asia Minor as well as some additional crops (Vicia faba, Lathyrus ochrus, Vicia sativa, Hedysarum coronarium, Ornithopus sativus, Olea europaea, Ceratonia siliqua, Beta vulgaris, Brassica oleracea, B. rapa and B. napus, Portulaca oleracea, Allium, Asparagus, Lactuca, Pastinaca, and Tragopogon spp.). As such the Fertile Crescent is the most important centre for global food security (Vincent et al. 2013).

Although the number of crop landraces that are still cultivated in the Fertile Crescent is unknown we do know that it has a flora of 2,623 species of which 2500 are CWR taxa and these represent 484 genera from 100 families. 


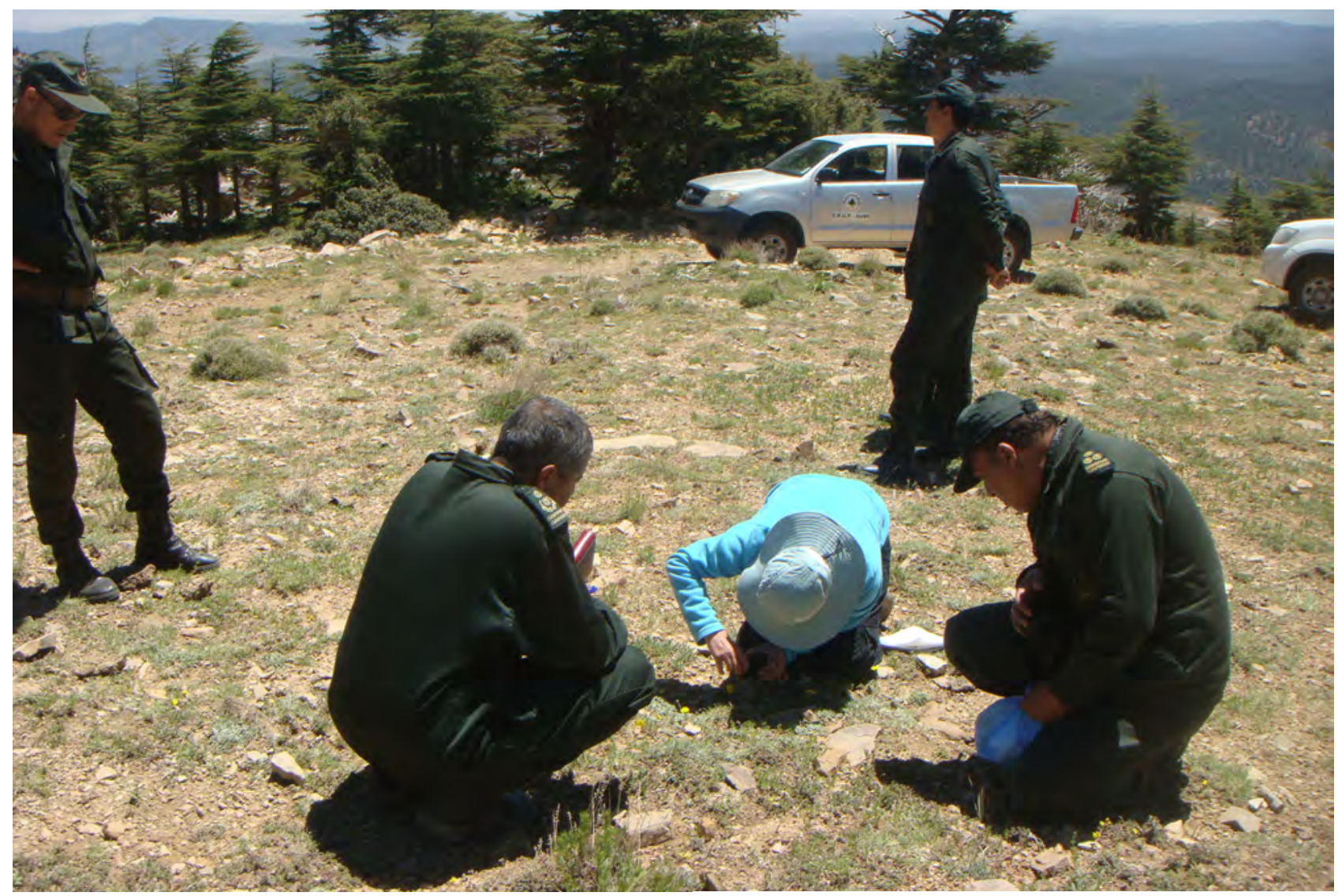

\subsection{State of knowledge and main gaps by country}

\section{MOROCCO}

\section{Author: Hassan Rankou}

Global Diversity Foundation, Marrakech - Royal Botanic Gardens Kew)

\section{State of knowledge}

The most recent reference material on the flora of Morocco is the Flore pratique du Maroc (Fennane et al., 1999-2014). Other recent volumes addressing or concerning the flora of Morocco are the Catalogue des plantes vasculaires rares, menacées ou endémiques du Maroc (Fennane \& Ibn Tattou, 1998), La Flore vasculaire du Maroc : inventaire et chorologie (Fennane \& Ibn Tattou, 2005) and The endemic flora of Morocco (Rankou et al., 2013).

There is no specific database that comprehensively covers the flora of the whole country, but regional databases are available - http://herbaria.plants. ox.ac.uk/bol/floraofmorocco/Explore.

At a subnational level, mention should be made of the Catalogue des plantes vasculaires du nord du Maroc incluant des clés d'identification. (Valdès et al., 2002).
$\Delta$

Botanist and ranger during field survey in Aures Chelia KBA (C) Khellaf Rebbas

The Index synonymique de la flore d'Afrique $d u$ Nord (Dobignard \& Chatelain, 2010-2013) covers the Moroccan flora.

Other regional floras or species checklists of Key Biodiversity Areas have been published or are in preparation, such us: The vascular flora of Oukaïmeden (Jury et al., 2008); Floristic diversity, composition and richness of Imegdale, a Key Biodiversity Area in the Mediterranean (Rankou et al., in prep.).

\section{Gaps}

The taxonomic coverage of the Moroccan flora is not homogeneous. The best-studied regions are primarily the High Atlas, Middle Atlas, Central Morocco, Rif and Anti-Atlas. Fewer studies have focused on the rest of the country, including MidAtlantic Morocco, Northern Atlantic Morocco, Saharan Morocco, the Mediterranean Coast, Plains and Plateaux of Eastern Morocco, High Plateaux, Mountains of Eastern Morocco and Saharan Atlas.

Generally speaking, the regions with the least remarkable biodiversity are not as well known as the 'hotspots', mainly because of the shortage of resources, experts and projects. 


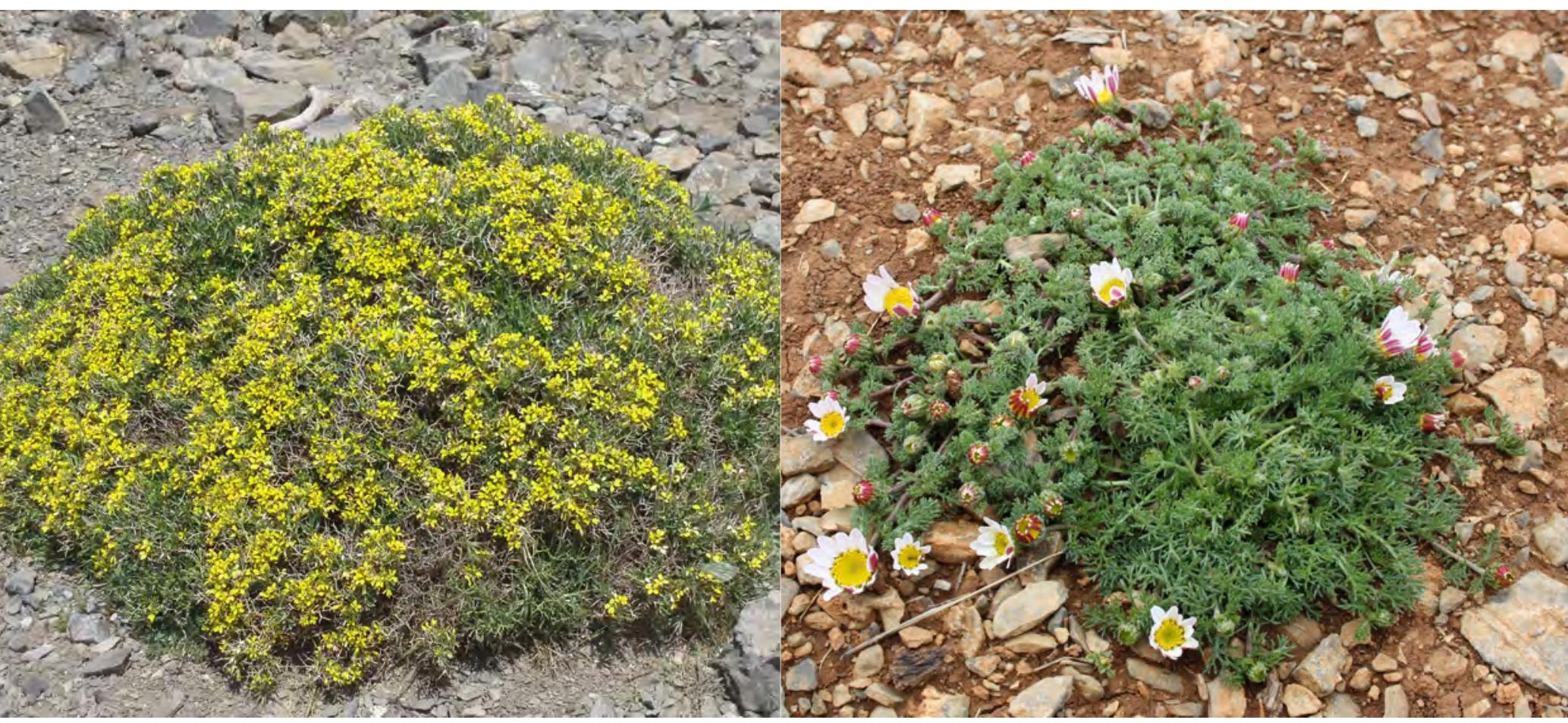

\section{$\Delta$}

Vella mairei

Bou, Morocco

C) Mohamed Sghir Taleb

Our knowledge of the precise distribution of the flora, particularly today, is insufficient. Most existing reference material gives merely a general distribution relating to a taxon's occurrence in one of the floral regions of Morocco. The main actions required to fill these gaps are intensive fieldwork in all parts of the country and the development of community and regional herbaria.

\section{Botanical institutions, associations and societies}

The institution primarily responsible for dealing with taxonomy and the distribution of species is the Institut Scientifique de Rabat.

Some amateur botanical associations exist in Morocco, specifically the Moroccan Biodiversity and Livelihood Association (MBLA) and the Global Diversity Foundation (GDF), which both work in coordination with the focal point for the Convention on Biological Diversity (CBD). A subgroup of the IUCN Species Survival Commission is currently being created: the Moroccan Plant and Livelihoods Specialist Group.

Multiple foreign institutions are active in the field of Moroccan taxonomy, specifically: Reading University (RNG), Conservatoire et Jardin botaniques de Genève (G), Université de Montpellier (MPU), Museu de l'Institut Botànic de Barcelona,
$\Delta$

Anacyclus pyrethrum

Bou, Morocco

(C) Mohamed Sghir Taleb

Muséum national d'histoire naturelle de Paris $(\mathrm{P})$, Royal Botanic Gardens, Kew (K), Natural History Museum, London (BM), Centro Conservazione Biodiversità (CCB) and Banca del Germoplasma della Sardegna (BG-SAR).

It is a challenge to encourage young botanists, since the younger generation does not find this field very attractive. Their awareness of the subject needs to be raised through other areas, such as conservation, ecology, climate change, etc.

\section{Recommendations to improve knowledge}

- Energise the official institutions responsible for the flora.

- Improve and deepen collaboration.

- Increase and diversify financial resources.

- Intensify fieldwork.

- Understand and include the needs of local communities.

- Invest in and consolidate a new generation of botanists. 


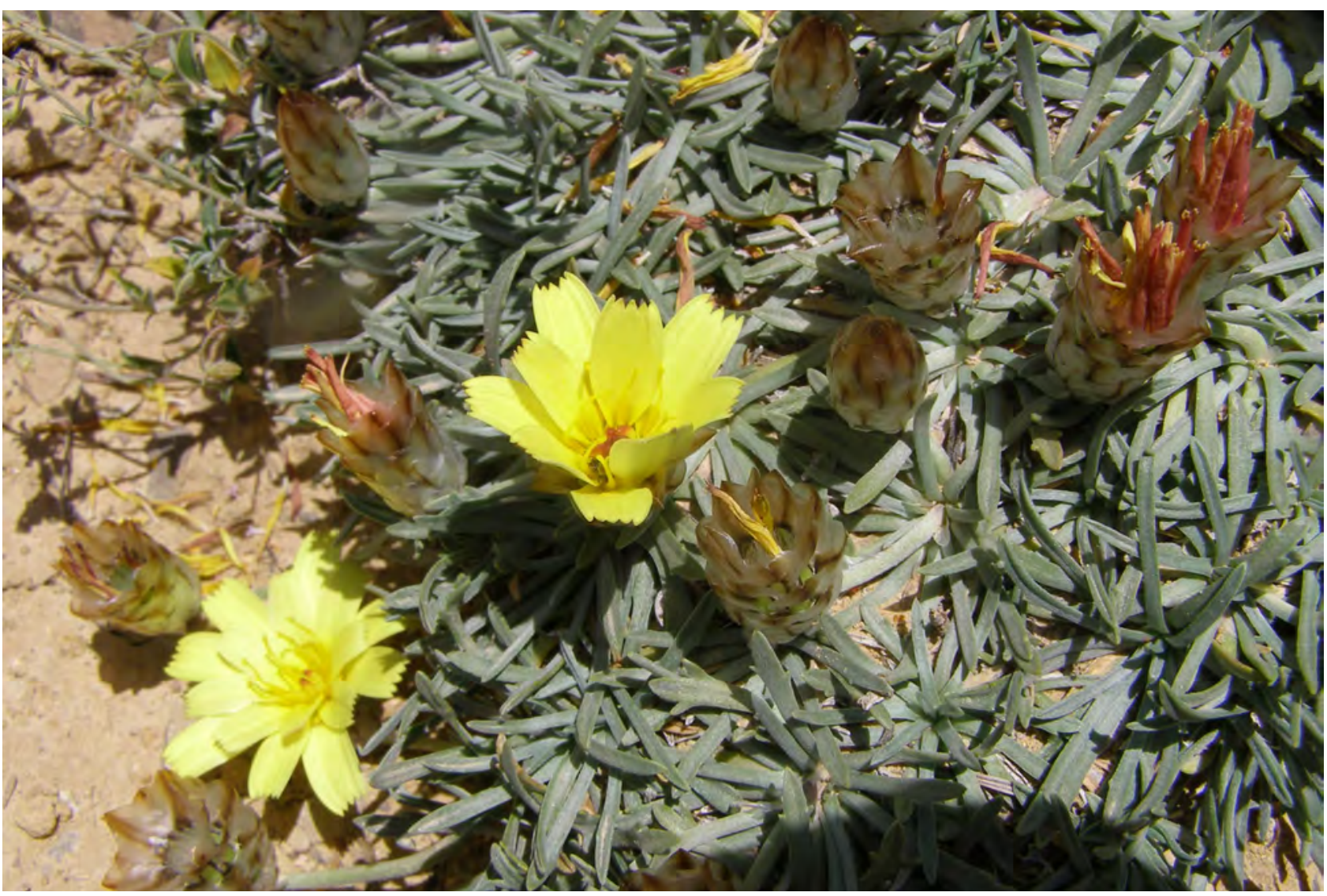

\section{ALGERIA}

Authors:

\section{Salima Benhouhou}

Ecole Nationale Supérieure d'Agronomie, El Harrach Nassima Yahi

Université des Sciences et de la Technologie Houari

Boumediene, Bab Ezzouar

\section{Errol Véla}

Université de Montpellier

\section{Contributor: Nabil Benghanem}

Université Mouloud Mammeri, Tizi-Ouzou

\section{State of knowledge}

The most widely used reference work for the flora of Algeria is the Nouvelle flore de l'Algérie et des régions désertiques méridionales by Quézel and Santa (1962-1963) for the whole territory and, for the Saharan part only, the work by Ozenda (1991). Other reference floras used for Algeria are the Flore analytique et synoptique de l'Algérie et de la Tunisie by Battandier and Trabut (1905), which is complete but old, and La Flore de l'Afrique du Nord by Maire (1957-1987), which is precise but incomplete. The Index synonymique de la flore d'Afrique du Nord by Dobignard and Chatelain (2010-2013) may be consulted for up-to-date nomenclature, because it is very complete and precise in this regard, but it does not allow for
$\Delta$

Catananche caespitosa endemic plant species (Chelia Aures KBA) (C) Yassine Begami

re-identification since it does not contain the information required.

There are no plans for a new Flora for Algeria as such. There is, however, a project to use the nomenclature from Dobignard and Chatelain to update the Flora by Quézel and Santa (1962-1963); this work is being coordinated by Cyrille Chatelain at the Conservatoire et Jardin botaniques de la Ville de Genève, with contributions from a number of researchers at university botany laboratories in Algiers (ENSA, USTHB), Tlemcen and Tizi-Ouzou.

A prototype database called 'Inventaire des Ressources Biologiques' (IRB - Inventory of Biological Resources) organised by the Ministry for the Environment, is available online (http:// cndrb.com) but is not up to date. Thanks to the tools provided by the Tela Botanica association (discussion forum, online notebook, identiplante, pictoflora, etc.) the eFlore project for North Africa is being progressively enriched.

There are regional Floras as well as checklists for Sahara, Hoggar and Tassili (Quézel, 1954; Leredde, 1957; Collenot et al., 1960), Oranie (Alcaraz \& Santa, 1968), Western Algeria and Eastern Morocco (Santa, 1949), Kabylie du Djurdjura (Debeaux, 1894), 
Blida (Gay, 1889), Constantine (Julien, 1894) and the Habibas Islands (Maire \& Wilczek, 1936). They are all either earlier than or contemporary with the national reference flora (Quézel \& Santa 1962-1963) and thus contain no 'new' data, but they do contain a lot of information.

At a supranational level, the following floras cover all or part of Algeria:

- For western Algeria, the recent Flore pratique du Maroc (Fennane et al., 1999-2014) and the Catalogue des plantes vasculaires du nord du Maroc (Valdès et al., 2002) are frequently consulted.

- For the extreme east of Algeria, Tunisian floras may be used (Cuénod et al., 1954; PottierAlapetite, 1979, 1981).

- La Flore de l'Afrique du Nord by Maire (19521987) covers all of Algeria but is incomplete.

- La Flore et végétation du Sahara by Ozenda (1991) covers the whole of Algerian Sahara but has not been updated.

- The Flora of Egypt by Boulos (1999-2005) is particularly useful for the Saharan region of the country.

\section{Gaps}

The geographical coverage of the Algerian flora is relatively homogeneous, but knowledge is most up to date for the north of the country, while the High Plains, the Saharan Atlas and the Sahara (apart from Tassili and the Tamanrasset region) suffer from a shortage of recent data. Historical knowledge of the flora was mapped by Quézel and Bounaga in 1975 and it has not developed much since, except in the region of Annaba/El Kala (studied in great detail by De Bélair and collaborators since the 1990s), the Hodna mountains (studied by Rebbas and colleagues since the 2000s), the Kabylie, the Bibans and Aghbalou (currently being studied by Véla and colleagues), and the High Plains of Tlemcen (studied by Medjahdi).

On an ecosystem level, the humid zones were very poorly understood until the 1990s and 2000s, when the works by De Bélair, Laribi and collaborators appeared. Rocky areas of difficult access in the east and centre of the country are currently being investigated in depth by Véla and collaborators. The dry Mediterranean grasslands of Oranie were recently studied by Sekkal. Few works have dealt with urban and agricultural areas, despite some observations by Véla, Kazi-Tani and colleagues.

Most of the information is old and difficult to access (herbaria and historical publications). The old data has not been built on and there has been no systematic updating. There have, however, been recent works on the coastal area, the Tell Atlas and the Sahara, but they remain insufficient and are not often referenced in databases. There are three referenced herbaria, AL (Algiers University), ENSA (Ecole Nationale Supérieure Agronomique) and (GDB (Gérard de Belair). The latter, kept at the National School of Agronomy (ENSA), is the only one to be digitised and geo-referenced (http://gdebelair.com/). The Tela Botanica online notebook allows data to be archived spatially but is rarely used these days (it has less than 1,500 items of data on less than 400 areas, with very few users). Participatory processes and data-rich papers need to be encouraged.

Overall, there are no major difficulties in obtaining access to the field. However, the size of the country and logistic issues are significant constraints on field work capacities.

\section{Botanical institutions, associations and societies}

On an institutional level, the Ministry for the Environment and Renewable Energy, through the organisations it supervises (CNDRB, CNL, ONEDD and ANCC), the Agence nationale pour la conservation de la nature (ANN), the Jardin botanique du Hamma (EPIC, Wilaya Alger) and the Ministry for Agriculture, Rural Development and Fisheries (DGF, INRF) are responsible for the flora and its conservation.

Professional and amateur botanists communicate using Tela Botanica's forum for North Africa.

A national network of botanists has recently been created under the supervision of the Direction Générale des Forêts (DGF). 


\section{TUNISIA}

\section{Authors:}

\section{Zeineb Ghrabi-Gammar}

Institut National Agronomique de Tunisie

Amina Daoud-Bouattour

Faculté des Sciences de Tunis

\section{Contributor: Amor M. Gammar}

Faculté des Lettres, des Arts et des Humanités de la Manouba, Tunisie

\section{State of knowledge}

The most recent reference work for the flora of Tunisia is the Catalogue synonymique commenté de la Flore de Tunisie (Le Floc'h et al., 2010). Older floras can also be used for reference, such as the Flore de Tunisie by Pottier-Alapetite $(1979,1981)$ and the Flore analytique et synoptique de la Tunisie (Cuénod, 1954). There are currently no plans for a new Flora. Some data on flora is collated in databases, particularly at the BiCADE (Unité de recherche Biogéographie, Climatologie appliquée et Dynamique Erosive) and the CBBC (Centre de Biodiversité de Borj Cedria), but they are not all accessible online. Some publications describe the flora at an infranational scale, such as Orchidées de Tunisie (Martin et al., 2015), Guide illustré des plantes du Parc National de l'Ichkeul (Daoud-Bouattour et al., 2007), Flore succincte et illustrée des zones arides est sahariennes de Tunisie (Chaieb \& Boukhris, 1998), Flore et végétation des îles et îlots satellites de l'archipel des Kerkennah (Médail et al., 2015) and Plantes naturelles du Sud Tunisien (Issaoui et al., 1996).

On a supranational level, the most recent reference work is the Index synonymique de la flore d'Afrique $d u$ Nord by Dobignard and Chatelain (2010-2013).

\section{Gaps}

The taxonomic cover of Tunisia is relatively homogeneous. Some national and international projects have led to improvements in the knowledge of certain parts of the country. Generally speaking, the border areas - often difficult to access for military reasons - are less well known. The freshwater limestone ecosystems and those in the south of the country are not sufficiently understood. Plant distribution data is currently being updated

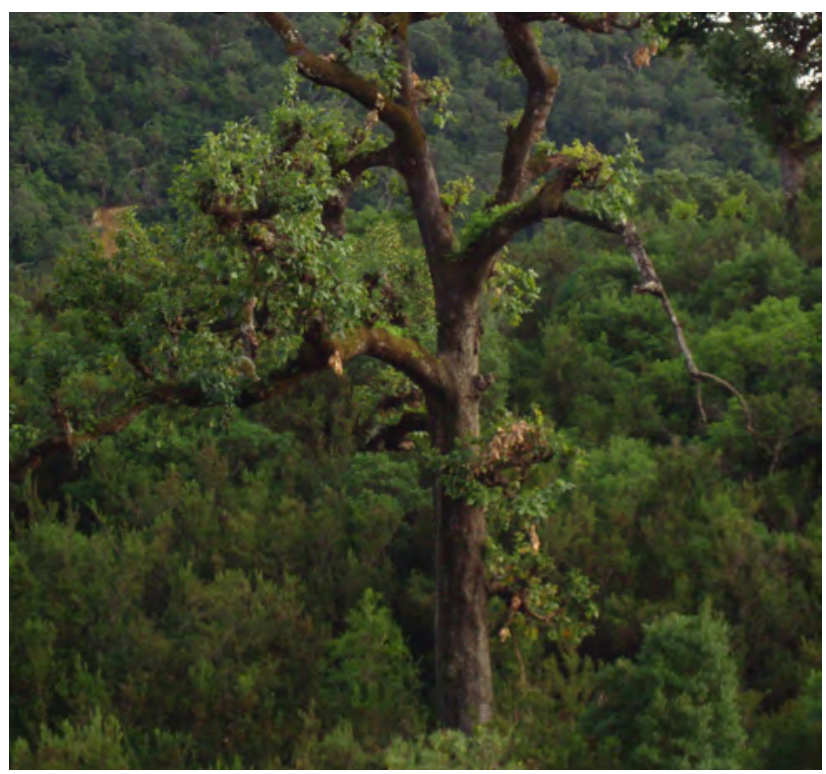

\section{$\Delta$}

Ain Zana KBA, Tunisia

(C) Ghrabi Gammar Zeineb

The main institutions in charge of taxonomy and species distributions are the BiCADE research unit at the Université de la Manouba, the biology department at the Faculté des Sciences de Tunis, the Institut National d'Agronomie de Tunisie, the Institut des Régions Arides de Médenine, the Université de Sfax, the Banque Nationale de Gènes, the Direction générale des Forêts and the Agence de Protection et d'Aménagement du Littoral (APAL).

Two amateur botanical associations exist in Tunisia and they work in coordination with the official institutions: the Association Tunisienne de Taxonomie (ATUTAX) and Recherche en Action / Association Tunisienne de Développement Durable (REACT).

It is a problem to find replacements for taxonomists, as students are not interested in botany and taxonomy in particular. Difficulties in publishing studies are partially responsible for this.

\section{Recommendations to improve knowledge}

- Work as a team on a national level.

- Collaborate with specialists on habitats and targeted taxonomic groups in Tunisia, the Maghreb and the Mediterranean.

- Develop short- and long-term projects for prospecting, inventory work and monitoring.

- Prepare and publish an updated Flora of Tunisia. 


\section{LIBBYA}

\section{Author: Errol Véla}

Université de Montpellier

Contributors:

Mohamed Makhlouf

University of Tripoli

Rafaa Essokne

University of Tripoli

Mohammad S. Al-Zein

American University of Beirut

\section{State of knowledge}

The reference flora for Libya is the Flora of Libya (Ali et al., 1976-1989). Because of its age, it is no longer representative. Several specific contributions have been published since and are referenced in the Index synonymique de la flore d'Afrique du Nord by Dobignard and Chatelain (2010-2013).

There are currently no plans for preparing a new national flora and there is no online database.

On an infranational level, there is the Catalogue raisonné des plantes de Tripolitaine (Durand \& Baratte, 1910) and the Prodromo della flora Cirenaica (Pampanini, 1930), but these works are too dated to be of any real use. Several more recent works have been published on the northern part of the country by Sicilian botanists, for example La vegetazione costiera della Cirenaica (Brullo \& Furnari, 1988).

An updated checklist covering 43 families, 138 genera and 411 species of the Libyan flora as treated in the Flora of Libya was recently published (Gawhari et al. 2018). In this checklist, $45 \%$ of the taxa were reclassified at the family, genus, or species level based on modern taxonomic treatements. This partial checklist will form the basis of a comprehensive updated checklist of the Libyan flora.

\section{Gaps}

The taxonomic coverage of Libya is relatively homogeneous, while geographically Fezzan and the Saharan zones in general are less well known than the Mediterranean coast.

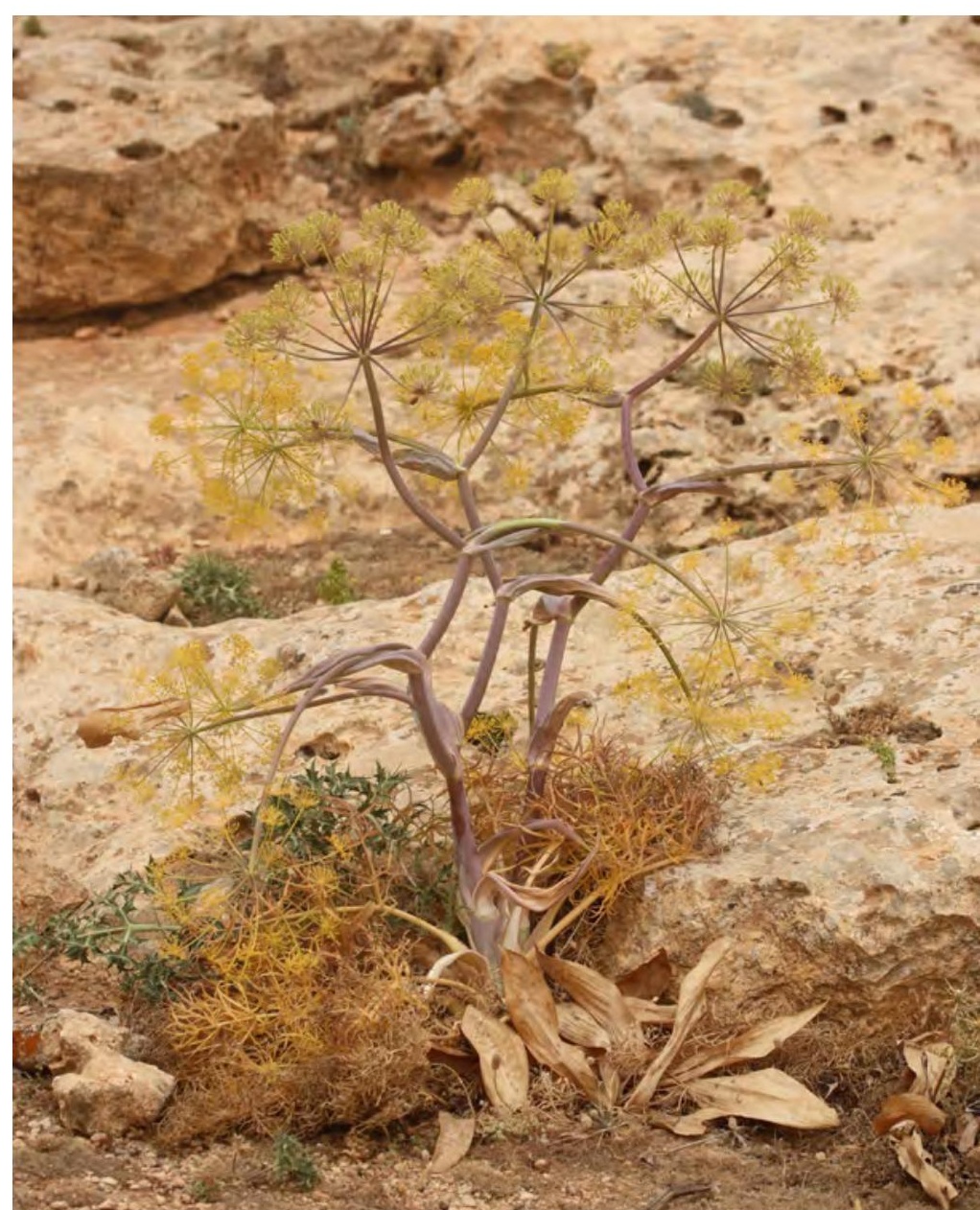

$\Delta$

Thapsia garganica var. sylphium endemic to the Cyrenaica peninsula, Libya (c) Stephen Jury

The flora of anthropised areas as well as xenophytes and invasive species are very rarely documented.

Generally speaking, data on the current distribution of the flora is very incomplete, particularly because of the lack of security in large parts of the country. It would be very useful to make the most of historic data from herbaria and publications to start a database and distribution atlas.

\section{Botanical institutions, associations and societies}

The institutions in charge of the flora are principally the University of Tripoli and the Environment General Authority. 


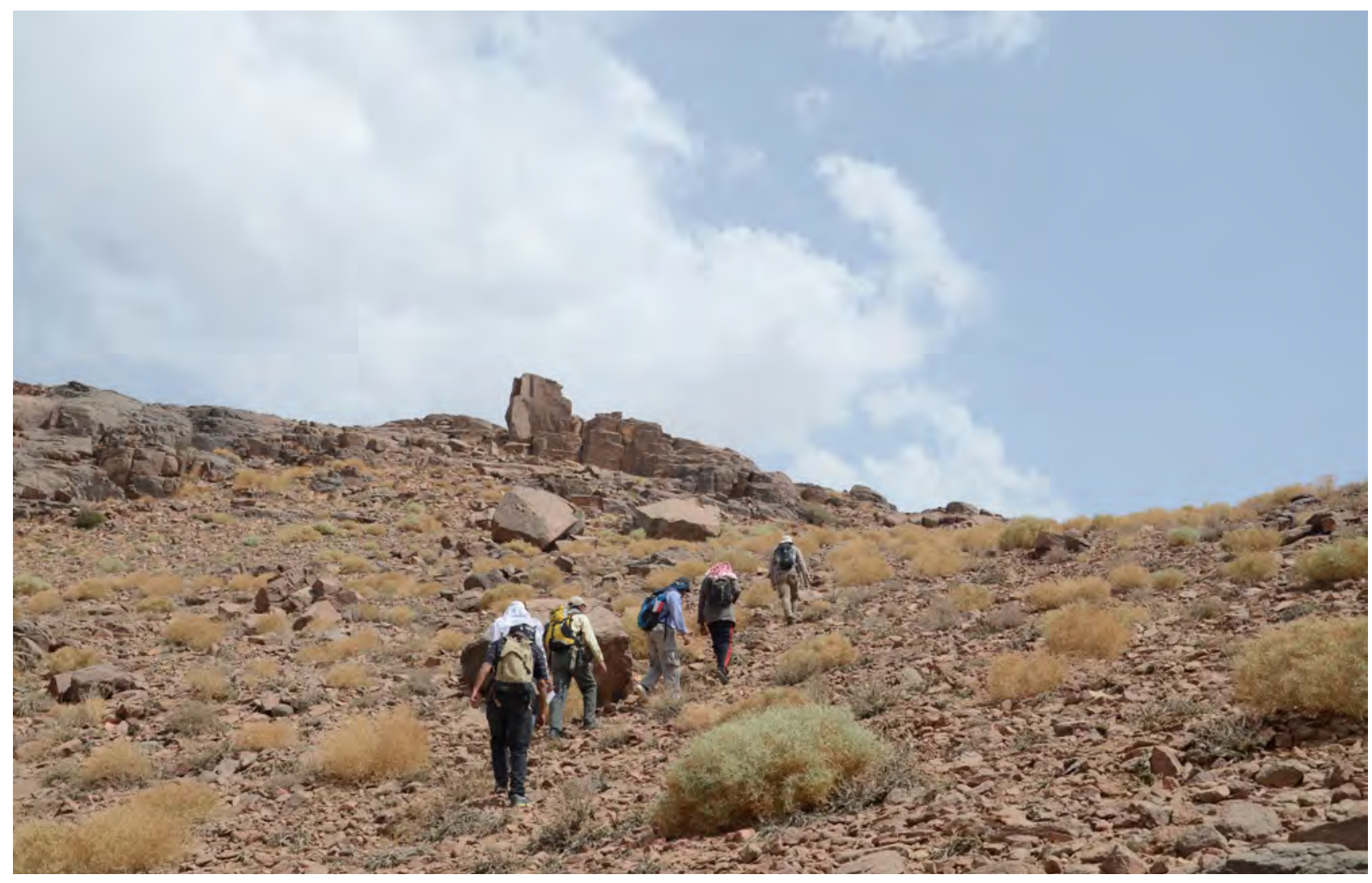

$\Delta$

Botanists during field survey in St. Catherine KBA, Egypt (c) Karim Omar

\section{Botanical institutions, associations and societies}

The main institutions in charge of the flora are the botany departments of various universities, the Agricultural Museum and some herbaria (for example, CAI, CAIM, ASTU and TANE).

Amateur botanists work in coordination with the official institutions and come together in the Egyptian Botanical Society (EBS), where they exchange information, particularly during the annual assembly or other meetings in university botany departments.

The lack of young botanists is a problem.

Essentially, young researchers are more attracted to subjects like molecular biology and genetic engineering. Universities and research centres should encourage young researchers to specialise in taxonomy and participate in the Global Taxonomy Initiative (GTI).

\section{Recommendations to improve knowledge}

- Check and complete the preliminary Red List for vascular plants, applying the IUCN Red List criteria.

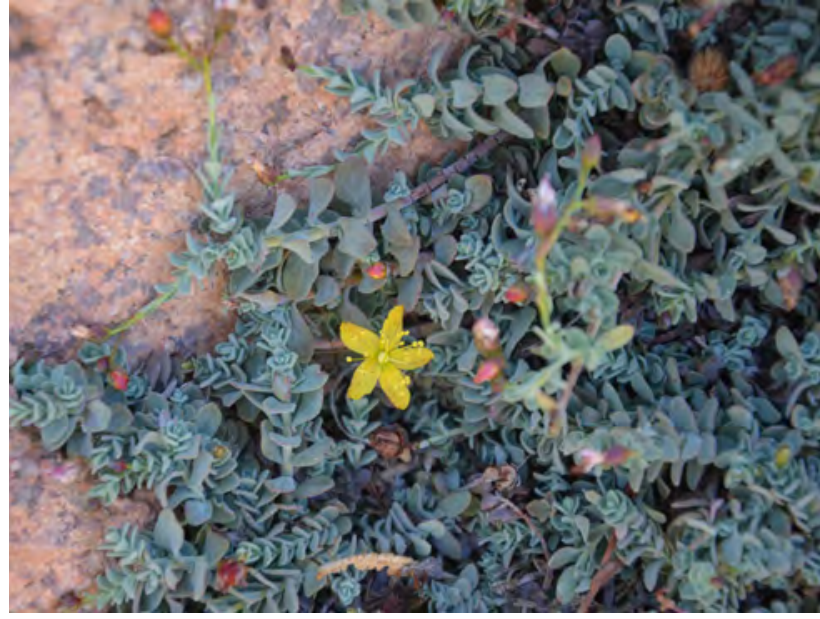

Hypericum sinaicum in St. Catherine KBA, Egypt (C) Karim 0mar@ Karim Omar

- Intensify research into the history of invasive species and reasons for their introduction to Egypt.

- Prioritise a programme for the conservation of endangered rare plants.

- Participate in the GTI to fill gaps in taxonomic knowledge.

- Intensify training and capacity-building programmes, prioritising aspects that are essential for the success of conservation projects. 


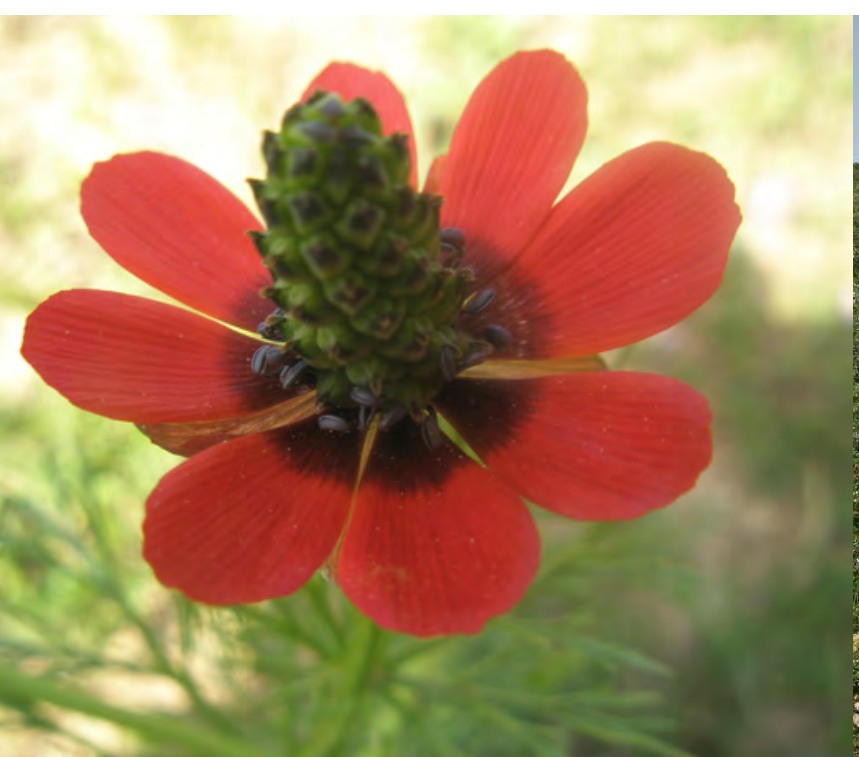

\section{$\Delta$}

Adonis palaestina, Palestine

(C) Banan Al Sheikh

\section{PALESTINE}

\section{Author: Banan Al Sheikh}

National Agricultural Research Center, Jenin

\section{State of knowledge}

The main reference volume for Palestine is the Flora Palestina by Zohary (1966-1972), which is complemented by the Checklist and Ecological Data-Base of the Flora of Israel and its Surroundings (Fragman et al., 1999) and the Preliminary Checklist and Ecological Data-Base of Plants of the West Bank (Al Sheikh et al., 2000).

There are no plans to prepare a new flora for Palestine.

Data on the flora of Palestine is available online from Flora of Israel Online (www.flora.org.il) and (www. narc.moa.ps).

On a supraregional level, the Flora of Turkey (Davis, 1965-1988), Flora of Egypt (Boulos, 1999-2005), Illustrated Flora of Lebanon (Tohmé \& Tohmé, 2014) and Flora of Syria, Palestine and Sinai (Post, 1932-1933) are used.

\section{Gaps}

Generally, the data is more precise and up to date for the West Bank than for the Gaza Strip, which is difficult to access for security reasons. For the same security reasons, the Israeli settlements in the West Bank are poorly documented but are under severe pressure from urbanisation and intensive agriculture.

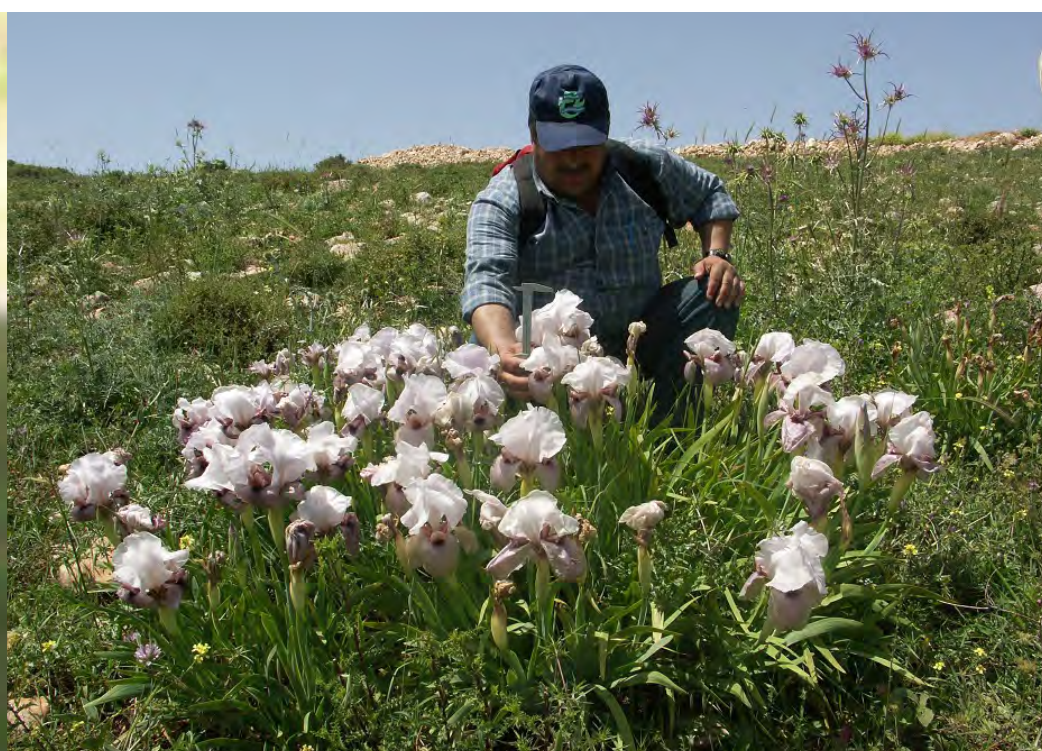

\section{$\Delta$}

Iris lortetii, Palestine

(C) Banan Al Sheikh

The distribution of numerous taxa is insufficiently documented, particularly rare species and especially those in wetlands, which are under threat from water extraction for agriculture and settlements.

\section{Botanical institutions, associations and societies}

The main institution in charge of the flora is the National Agricultural Research Center (NARC). There are almost no amateur botanists and they are not organised in a network.

On occasion there is collaboration with universities in Israel (mainly the Hebrew University).

There are next to no young botanists and access to numerous sites is impossible or dangerous for military or security reasons.

\section{Recommendations to improve knowledge}

- Conduct intensive fieldwork, especially to update the plant species diversity in Palestine.

- Seek technical assistance (capacity building) to conserve plant species (seed collection and storage).

- Train young people and students in plant identification and data collection.

- Determine rare species that are endangered and preserve them in situ and ex situ. 


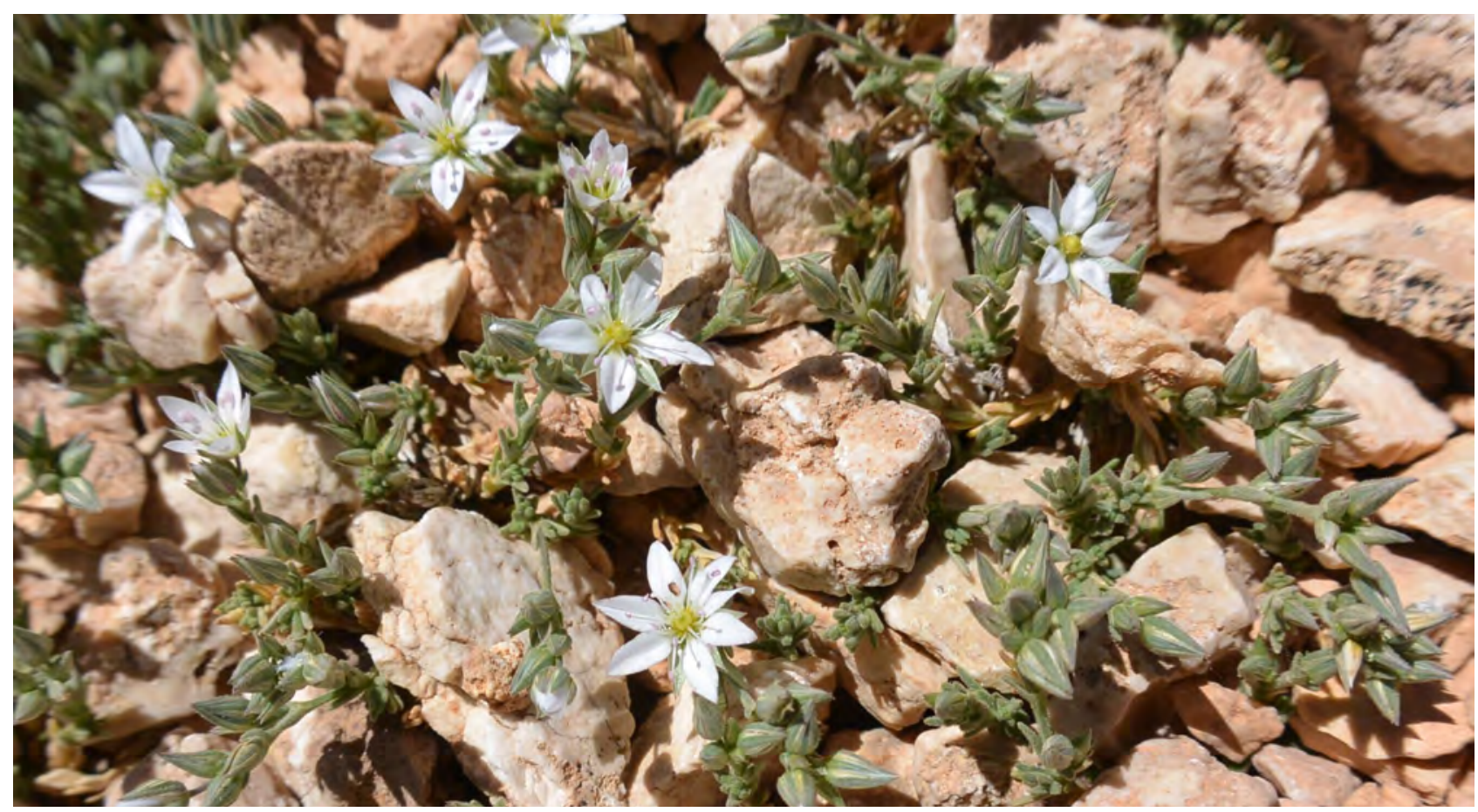

\section{LEBANON}

\section{Authors:}

Mohammad S. Al-Zein

Biology Department, American University

of Beirut - AUB

\section{Myrna Semaan}

Friends of Nature

Mariana Yazbek

Genetic Resources Section, International Center for Agricultural Research in the Dry Areas

\section{State of knowledge}

The most recent reference work for the flora of Lebanon is the second edition of the Illustrated Flora of Lebanon (Tohmé \& Tohmé, 2014). It is based on recent fieldwork by the two authors and includes the descriptions, locations and photographs of 2,612 species of vascular plants. Herbarium specimens for a great number of these species are stored in the Georges and Henriette Tohmé herbarium. However, the taxonomy used follows the somewhat outdated Nouvelle flore du Liban et de la Syrie (Mouterde, 1966-1983) and does not include several recently described and published taxa. Mouterde's flora remains of great scientific value, however, because it not only gives detailed descriptions of all the species, but it also contains very helpful illustrations and very useful identification keys. Moreover, although it is predominantly the fruit of some 40 years of fieldwork by its author, it also includes older data about the local flora (from publications, herbarium specimens, etc.).

Despite the absence of a national initiative to prepare a new flora for Lebanon, botanists from a range of institutions have taken on the work

\section{$\Delta$}

Minuartia libanotic (Boiss). Bornm. is an endemic species limited to the high plateaux of Mount Lebanon. Very low and discreet, it occurs only on Mount Makmel and Mount Sannine. However it was not observed recently in Sannine and thus, may have become restricted to Makmel (Mount Makmel KBA) Lebanon

(C) Hicham Elzein

of reviewing multiple groups of plants, including endemics, medicinal plants, wild relatives of cultivated plants, orchids, bellflowers, ferns, etc. These revisions could be used as a basis for preparing a new flora for Lebanon.

\section{A Checklist of Plants of Lebanon and Syria has} been prepared by Lytton J. Musselman. It is essentially based on Mouterde's list stored at the Post Herbarium (AUB). More recently Lebanon Flora (www.lebanon-flora.org), a database documenting indigenous species and their distribution, has been published by Saint-Joseph University.

Lists of plants have been generated up for several protected areas in Lebanon, and guides and books have been published on specific groups of plants, such as orchids (Haber \& Semaan-Haber, 2009) and milk-vetch (Astragalus (Makhoul, 2012)).

The flora of Lebanon is partly covered by checklists, flora and online databases for neighbouring countries, such as the Flora of Syria, Palestine and Sinai by Post (1932-1933).

\section{Gaps}

While interest in the flora of Lebanon dates back to at least the 18th century at least, with intensive fieldwork having been performed by pioneers (particularly Boissier), followed by 


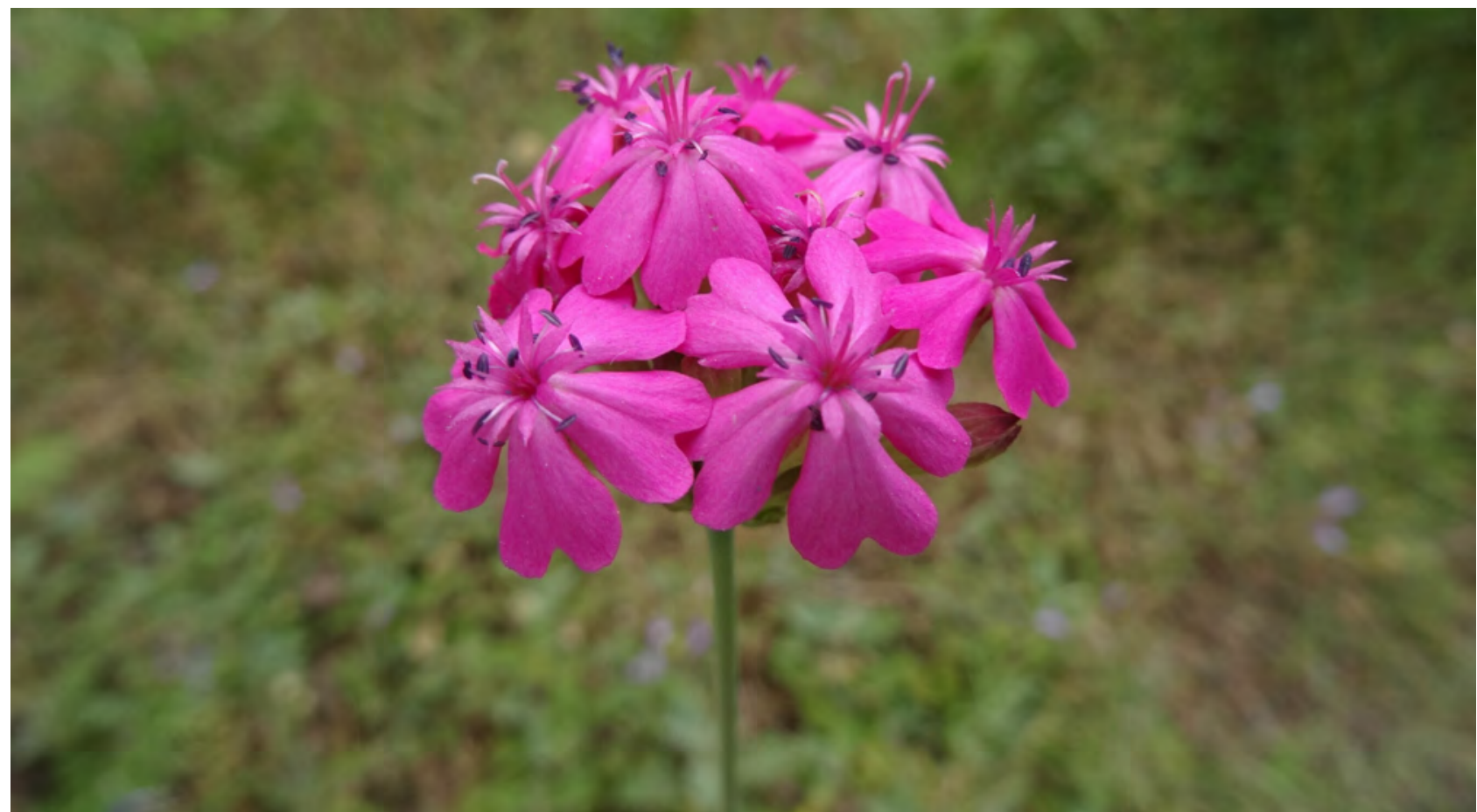

Post, Mouterde and more recently Tohmé and Tohmé, the taxonomic coverage of the country is not homogeneous, as demonstrated by work performed to identify Important Plant Areas for Lebanon. On a geographical level, the coast and Mount Lebanon are better studied than the AntiLebanon mountains (with the exception of Mount Hermon). In general, the areas that are harder to access are less well known, above all the conflict areas along the borders, especially in the south of the country.

On a taxonomic level, the non-vascular flora is less well known than the vascular flora, in particular because of the lack of national experts for certain groups (e.g. mosses, liverworts and hornworts). Moreover, knowledge of the Lebanese flora is largely based on global studies of regions or local expertise, rather than on revisions of taxonomic groups. This results in knowledge gaps for many taxonomic groups, especially those with cryptic or difficult taxa, such as grasses or thistles.

Aquatic ecosystems have been less well studied, especially in the Beqaa.

\section{Botanical institutions, associations and societies}

The main institutions in charge of taxonomy and biogeography are the Lebanese University, the Lebanese National Council for Scientific Research (CNRS-L) and the Lebanese Agricultural Research Institute (LARI). Researchers in universities and private institutions (such as the International Center for Agricultural Research in the Dry Areas
$\Delta$

Silene reuteriana (Boiss) is an endemic species to Mount Lebanon that occurs on sandstone in middle mountain regions (Nahr el-Kalb KBA), Lebanon (C) Hicham Elzein

- ICARDA), as well as independent botanists are working in these areas.

Amateur botanists are not brought together in an organisation or network, and do not always coordinate their activities with official institutions. There are plans to form a Lebanese botanical society.

Numerous foreign botanists visit Lebanon to study specific taxonomic groups and collaborate with experts and national institutions. Lebanese botanists also frequently collaborate with foreign experts.

There is a shortage of taxonomists at the national level. The young generation of botanists are more interested in plant ecology and conservation rather than plant systematics.

\section{Recommendations to improve knowledge}

- Increase the number of taxonomists.

- Find funding for exhaustive research into the flora with the aim of expanding collections to serve as a basis for a new flora of Lebanon.

- Increase the intensity of work on the ground, particularly in the regions that are not so well explored and on taxa that are rare, endemic, endangered and/or very localised. 


\section{SYRIA}

\section{Author: Sami Youssef \\ AMAP, Université de Montpellier}

Contributors:

\section{Errol Véla}

AMAP, Université de Montpellier

Nigel Maxted

University of Birmingham

\section{State of knowledge}

The reference flora for Syria is the Nouvelle flore du Liban et de la Syrie by Mouterde (1966-1983), but it is outdated and limited in terms of both completeness and taxonomy. New species have been discovered since and the taxonomy of numerous types and families has evolved. An atlas of biodiversity has been published by the Syrian government (Ministry of State for Environmental Affairs, 2001). The flora part of this atlas uses Mouterde's data.

Targeted research has been performed recently for some groups of flora, such as orchids (Véla \& Viglione, 2015), irises (Al-Holani, 2013) and halophytes (Al-Oudat \& Qadir, 2011).

No activities are planned to establish a new Flora, mainly because Syrian botanists have not been very interested on account of the ongoing armed conflict. An online database project has been started, but has not yet been completed (Flora Syria On Line: www.florasyria.com). Works by Karzon (2010) on the Jabal Abdalaziz and by Chikhali $(1994,2000)$ on the Jabal Al-Arab illustrate the distribution of species at an infranational level.

On a supranational level, only the floras by Post (1883-1896) and Boissier (1867-1888) cover Syria.

The historical presence of the International Center for Agricultural Research in Dry Areas at Tel Hadya,

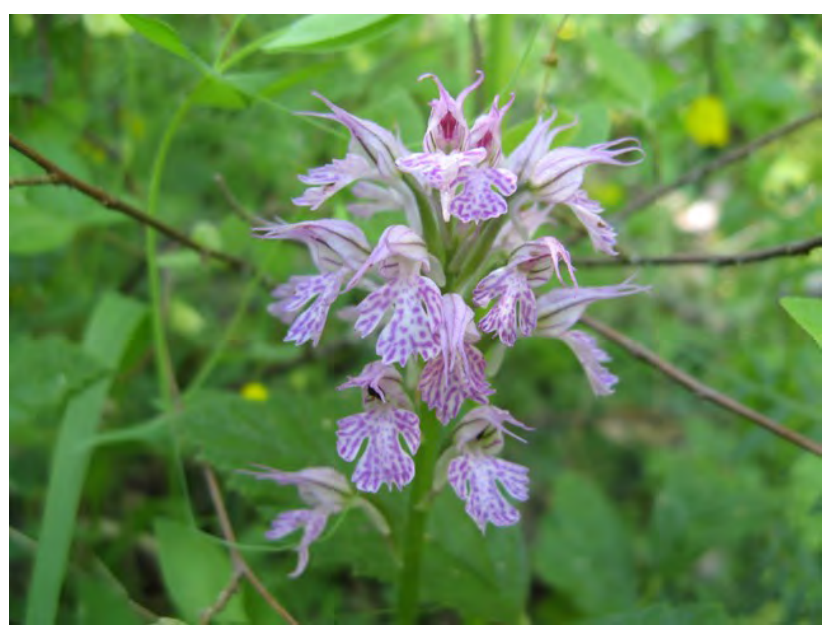

Orchis tridentata in Abu Qbeis KBA, Syria (c) Fadi Al-Mahmoud

about $40 \mathrm{~km}$ south of Aleppo, means that the crop wild relative flora of Syria is well known, particularly down to individual population levels for the Poaceae and Fabaceae families.

\section{Gaps}

The taxonomic status of the Syrian flora is incomplete and outdated. In addition, there is no reliable geographical distribution data for the Syrian flora.

In geographical terms, the north-eastern (Mesopotamia) and central (desert) parts of the country have been neglected by government botanists and are less well known. The Mediterranean region of north-western Syria (Ghazal, 2008) and the Jabal El-Arab (Chikhali, 1994, 2000) are better understood.

The forest ecosystems are the best studied.

Information on the flora is mainly dated, and the overall lack of security, resources and political will make it difficult to bring it up to date.

\section{Botanical institutions, associations and societies}

The institutions active in plant biodiversity are mainly the National Commission for Biotechnology - Department of Biodiversity Conservation, the National Biodiversity Unit at the Ministry of State for Environmental Affairs, the Department for Steppes and Grasslands at the Ministry for Agriculture, and the Universities in Damascus and Latakia. The Syrian Society for Conservation of Wildlife performs research financed by international institutions. There is no formal network of botanists in Syria. 


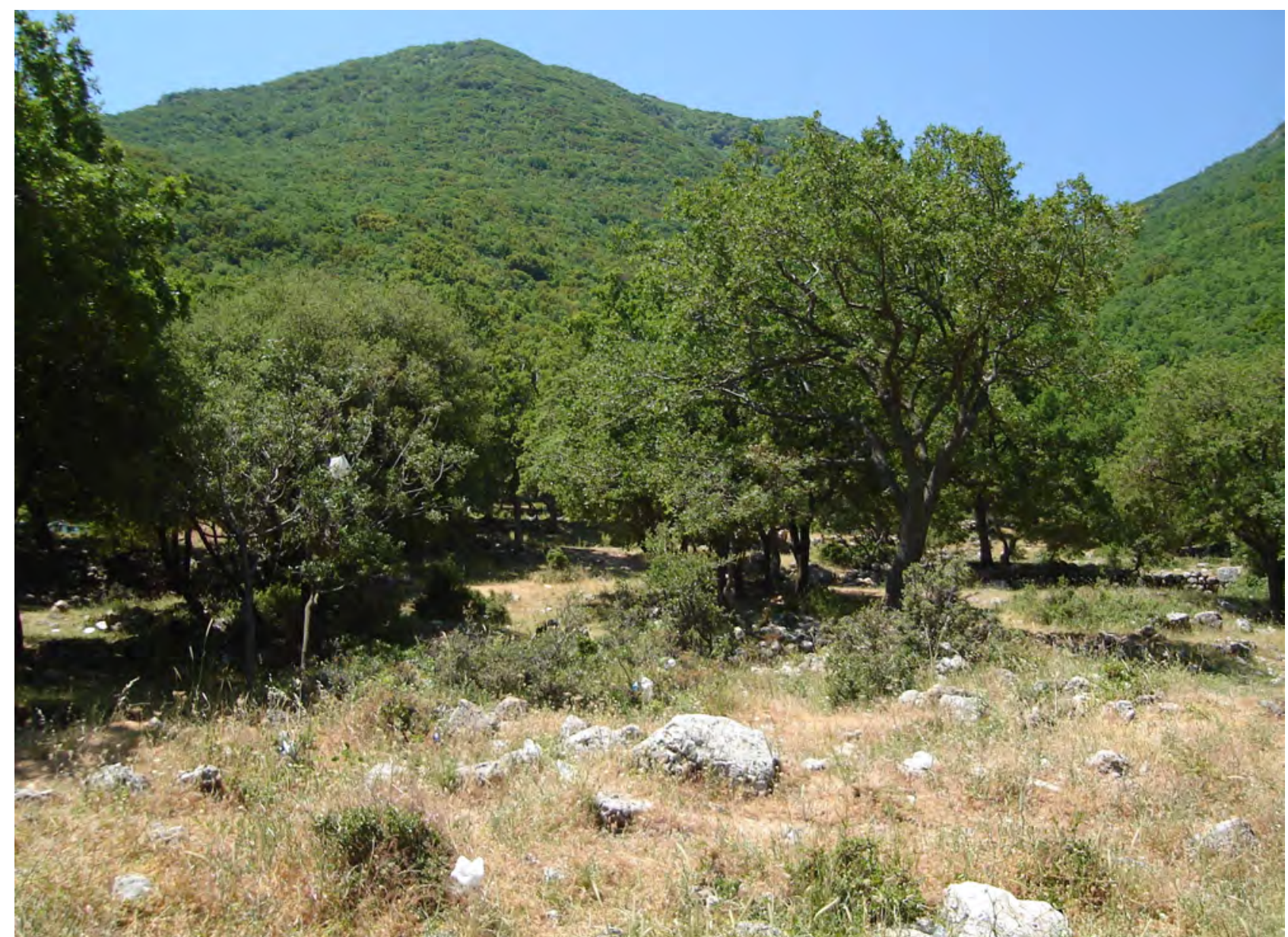

\section{$\Delta$}

Jabal Abdul Aziz Pistacia khinjuk open woodland, Jabal Abdul Aziz KBA, Syria (C) Hayan Himidan

The few young taxonomists coming through are mainly being trained abroad, particularly since the start of the current conflict.

In terms of agrobiodiversity conservation, the Ministry of Agriculture and Agrarian Reform (Douma, Damascus) actively collaborated with the International Center for Agricultural Research in Dry Areas at Tel Hadya to systematically map the crop wild relative diversity of Syria and collect material for ex situ conservation. It seems likely that the national gene bank in Douma has now been completely destroyed and the state of the ICARDA gene bank is unclear, but many accessions were duplicated in Morocco and Lebanon prior to Tel Hadya falling outside government control.

\section{Recommendations to improve knowledge}

- Create a complete database from Mouterde's Flora.

- Update the national checklist with data from regional and international papers.

- Initiate sustainable partnerships in each region between local botanists and international experts (with a view to training and publication);

- While waiting for a resolution to the current conflict, encourage regional scientific progress in stable areas (e.g. the Mediterranean zone, Jabal Al-Arab (Djebel Druze), Mesopotamia (AlJazira), etc.).

- Establish the current status of the ex situ crop wild relative collections and datasets previously held at the Douma and Tel Hadya gene banks and regenerate collections where necessary. 


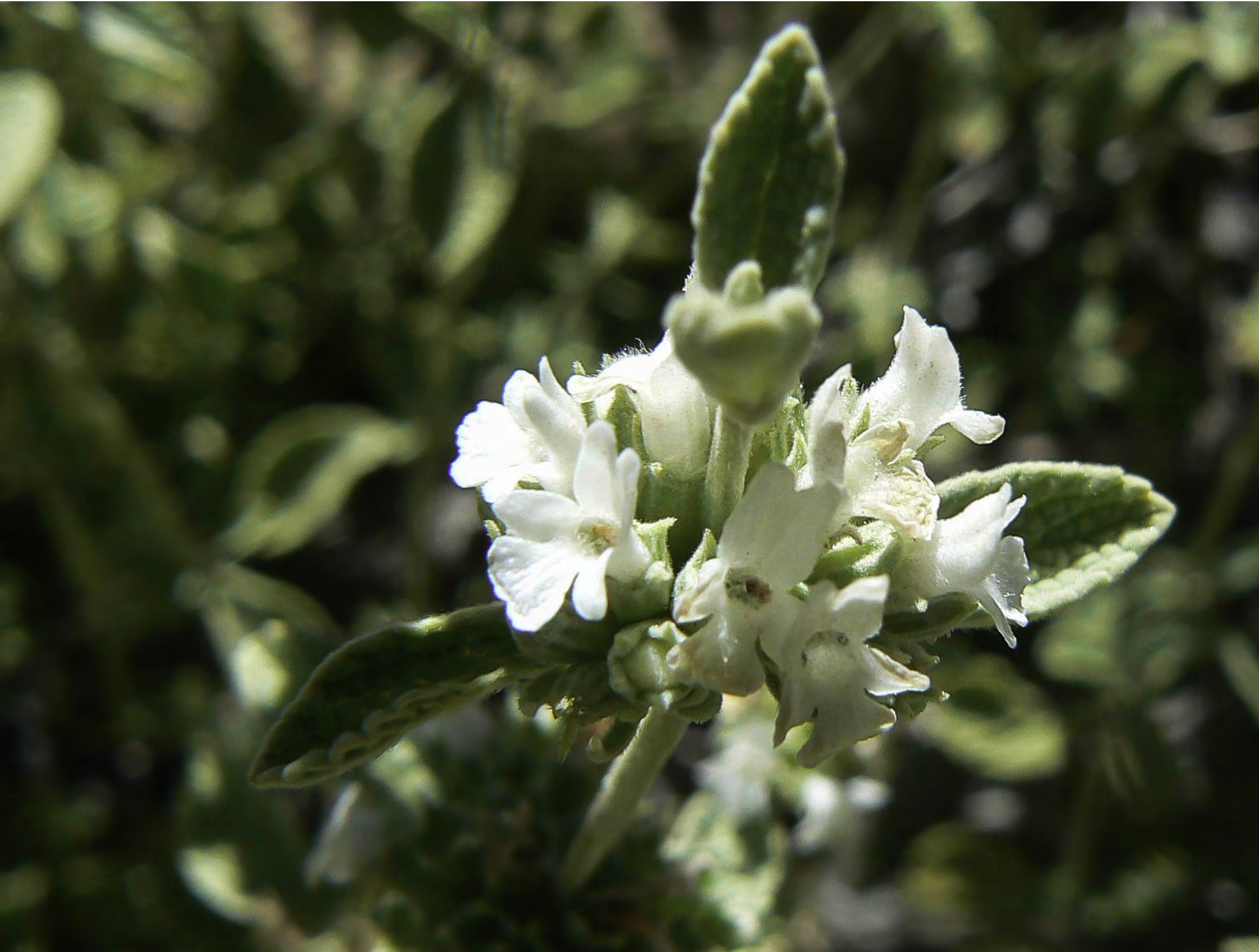

\subsection{Conclusions and recommendations}

The taxonomy and nomenclature of the flora in the south and east Mediterranean region is relatively well known. On the other hand, some areas remain little explored and recent species distribution data are missing for most of the region. This is especially the case in conflict-ridden or unsafe countries or regions. The number of botanists and taxonomists is insufficient, and there are not enough young scientists coming through to replace those ending their careers.

Improving the quality of information necessarily involves training field botanists, developing national and international networks of botanists and creating and maintaining public databases. Human and financial resources must be increased to improve the quality and quantity of information, which is an essential prerequisite for conservation actions.
Marrubium litardierei, endemic species of Morocco, grows only on stony environments of the siliceous mountains (or decalcified) of the High Atlas and the Anti-Atlas. C) Fouad Msanda / www.teline.fr

For successful plant conservation, we need not just scientific input but, equally important, if not more so, field experience. 



\subsection{Introduction}

\section{Chapter objectives}

Planning and then implementing conservation actions for one or more plant species, their habitats and the sites where they are found requires a detailed understanding of the threats and risks that they face. A method for evaluating the degree of threat therefore needs to be established in order to set conservation priorities and target interventions appropriately.

The aim of this chapter is to present a country-bycountry evaluation of current knowledge of species risk of extinction and the types of threat the plants and their habitats face. The fact that a specific taxon is evaluated and included on the IUCN Red List of Threatened Species ${ }^{\mathrm{TM}}$ does not imply any legal protection status.

\section{The IUCN Red List}

The IUCN Red List is the most complete global inventory of the conservation status of species. It uses a series of objective criteria to evaluate their risk of extinction (Figure 2.1) (IUCN, 2012a). For all species evaluated, the Red List provides information about threats, ecological requirements and habitats, and for some taxa it also proposes conservation actions that could be undertaken to reduce or prevent the risk of extinction.

All species that have had their extinction risk evaluated globally, meaning for their entire area of distribution, figure in the IUCN global database (www.iucnredlist.org).

\section{The Mediterranean Red List}

The Mediterranean Red List of Species constitutes a review of the conservation status of species and subspecies at the Mediterranean level, following the Biodiversity Hotspot limits (Ref Hots) excluding macaronesia.

All species and subspecies evaluated evaluated regionally are available at: https://www.iucnredlist. org/regions/mediterranean
Figure 2.1. Structure of the IUCN Red List categories.

The text in this chapter includes the abreviations CR, EN VU, NT, DD, LC and NE according to these risk categories.

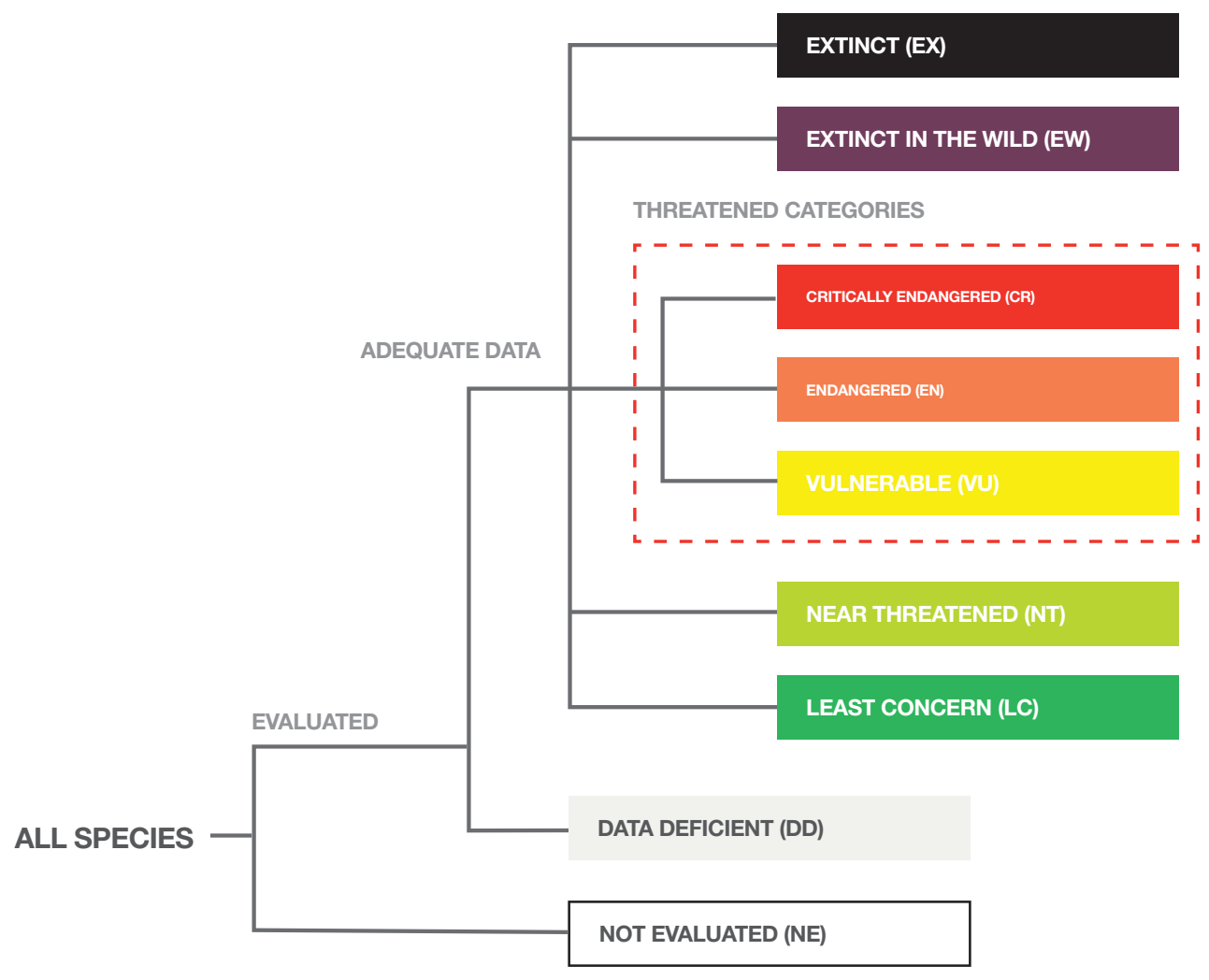




\section{National Red Lists}

Red Lists are often drawn up by individual countries based on the IUCN criteria or other criteria established in a similar way. Listed species are only evaluated for their risk of extinction within that country. The assessments included in the red lists need to be revised at regular intervals, which in some countries occurs, more frequently than at global level. IUCN has established guidelines for applying the Red List criteria at regional and national levels (IUCN, 2012b).

\subsection{IUCN Red List of threatened plant species}

The IUCN Red List currently comprises 1,810 plant taxa (species and subspecies) that are present in one or more of the 30 or so countries that have part or all of their territory within the Mediterranean Basin. This means that only $7 \%$ of the approximately 25,000 plant taxa of the region have been assessed for their extinction risk in the IUCN Red List. Of these, 572 (32\%) are plant taxa threatened with extinction, including Critically Endangered (CR), Endangered (EN) and Vulnerable (VU) taxa, and a further 141 (8\%) face a slight threat (Near Threatened - NT) 183 species (10\%) could not be categorised due to a lack of information (Data Deficient - DD). This highlights the need for individual countries in the region to take urgent action to establish the threat status of their flora.

If only endemic Mediterranean plants are considered, the total number of taxa causing concern is 529 (Table 2.1).

\begin{tabular}{lrr}
\hline Threat category & Number & $\%$ \\
\hline CR & 106 & $20 \%$ \\
\hline EN & 106 & $20 \%$ \\
\hline VU & 114 & $21 \%$ \\
\hline NT & 101 & $19 \%$ \\
\hline DD & 102 & $19 \%$ \\
\hline Total & $\mathbf{5 2 9}$ & $\mathbf{1 0 0 \%}$ \\
\hline
\end{tabular}

Table 2.1. Plant taxa in CR, EN, VU, NT and DD Red List categories that are endemic to the Mediterranean.

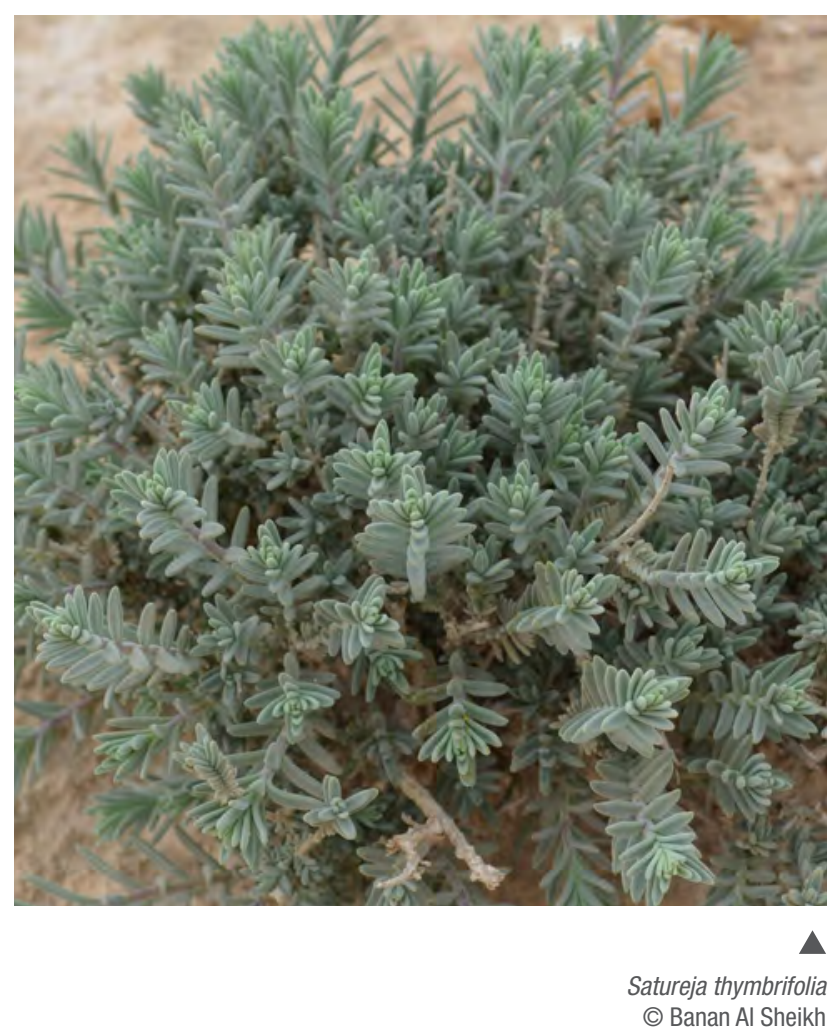

There is also one Extinct endemic Mediterranean plant species (EX) and one species that is Extinct in the Wild (EW).

Given the small number of plant taxa endemic to the Mediterranean that feature on the IUCN global Red List, it is unlikely that conclusions can be drawn from these statistics, because the taxa assessed are not representative, either geographically or taxonomically.

The number of Mediterranean taxa assessed for the IUCN Red List increases every year. These evaluations are most often carried out within regional projects. For instance, the IUCN Centre for Mediterranean Cooperation is currently assessing close to 400 monocotyledons that are endemic to the Mediterranean region. Evaluations of trees and bushes endemic to North Africa are also ongoing. Regional red list assessments evaluate the risk of extinction of species within specific geographical boundaries.

In the following section, the analysis at country level shows taxa assessed both at global level and regional (Mediterranean level) for the IUCN Red List. Mediterranean boundaries used in assessment of plants, were the ones defined by Conservation International for definition of hotspot (Mittermeier et al. 2004).

The number of Mediterranean plants that have been assessed is still very low compared to the diversity of the flora in the region. 


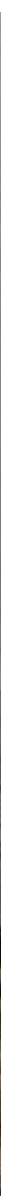

\subsection{Red Lists and threats by country}

\section{Author: Hassan Rankou}

Global Diversity Foundation, Marrakech

Royal Botanic Gardens Kew, London

\section{Contributors}

Aline Perez-Graber and Bertrand de Montmollin IUCN/SSC/Mediterranean Plant Specialist Group

\section{National Red Lists}

The flora of Morocco includes 3,913 species-group taxa, and 872 subspecies, in 981 genera and 155 families (Fennane \& Ibn Tattou, 2012; Rankou et al., 2013). It has a particularly high level of endemism (18\%) with 878 endemic taxa, 599 of them at species level.

There is as yet no national Red List that covers the complete flora of Morocco. Four fascicles containing essential information for a Red Book of the vascular flora of Morocco (Fennane, 2016-2017) have been published in preparation for a Red Book.

Monocotyledons (Rankou et al., 2015) are the taxonomic group that is currently best evaluated using the IUCN Red List criteria. The degree of threat faced by monocotyledons in Morocco is high, with $95 \%$ of taxa in a threatened category $(20 \% \mathrm{CR}$, $50 \% \mathrm{EN}, 25 \% \mathrm{VU})$, while only $5 \%$ of taxa face little or no threat ( $2 \%$ NT and $3 \%$ LC).

Current data is generally insufficient for precisely evaluating taxa according to IUCN criteria; inaccurate distribution maps, for example, make it difficult to estimate the Extent of Occurrence (EOO) or Area of Occupancy (AOO) as defined in the IUCN Red List guidelines (IUCN, 2012a).

Taxa that feature on a Red List are not automatically protected in national legislation.

\section{Moroccan taxa evaluated (at global or Mediterranean level) for IUCN Red List}

The IUCN global Red List contains 418 plant taxa with a distribution area that includes Morocco, or $11 \%$ of the total flora of Morocco. Including the Mediterranean Red Lists raises the number of assessed taxa to $539,10 \%$ of which are in one of the threatened categories (CR, EN, VU). 


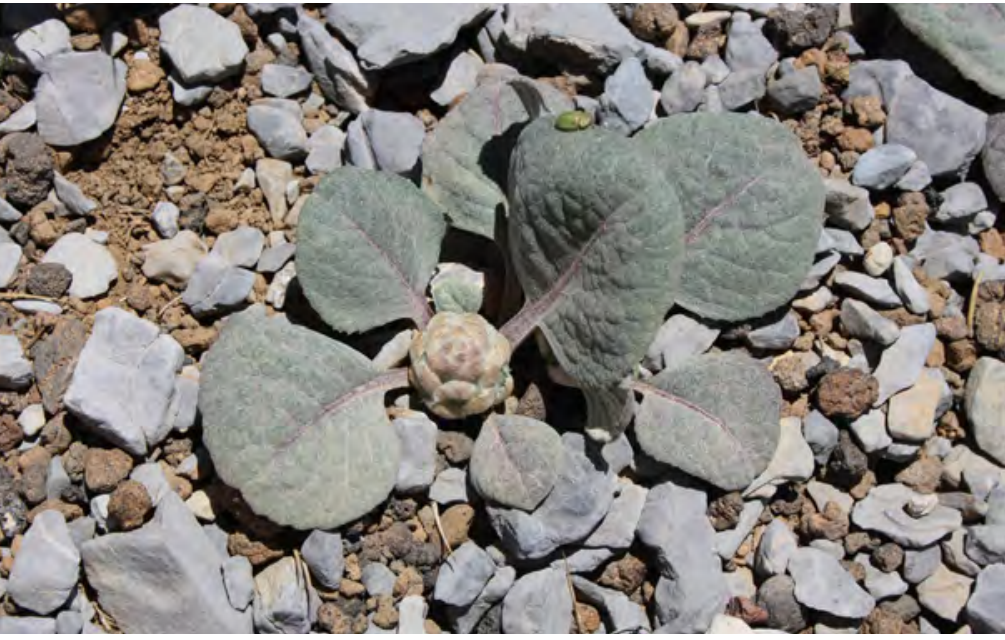

$\Delta$

Rhaponticum coniferum subsp. beardioides, morocan endemic ○ Mohamed Sghir Taleb

\section{Threats}

Given the small number of Moroccan plant taxa featuring on the Red List and as they are unrepresentative of the total and, in particular, the Mediterranean flora of Morocco, it is not possible to draw conclusions from these statistics.

The diversity of the country's flora is mainly threatened by the loss and degradation of habitats, direct and indirect disruption caused by human activity, changes in vegetation dynamics and factors intrinsic to certain species.

More specifically, the most significant threats come from overgrazing, climate change and drought, the intensification of agriculture, deforestation, tourism and leisure activities, plant collecting, urbanisation and infrastructure development. Pollution and wildfires are also threats, but to a lesser degree than those listed above.

\section{Institutions responsible for conserving the flora}

The Haut Commissariat aux Eaux et Forêts et à la Lutte Contre la Désertification is responsible for the implementation of conservation actions and policies. It uses data supplied by the Institut Scientifique de Rabat, other universities and publications.

\section{ALGERIA}

Authors:

\section{Salima Benhouhou}

Ecole Nationale Supérieure d'Agronomie, El Harrach Nassima Yahi

Université des Sciences et de la Technologie Houari Boumediene, Bab Ezzouar

Errol Véla

Université de Montpellier)

Contributors:

Aline Perez-Graber and Bertrand de Montmollin IUCN/SSC/Mediterranean Plant Specialist Group

Abdelkader Benkheira

Direction Générale des Forêts, Alger

Wissam Toubal

Direction Générale des Forêts, Alger

Loucif Kabouya

Direction Générale des Forêts, Alger

\section{National Red Lists}

The flora of Algeria includes 4,449 taxa, 3,951 of which are indigenous and 290 (6.5\% of the total flora) endemic to the country (Dobignard \& Chatelain, 2010-2013).

There is as yet no national Red List established in line with the IUCN criteria. There are plans to establish one collaboratively by the main institutions for managing the natural heritage (flora) in Algeria, under the guidance of the Ministère de l'environnement et des énergies renouvelables (MEER) and the Agence nationale pour la conservation de la nature (ANN).

Evaluations using the IUCN criteria have been performed for the aquatic and semi-aquatic plants of Algeria (Garcia et al., 2010) and some gymnosperms, and evaluations are ongoing for monocotyledons.

The data is often insufficient for proper evaluation, which is why so many taxa are in the DD (Data Deficient) category. This specifically affects Areas of Occupancy (AOO), population numbers and locations as well as threats, which have often been extrapolated. 


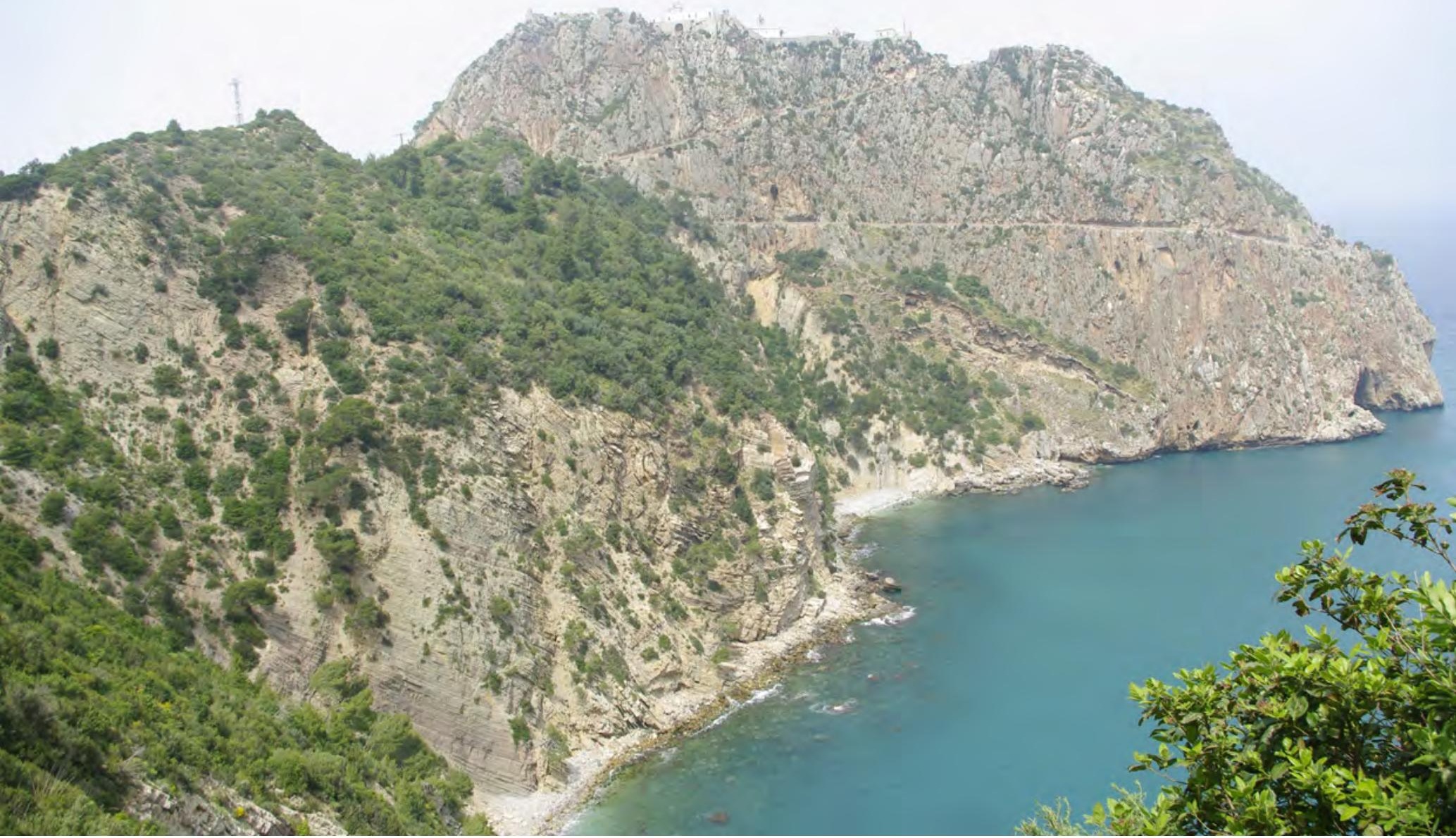

The legal instruments for making forecasts for flora are:

- Law 84-12, establishing general regulations for forests;

- Law 11-02, relating to protected areas in the context of sustainable development;

- Law 14-07, relating to biological resources;

- Law 2004-03, relating to the protection of mountain areas in the context of sustainable development;

- Law 02-02, relating to the protection and use of the coast;

- Executive decrees establishing the list of protected non-cultivated vegetable species (93285 of 23/11/1993 and 12-03 of 04/01/2012). They protect over 500 species.

\section{Algerian taxa evaluated (at global or Mediterranean level) for IUCN Red List}

The IUCN global Red List contains 345 plant taxa with a distribution area that includes Algeria, or $7.8 \%$ of the total flora of Algeria. Including the
Le grand Phare de Cap Carbon, Algeria (C) Khellaf Rebbas

Mediterranean Red Lists raises the number of assessed taxa to $463,6 \%$ of which are in one of the threatened categories (CR, EN, VU).

\section{Threats}

Given the small number of Algerian plant taxa featuring on the Red List, and since they are unrepresentative of the total and, in particular, the Mediterranean flora of Algeria, it is not possible to draw conclusions from these statistics.

The diversity of flora is mainly threatened by:

- Urbanisation and the development of road and industrial infrastructure;

- Overgrazing, particularly in rural areas around the Tell Atlas and the High Plains, and to a lesser degree in the peri-urban areas of the Sahara;

- Pollution of water sources: mountain streams in Kabylie, the Tell Atlas and the Sahara, rivers in the valleys, floodplain wetlands; 


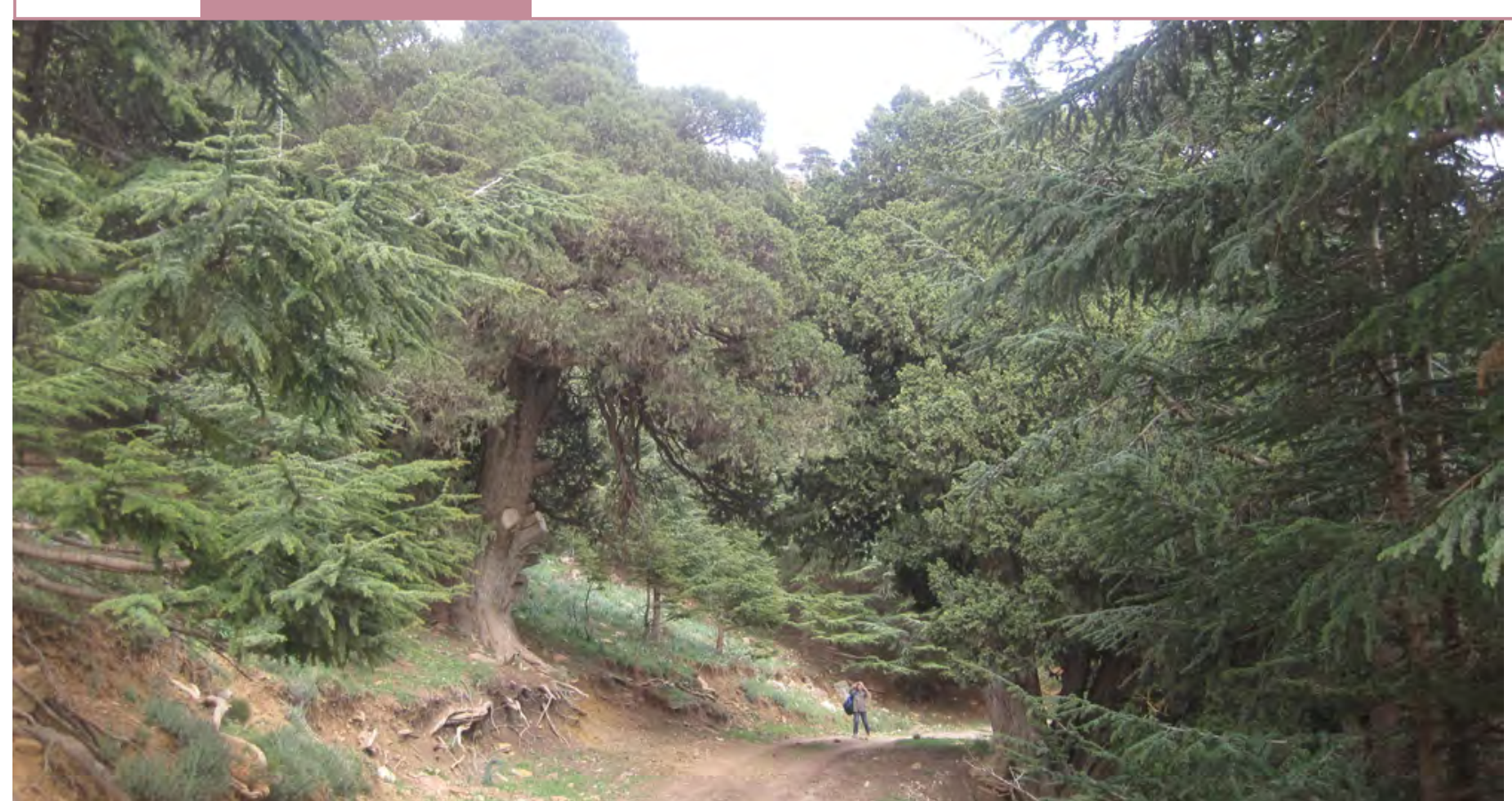

\section{$\Delta$}

Chelia Aures KBA, Algeria

(C) Attamane Briki

- Wildfires in old forests (old cedars, Algerian oak forests, old cork oaks, etc.);

- Pressure of tourism on natural sites (forests, waterfalls, etc.) and the coastline;

- Uncontrolled collecting of plants for medicine and/or food;

- Illegal felling of forest trees (oaks, cedars, etc.);

- Climate change and its consequences: recurrent wildfires, desertification, aridification;

- Land-use changes.

\section{Institutions responsible for conserving the flora}

- Ministère de l'agriculture, du développement rural et de la pêche, through the : Direction Générale des Forêts; National parks; Haut Commissariat au Développement de la Steppe; Institut National de Protection des Végétaux; Institut National de la Recherche Agronomique d'Algérie; Institut National de la Recherche Forestière; Agence nationale pour la conservation de la nature;

- Ministère de l'environnement et des énergies renouvelables, through the department responsible for biodiversity - the Centre National de Développement des Ressources Biologiques;

- The Hamma Botanical Garden in Algiers. 


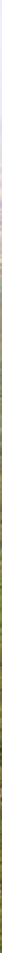

\section{$\Delta$}

El Feidja National Park and KBA

(C) Tunisia WWF

\section{TUNISIA}

Authors:

\section{Zeineb Ghrabi-Gammar}

Institut National Agronomique de Tunisie

Amina Daoud-Bouattour

Faculté des Sciences de Tunis

\section{Contributor: Amor Gammar}

Faculté des Lettres, des Arts et des Humanités de la Manouba

\section{National Red Lists}

The flora of Tunisia has around 2,700 taxa based on Le Floc'h et al. (2010), of which 26 species and 13 subspecies are nationally endemic (2.3\%).

A national Red List, not based on the IUCN criteria, has been drafted by the Ministère de l'Agriculture and includes approximately $2 \%$ of the taxa present in Tunisia. This list is not updated regularly. A hundred species feature on the Red List of the Registre National des Espèces Sauvages, initiated in 2010 by the Ministère de l'Environnement, which should soon be completed.

Evaluations using the IUCN criteria have been performed for Tunisia's aquatic and semi-aquatic plants (Garcia et al., 2010).

The species featuring on the national Red List benefit from legal protection, but the application of this protection is variable depending on the species.

\section{Tunisian taxa evaluated (at global or Mediterranean level) for IUCN Red List}

The IUCN global Red List contains 242 plant taxa with a distribution area that includes Tunisia, or $9 \%$ of the total flora of Tunisia. Including the Mediterranean Red Lists raises the number of assessed taxa to $337,3 \%$ of which are in one of the threatened categories (CR, EN, VU).

\section{Threats}

Given the small number of Tunisian plant taxa featuring on the Red List, and since they are unrepresentative of the total and, in particular, the Mediterranean flora of Tunisia, it is not possible to draw conclusions from these statistics.

The diversity of the flora is mainly threatened by: urbanisation, drought, overgrazing, pollution, climate change, fires and drainage waters.

\section{Institutions responsible for conserving the flora}

The institutions in charge of conserving flora are the Ministère de l'Environnement, le Ministère de l'Agriculture the Direction générale des Forêts (DGF), la Banque Nationale de Gènes (BNG) and the Agence de Protection et d'Aménagement du Littoral (APAL) as well as various research and education institutions, such as the Institut National Agronomique in Tunis, the Faculté des Sciences de Tunis, the Faculté des Sciences de Sfax, the Faculté des Lettres, des Arts et des Humanités de la Manouba and the Institut des Régions Arides de Médenine. 


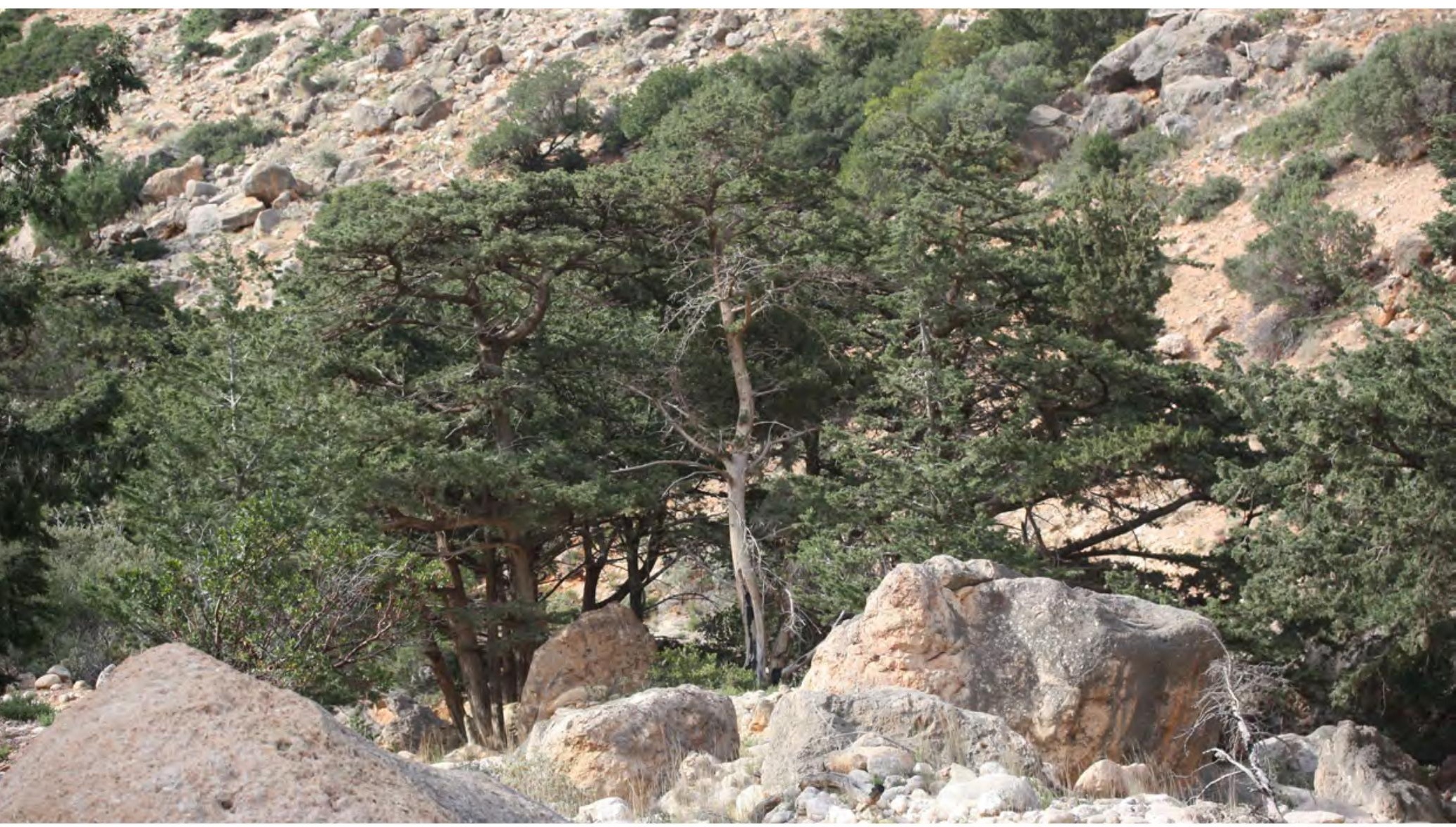

$\Delta$

Cupressus sempervirens in Wadi Mahboul, Al Jebel Al Akhdar, Libya (C) Stephen Jury

\section{LYBIA}

\section{Author: Errol Véla}

Université de Montpellier

Contributors:

Mohamed Makhlouf

Université de Tripoli

\section{Rafaa Essokne}

Université de Tripoli

\section{National Red Lists}

The flora of Libya includes 1,907 taxa of specific or subspecific rank, or 2,154 if we include cultivated or naturalised species (Dobignard \& Chatelain, 2010-2013). The number of endemic taxa is 130 , corresponding to $6 \%$ of the total.

There is no national Red List for Libya and there are no plans to prepare one.

The only legal protection applicable to the flora comes from the national parks regulations.

\section{Libyan taxa evaluated (at global or Mediterranean level) for IUCN Red List}

The IUCN global Red List contains 158 plant taxa with a distribution area that includes Libya, or $7.3 \%$ of the total flora of Libya. Including the Mediterranean Red Lists raises the number of assessed taxa to $218,2 \%$ of which are in one of the threatened categories (CR, EN, VU).

\section{Threats}

Given the small number of Libyan plant taxa featuring on the Red List, and since they are unrepresentative of the total and, in particular, the Mediterranean flora of Libya, it is not possible to draw conclusions from these statistics.

The diversity of the flora is mainly threatened by: the illegal and non-sustainable use of wood and plants by local populations, particularly since the start of the civil war; overgrazing by sheep and goats, as well as by camels in desert areas; uncontrolled urbanisation; and armed conflict.

\section{Institutions responsible for conserving the flora}

The main organisation in charge of conserving the flora is the Environment General Authority in Tripoli. 


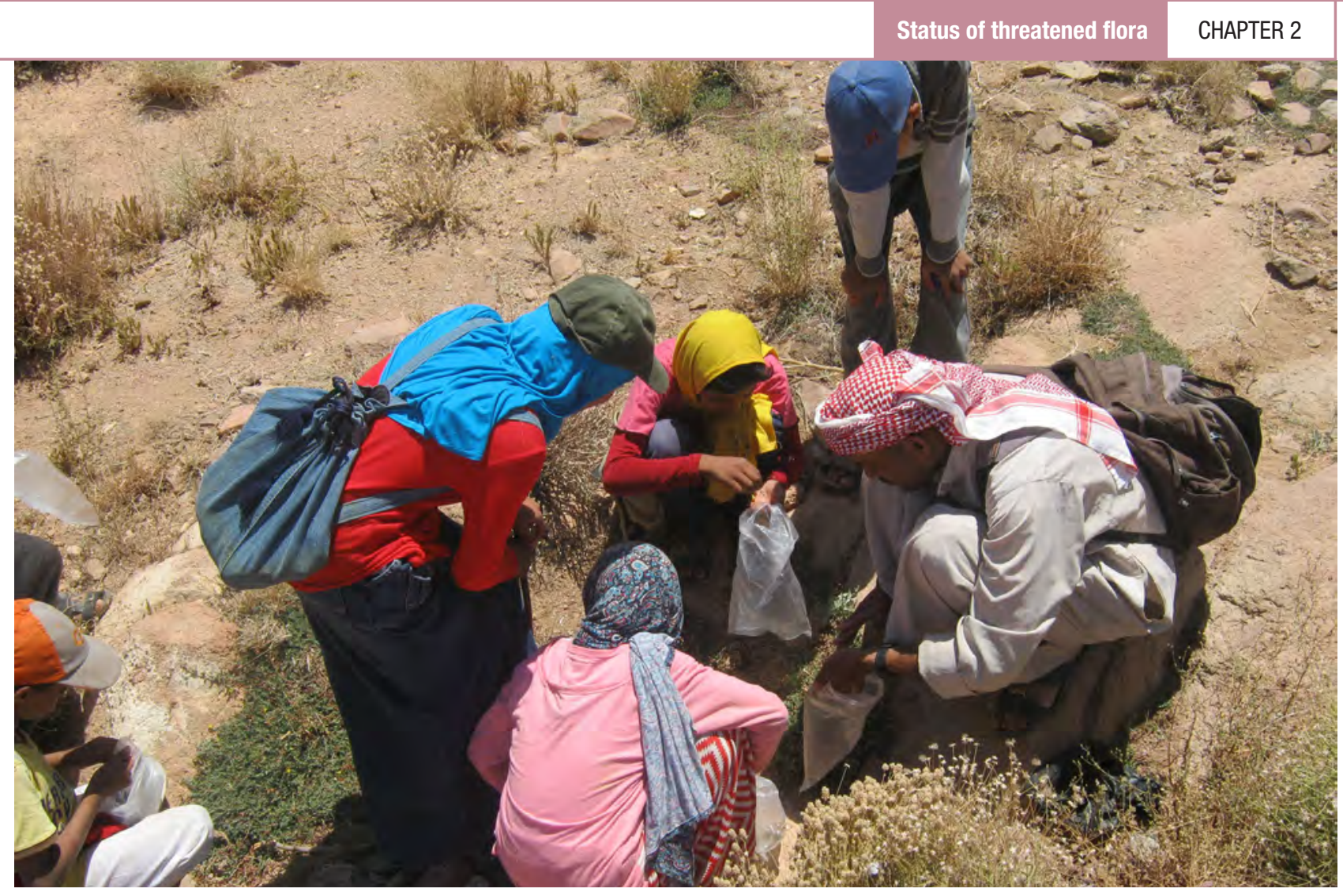

Author: Kamal Shaltout

Tanta University

\section{National Red Lists}

The flora of Egypt includes 2,145 species and 220 subspecies of indigenous and naturalised vascular plants (Boulos, 2009). There are also 175 species of bryophytes (El-Saadawi et al., 2003. El-Saadawi \& Shabbara, 2007). 60 species are strictly nationally endemic (2.5\%) and 93 are sub-endemic, meaning endemic to Egypt and a single neighbouring country (Boulos, 2009).

The preliminary national Red List includes 457 species (or close to $20 \%$ of the flora) classified in the following categories: 14 extinct, 123 endangered, 54 vulnerable, 173 rare and 93 not determined (El-Hadidi \& Hosni, 2000). The IUCN criteria and categories were not used for a number of geographically restricted species primarily because of the lack of sufficiently precise data to establish their Areas of Occupancy (AOO). This Red List has not been updated regularly. It is probable that a new national Red List will be drawn up by the Nature Conservation Sector of the Egyptian Environmental Affairs Agency (EEAA).

The conservation of the flora is essentially provided through 30 protected areas, which cover the majority of the significant ecological areas and have a total area of around $150,000 \mathrm{~km}^{2}$ (or $15 \%$ of the country).

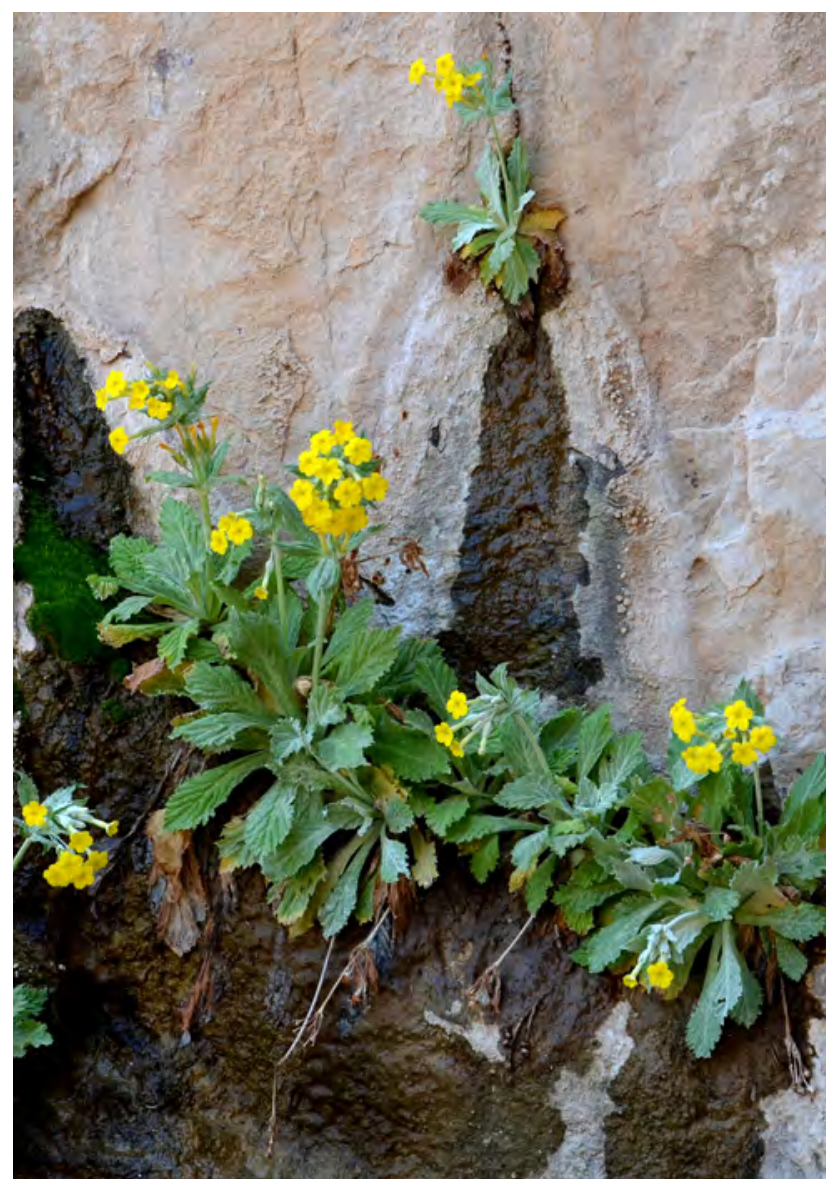

Primula boveana. Critically Endangered (CR), restricted to the environs of Mount Sinai, Egypt (C) Kamir Omar 


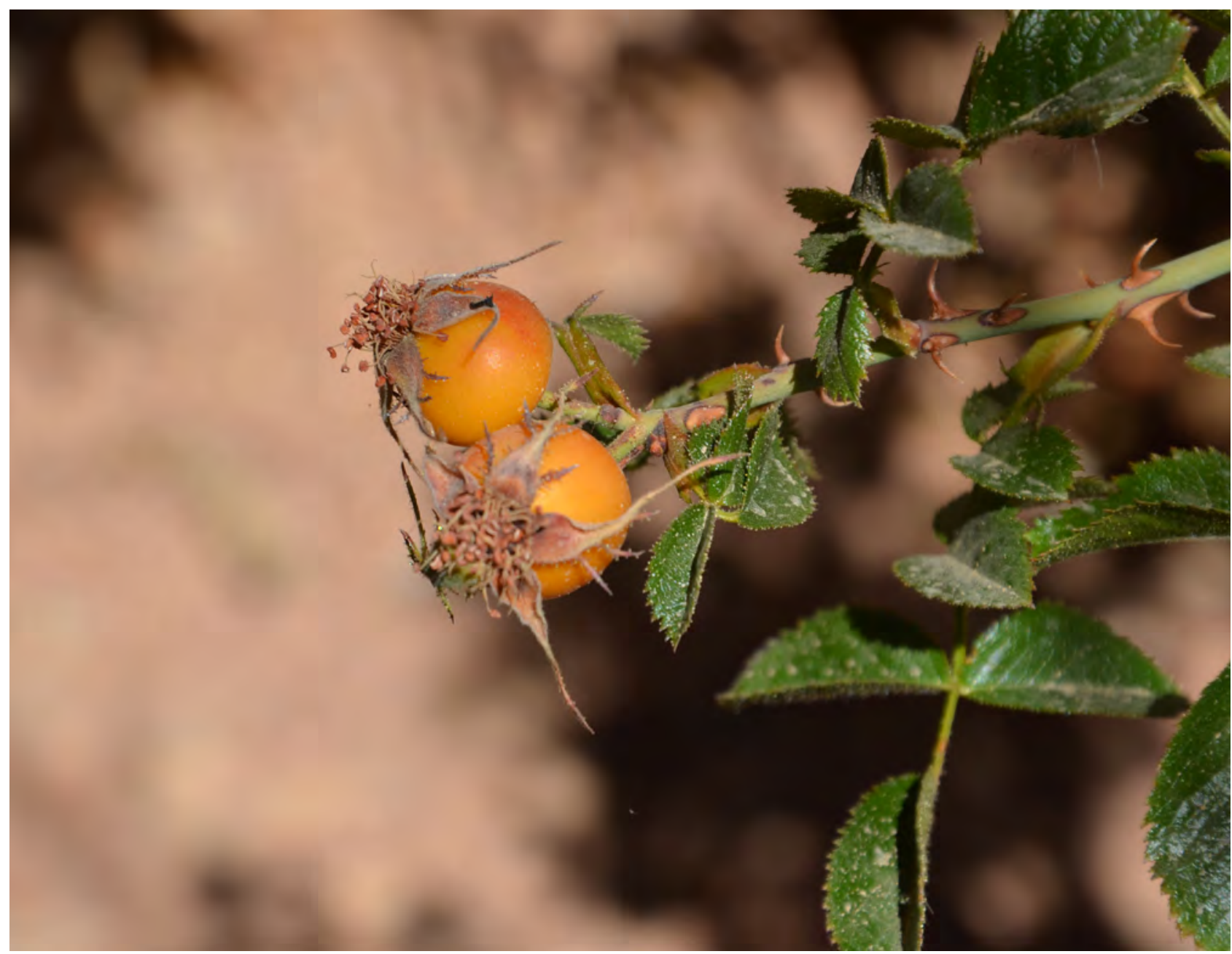

\section{Egyptian taxa evaluated (at global or Mediterranean level) for IUCN Red List}

The IUCN global Red List contains 227 plant taxa with a distribution area that includes Egypt, or $9.6 \%$ of the total flora of Egypt. Including the Mediterranean Red Lists raises the number of assessed taxa to $291,4 \%$ of which are in one of the threatened categories (CR, EN, VU).

\section{Threats}

Because of the relatively low number of Egyptian plant taxa featuring on the Red List, it is not possible to draw significant conclusions from these statistics.

The main threats to the flora are as follows:

- The main threats to wetland ecosystems and flora are: aquaculture and fisheries, eutrophication due to drainage from agriculture and industrial effluents, urbanisation (road infrastructure, construction), erosion of sandy coasts, and the rise in sea level, probably due to climate change.
Rosa arabica, Critically Endangered (CR) threatened by overgrazing and collection, is only present in the St Catherine KBA, Sinai, Egypt. (C) Kamir Omar

- The main threats to desert ecosystems and flora are: the expansion of agriculture, invasive plants, tourist activities, urbanisation (holiday villages and roads), overgrazing (mainly by sheep, goats and camels), the use of wood (as a fuel and for making charcoal), collecting of medicinal plants and quarrying.

- The main threats to coastal ecosystems and flora are: pollution from hydrocarbons, municipal and industrial waste and major flooding caused by heavy rainfall.

\section{Institutions responsible for conserving the flora}

The main institution in charge of conserving the flora in Egypt is the Nature Conservation Sector of the EEAA. The National Gene Bank, which forms part of the Agricultural Research Center, contributes to conserving the genetic resources of Egypt's flora. Six botanical gardens in Egypt conserve a total of 81 indigenous species, along with 2,392 cultivated taxa (Ammar, 2015). 


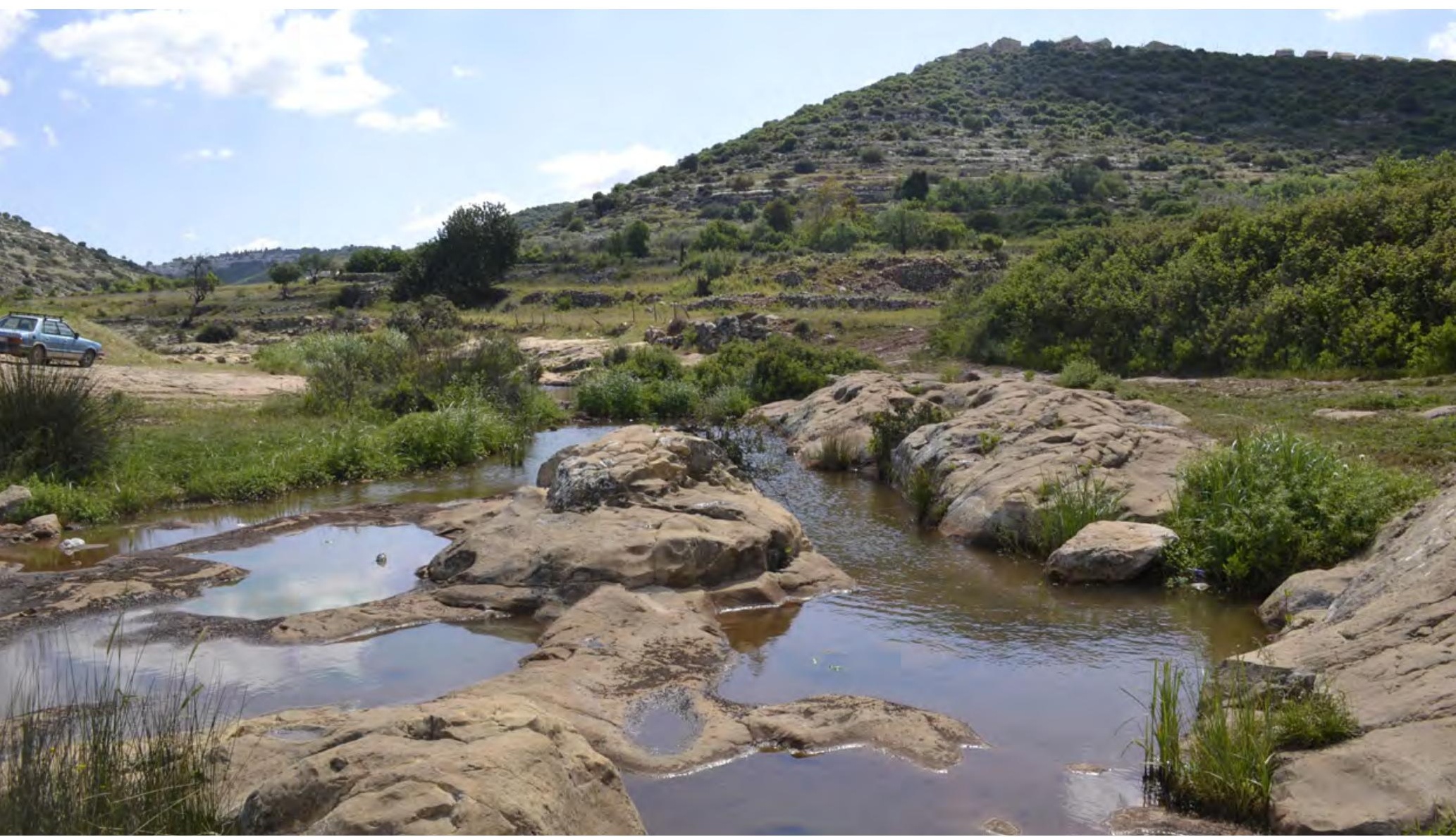

\section{PALESTINE}

\section{Author: Banan Al Sheikh}

National Agricultural Research Center, Jenin

\section{National Red Lists}

The flora of the West Bank includes 1,613 species of vascular flora, while the flora of 'Historic Palestine' comprises 2,665 species. Six taxa are endemic to the West Bank ( $0.3 \%$ of the flora).

There is no Red List for the West Bank or the Gaza Strip. A list of rare and threatened species for the West Bank is currently being published, including 617 taxa (38\% of the flora).

There is no regulation for the protection of rare and threatened plant species.

\section{Palestinian taxa evaluated (at global or Mediterranean level) for IUCN Red List}

The IUCN global Red List contains 163 plant taxa with a distribution area that includes Palestine, or $10 \%$ of the total flora of Palestine. Including the Mediterranean Red Lists raises the number of assessed taxa to $255,5 \%$ of which are in one of the threatened categories (CR, EN, VU).
Wadi Qana, Palestine (c) Banan Al Sheikh

\section{Threat}

Given the small number of Palestinian plant taxa featuring on the Red List, and since they are unrepresentative of the total flora, it is not possible to draw conclusions from these statistics.

The main threats are posed by intensive agriculture, particularly the use of pesticides and fertilisers, overgrazing, overcollecting of medicinal plants, wildfires, urbanisation and infrastructure development. The occupation of land, the creation of settlements (particularly in the Wadi Qana Nature Reserve) and transport infrastructure, security and military training, and the overuse of groundwater reserves have a significant negative effect on the flora and ecosystems.

\section{Institutions responsible for conserving the flora}

The main Palestinian institutions in charge of conserving the flora are the Ministry of Agriculture (through its forestry department) and the Environmental Quality Authority. 


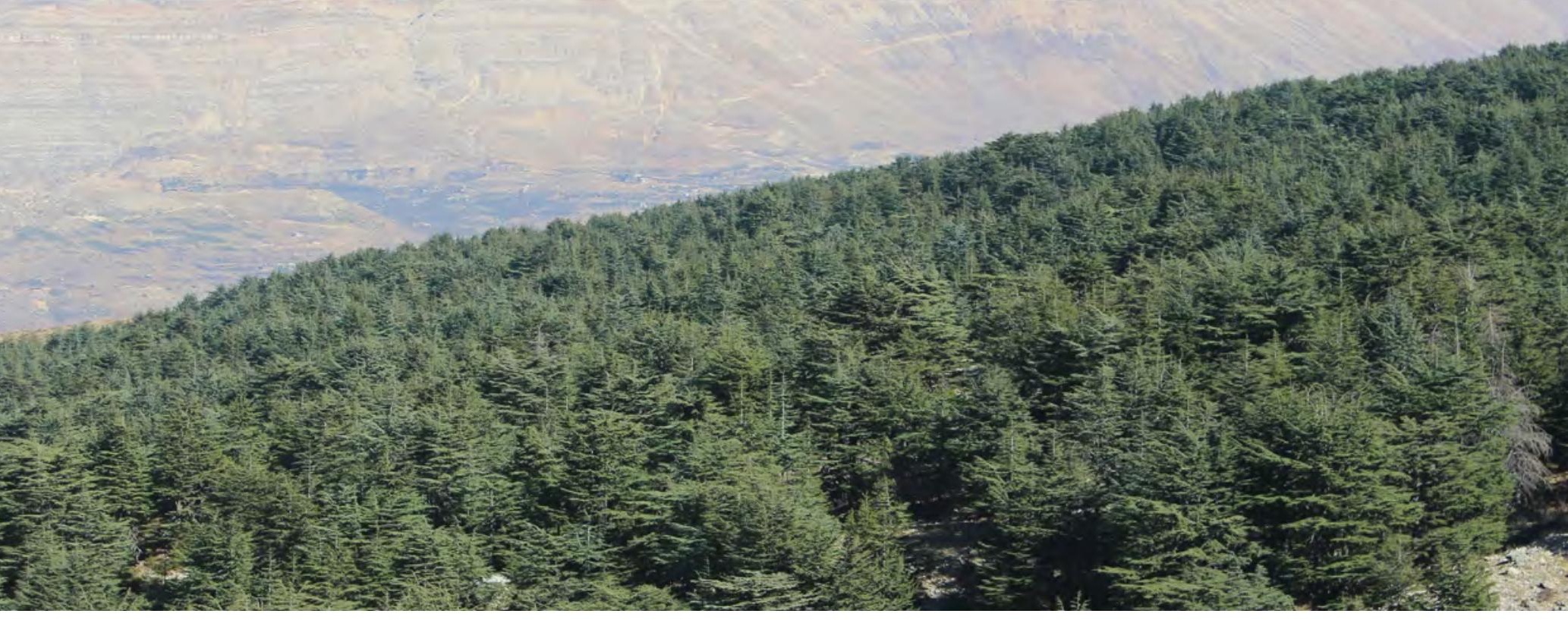

\section{LEBANON}

Authors:

Mohammad S. Al-Zein

American University of Beirut

Safaa Baydoun

Beirut Arab University

Magda Bou Dagher Kharrat

Université Saint-Joseph de Beyrouth

Sawsan Bou Fakhreddine

Association for Forests, Development and

Conservation

\section{Lamis Chalak}

Lebanese University

Hicham El Zein

American University of Beirut

Moustapha Itani

American University of Beirut

Nisrine Machaka-Houri

Université Saint-Joseph de Beyrouth

Lara Samaha

Ministry of Environment

Myrna Semaan

Friends of Nature

Jean Stephan

Lebanese University

Salma N. Talhouk

American University of Beirut

Mariana Yazbek

International Center for Agricultural Research in the

Dry Areas

\section{National Red Lists}

The flora of Lebanon currently includes 2,612 taxa, 108 of which are nationally endemic, which corresponds to a rate of endemism of $4.1 \%$ (Tohmé \& Tohmé, 2014). This rate is due to change upon the revision and updating of the flora and the incorporation of recently described taxa.

There is as yet no national Red List; however, numerous taxa have been assessed using the IUCN Red List criteria: seven species were evaluated as part of a project on the conservation of medicinal and aromatic plants; two species of aquatic plants were assessed within a project on aquatic plants of the eastern Mediterranean (Lansdown et al., 2014); and a project financed by the CEPF and directed by Saint-Joseph University has recently completed the evaluation of 200 species, 89 of which are endemic. The Lebanese University, which has made a significant contribution to this project, is involved in assessing trees and shrubs on a regional and global scale. Lebanon's monocotyledons have been evaluated as part of a project by the IUCN Centre for Mediterranean Cooperation.

The information required for these evaluations was compiled from a range of sources (literature, expert knowledge and data from fieldwork and inventories), providing adequate and sufficiently accurate data. 


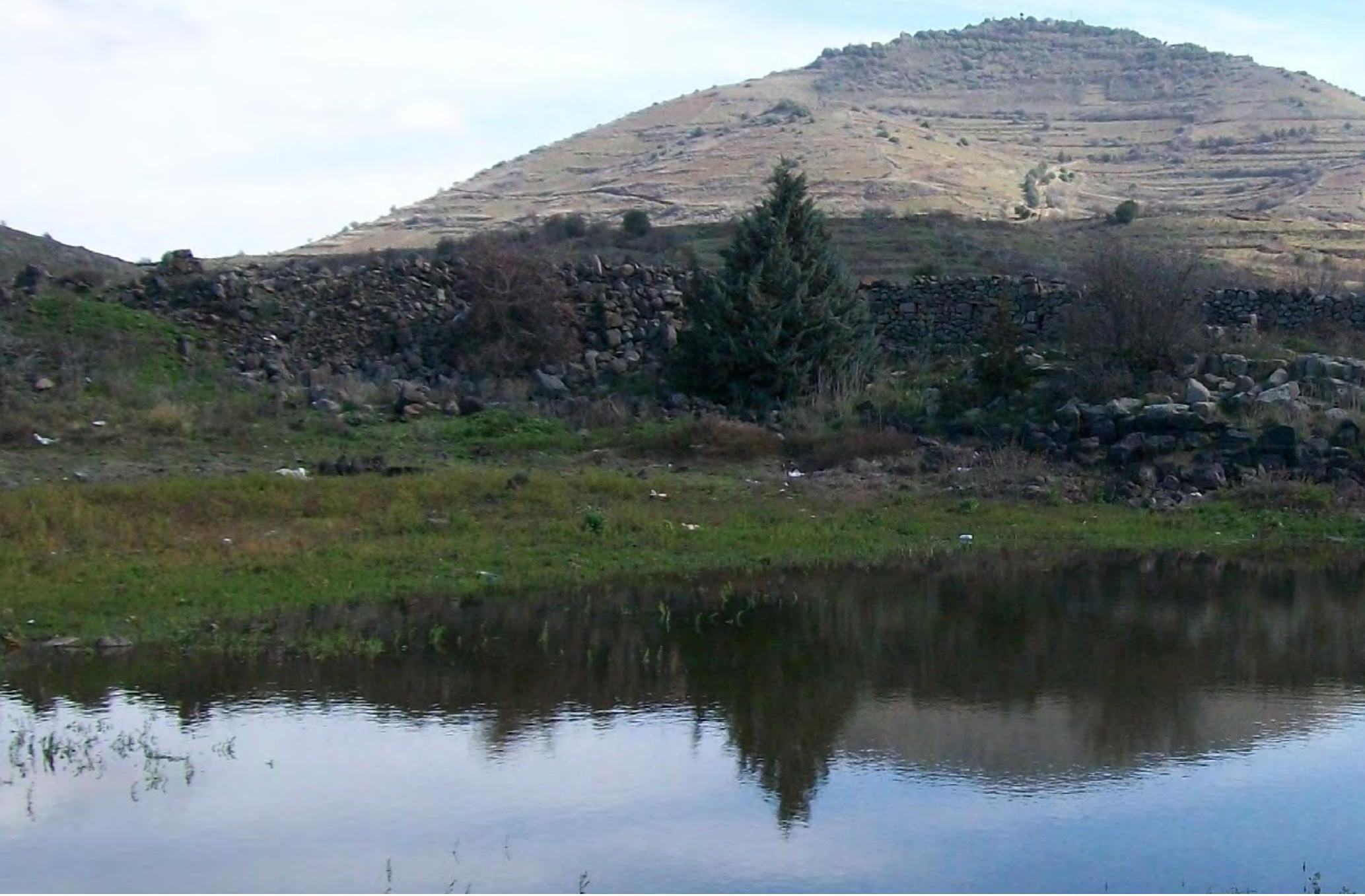

SYRIA

\section{Author: Sami Youssef}

AMAP, Université de Montpellier

Contributors

\section{Errol Véla}

AMAP, Université de Montpellier

Nigel Maxted

University of Birmingham

\section{National Red Lists}

The flora of Syria has 3,077 species (Mouterde, 1966-1983; Chikhali, 2001; Ghazal, 2008), 243 of which are endemic, an endemism rate of $7.9 \%$ (Chikhali, 2001).

There is still no Red List for Syria and there are no plans to establish one.

A list of protected species has been drawn up by the Ministries for Agriculture and the Environment. However, far too little attention has been paid to protect threatened plants in the field. Plant collecting is in principle forbidden in protected areas.

\section{Syrian taxa evaluated (at global or Mediterranean level) for IUCN Red List}

The IUCN global Red List contains 213 plant taxa with a distribution area that includes Syria, or $6.9 \%$ of the total flora of Syria. Including the Mediterranean Red Lists raises the number of assessed taxa to $346,8 \%$ of which are in one of the threatened categories (CR, EN, VU).

\section{Threats}

Given the small number of Syrian plant taxa featuring on the Red List, and since they are unrepresentative of the total flora, it is not possible to draw conclusions from these statistics.

The main threats faced by the flora are:

- Changes in land use, with increasing intensive farming (for wheat, barley and cotton) and/ or draining of marshes (for sugar beet) by mechanical means. 
- Urbanisation for tourism and second homes in the Mediterranean area (around Latakia) as well as in the mountain areas (around Damascus).

- Overuse of local resources - food plants in Mesopotamia ('al-Jazira'), aromatic and medicinal plants in the Mediterranean area, and both in Jabal-al-Arab ('Djebel Druze').

- Armed conflict in mountain areas, because of mines and bombs (but this has also caused visits to natural sites and resource exploitation to diminish, unlike on the plains).

- Forest fires in the Mediterranean region (more frequent because of greater numbers of people that do not take care).

- Overgrazing, according to population density (previously a greater threat, but now declining because of government distribution of fodder).

- Climate change (probably, but no reliable data currently available).

\section{Institutions responsible for conserving the flora}

The institutions in charge of conserving the flora in Syria are:

- The NCBT (National Commission for Biotechnology - Department of Biodiversity Conservation);

- The Ministry of State for Environmental Affairs (Biodiversity Department);

- The Ministry of Agriculture (Environment and Forest Department, as well as the Department of Steppes and Pastures). 


\subsection{State of knowledge of the extinction risk for plant species}

None of the countries studied in this book have a complete or recent national Red List and most have none at all or one that contains only a few taxa.

Table 2.2 summarises the data contained in the IUCN global Red List of Threatened Species (CR, EN, VU, NT and DD). The figures in this table refer to the total flora of the country concerned and not only to its Mediterranean part.

The rate of national endemics varies widely by country. It ranges from $0.4 \%$ for Palestine to $18.3 \%$ for Morocco, which is by far the country with the highest rate of endemism.

The percentage of each country's flora on the IUCN global Red List is small. It varies between $6.9 \%$ for Syria and $14.2 \%$ for Tunisia. In absolute terms, Morocco and Algeria have the highest number of taxa assessed, followed by Tunisia and Lebanon.
It should be noted, however, that the vast majority of the taxa assessed have a distribution covering several countries, or even extending well beyond the south and east Mediterranean.

It is therefore illusory to try to draw conclusions from so unrepresentative a sample. On average, however, $10 \%$ of the taxa assessed may be considered threatened or potentially threatened (CR, EN, VU, NT, DD), with a maximum of $22 \%$ for Morocco and a minimum of $3.7 \%$ for Palestine. It is therefore necessary to continue to perform assessments according to the IUCN Red List criteria, and to update them regularly. Priority should be given to restricted-range endemics and taxa considered rare and/or potentially threatened, especially those of economic or scientific importance such as Crop Wild Relatives that are important for food security in mitigatin the effects of climate change.

Table 2.2. Globally Threatened taxa on the IUCN Red List, by country.

\begin{tabular}{lrrrrrrrr}
\hline Country & Taxtot & Endtot & End\% & $\begin{array}{r}\text { Global } \\
\text { RL tot }\end{array}$ & $\begin{array}{r}\text { Global } \\
\text { RL \% }\end{array}$ & $\begin{array}{r}\text { Global RL } \\
\text { Pot Threat Pot Threat \% }\end{array}$ & $\begin{array}{r}\text { Global RL } \\
\text { Threat tot fl \% }\end{array}$ \\
\hline Morocco & 4,785 & 878 & $18.3 \%$ & 418 & $10.7 \%$ & 92 & $22.0 \%$ & $2.4 \%$ \\
\hline Algeria & 4,449 & 290 & $6.5 \%$ & 345 & $7.8 \%$ & 53 & $15.4 \%$ & $1.2 \%$ \\
\hline Tunisia & 2,700 & 39 & $2.3 \%$ & 242 & $9 \%$ & 30 & $12.4 \%$ & $1.1 \%$ \\
\hline Libya & 2,154 & 130 & $6.0 \%$ & 158 & $7.3 \%$ & 6 & $3.8 \%$ & $0.3 \%$ \\
\hline Egypt & 2,365 & 60 & $2.5 \%$ & 227 & $9.6 \%$ & 10 & $4.4 \%$ & $0.4 \%$ \\
\hline Palestine & 1,613 & 6 & $0.4 \%$ & 163 & $10.1 \%$ & 6 & $3.7 \%$ & $0.4 \%$ \\
\hline Lebanon & 2,612 & 108 & $4.1 \%$ & 227 & $8.7 \%$ & 25 & $11.0 \%$ & $1.0 \%$ \\
\hline Syria & 3,077 & 243 & $7.9 \%$ & 213 & $6.9 \%$ & 36 & $16.9 \%$ & $1.2 \%$ \\
\hline
\end{tabular}

Taxtot: Total number of taxa

Endtot: Total number of national endemics

End\%: Rate of endemism

Global RL tot: Number of taxa assessed on the IUCN global Red List

Global RL \%: Taxa assessed on the IUCN global Red List as a percentage of the total number of taxa

Global RL Pot Threat: Number of taxa assessed as threatened (CR, EN, VU), Near Threatened (NT) and Data Deficient (DD) on the IUCN global Red List
Global RL Pot Threat \%: Taxa assessed as threatened (CR, EN, VU), Near Threatened (NT) and Data Deficient (DD) on the IUCN global Red List as a percentage of the number of assessed taxa

Global RL Pot Threat tot fl \%: Taxa assessed as threatened (CR, EN, VU), Near Threatened (NT) and Data Deficient (DD) on the IUCN global Red List as a percentage of the total number of taxa in the country 


\subsection{Main threats to plants in the south and east Mediterranean}

The main threats to plants identified by the national experts are (in decreasing order of importance and according to the IUCN Threats Classification Scheme - www. iucnredlist.org/technical-documents/ classification-schemes):

Agriculture: mainly overgrazing but also intensive farming and use of fertilisers and biocides

Residential and commercial development: housing and urban areas, tourism

Biological resource use: gathering plants and (illegal) logging

Human intrusions and disturbance: recreational activities, and also war, civil unrest and military exercises (for Libya, Palestine and Syria)

Natural system modifications: forest fires, water abstraction (ground and surface)

Pollution: domestic and urban waste water, industrial and agricultural effluents

Climate change: droughts, habitat shifting and alteration

Transportation and service corridors: roads and railroads

\section{Energy production and mining: quarrying}

Invasive species: invasive alien plants

These threats vary across countries and regions, but overgrazing and urbanisation are often considered to be the most important threats.

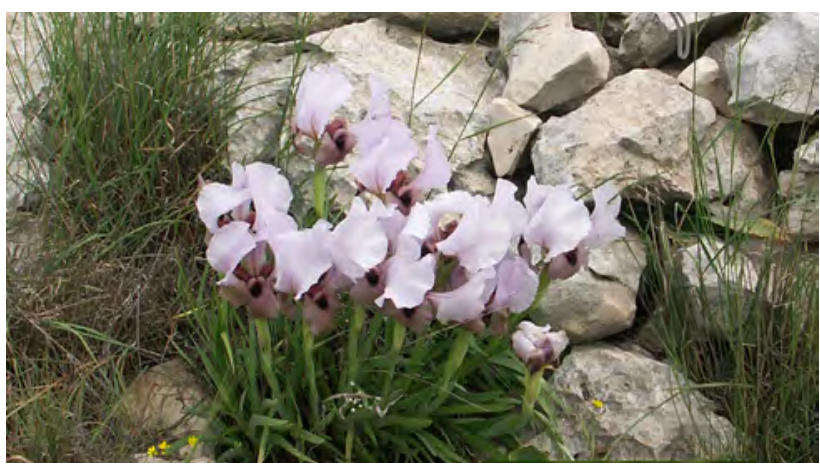

Iris lortetii, endemic to Palestine and Israel, evaluated Endangered (EN), it is threatened by the uncontrolled collection and the uprooting of its rhizomes (C) Banan Al Sheikh

\subsection{Conclusions and recommendations}

Current data on threatened plant species and types of threat are far too limited for any conclusions to be drawn that may be statistically significant and applicable to specific conservation measures. That is why a Key Biodiversity Area (KBA)-based approach is particularly relevant, and this is developed in the next chapter.

It is vitally important to continue gathering field data and to actively pursue taxon assessments, using the IUCN Red List or any other suitable methodology. The data included in the Red List assessments, provide guidance for further research and conservation, however, do not usually provide a sufficient basis for species recovery. Moreover, since almost 12,500 plant taxa are endemic to the Mediterranean, the work of assessing them all remains a huge challenge. Species recovery programmes and action plans require much more thorough threat assessments and detailed plans of work, because incorrect or incomplete assessments are the commonest cause for such programmes to fail.

It should also be noted that threatened plants receive legal protection in only a few countries. National policies for the conservation of flora should be strengthened.

However, even if data on threats are incomplete, it is clear that many taxa and their habitats are threatened and that it is urgent and important to implement conservation measures. 


\subsection{Introduction}

Key Biodiversity Areas (KBAs) are sites that contribute significantly to the persistence of globally important biodiversity. In 2016, a partnership of institutions joined forces to agree on a methodology for countries to identify KBAs. As a result the Global Standards for the Identification of KBAs (hereafter the KBA standards) were published (IUCN, 2016).

The reason for developing agreed criteria for identifying KBAs was to harmonise existing approaches to the identification of important sites for biodiversity. Since they can be applied consistently and repeatedly by different institutions, the KBA standards are expected to provide improved understanding of why particular sites are important for biodiversity.

KBAs are sites, meaning that they have a boundary which can be shown on a map, and the KBA boundary should delimit an ecologically meaningful management unit to ensure persistence of the biodiversity elements for which it is important. The identification of KBAs uses multiple criteria and subcriteria, each with associated thresholds. The criteria and thresholds of the global KBA standards are not identical to those by which Important Plant Areas (IPAs) or other significant sites (Important Bird and Biodiversity Areas - IBAs; Alliance for Zero Extinction sites - AZEs; etc.) were identified in the past.

The process of outlining key areas for plants in the south and east Mediterranean started with the identification of IPAs (Radford et al., 2011). Given the differences between IPAs and KBAs in their criteria, thresholds and minimum information requirements, a correspondence between the two systems was developed. Those IPAs that met the requirements of the KBA standards were recognised as 'global KBAs for plants', while IPAs that did not meet the KBA standards were considered 'regional KBAs for plants'.

The process of validating sites against KBA criteria took place between late 2016 and early 2017, and was conducted not only for IPAs but also for sites identified as important for other taxa, such as birds (IBAs) or freshwater species (FWKBAs). Integrating all these different databases required the redrawing

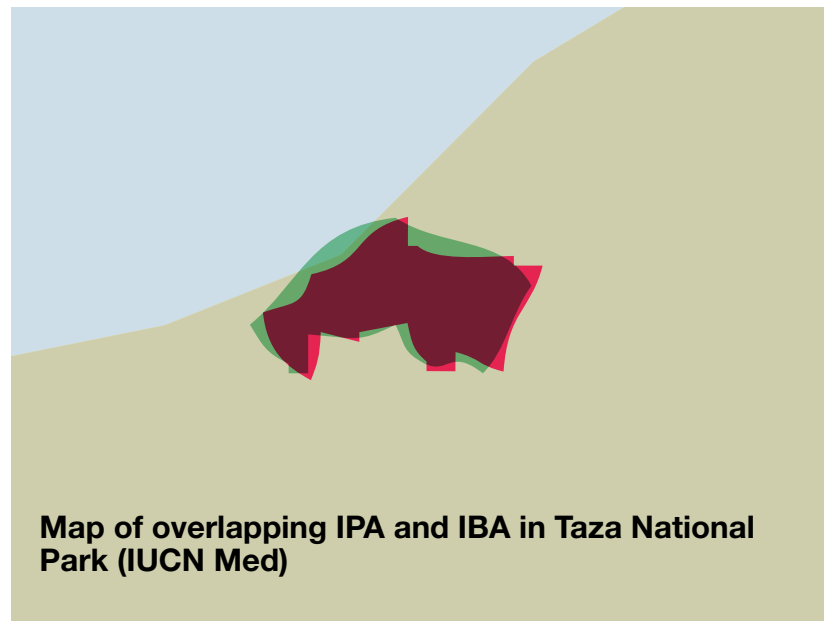

Overlapping IPA and IBA in the Taza National Park (Algeria). Redefining the boundaries of a KBA composed of overlapping sites requires an extensive consultation process.

of boundaries and an extensive consultation process, which was incorporated in the update to the Mediterranean Ecosystem Profile (CEPF, 2017).

\section{DISCLAIMER: This chapter focuses on the} subset of KBAs identified for plants. For practical reasons, these are described in the following section as 'KBAs for plants', defined as KBAs that have been identified on the basis of plant species (as trigger species). There might be KBAs where endangered plants are present, but which were identified and delineated on the basis of other taxa. KBAs for plants may overlap with other subsets of KBAs, resulting in a final KBA with different boundaries.

Site delimitation has been based on the principle of manageability, adapting to existing management units. Delineation is, however, an iterative process, and to facilitate the national interpretation of results and application of conservation policies, the boundaries of KBAs for plants as presented here may be reviewed in future.

The iterative delineation process may result in boundary changes in order to form practical management units, where KBAs for plants overlap with other KBAs, protected areas or other site elements. Once their final boundaries have been agreed, they have undergone scientific review and the documentation requirements have been met, 
the sites are submitted to the KBA secretariat and, if confirmed, will appear in the KBA database. This chapter deals only with the subset of KBAs identified for plants.

Sites are identified as KBAs when they meet at least one of the criteria in. For a detailed set of subcriteria and thresholds, please refer to the annexes or to the KBA Partnership website:

\section{http://www.keybiodiversityareas.org}

Box 3.1. Criteria for the identification of KBAs. For further details on subcriteria and thresholds, see Annexes.

Criterion A: Presence of a significant proportion of threatened biodiversity (including species and ecosystems).

Criterion B: Presence of geographically restricted biodiversity (which may not necessarily be threatened), including individual species, co-occurring species, assemblages of species, and ecosystem types.

Criterion C: Ecological integrity: sites hold exceptionally intact ecological communities with supporting ecological processes.

Criterion D: Exceptional biological processes, including aggregations of a large proportion of a species' population, ecological refugia, and source populations essential for the survival of the species.

Criterion E: High irreplaceability: quantitative analysis of complementarity between sites shows that a site has very high irreplaceability (i.e. is highly unique) in terms of global biodiversity.

The following section includes a description of the KBAs identified in the Mediterranean parts of the target countries. Information is provided for each site, including at least the elements listed in Box 3.2.
Box 3.2. Example of a map entry showing information on a KBA for plants.

0107 Tazekka National Park (22)

03)A1a, B1 Festuca humbertii Litard. \& Maire (04)

05) The Tazekka National Park is located in Taza Province at the northern end of the Middle Atlas. It includes forest areas of oak and cedar.

1. KBA number: Number to locate the KBA on the map

2. KBA name: Name of the KBA for plants in English. The site name may differ if the site is part of a broader KBA based on other taxa, or if it is expressed in the local language.

3. KBA criteria met: This refers to the global KBA criteria and subcriteria as given in the annexes.

4. Trigger species: The species that led to the site being considered a global KBA. The species should meet the criteria mentioned above. For regional KBAs (old IPAs that do not meet the global KBA criteria) no species are mentioned.

5. Description: Brief description of the site.

Clearly, the identification of KBAs is just the first step in a continuing conservation process. Following identification, considerable investment must be devoted to gap analysis, scheduling and planning, to ensure that the right conservation tactics can be brought to bear on each site. After this, conservation implementation involves putting these plans into effect to safeguard a given KBA. This is followed by the development of monitoring systems to measure the effectiveness of these actions over time, and by further refinement of planning and interventions (Eken et al., 2004).

KBAs are not only sites of biological importance. Their delimitation - the actual drawing of boundaries to delineate the site - has to take the site's 'manageability' into account. In other words, the raison d'être of KBAs is to serve as territorial units where management planning, actions and monitoring can take place. 


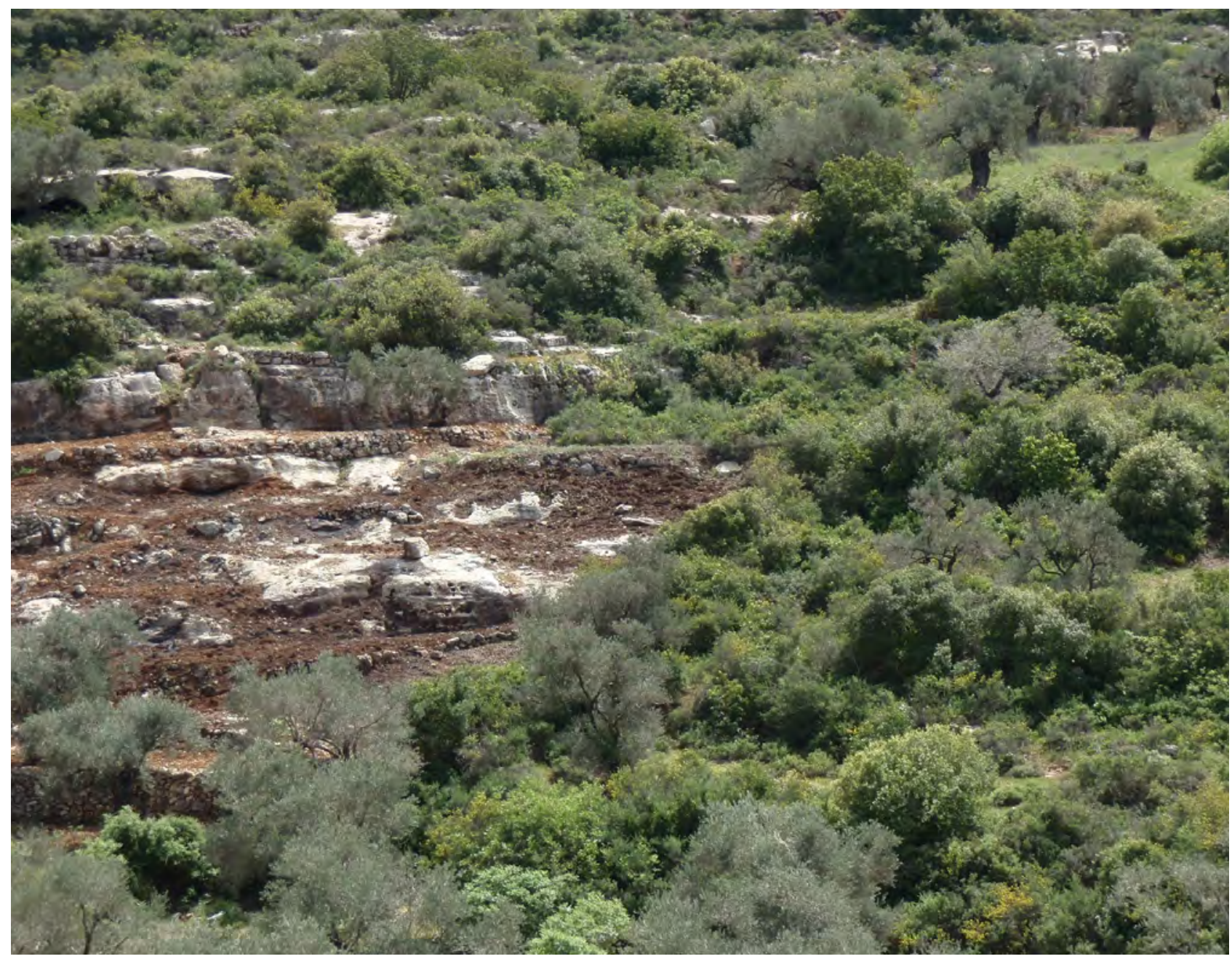

\section{$\Delta$}

KBA of Wad Qana-Wad Eshai'r located in mountains of central Palestine (C) Banan Al Sheikh

Therefore, even though KBAs are not necessarily protected areas, there are very interesting synergies between the two types of network. The most obvious may be the achievement of common conservation goals by developing a network of sites that goes beyond conservation areas. It is also worth noting that much of the knowledge developed in (or for) protected areas can be very useful in the management of KBAs. The next chapter will explore the approaches to plant conservation developed in the region. Many conservation approaches and tactics are especially suitable for applying at site (i.e. KBA) level, where they can be adapted to the needs or perceptions of the local population.

\section{Recommended reading}

http://www.keybiodiversityareas.org

A global standard for the identification of Key Biodiversity Areas (IUCN 2016).

https://portals.iucn.org/library/node/46259). 


\subsection{KBAs for plants in the south and east Mediterranean}

The following section includes an analysis of Key Biodiversity Areas for plants in the south and east Mediterranean, based on KBAs identified in the Mediterranean parts of the countries or territories analysed (Morocco, Algeria, Tunisia, Libya, Egypt, Palestine, Lebanon and Syria).
To distinguish the 'Mediterranean' parts of the target countries, this publication uses the Mediterranean hotspot boundaries prepared by the Conservation International Foundation (Conservation International, 2005).

The target countries include $150 \mathrm{KBAs}$ for plants with a total area of nearly $850,000 \mathrm{~km}^{2}$, as shown in Table 3.1.

Table 3.1. KBAs for plants in the south and east Mediterranean, by country

\begin{tabular}{lcccccc}
\hline Country & $\mathbf{N}^{*}$ KBAs* & $\begin{array}{c}\text { Regional } \\
\text { KBAs* }\end{array}$ & Global KBAS* & $\begin{array}{c}\text { Total KBA } \\
\text { area }\left(\mathbf{k m}^{2}\right)^{\star *}\end{array}$ & $\begin{array}{c}\text { Hotspot land } \\
\text { area }\left(\mathbf{k m}^{2}\right)\end{array}$ & $\begin{array}{c}\% \text { of hotspot } \\
\text { in KBAs }\end{array}$ \\
\hline Algeria & 39 & 1 & 38 & 26,116 & 302,050 & $9 \%$ \\
\hline Egypt & 8 & 5 & 3 & 147 & 3,740 & $4 \%$ \\
\hline Lebanon & 26 & 2 & 24 & 2,662 & 10,140 & $26 \%$ \\
\hline Libya & 3 & 3 & 0 & 21,209 & 63,910 & $33 \%$ \\
\hline Morocco & 22 & 1 & 21 & 7,266 & 323,580 & $2 \%$ \\
\hline Palestine & 6 & 0 & 6 & 748 & 5,060 & $15 \%$ \\
\hline Syria & 25 & 9 & 16 & 6,596 & 51,700 & $13 \%$ \\
\hline Tunisia & 21 & 7 & 14 & 2,468 & 81,890 & $3 \%$ \\
\hline TOTAL study area & $\mathbf{1 5 0}$ & $\mathbf{4 4}(\mathbf{1 9} \%)$ & $\mathbf{1 0 6}(\mathbf{8 1} \%)$ & $\mathbf{6 7 , 2 1 2}$ & $\mathbf{8 4 2 , 0 7 3}$ & $\mathbf{8} \%$ \\
\hline
\end{tabular}

* Number of sites within the Mediterranean hotspot only

** Land area of KBAs within the Mediterranean hotspot only

The analysis of area coverage or the percentage of a country's area covered by KBAs needs to be interpreted with caution. The size of each KBA depends on the delineation procedure, which is directly linked to a manageable unit, and therefore conclusions need to be drawn carefully. For example, if a short-range endemic species occurs on a single site measuring just a few hundred square metres, the KBA to be delimited may be as small as 1 ha (if the best management unit is a micro-reserve, for instance) or as big as 1,000 ha (if it is included within a protected area, and the best management unit is the protected area itself).
In total $150 \mathrm{KBAs}$ are identified for plants in the Mediterranean area of the selected countries. Of the KBAs identified $81 \%$ are Global KBAs and $19 \%$ are regional KBAs (Previously identified IPAs that don't fullfill the Global KBA standards) 


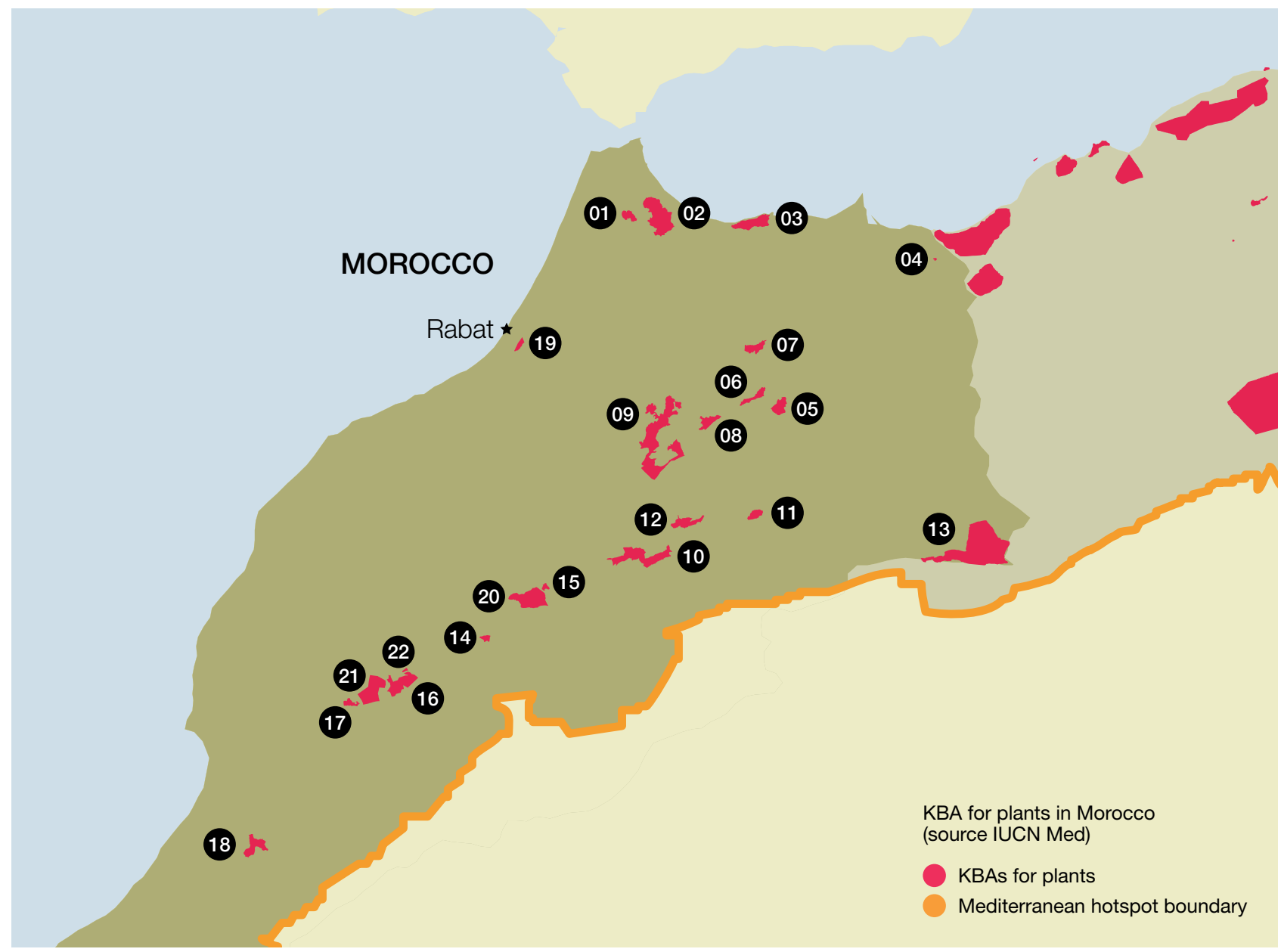

\subsection{KBAs for plants by country}

\section{MOROCCO}

\section{Authors}

\section{Hassan Rankou}

Global Diversity Foundation, Marrakech

Royal Botanic Gardens Kew, Ugo D'Ambrosio

Global Diversity Foundation, Marrakech

\section{Emily Caruso}

Global Diversity Foundation, Marrakech

\section{Gary Martin}

Global Diversity Foundation, Marrakech
01 Jbel Bouhachem

A1a, B1 Acis tingitana (Baker) Lledó, A.P. Davis \& M.B. Crespo Jbel Bouhachem is located in the Rif. The bioclimate is cool and wet, with temperate to cold stages of thermomediterranean, as well as meso- and supramediterranean vegetation.

02 Talassemtane National Park A1a, B1 Festuca rifana Litard. \& Maire The Talassemtane National Park in the eastern part of the Rif limestone ridge is characterised by its biodiversity and its remarkable landscapes. With its rugged terrain typical of the Rif mountains, this unique area offers natural landscapes of great heritage value.

03 Al Hoceima National Park A1a, B1 Bromopsis maroccana (Pau \& Font Quer) Holub

Al Hoceima National Park is the most important protected area on the Mediterranean coast of Morocco. It is dominated by a stretch of wild, unspoilt rocky coast where limestone cliffs dive into the sea.

04 Beni Snassene Regional KBA (IPA)

Beni Snassene is located in the Monts de l'Oriental (Berkane Province). It is a mountainous massif reaching 1,532 m at Ras Foughal, the highest point in the region, offering a unique wooded landscape of high quality. It is characterised by numerous caves and gorges in karstified limestone, which form remarkable cultural sites.

$05 \mathrm{Jbel}$ Bou-Naceur

B1 Artemisia flahaultii Emb. \& Maire The Jbel Bou-Naceur KBA occupies the highest massif of the Middle Atlas, reaching an elevation of $3,340 \mathrm{~m}$. This massif is subjected to both oceanic and continental influences. The main plant formations are based on cedar, holm oak, juniper, red juniper and thorny xerophytes, which form the main structure of the KBA, with pine appearing on marl-limestone outcrops. The cedar and Juniperus thurifera formations are severely degraded and natural regeneration is practically nil. The site also features numerous endemic plant species.

\section{Jbel Bou lblane}

B1 Crepis hookeriana Ball

Jbel Bou Iblane is located in the eastern part of the Middle Atlas. It is spread over two sectors, Taffert and Moussa or Salah. The site occupies the northern slope of the limestone ridge up to Jurassic limestone formations on the north-western slope of Moussa or Salah, culminating at 3,000 m. 
07 Tazekka National Park A1a, B1 Festuca humbertii Litard. \& Maire

The Tazekka National Park is located in Taza Province at the northern end of the Middle Atlas. It includes forest areas of oak and cedar.

\section{Jbel Tichoukt}

A1b, B1 Tricholemma jahandiezii (Jahandiez \& Maire) Röser

Jbel Tichoukt is a secondary Jurassic limestone range located between the central Middle Atlas and the eastern Middle Atlas with an area of 12,500 ha. It rises to $2,787 \mathrm{~m}$ with a ridge line that stays above $2,400 \mathrm{~m}$ for most of its length. The Oued Guigou delimits the range to the north with the Tarhroute depression and the Skoura basin.

09 Ifrane National Park B1 Argyrocytisus battandieri (Maire) Raynaud

Ifrane National Park in Ifrane province has both forest and pasture. Pastureland occupies $44 \%$ of its area, forest $33 \%$ and farmland $23 \%$.

10 Eastern High Atlas National Park B1 Carum lacuum Emb.

The Eastern High Atlas National Park consists of very rugged mountainous massifs ranging from 1,600 to over $3,000 \mathrm{~m}$ in height.

\section{$11 \mathrm{Jbel}$ Ayachi}

A1a, B1 Elymus festucoides (Maire) Ibn Tattou

Jbel Ayachi is the highest peak in the eastern High Atlas (3,757 m), overlooking the Moulouya plain. It is a complex massif consisting of a series of parallel secondary ranges of varying heights. In the north, these ranges are Jbel Taarbat, Jbel Toufli n'Ou Addou and the Amkaïdou; in the south, the Jbel Maoutfoud almost equals the Ayachi range. Between these secondary ranges there are deep valleys.

\section{Jbel Maâsker}

\section{B1 Lotononis tapetiformis Emb. \&} Maire

Jbel Maâsker is an important mountain in the eastern High Atlas with elevations ranging from $1,950 \mathrm{~m}$ to more than $3,000 \mathrm{~m}$. It extends westwards towards the Ayachi massif, from which it is separated by the cross valley of Oued Ansegmir. Geomorphologically, Maâsker is characterised by the outcropping of very high, steep cliffs, which are generally inaccessible especially on the northern slopes.

\section{$13 \mathrm{Jbel}$ Krouz}

\section{B1 Borago trabutii Maire}

Jbel Krouz is in a mountain range aligned east-west, about $70 \mathrm{~km}$ long with elevations of 900 to $1,700 \mathrm{~m}$. The lithology is dominated by secondary limestone. Steep slopes appearing to be bare of all vegetation form a landscape of lines and ridges. This KBA is considered one of the most original in pre-Saharan Morocco.

\section{Jbel Mgoun}

\section{A1a, B1 Elymus festucoides (Maire)} Ibn Tattou

Jbel Mgoun is the highest peak in the central High Atlas. It reaches 4,068 m in elevation, with a large area above $3,000 \mathrm{~m}$ The neighbouring peaks and valleys show diverse ecosystems representative of the central High Atlas limestone.

\section{Tamga}

\section{B1 Onopordum dyris Maire}

Tamga KBA is located in the High Atlas (Azilal Province) in the heart of the Ahansal valley, with steep slopes, secondary limestone cliffs and areas of marl-limestone. Elevations vary between 1,200 and $2,800 \mathrm{~m}$. It contains unique landscapes such as the 'cathedral', a huge rock overlooking the valley, cliffs and escarpments.

\section{Toubkal National Park B1 Viola dyris Maire}

Toubkal National Park covers the central block of the High Atlas with medium to high mountains. It contains the highest points in North Africa, with many peaks exceeding $3,500 \mathrm{~m}$. Its elevation ranges from $1,200 \mathrm{~m}$ at Takherkhort to 4,167 $\mathrm{m}$ at the summit of Toubkal. Toubkal KBA has an asymmetrical shape with an elongation from west to east.

\section{Aghbar}

\section{A1a, B1 Cedrus atlantica (Endl.) Carrière}

Aghbar KBA is located in the western High Atlas, at elevations between 1,300 and $3,000 \mathrm{~m}$ on the ridges bordering the Tichka plateau.
18 Jbel Kest, Anezi and Jbel Imzi B1 Argania spinosa (L.) Skeels The site corresponds to a contact zone where varied phytogeographical elements meet, making this KBA a botanical crossroads. The vegetation comprises Mediterranean, Macaronesian, Saharan and tropical elements that cohabit or not depending on the climatic conditions.

\section{Maâmora}

\section{B1 Pyrus mamorensis Trab.}

The Maâmora forest is located in northwestern Morocco and is part of the state's private forest, which is managed by the forest service of Kenitra Province. It includes open cork oak forest.

\section{Ait M'hamed}

\section{A1b, B1 Anacyclus pyrethrum (L.) Lag.}

Ait M'hamed lies approximately $180 \mathrm{~km}$ east of Marrakesh in Azilal province. It ranges in elevation from 950 to $2,600 \mathrm{~m}$ (average 1,822 $\mathrm{m}$ ). It belongs to the semi-arid area with cold winters and dry summers. The habitat is highly degraded with large areas fully or partly deforested. The dominant species are Quercus ilex, Juniperus phoenicea, Juniperus oxycedrus and Fraxinus dimorpha. Ait M'hamed has a rich flora estimated to consist of 260 taxa belonging to 174 genera and 58 families, with a high rate of endemism at $40 \%$.

\section{Imegdale}

A1a, B1 Cupressus atlantica Gaussen (=Cupressus dupreziana var. atlantica)

Imegdale is located approximately $75 \mathrm{~km}$ south of Marrakesh in Al Haouz Province (Marrakesh-Safi region) at elevations ranging from 900 to $2,500 \mathrm{~m}$. The climate is arid Mediterranean and the vegetation is dominated mainly by Quercus ilex, Juniperus phoenicea, Juniperus thurifera and scrublands with spiny xerophytes. However, the vegetation is highly degraded.

\section{Oukaiimmeden}

\section{A1a, B1}

Dactylorhiza atlantica Kreutz \& Vlacih The Oukaïmeden plateau is located $75 \mathrm{~km}$ south of Marrakesh; it lies at an altitude of 2,650 m. The Oukaïmeden site is dominated by wet grasslands, pozzines and dry grasslands. The flora is estimated to comprise 198 species in 122 genera and 38 families. 


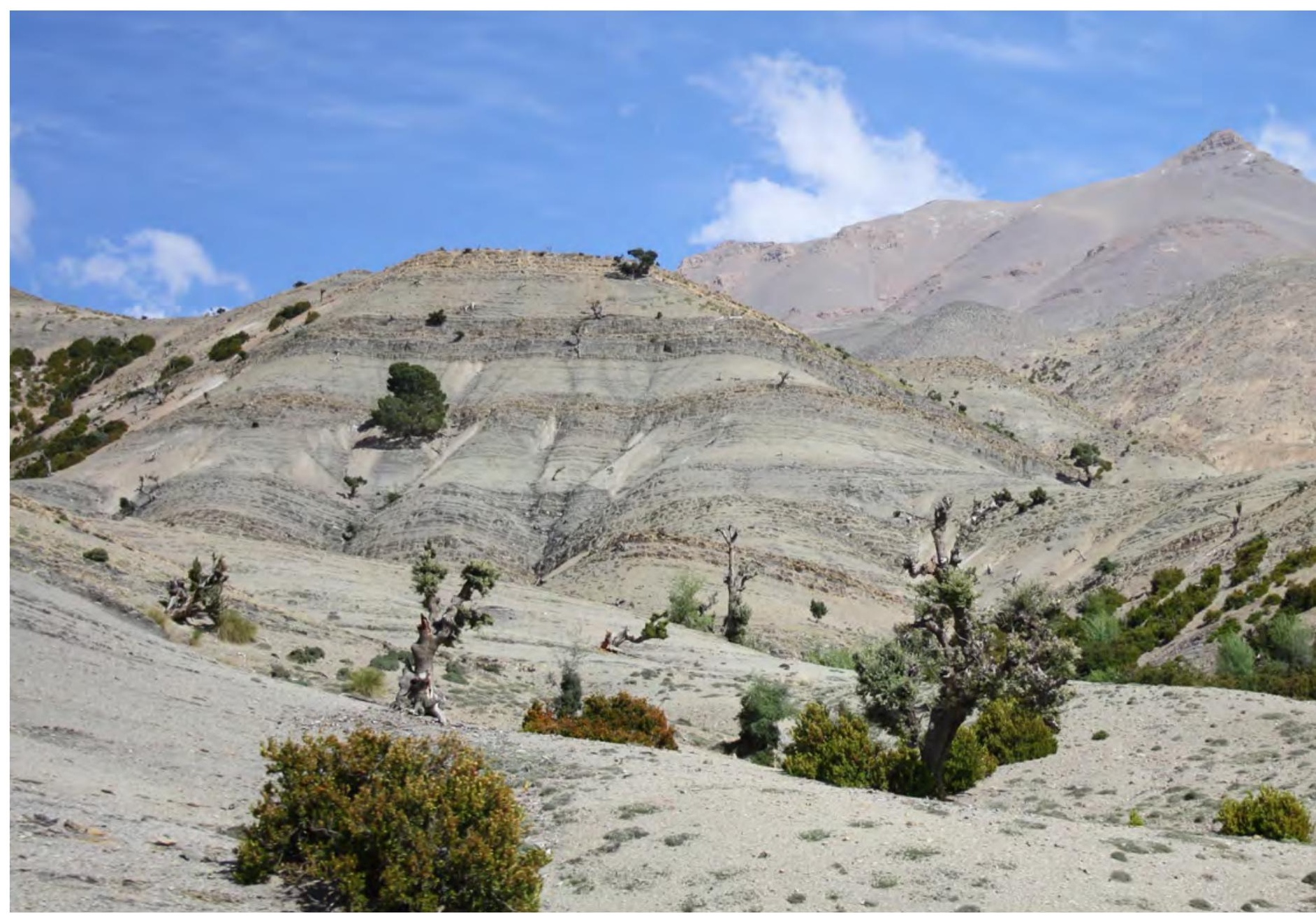

\section{Description of the Moroccan KBA network}

To date, 22 KBAs for plants have been described in the Mediterranean part of Morocco. Most of the KBAs in Morocco are situated in mountain areas (High, Middle and Saharan Atlas); some (Toubkal and Jbel Mgoun) are found at elevations above 2,500 m; while a few KBAs are situated in the coastal areas (Al Hoceima National Park and Maâmora).

Morocco was a pioneer in the identification of important places for biodiversity, starting with a network of SIBES (sites of biological and ecological interest) in 1996. In 2004 the first network of sites specifically identified for plants was proposed with 15 sites (Fennane, 2004). Later in 2010, 19 Important Plant Areas were identified in the Mediterranean part of Morocco (Radford et al., 2011) and, in 2016, an evaluation using the new KBA criteria took place, which identified target species and revised boundaries. A further review of the sites in 2017 led to the proposed network included here, with the inclusion of three new sites identified for plants (Imegdale, Ait M'hamed and Oukaïmeden).
KBAs are mainly situated within the two Mediterranean Basin hotspots in Morocco: the Moroccan Atlas Mountains and the Rifan complex, including all their floristic divisions.

The predominant vegetation in most of the KBAs is mountainous degraded forest, woody vegetation and Mediterranean-type shrubby vegetation dominated by Quercus ilex (holm oak), Quercus suber (cork oak), Pinus (pine), Cedrus (cedar), Abies (fir), Tetraclinis (thuja) and Juniperus (juniper). The coastal KBAs have a vegetation characterised by tall oak forest (e.g. Maâmora) or rocky cliffs (e.g. Al Hoceima National Park).

The majority of the 878 restricted-range endemic (RRE) and short-range or stenoendemic (SRE) plant species of Morocco can be found in four floristic regions: the High Atlas with 439 taxa $(49.1 \%$ endemic), Middle Atlas with 294 taxa (32.9\% endemic), Anti-Atlas with 236 taxa (26.4\% endemic), and the Rif with 223 taxa (25.0\% endemic). In addition, the high-elevation floristic regions known as MAN (North Atlantic of Morocco) and NAM (Middle Atlantic of Morocco) are also important with 186 taxa (20.8\% endemic) and 182 taxa $(20.3 \%$ endemic), respectively. 


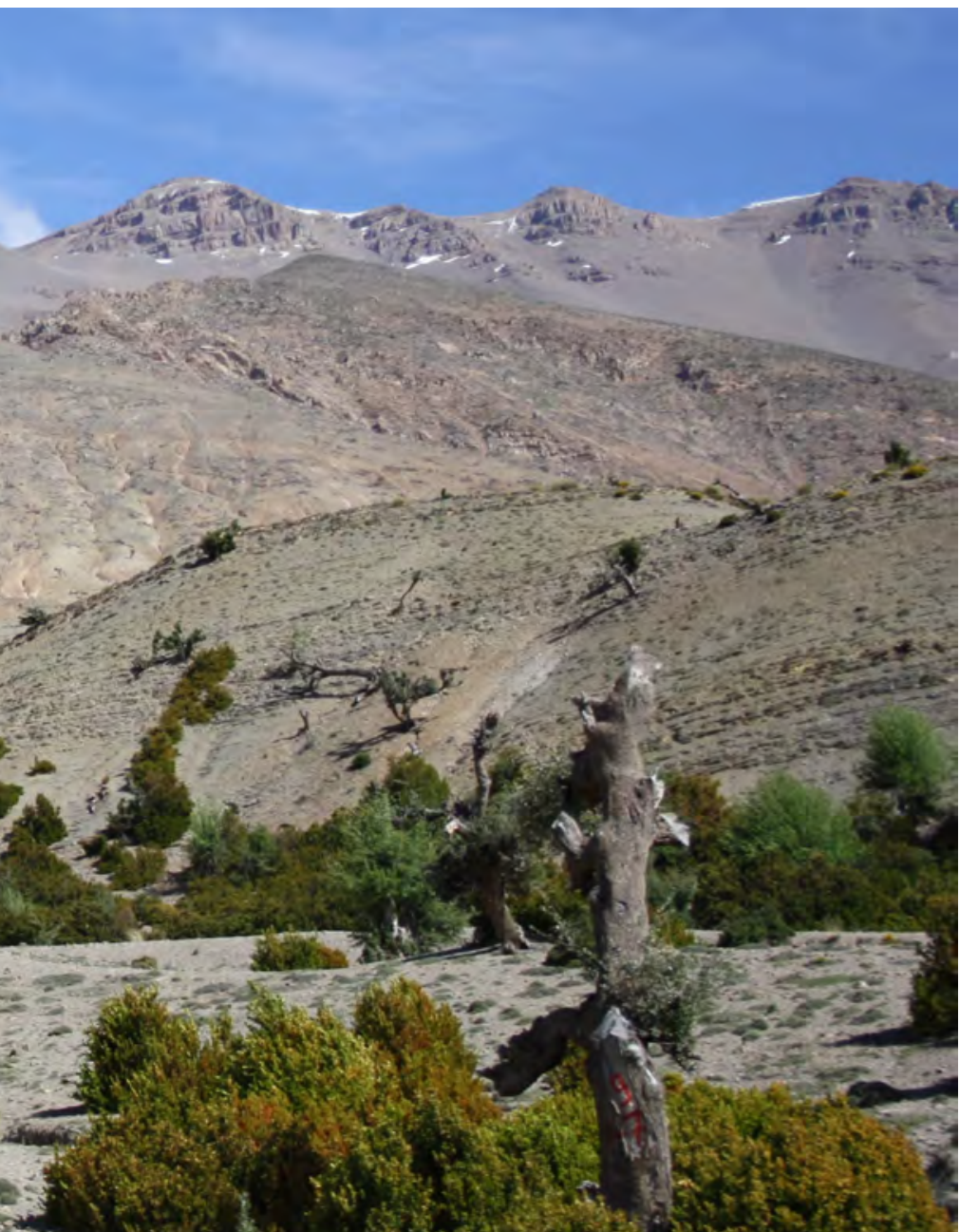

The KBAs richest in RRE and SRE species are Ifrane National Park (with 196 endemic species), Toubkal National Park (164), Jbel Ayachi (75), Jbel BouNaceur and Jbel Bou Iblane (92), Ait M'hamed (49), Imegdale (39) and Oukaïmeden (36).

Twenty trigger species were used to qualify 20 global KBAs in the Mediterranean part of Morocco.

Six KBAs are included within national parks. However, there is an ongoing debate in Morocco on whether to include the 160 or so SIBES in the main five categories of legally protected areas in Morocco: national park, natural park, natural reserve, biological reserve and natural site.

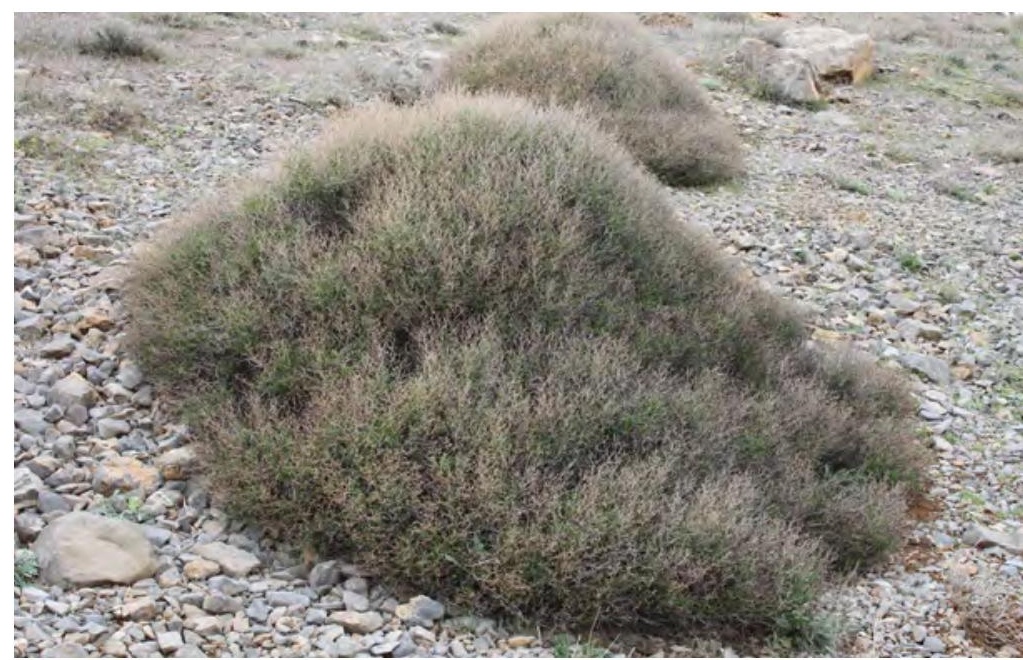

\section{$\Delta$}

Artemisia negrei

KBA Bou Naceur, Morocco

(C) Mohamed Sghir Taleb
Degraded Ecosystems in Bou Naceur KBA, Morocco (C) Mohamed Sghir Taleb

\section{Main threats to the Moroccan KBA network}

- Overgrazing

- Climate change and drought

- Agriculture intensification

- Deforestation and wood harvesting

- Tourism and recreation activities

- Overcollecting and collecting methods

- Urbanisation and infrastructure development

- Fire

- Pollution

(Rankou et al., 2015; Radford et al., 2011; and Fennane, 2004) 


\section{Main conservation actions recommended for the Moroccan KBA network}

The main conservation measures that should be taken for the Moroccan KBAs in terms of site and habitat protection require community-based methodologies.

Given the population distribution in the country and its long tradition of natural resource use, involving local communities is a necessary step in any KBA conservation measures. The stakeholders to be engaged come not only from local communities, but often also from the Ministry of Water and Environment, the forest administration (Haut Commissariat aux Eaux et Forêts), NGOs, government institutions and scientists. The first of the following examples illustrates one possible approach to participatory involvement that includes documentation, understanding, communication and education about the importance and role of KBAs.

There are, however, some major gaps in documentation, KBA monitoring and research into trigger species. The second example proposed in the following section illustrates possible ways to improve knowledge on the distribution of rare species in KBAs.

\section{Examples of conservation actions}

\section{HIGH ATLAS CULTURAL LANDSCAPE PROGRAMME}

The Global Diversity Foundation (GDF) and the Moroccan Biodiversity Livelihoods Association (MBLA) are developing an integrated conservation approach - consolidated in the High Atlas Cultural Landscapes programme - which includes, among other biodiversity-rich areas, the KBAs of Imegdale and Ait M'hamed.

The Imegdale flora is very rich, comprising 159 species belonging to 123 genera in 39 families; around a quarter of the species (24.5\%) are endemic to Morocco. The main threats are overgrazing, drought, climate change, erosion, deforestation and overcollection. The Ait M'hamed flora is also very rich, comprising 260 species belonging to 174 genera and 58 families, of wich $39 \%$ are endemic to Morocco. The main threats are overgrazing, drought, climate change, erosion and deforestation.

The High Atlas Cultural Landscape programme combines research and action on (i) biodiversity conservation and landscape management, (ii) agroecology and livelihoods, and (iii) water management. 


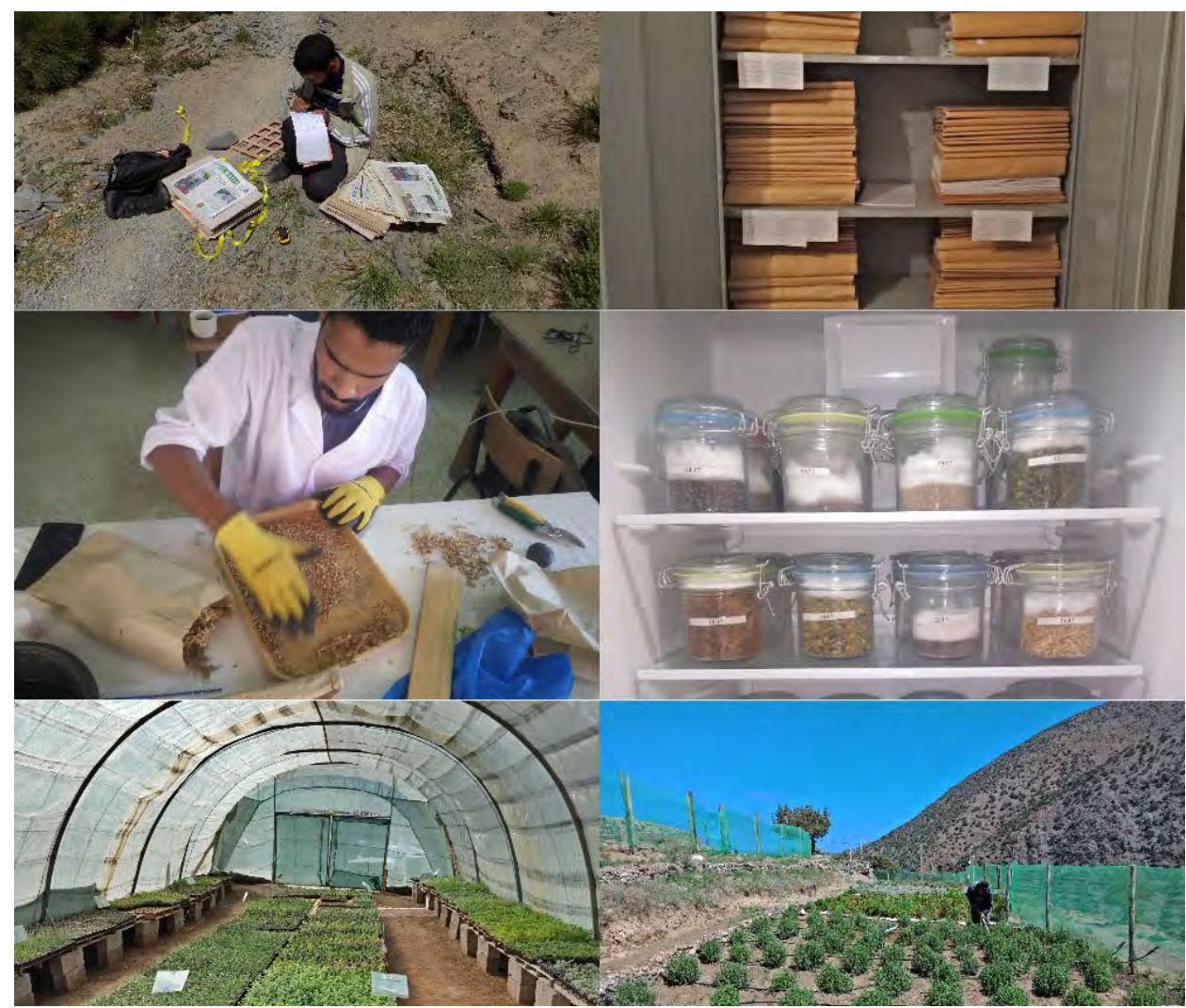

4 Left page

Juniperus thurifera

jbel Bou Mrhald, Morocco (c) Mohamed Sghir Taleb

4 This page

Community herbaria, Morocco (c) Hassan Rankou
This integrated conservation approach combines ecological restoration and biodiversity conservation, the promotion of sustainable local economies to enhance livelihoods and well-being, and the revitalisation of beneficial traditional landuse practices and governance systems. A clear set of strategies and steps have been established to achieve the desired results: assess and monitor the status of biodiversity in the context of environmental change, document sustainable land-use practices and how these are changing, and analyse the ability of traditional governance systems to persist in a shifting political landscape. This approach contains targeted actions to (a) halt biodiversity loss by using ecological restoration methods and applying sustainable biodiversity management practices, (b) enhance ecologically sound local economies by combining traditional land and resource use with innovative methods, including sustainable marketing of crops, (c) work with communities to strengthen local governance practices that support biodiversity and wellbeing, and (d) ensure the success and long-term sustainability of these actions by implementing a state-of-the-art structured capacity-building strategy for stakeholders at all scales from community researchers and liaison coordinators to project partners.

The main strategies of the conservation approach on the sites are:
- (a) documentation of biodiversity richness through ecological monitoring and floristic surveys, and documentation of cultural conservation practices by using a communitybased participatory approach in order to understand the factors underlying the abandonment of such practices and propose strategies to strengthen them and contribute to the conservation of biological and cultural diversity;

- (b) implementation of conservation actions in situ and ex situ, especially the creation of community herbaria, plant nurseries and seed banks with the development of participatory species management plans and enrichment planting so as to reintroduce plants and distribute them to local communities, targeting the local flora, and particularly endemic, useful, medicinal and threatened species;

- (c) capacity building: training and awareness raising in the local communities to ensure community ownership and sustainability;

- (d) dissemination of the results, activities and outcomes to ensure that High Atlas cultural landscape management is widely recognised as essential for biodiversity, human well-being, Moroccan culture and Mediterranean heritage.

Link: https://www.global-diversity.org/ mediterranean/ 


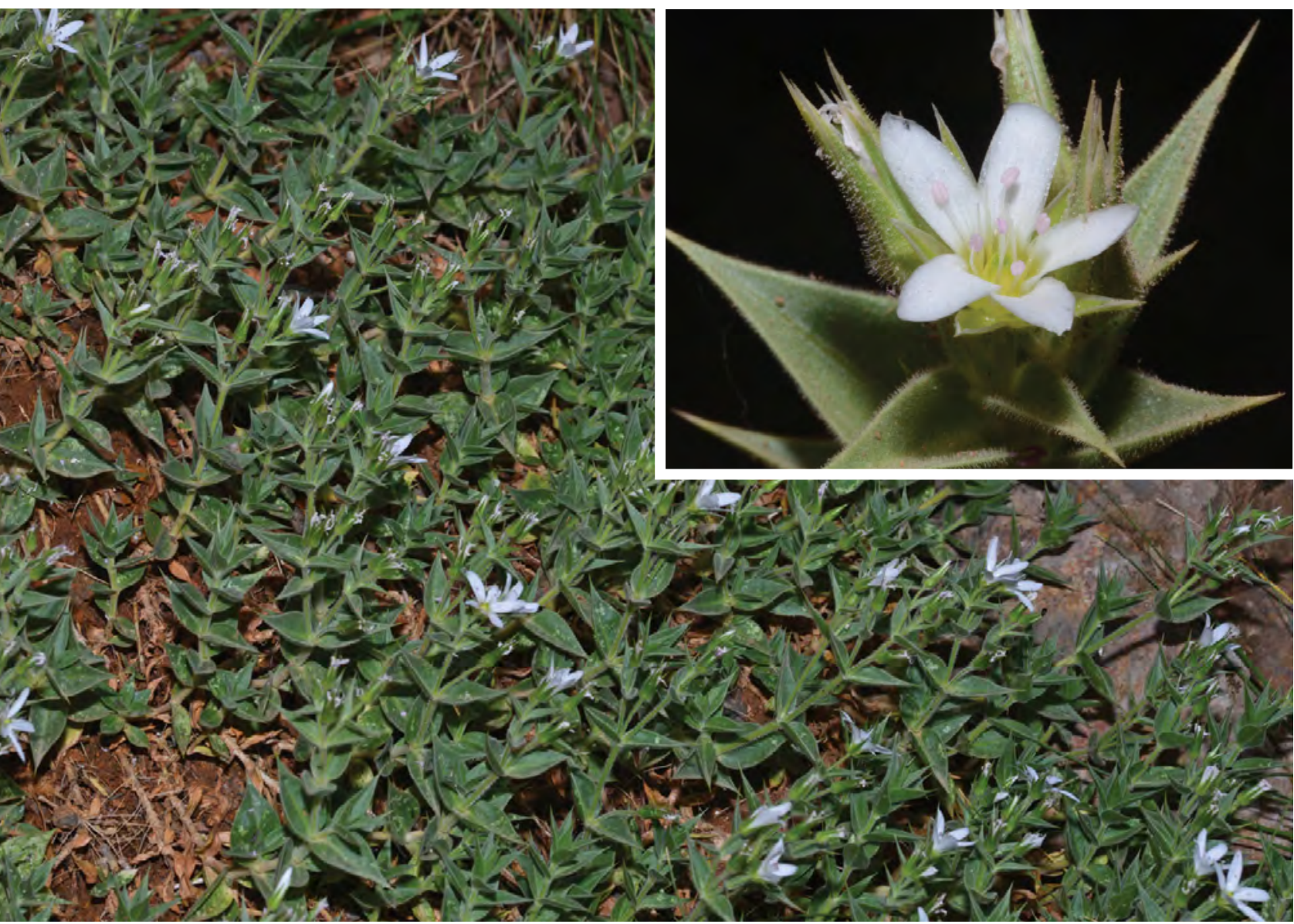

Arenaria dyris, Jbel Tanrhourt, one of the species described in the "information sheets", is a Morocan endemic only known in few location in the High Atlas

(C) M.Charrier

\section{IMPROVING KNOWLEDGE OF PLANT DISTRIBUTION IN EASTERN HIGH ATLAS NATIONAL PARK}

The Eastern High Atlas National Park (EHANP) hosts a flora of 400 species and subspecies of which about 50 are Moroccan endemics (Fennane, 2004). One major challenge that managers are facing is availability of up to date botanical information and data to support management decisions.

As part of the project IPAS Med (funded by MAVA and coordinated by IUCN), the Institut Scientifique de Rabat conducted several field missions in EHANP and Jebel Bou Naceur to update field data on species and habitat distribution.

In 2017 the project also involved Biotope Foundation, which organized a mission in the EHANP in coordination with park authorities. The objective of this mission was to conduct a botanical field data collection that could later be analyzed and organized in a useful way for managers. During the 10 days field work, 234 taxa were identified.

To address the difficulties of identification and future monitoring of endemic species, 19 endemic species were described in detail in "information sheets" (see image Arenaria dyris below). Information sheets include short description, ecology and distribution, and together with maps, precise geographical coordinates and photos will help future monitoring and identification.

Reference : Bouchet M.-A., Charrier M., Pichillou T., Fekrani Y., Zine H., Babahmad R. A., Dewynter M. \& Cambou J. (2018) Aperçu de la flore rare, menacée et endémique du Haut-Atlas oriental, Maroc. Les cahiers de la fondation Biotope 22 : 1-42 + annexes.

Link: http://www.biotope.fr/fondation-biotope-pourla-biodiversite/cahiers-fondation/ 


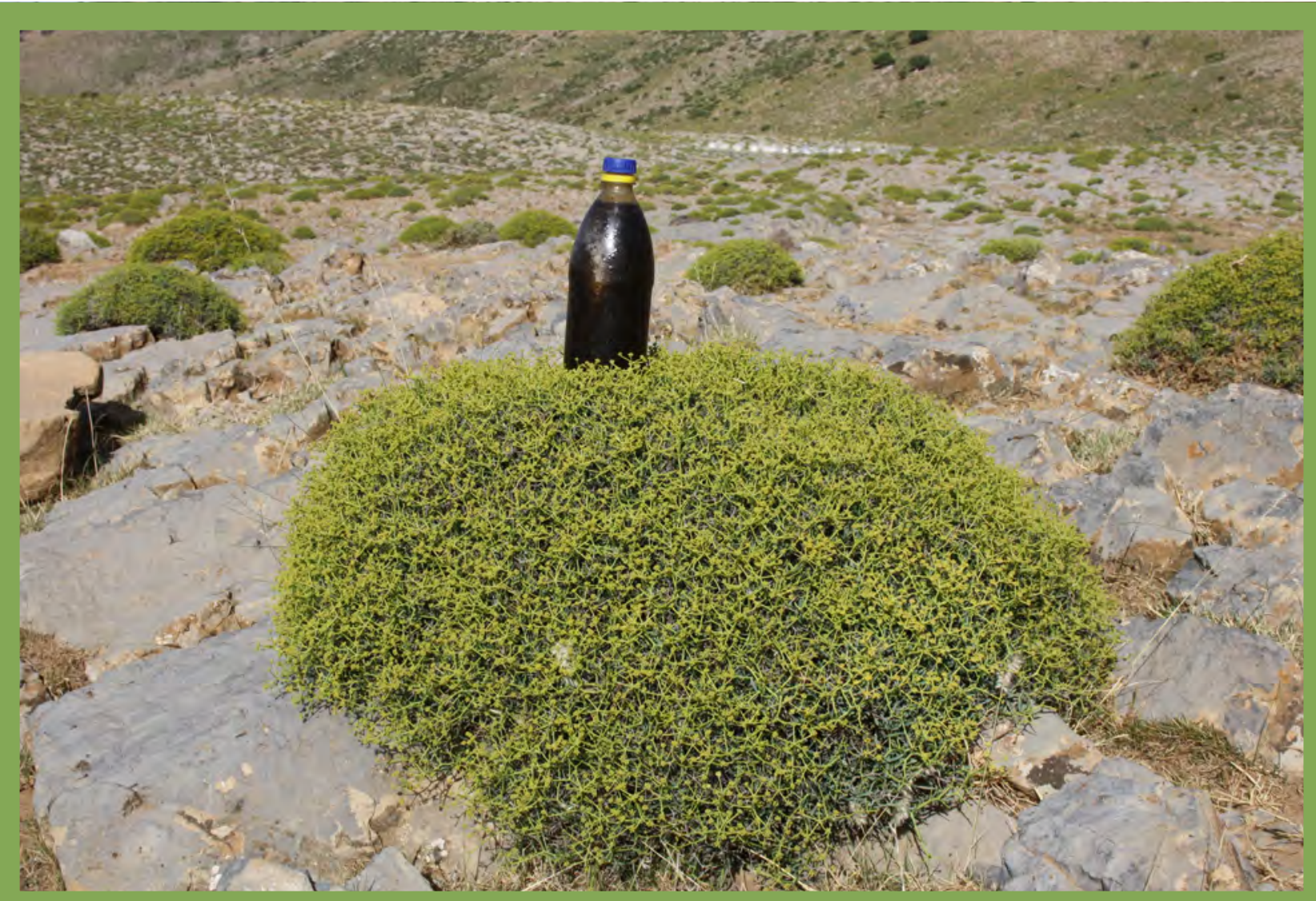

\section{CONCLUSIONS AND RECOMMENDATIONS}

The following conservation actions are recommended to improve the state of the local KBAs for plants in Morocco :

- Species management and protection: In situ conservation of threatened species that involves area-based actions such as maintaining the integrity of protected areas, the inclusion of protection of target species in the management plans of protected areas, the negotiation of conservation assessments and similar arrangements for land outside protected areas, community/participatory conservation areas, habitat restoration; and species-based actions such as recovery and reintroduction.

\section{Ex situ conservation measures include the} cultivation of threatened species in gene banks (including community seedbanks, botanic garden seedbanks, tissue and cell culture) field gene banks, botanic garden living collections, community nurseries, etc. which may provide material for population augmentation and reintroduction.
Bupleurum spinosum and sample of honey produced from it. Bou Naceur KBA, Morocco (C) Mohamed Sghir Taleb

- Site and habitat protection: Site protection measures can involve zoning restrictions, time exclusions and pasture rotation systems to reduce overgrazing; pastoral and silvopastoral improvement in collective sites; and the introduction of livestock watering points to reduce the impact of trampling. The most urgent actions will be the delimitation of forest lands negotiated between the forest administration (Haut Commissariat aux Eaux et Forêts) and local people, and the establishment of natural sanctuaries where a traditional pastoral system with managed livestock numbers operates (Agdal).

- Monitoring and research: Arrangements for monitoring programmes to track the status of threatened species and flagship and trigger species, changes in habitat status and management practices, and evaluating the success of management interventions and conservation actions.

- Communication and education: Achieving successful conservation results depends on the participation of local people. 


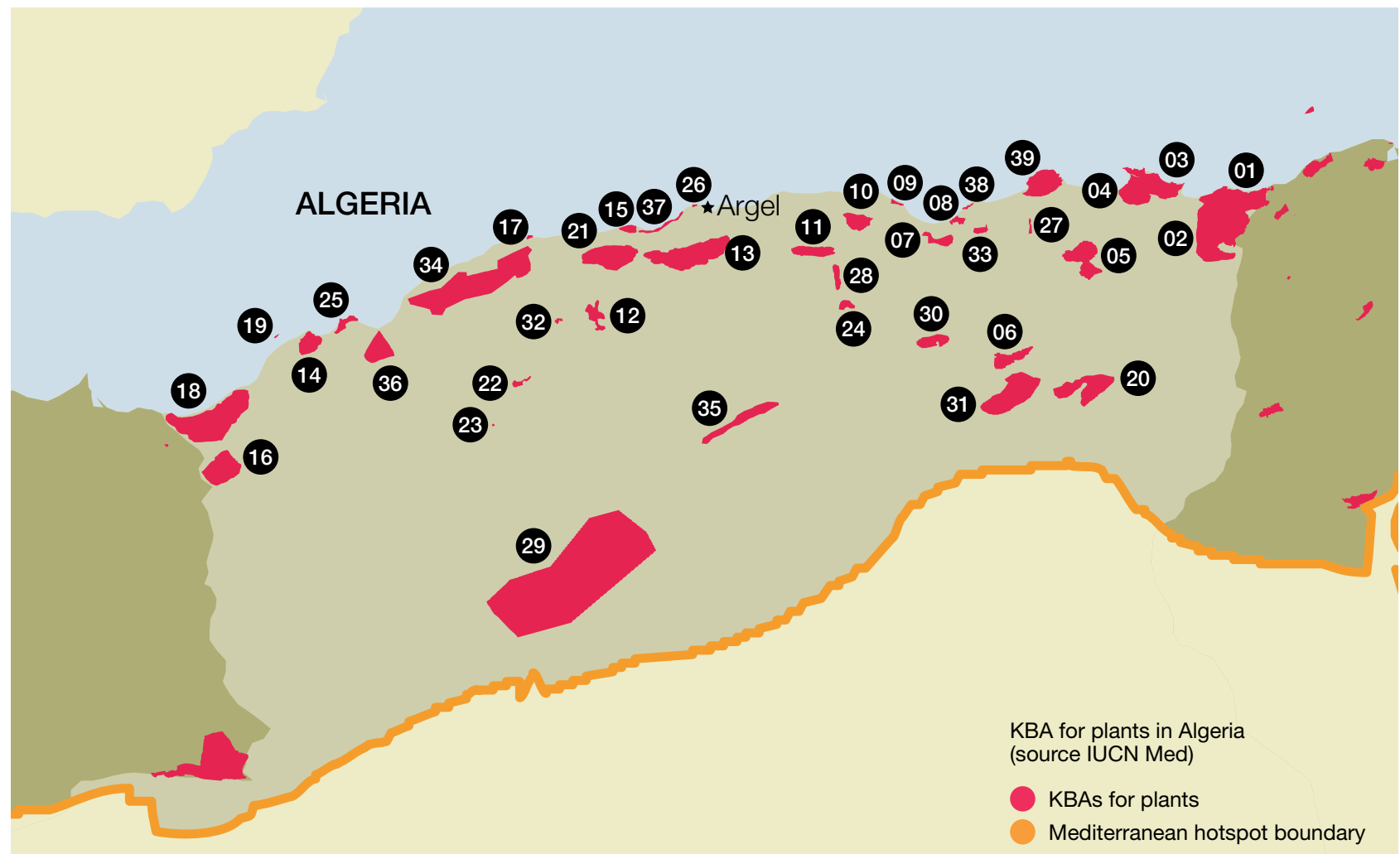

\section{ALGERIA}

\section{Authors}

\section{Salima Benhouhou}

Ecole Nationale Supérieure

d'Agronomie, El Harrach

\section{Nassima Yahi}

Université des Sciences et de la

Technologie Houari Boumediene,

\section{Bab Ezzouar}

\section{Errol Véla}

Université de Montpellier

\section{Contributors}

\section{Abdelkader Benkheira}

Direction Générale des Forêts

Ministère de l'Agriculture, du

Développement Rural et de la

Pêche de l'Algérie

\section{Ilham Loucif Kabouya}

Direction Générale des Forêts

Ministère de l'Agriculture, du

Développement Rural et de la

Pêche de l'Algérie

\section{Wissam Toubal}

Direction Générale des Forêts, Ministère de l'Agriculture, du Développement Rural et de la Pêche de l'Algérie

\section{Roger Manière}

SIG consultant for methodology and habitat mapping, Nice,

France

\section{El Kala 1}

B1 Erodium populifolium L'Hér Formed of sand dunes, alluvial plains and sandstone and clay hills in Numidia. The richness of its flora is due to the high diversity of habitats, the most remarkable of which are lagoons, marshes, lakes, meadows and hills. This KBA hosts twothirds of Algeria's orchids and pteridophytes and nearly $10 \%$ of its taxa of Afrotropical origin.

\section{El Kala 2}

B1 Odontites triboutii Gren. \& Paill. The cork oak and zeen oak forests of the Medjerda mountains in this KBA, based on the sandstones and clays of Numidia, are characterised by a diversity of habitats (cliffs, small rivers, springs and temporary ponds) with high species richness.

\section{Edough peninsula}

B1 Calamintha hispidula Boiss. \& Reut.

The Edough crystalline complex forms a promontory in the Mediterranean, which reaches an elevation of $1,008 \mathrm{~m}$ at Kef Sebaâ. The varied lithology combined with the insularity of this massif and its generous rainfall are responsible for a high level of biodiversity dominated by forests of cork oak and zeen oak.

\section{Guerbes}

B1 Bellis prostrata Pomel

This complex comprises more than

41 wetlands, including lagoons,

ponds, marshes and riparian areas. Its morphological and lithological diversity, combined with $700 \mathrm{~mm}$ annual rainfall, explain the diversity of the area's flora and fauna.

\section{Djebel Ouahch}

B1 Ranunculus batrachioides Pomel subsp. maghrebianus Dobignard.

Djebel Ouahch, located north-east of Constantine on Numidian sandstone in the sub-humid zone with cool winters, is very favourable for orchids and bulb species (Iridaceae and Liliaceae), with around 10 endemic taxa.

\section{Belezma}

B1 Hedysarum perrauderianum Coss. \& Durieu

Belezma KBA is located in a continental high-mountain national park at 1,000 to 2,178 $\mathrm{m}$ above sea level). The pedological diversity (marl, sandstone and dolomitic limestone) and the cool sub-humid to cold semi-arid bioclimatic zone favours a varied vegetation with cedar forests, Quercus ilex forest and open formations that contain numerous endemic plant species.

\section{Babor mountains}

\section{A1, B1 Abies numidica Carrière}

The Babor range is a hilly area $15 \mathrm{~km}$ from the sea that receives high rainfall. The mainly limestone substrate favours the establishment of a diverse vegetation dominated by many remarkable tree species (Atlas cedar, Numidian fir, oak, maples, mountain ash, aspen poplar). 
08 Taza National Park

\section{B1 Digitalis atlantica Pomel}

Taza National Park is a very rugged, mountainous area that rises to $1,121 \mathrm{~m}$, comprising sedimentary terrains with igneous parent rock and volcanic terrains. The temperate humid zone favours the development of major forest formations hosting many endemic and more than 100 rare and very rare plant species.

09 Gouraya National Park B1 Bupleurum plantagineum Desf.

This dolomitic limestone massif stretches from the Wadi Tazeboudt coast in the west to the end of the Cape Bouak peninsula in the east. Its unique geography makes it an exceptional site for the establishment of a stenoendemic flora on vertical limestone walls with north-facing exposure to the sea.

\section{Akfadou Forest}

\section{B1 Teucrium kabylicum Batt.}

This KBA contains one of the most important deciduous oak forests in Algeria (primarily zeen and afares oaks) as well as well-developed keratin trees. These forest formations have developed on substrates composed mainly of Numidian sandstones in the warm sub-humid to cold humid bioclimatic zones.

\section{Djurdjura National Park}

B1 Bunium chabertii (Batt.) Batt.

Djurdjura National Park consists of a limestone range rising to 2,308 $\mathrm{m}$ at LallaKhedidja. The high annual rainfall $(1,200$ to $1,500 \mathrm{~mm}$ ) allows a remarkable flora to develop. It is a biodiversity hotspot with nearly 1,100 plant species, including many that are endemic or rare.

\section{Theniet El Had National Park} B1 Silene reticulate Desf.

This KBA is home to the westernmost cedars in Algeria, in a humid to sub-humid bioclimate with cold winters. The soils, established on Numidian sandstones, are poorly developed and allow cedar trees to grow in association with zeen oaks, holm oaks and cork oaks.

\section{Chrea National Park \\ B1 Cirsium kirbense Pomel}

This KBA is home to the northernmost cedars in the country, together with centenarian yew and holly trees. Rainfall varies between 700 and $1,400 \mathrm{~mm}$. It also contains formations of green oak, cork oak, Aleppo pine, thuja and riverine forest alongside stunning gorges and waterfalls.

\section{Oran Hills}

\section{B1 Bellevalia pomelii Maire}

Occupying a limestone hill in a semi-arid bioclimate, this KBA contains a relict Quercus suber forest.

\section{Mount Chenoua}

B1 Polygala munbyana Boiss. \& Reut.

Mount Chenoua is a rugged coastal area that rises to $905 \mathrm{~m}$. It receives an annual rainfall ranging between 600 and $1,000 \mathrm{~mm}$. The main plant formation is pure Tetraclinis or mixed with Aleppo pine and, more rarely, holm oak. There is also a remarkable formation on rocks and limestone scree represented by Crucianella latifolia and Lathyrus saxatilis.

\section{Ghar Rouban}

\section{B1 Linaria burceziana Maire}

This area of mountain forest cut by gorges was formerly well known for its now abandoned mines. This border area is difficult to access and has not been explored botanically for a long time.

\section{Cap Tenes}

\section{B1 Limonium letourneuxii (Batt.)}

Greuter \& Burdet

A narrow strip of compact Eocene conglomerates forms the 'prow' of this headland. The Cape itself is made up of compact Jurassic limestone. The remarkable palaeogeographical history of this site is undoubtedly why several stenoendemic plant species occur here.

\section{Traras mountains}

\section{B1 Orobanche leptantha Pomel}

These coastal mountains have a semi-arid bioclimate with warm winters. Occupying a variety of pedological and geological substrata, this KBA is characterised by well-preserved vegetation that holds many endemics.

\section{Habibas Islands}

\section{B1 Brassica spinescens Pomel}

The Habibas Islands, devoid of watercourses, have a land area of about 40 hectares. From a geological and sedimentary point of view, the Habibas are almost entirely made up of volcanic rocks and harbour a flora of high heritage value.
20 Eastern Aurès (Chelia and Ouled Yagoub)

\section{B1 Centaurea tougourensis Boiss. \&}

Reut.,

The Aurès massif rises to 2,326 $m$ at Jebel Chelia, which receives enough rainfall to maintain cedar forests. The ridges are covered with grassland with thorny chamaephytes, rich in taxa. In the eastern part of Aurès, the Ouled Yagoub massif is home to Crepis faureliana, which has not been seen since 1938 .

\section{Mount Zaccar}

B1 Hedysarum naudinianum Coss. \& Durieu

Mount Zaccar is a forested area dominated by green oak in which innumerable springs give rise to a flourishing hygrophilous vegetation. Despite the richness of this site, very few studies have been carried out because of its inaccessibility.

\section{Tiaret Mountains}

B1 Centaurea phaeolepis Coss.

The Guezoul mountains south of Tiaret reach $1200 \mathrm{~m}$ and are influenced by a semi-arid climate with cold winters. The sandy soils are mostly decarbonated and rest on a sandstone basement. The KBA contains beautiful green oak formations and hosts an appreciable number of endemic plants.

\section{Djebel Boughachwa}

B1 Otocarpus virgatus Durieu Djebel Boughachwa is a small, isolated mountain with a mesomediterranean climate and limestone-clay soils. On its northern flank is a vegetation of pre-forest formations with Barbary thuja (Tetraclinis reticulata). It contains the noteworthy monospecific taxon Otocarpus, which deserves proper study and conservation.

\section{Dréat Mountains}

\section{B1 Thymus dreatensis Batt.}

The Dréat Mountains rise to $1,555 \mathrm{~m}$. They lie under the influence of a sub-humid climate on their northern slopes, with Aleppo pine and juniper. The southern slopes have a semi-arid climate with Stipa and white wormwood.

\section{Sahel d'Arzew}

\section{B1 Anthemis boveana J.Gay}

The 'Sahel' (coastal hills) of Arzew is characterised by the alternation of limestone and siliceous rocks with the presence of sandy soils. The climate is 
coastal semi-arid Mediterranean and the state of conservation of the site is variable, very good in inaccessible areas but degraded in areas accessible by road between Canastel and Gdyel as well as around villages.

26 Bainem forest - Bouzaréah hills B1 Onopordum algeriense (Munby) Pomel

The state-owned forest of Bainem is a remarkable remainder of natural vegetation on a metamorphic, siliceous base, dominated by cork oak and Aleppo pine. The bioclimate is sub-humid thermomediterranean with temperate winters and relatively temperate summers.

\section{Ben Haroun Gorges (Oued el Kebir)}

B1 Campanula baborensis Quézel

The gorges of the Oued el Kebir immediately downstream of the Ben Haroun dam are framed by limestone cliffs. The climate is sub-humid thermomediterranean. This site has not been studied for a long time despite the presence of a unique stenoendemic campanula.

\section{Bibans}

B1 Bunium elatum (Batt.) Batt. This KBA consists of a natural gorge cutting through vertical marly layers. The climate varies from warm semi-arid at low elevations to a milder bioclimate at high elevations. The area is dominated by matorral with juniper and holm oak and harbours many endemic plant species. Its state of conservation is generally good.

\section{Djebel Amour}

B1 Centaurea djebel-amouri Greuter This KBA corresponds to a mountain range in the Saharan Atlas where tabular surfaces and deep valleys alternate. Precipitation is between 300 and $400 \mathrm{~mm}$ per year, enough to maintain forests of Aleppo pine and green oak. Very little studied, this region contains endemic plants that have not been reviewed in the last 50 years.

\section{Djebel Boutaleb}

\section{B1 Mauranthemum reboudianum}

\section{(Pomel) Vogt \& Oberpr.}

Djebel Boutaleb, which rises to $1,890 \mathrm{~m}$, has a rainy-snowy climate in winter and is dry in summer. The rocks are sedimentary (sandstone, limestone, dolomite, marl, clay and gypsum). The mountain shelters a beautiful stand of Atlas cedars towards the main summit. The state of conservation of the site seems reasonable but is not known with any accuracy.

\section{Western Aures (Djebel Mahmel) B1 Festuca aurasiaca Trab.}

Located in the north of the Aurès massif, Djebel Mahmel rises to 2,321 m, on a calcareous basement. This KBA is subject to an upper sub-humid to lower humid bioclimate varying from cold to very cold. The mountain has high-elevation grasslands resulting from the degradation of old stands of cedar and Juniperus thurifera.

\section{Djebel Ouarseniss}

B1 Astragalus reinii subsp.nemorosus (Batt.) Maire

Djebel Ouarsenis is an isolated mountain of $1,985 \mathrm{~m}$. The slopes are covered in open forest and the summit in herbaceous vegetation. The mountain boasts the westernmost Cedrus forest in Algeria. The Aleppo pine forest of D'Ain Lellout became known to the botanical community after Battandier collected the unique endemics Astragalus nemorosus and Silene pseudovestita there in the late 19th century.

\section{Tamesguida-Djendjen \\ B1 Thlaspi atlanticum Batt.}

Djebel Tamesguida rises to 1,626 $\mathrm{m}$ and dominates the Djendjen valley south of Texenna. The climate of the region is extremely cold and wet in winter. There are few recent studies on this site, where the vegetation of the summits and slopes is lush, with mature forests of zeen and afares oaks and a permanent lake rich in aquatic vegetation.

\section{Western Dahra Range \\ B1 Salvia balansae Coss.}

The western Dahras are dominated by Miocene clays and marls and the climate of the region is very varied, with maritime influences giving mild winters and cool summers in the north, and very dry and warm summers on the southern slopes. The state of conservation of the site is generally good because it does not attract human activities.

\section{Zahrez Chergui dune belt B1 Tricholemma breviaristatum (Barratte) Röser}

This KBA is the largest non-Saharan continental dune belt in Algeria and the Maghreb. The climate is semi-arid. The dune complex is interspersed with small wetlands in the intra-dune depressions and bordered by pastureland of therophytic grasslands. The patrimonial flora and the state of conservation of the vegetation on the site are not known.

\section{Macta wetlands}

\section{A1, B1 Spergularia doumerguei Monnier}

This KBA consists of a series of coasta marshes. Alluvial deposits are clay and silty-clay with accumulations of salt. The Mediterranean climate is semiarid. Although Macta is classified as a Ramsar site, it suffers from anthropogenic degradation.

\section{Algiers Sahel}

B1 Calendula suffruticosa Vahl. subsp. monardii (Boiss. \& Reut.) Ohle The Algiers Sahel (coastal zone) stretches from the $407 \mathrm{~m}$ Bouzaréah hills in the east to the foothills of Mount Chenoua in the west. It comprises small coastal plains, plateaux, hills and lowland agricultural or forested slopes, including the forest of Ben Aknoun zoological and leisure park, the beaches of Zéralda and the hills east of Tipaza. The entire site is extremely fragmented by rampant urbanisation in the suburbs of Algiers and many roads and motorways.

\section{El Aouana coastline B1 Limonium acutifolium (Rchb.) Salmon}

The coastline of El Aouana stretches for about $10 \mathrm{~km}$. The geology is quite varied and changes from island to island and from peninsula to island. The climate of the region is the rainiest of the entire Algerian coast ( $>1,000 \mathrm{~mm}$ per year on the shore). The state of conservation is still reasonable but has deteriorated rapidly since summer tourist activities resumed at the end of the first decade of the 21 st century.

\section{El Collo Peninsula}

\section{Regional KBA (IPA)}

The forested hills of El Collo Peninsula, which rise higher than 1,000 $\mathrm{m}$, are covered with a variety of oaks and an endemic vegetation of Pinus pinaster subsp. renoui, which is also found in Kroumirie. This forest is in a relatively good state of conservation and hosts numerous stenoendemics, including Pedicularis numidica Pomel, Stachys durieui f. rubriflora Batt, Carduus numidicus Durieu, and Moehringia stellarioides Coss. 


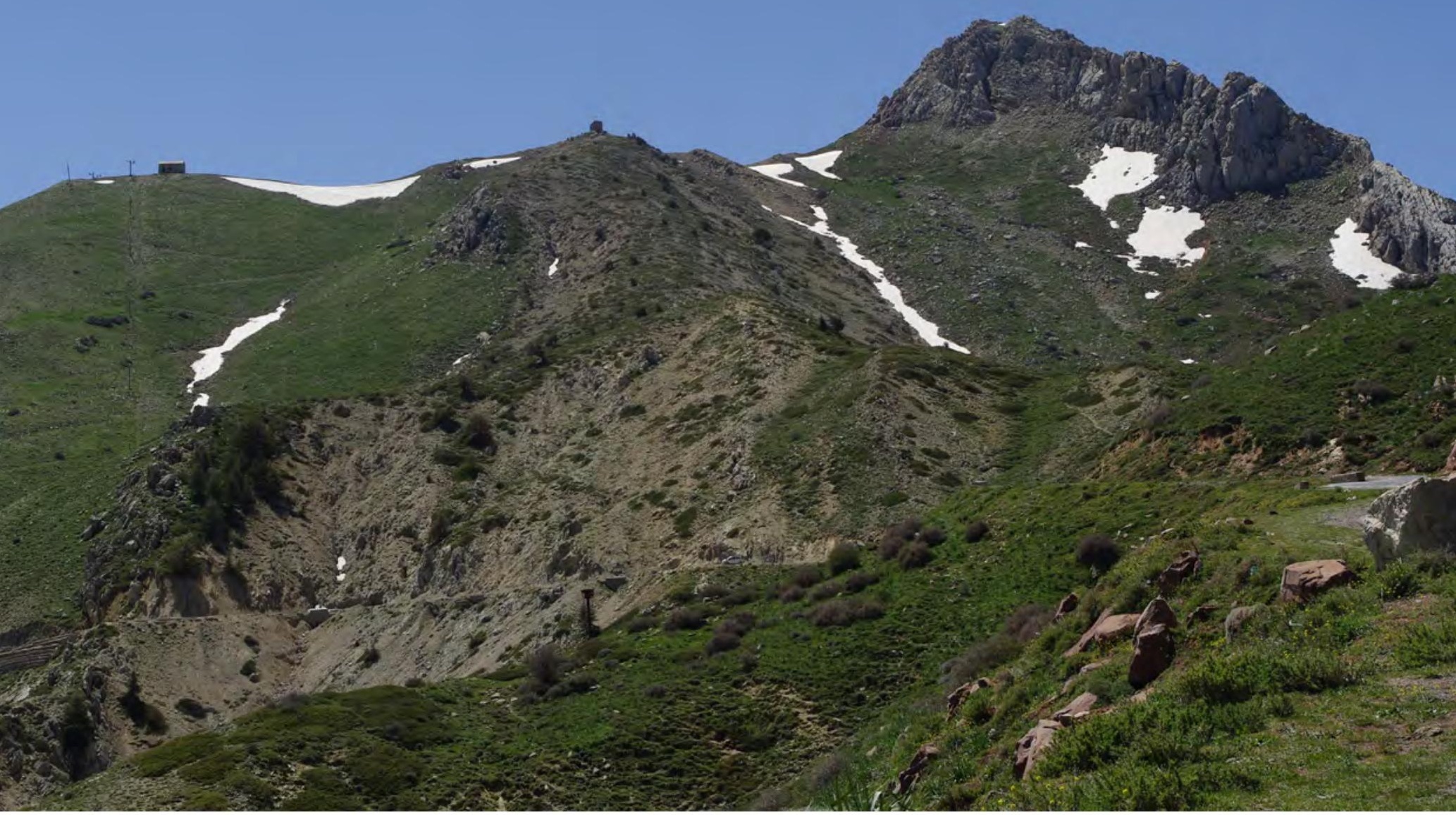

\section{Description of the Algerian KBA network}

To date, 39 KBAs for plants have been described in the Mediterranean part of Algeria. They are mostly located in the northern part of the country, especially along the coast and the Tell Atlas, with only five southern KBAs in the Saharan Atlas and the Aurès (Djebel Amour, Zahrez Chergui continental dunes, Djebel Mahmel, Belezma, Aurès-Chelia). They include a mosaic of diverse environments encompassing wetlands, salt marshes, rocky coastlines, coastal dunes, continental dunes, forest massifs, rocky areas and riparian zones.

Initially, 21 important sites were identified in northern Algeria in 2010 (Radford et al., 2011), where 152 target species were identified, mainly RRE and SRE species. Among them there are several Algerian-Moroccan and Algerian-Tunisian endemic plant species (Yahi et al., 2012). El Kala 1 KBA (wetland) and El Kala 2 KBA (forests of the Medjerda Mountains) have the highest endemicity rates with 11 and 8 stenoendemic plant species, respectively, followed by Djebel Chelia-Aurès and Mont Gouraya with 7 stenoendemics (Yahi et al., 2012).

After the agreement on the KBA criteria in 2016, sites were re-evaluated against the new criteria and 16 new sites were proposed (Véla et al., 2016) that also include a mosaic of habitats and a large number of endemic plant species. Global KBAs were qualified on the basis of 38 trigger species.

Finally, a third review of sites, boundaries, species and thresholds took place in 2017, resulting in a total of $39 \mathrm{KBAs}$ in northern Algeria. Remarkable KBAs due to their high number of endemics include El Kala, Djurdjura, Eastern Aurès and Gouraya.

Of the 39 KBAs identified, 9 are included in nationally protected areas ( 7 in national parks and 2 in the nature reserves of Babor and Chenoua). 


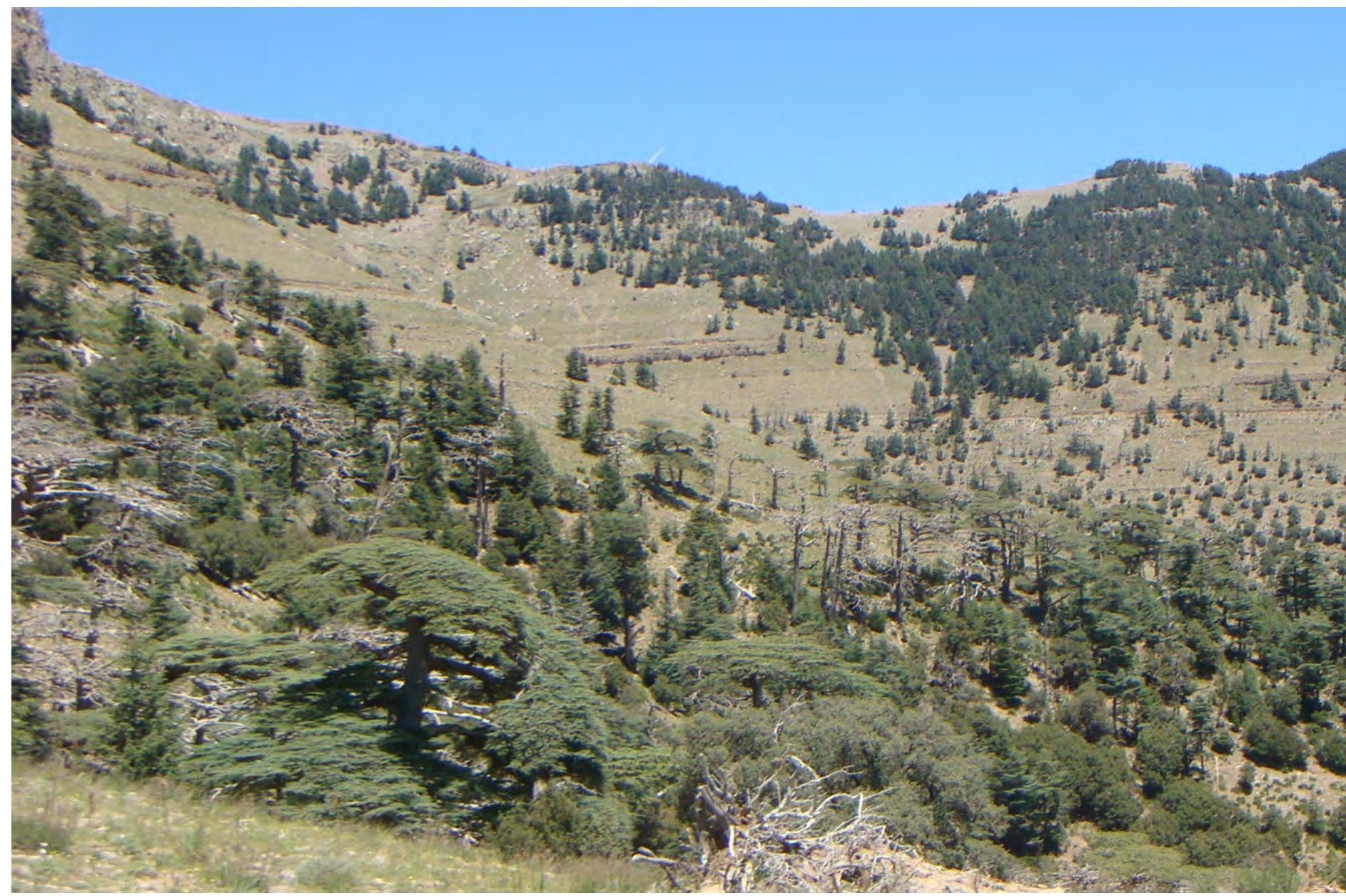

\section{Main threats to the Algerian KBA network}

In forests and mountain areas, the main threats to KBAs are wildfires and overgrazing. In coastal areas, KBAs are mainly threatened by urbanisation, excessive tourism pressure and pollution.

- Urbanisation

- Fire

- Overgrazing

- Pollution

- Excessive tourism pressure

\section{Main conservation actions recommended for the Algerian KBA network}

There is an urgent need to reduce the anthropic pressures listed as the main threats to KBAs.

In the KBAs included in nationally protected areas, management plans should be implemented to protect the target plant species and to reduce pressures through participatory methods that promote alternative solutions (such as beekeeping, arboriculture and cultivation of aromatic or medicinal plants). For KBAs outside protected areas, efforts are needed to have them classified as nature reserves so that management plans can be put in place for the in situ conservation and monitoring of their endemic species.

Our knowledge of the biology and ecology of these plant species must be improved in order to target conservation actions most effectively.

At the same time, the ex situ conservation of endemic plant species is a paramount conservation measure. Living plant collections should be grown in botanical gardens and properly sampled collections of seeds and other propagules should be stored in gene banks.

It is also important to provide legal cover for those endemic plant species that do not have any.

Endemic and threatened plant species should be included on a future national Red List. 


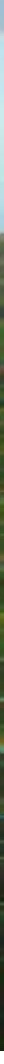

\section{EASTERN AURĖS KBA}

Eleven endemic plant species have been reported in Eastern Aurès KBA ( 5 SRE and 6 RRE). The stenoendemic (SRE) species are Crepis faureliana, Festuca aurasiaca, Galium numidicum, Juniperus thurifera var. aurasiaca and Romulea vaillantii, while the endemics with a wider distribution area (RRE) are Ammoides atlantica, Campanula jurjurensis, Centaurea tougourensis, Jacobaea gallerandiana, Cedrus atlantica and Quercus faginea subsp. faginea.

Overgrazing is the main threat to vegetation and flora in Eastern Aurès. Local residents allow their herds (sheep and goat) to graze freely all over the KBA for long periods.

The main conservation measure to be recommended concerns grazing management. Land tenure issues, local customs and traditions that determine rangeland management have to be taken into consideration. It is also essential to involve local populations in conservation through participatory management of sites, offering rotating use of tracks and alternative solutions such as beekeeping and mountain arboriculture.
Among the conservation actions in this KBA there is a project to restore an ancient nursery on the heights of Mt Chelia, to produce endemic plants that will be used to reinforce natural populations.

\section{GOURAYA NATIONAL PARK KBA}

Twelve endemic plant species have been reported in Gouraya KBA (7 SRE and 5 RRE). The SRE species are Bupleurum plantagineum, Erysimum cheiri subsp. inexpectans, Hypochaeris saldensis, Sanguisorba ancistroides var. battandieri, Silene sessionis, Genista ferox var. salditana, and Pancratium foetidum var. saldense. The five RRE species are Erodium battandieranum, Sedum multiceps, Genista vepres, Allium trichocnemis and Calamintha nervosa. The last has been reported from Gouraya KBA in the past but it was not found there during field work in 2014-2016.

The main threat to this KBA is pressure from tourism. Gouraya is not only a national park but also a leisure area with outstanding landscapes that attracts people from both nearby Béjaia and other parts of the country. The excessive number of visitors has led to the emergence of harmful waste dumps and the significant deterioration of footpaths. 
Gouraya National Park and KBA, Algeria

(C) Khellaf Rebbas

Gouraya National Park and KBA, Algeria

(C) Nassima Yahi

Conservation actions to raise awareness in local communities should be a priority. These could include:

- producing flyers to make visitors aware of the richness of the site and the need to preserve it.

- involving the younger generation by extending the awareness-raising campaigns to schoolchildren in Béjaia regarding the importance of preserving the biodiversity of the KBA.

- displaying posters in public places such as town halls, post offices, banks, cultural centres and libraries in order to target a wider audience.

- producing an ecotourism guide with the aim of making the local and regional population aware of the importance of conserving habitats and rare and endemic plant species, in collaboration with ecological associations in the region.

- establishing an experimental plot for the ex situ conservation of endemic plant species (Yahi et al., 2016). Of the 12 endemic taxa identified in Gouraya KBA, it might be worth focusing on the rarer species, such as Erysimum cheiri subsp. inexpectans, Sanguisorba ancistroides var. battandieri, Silene sessionis, Erodium battandieranum, Allium trichocnemis and Calamintha nervosa.

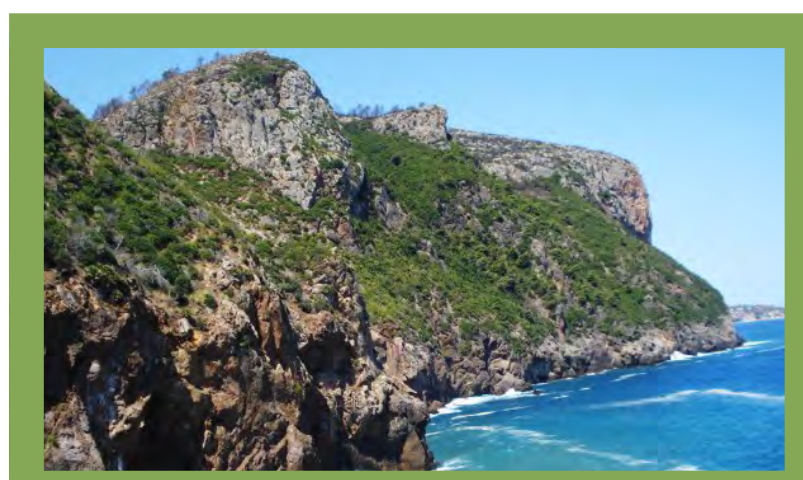

\section{CONCLUSIONS AND RECOMMENDATIONS}

The main challenge to ensure sustainable management of KBAs across the country is to reduce the impact of overgrazing in KBAs. Some special consideration: in the case of freshwater KBAs consensus for management of riparian habitats involving local people, in a participatory management process is also critical; In coastal KBAs, it is essential to keep fighting uncontrolled urbanisation and excessive tourist development.

- For KBAs included in the national protected areas system, it is vital to ensure that management plans are implemented that will promote habitat protection, reduce pressures and encourage participatory management actions.

- For KBAs outside protected areas, efforts must be made to have them classified as nature reserves in order to implement suitable management plans.

- Ex situ conservation of endemic species is also a recommended conservation measure. Plants grown in botanical gardens and seeds stored in seed banks would help to conserve geographically restricted endemic species.

- At a legal level, it would be beneficial to draw up a national Red List of plant species, including endemic species that exist in KBAs. 


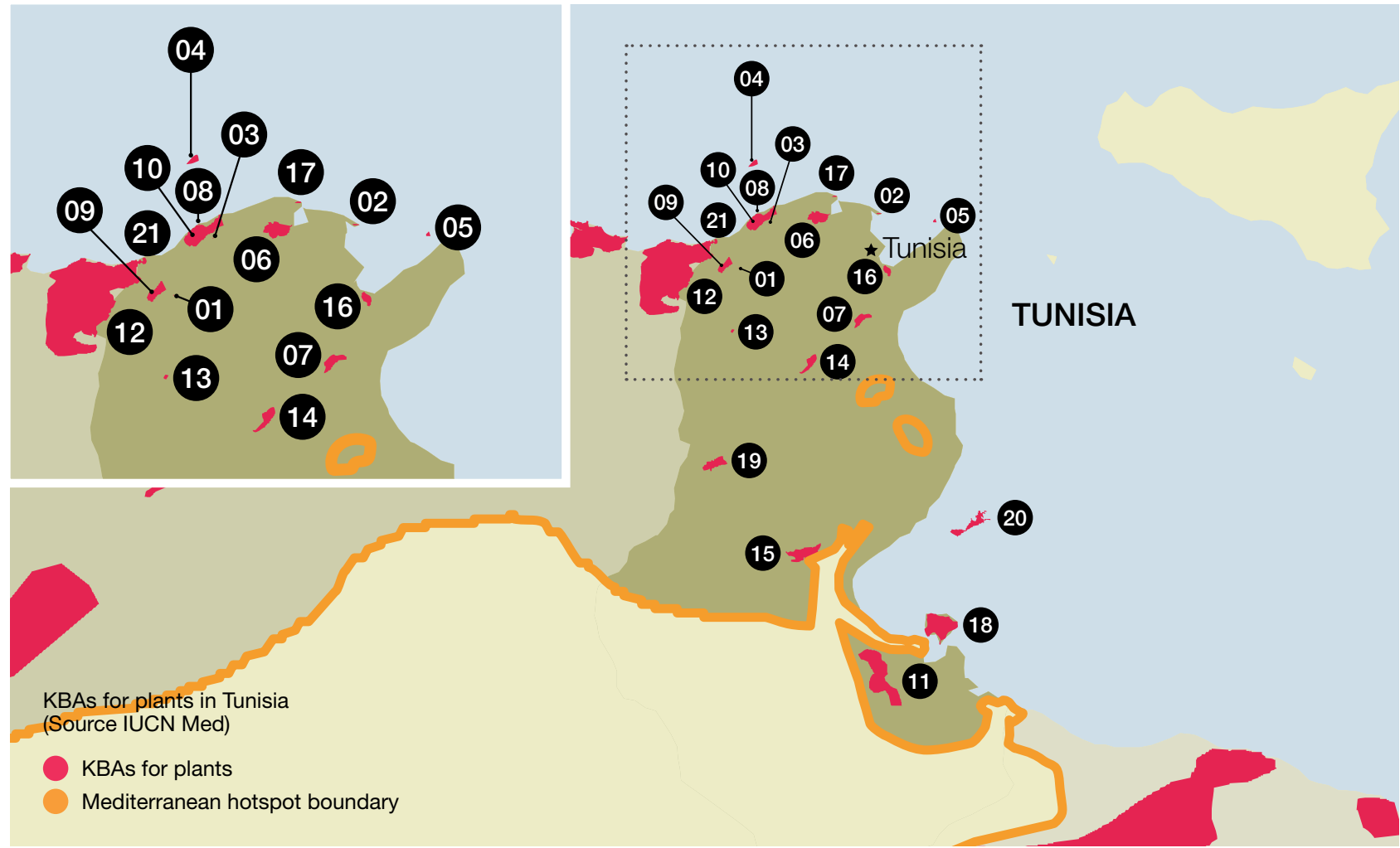

\section{TUNISIA}

\section{Authors}

\section{Zeineb Ghrabi-Gammar}

Institut National Agronomique de

Tunisie

\section{Amina Daoud-Bouattour}

Faculté des Sciences de Tunis

\section{Contributors}

\section{Khaled Abaza}

Institut Préparatoire aux Etudes Littéraires et de Sciences

Humaines de Tunis

Imtinène Ben Haj Jilani

Institut National Agronomique de

Tunisie

\section{Safa Ben Khalifa}

Institut National Agronomique de

Tunisie

\section{Ridha El Mokni}

Faculté de Pharmacie de

Monastir

\section{Amor M. Gammar}

Faculté des Lettres, des Arts et des Humanités de la Manouba

\section{Olfa Karous}

Institut National Agronomique de Tunisie

\section{Serge D. Muller}

ISE-M, Université de Montpellier, France

\section{Mohamed Neffati}

Institut des Régions Arides de

\section{Médenine}

\section{Slim Rouz}

Ecole supérieure d'Agriculture de Mograne

Errol Véla

Université de Montpellier, France

\section{Ain Zana}

Regional KBA (IPA)

Ain Zana Nature Reserve (47 ha) is located in Kroumirie, southeast of Ain Draham, on both sides of a ravine. The TunisianAlgerian endemic Quercus afares was the reason for creating this KBA.

\section{Sidi Ali El Mekki}

\section{B1 Linaria cossonii Barratte}

Sidi Ali el Mekki KBA encompasses the whole peninsula of the same name. It is a kind of natural extension to the $325 \mathrm{~m}$ Jebel Nadhour, east of a virtual line connecting Raf Raf beach in the north-west to Ghar el Melh beach in the south-east.

\section{Majen Choucha}

Regional KBA (IPA)

Majen Choucha occupies a depression on Jebel Choucha (445 m), in the region of the Mogods. It is a small, semi-permanent, acidic, freshwater lake (0.6 ha) in the middle of a cork oak forest.

\section{Galite Archipelago}

B1 Bellevalia galitensis Bocchieri \& Mossa

The Galite Archipelago (800 ha) is located off Tabarka. It consists of the island of Galite and five islets (Galiton, Fauchelle, Gallo, Gallino and Pallastro). They have a rocky volcanic origin, with rugged topography and varied landscapes.

\section{Zembra and Zembretta National} Park

B1 Silene barrattei Murb.

Zembra and Zembretta National Park is located north-east of the Gulf of Tunis. Zembra (391 ha) and Zembretta (2 ha) are two rocky islands that form a natural extension to the Cap Bon Peninsula.

\section{Ichkeul National Park}

B1 Teucrium schoenenbergeri Nabli, Limonium boitardii Maire

chkeul National Park is made up of three geomorphological units: a lake, marshes, and a jebel (mountain) that rises to $511 \mathrm{~m}$. The latter is covered by Oleo-Lentiscetum (olive-mastic) complex with carob, and the stenoendemic Teucrium schoenenbergeri.

\section{Jebel Zaghouan}

B1 Arabis tunetana Murb.

Jebel Zaghouan KBA corresponds to the north-western slope of this mountain. Located $50 \mathrm{~km}$ from Tunis, it is a rugged massif that is part of the Tunisian Dorsal, an extension of the Saharan Atlas, and rises to $1,295 \mathrm{~m}$. It is covered by several plant associations, including the Aleppo pine and holm oak complex, with a remnant of OleoLentiscetum with carob. 


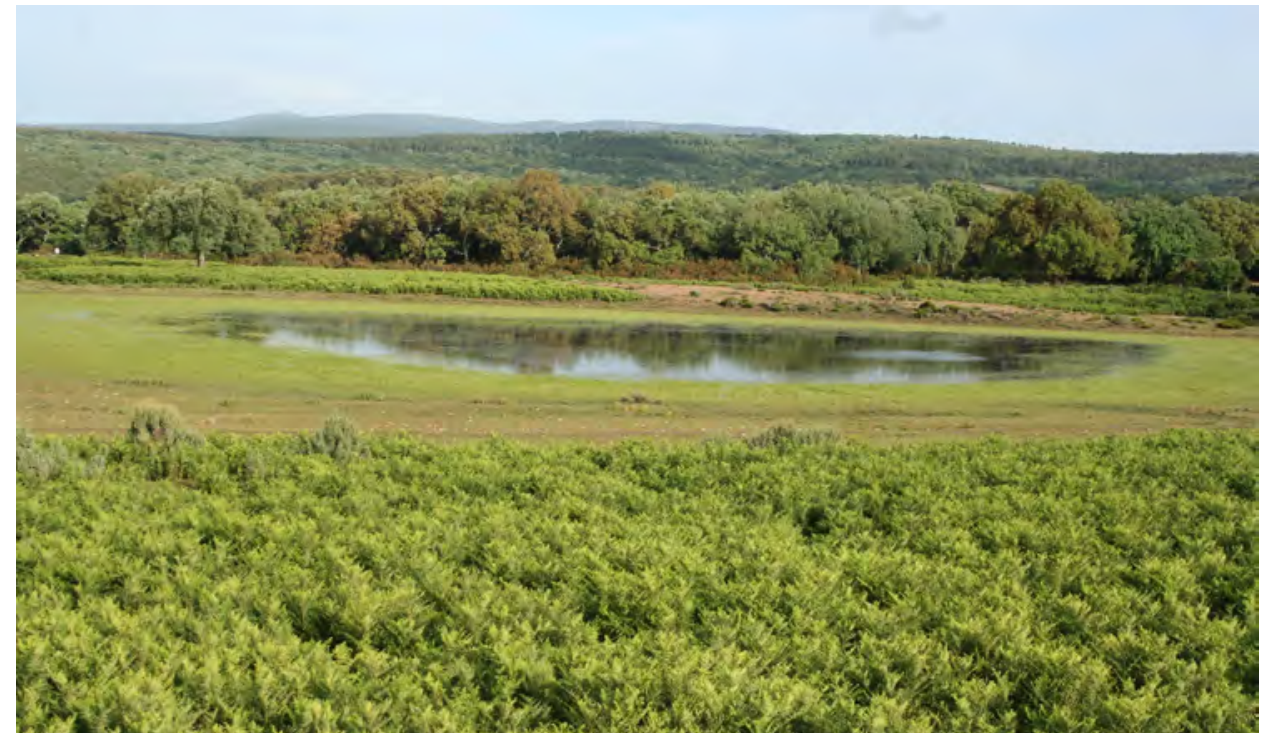

Mediterranean wetland Majen el Ma, KBA Kroumirie1, Tunisia

08 Garâa Sejenane

\section{A1, B1 Rumex tunetanus Barratte \&} Murb., Pilularia minuta Durieu. Located in the Mogods region, Garâa Sejenane is a large freshwater wetland $(1,500 \mathrm{ha})$ consisting of a mosaic of flooded fields, temporary marshes and temporary pools, wet meadows and wet lawns, with the remnant of a small peat habitat at the edge of the site.

\section{Kroumirie 1}

A1, B1 Lathyrus brachyodon Murb., Clematis tunisiatica W.T.Wang, Pilularia minuta Durieu

Kroumirie in north-western Tunisia consists of low mountains (500-900 m in height) covered mainly by cork oak forests. It is the wettest region in the country. 'Kroumirie 1' KBA contains several small Sphagnum peat habitats (including the Dar Fatma Natural Reserve), semi-permanent lakes (Majen Barbit, El Mouajène) and temporary pools (Majen el Ma, Majen Sghaïer).

\section{Cap Négro-Cap Serrat}

\section{B1 Teucrium radicans Bonnet \&}

\section{Barratte}

Cap Négro-Cap Serrat is a forest area located in the Mogods region, on a $30 \mathrm{~km}$ long coastal strip. From west to east it comprises Cap Négro, the Lake Majen Chitane-Tourbière Dar el Orbi complex, the alder peat swamp of Oued Ziatine, and the temporary pools of Cap Serrat.

\section{Toujane-Ghomrassen \\ B1 Ferula tunetana Pomel,} Marrubium aschersonii Magnus, Teucrium alopecurus Noë, Linaria paradoxa Murb.

Toujane-Ghomrassen is part of the northern half of Jebel Dhahar, a low mountain (120 m high) oriented north-south that belongs to the Saharan platform. It is covered by degraded formations of Juniperus phoenicea forest.
12 Kroumirie 2

\section{Regional KBA (IPA)}

'Kroumirie 2' includes Jebel Ghorra, the highest point in Kroumirie (1,203 m), on the Algerian border, and the El Feija National Park (2,632 ha), which contains an old 400 ha faunal reserve created in 1965 to protect the Barbary red deer (Cervus elaphus barbarus).

\section{Dyr El Kef}

B1 Trifolium tunetanum Murb.

Dyr el Kef is located north of Kef town, in the Upper Tell region. It is a limestone plateau of perched synclinals with steep cliffs. It dominates the plains of western Tunisia, and rises to 1,084 $\mathrm{m}$ above sea level.

\section{Jebel Serj}

\section{B1 Arabis tunetana Murb.}

Jebel Serj KBA occupies part of the northwestern slope of Jebel Serj, one of the highest limestone mountains in the Tunisian Dorsal. It is covered in Aleppo pine with green oak matorral and contains a small Acer monspessulanum forest. Part of the $\mathrm{KBA}$ is a national park.

\section{Jebel Bouhedma}

\section{B1 Teucrium nablii S. Puech}

Bouhedma National Park is also part of a UNESCO biosphere reserve, located in the Orbata-Bouhedma range of the Saharan Atlas in the centre of Tunisia. Its flora, essentially tree steppe, includes Acacia tortilis subsp. raddiana, a 'living fossil' dating back to the Tertiary.

\section{Boukornine National Park Regional KBA (IPA)}

Boukornine National Park is located a few hundred metres from the sea, about $18 \mathrm{~km}$ from the centre of Tunis. It is centred on the Jebel Boukornine, which is the northeasternmost mountain of the Tunisian Dorsal. It rises to $576 \mathrm{~m}$ above sea level, and it is covered by a Tetraclinis articulata forest of varied appearance.

\section{Cap Blanc}

B1 Odontites citrinus Bolliger

Cap Blanc is located on the northern coast of Tunisia, about 10 kilometres from Bizerte. It consists of two promontories formed of cliffs. Strictly speaking, Cap Blanc is the western promontory and the higher of the two (102 m). It harbours Odontites citrinus, endemic to Cap Blanc.

\section{Jerba}

B1 Limonium formosum Bartolo, Brullo \& Giusso

Jerba is an island of $514 \mathrm{~km}^{2}$ in the southeast of Tunisia. It is the largest island on the North African coast. It is connected to the mainland by a seven-kilometre causeway. It is home to Limonium formosum, a stenoendemic of the island, and Marrubium aschersonii, a Tunisian endemic.

\section{Jebel Chaambi}

\section{Regional KBA (IPA)}

Jebel Chaambi, the highest mountain in Tunisia (1,544 m), is part of the Tunisian Dorsal. Its vegetation is dominated by alfa at low elevations, and by Aleppo pine forest associated with holm oak higher up.

\section{Kerkennah Archipelago}

\section{Regional KBA (IPA)}

The Kerkennah archipelago is located about $20 \mathrm{~km}$ off Sfax (south-eastern Tunisia). With an area of about $160 \mathrm{~km}^{2}$, it consists of two main islands (Gharbi and Chergui) and 12 islets. The topography is very low and covered by vast sebkhas (salt flats).

\section{Melloula}

\section{Regional KBA (IPA)}

Melloula KBA stretches over 1,500 ha north-west of Kroumirie. It corresponds to hills about $300 \mathrm{~m}$ high, covered with pine forests (mainly maritime pine), mixed in some areas with cork oak forests, and degraded areas covered in dense maquis. 


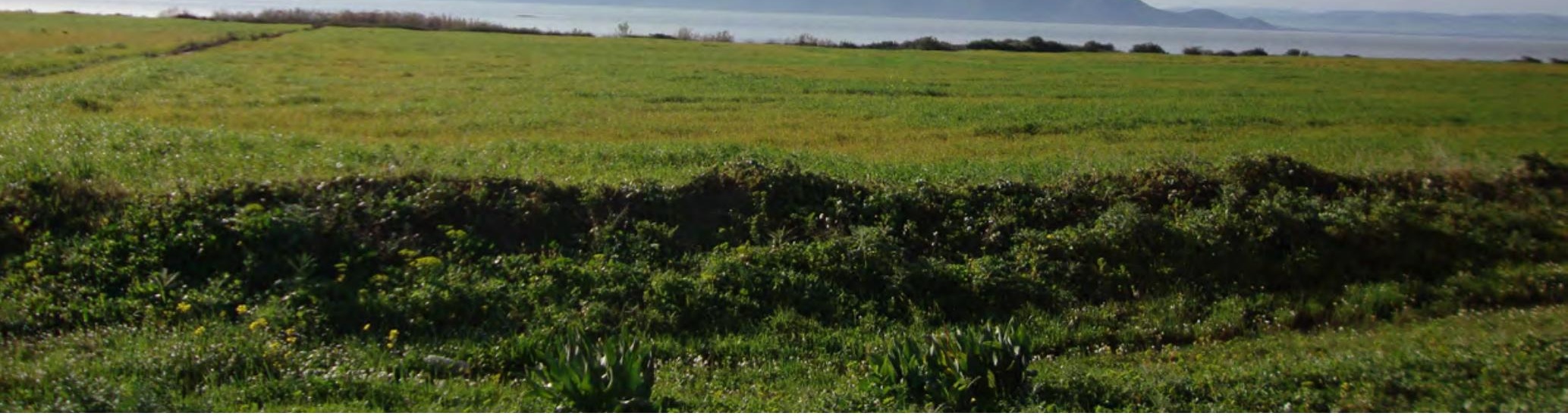

\section{Description of the Tunisian KBA network}

In the Mediterranean part of Tunisia there are $21 \mathrm{KBAs}$, distributed in the north, centre and south-east of the country. Forest ecosystems are predominant in most of them and they either have a relict vegetation (forests of Quercus canariensis, $Q$. ilex and $Q$. coccifera) or are under strong human pressure (Oleo-Lentiscetum (olive-mastic) complex, wetlands and coastlands).

In the KBAs there are 50 Mediterranean endemic plant species, including 22 Tunisian endemics and 12 stenoendemics. Some KBAs with a significant number of Mediterranean endemics are Kroumirie 1 (11), Kroumirie 2 (10), Cap Négro-Cap Serrat (11) and Ichkeul National Park (11).

Eighteen trigger species were used to qualify 14 sites as global KBAs, meeting global KBA criteria. The global KBA network also includes 15 of the regional KBAs, as they are areas of global importance for other taxa.

Initially, in 2010, 13 important sites were identified in Tunisia (Radford et al., 2011), mainly in the north of the country. More than half the sites identified were wetlands.

After the agreement on the KBA criteria in 2016, sites were re-evaluated against the new criteria as part of the process of updating the Critical Ecosystem Partnership Fund (CEPF) ecosystem profile. New sites were proposed, and the boundaries of old sites were redefined on the basis of the occurrence of other taxonomic groups of interest and site manageability.

Finally, a third review of sites, boundaries, species
Ichkeul national Park, Tunisia (c) Zeineb Ghrabi

and thresholds took place in 2017, resulting in a total of $21 \mathrm{KBAs}$ in Tunisia, including 14 sites of global importance and 7 sites of regional importance.

Of the $21 \mathrm{KBAs}$ identified, 14 are totally or partially included in nationally protected areas.

\section{Main threats to the Tunisian KBA network}

- Urbanisation

- Drought

- Overgrazing

- Pollution

- Climate change

- Fire

- Drainage

\section{Main conservation actions recommended for the Tunisian KBA network}

- Build capacity and raise the awareness of decision makers and local people about the importance of conserving KBAs.

- Include endangered species on the national list of protected species. 
- Promote the ex situ conservation of sensitive plant species.

- Create protected areas for endangered species (parks, reserves, Ramsar sites).

\section{Examples of conservation actions}

\section{GARÂA SEJENANE}

The mosaic of temporary freshwater wetlands that occupies the great depression of Garâa Sejenane is home to a large number of plant species considered rare and endangered at Tunisian level and sometimes at a North African and even Mediterranean level. This is the case for Rumex tunetanus Barratte, strictly endemic to the Garâa Sejenane (Ghrabi-Gammar et al., 2017), and Pilularia minuta, a stenomediterranean species emblematic of acidic temporary ponds (Daoud-Bouattour et al., 2009).

The Garâa Sejenane was a lake until the 1960s but has now largely been dried out due to numerous drainage schemes (involving drainage channels, wells and a dam) carried out between 1958 and 1980, which have allowed the development of forage crop cultivation and extensive grazing. The main threats to the site are currently (1) the impact of state-built facilities for supplying drinking water to douars (villages) around the garâa (leading to more wastewater discharge, population expansion, etc.), (2) the intensification of agriculture and grazing following improved drainage and water pumping, and (3) an expansion of introduced invasive species (Cotula coronopifolia, Crassula helmsii) (FerchichiBen Jamaa et al., 2010; Rouissi et al., 2016).

An initiative has been launched by researchers with support from IUCN to raise awareness among government stakeholders and local people (farmers, teachers, schoolchildren, etc.) of the importance of conserving the Garâa Sejenane. Several meetings have been held, as a result of which (1) a local NGO has been created to perform scientific monitoring of endemic plant species and their habitats, in order to quickly intervene in the event of threats; (2) a proposal to protect small parcels of land has been made by some farmers; and (3) a listing of the KBA as a Ramsar site is under way.

\section{CONCLUSIONS AND}

\section{RECOMMENDATIONS}

- Legal protection of endemic, rare and endangered species that are trigger species for Tunisian KBAs (those species that qualify a site as a KBA) should be introduced at a national level.

- Ex situ conservation measures should be adopted for endemic, rare and threatened species that are trigger species for Tunisian KBAs (seed collecting, multiplication and cultivation of target plant species in the national gene bank and botanical gardens).

- Scientific projects should be developed that focus on endemic, rare and threatened species that are trigger species for Tunisian KBAs (particularly addressing their taxonomic status, ecology, reproductive biology, etc.)

- Projects that emphasise the value of KBAs and promote their conservation should be developed (with a particular focus on medicinal plants, honey, ecological tourism, etc...).

- The Tunisian authorities need to be made more aware of the importance of KBA management and endangered/endemic plant species conservation.

- Management actions should be implemented at local level with the active involvement of local people and the scientific community.

- Work is needed to raise the awareness of local people and NGOs to the ecological and economic value of conserving KBAs, to the threats posed by human activities and to the conservation measures to be applied at KBA level. 


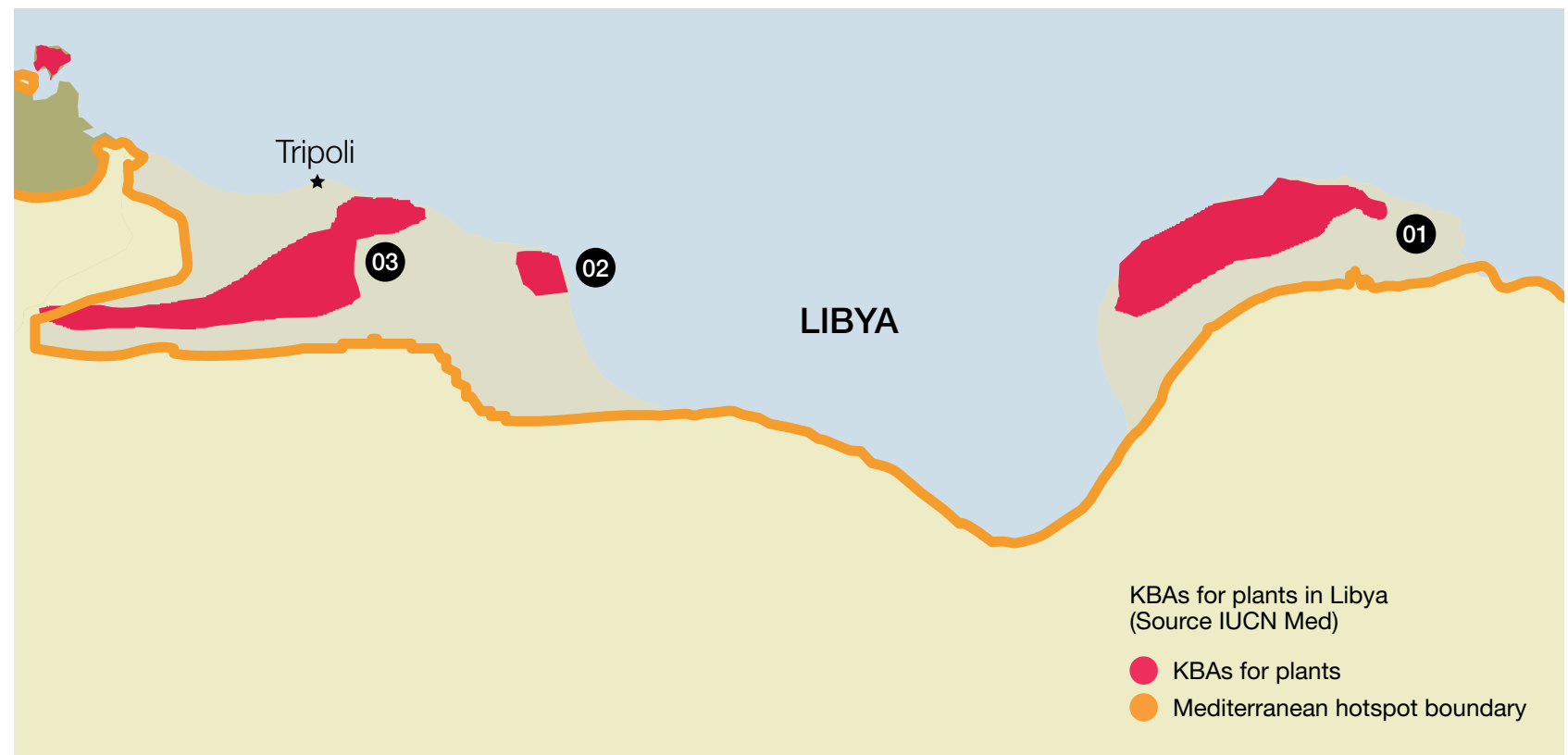

\section{니BYA}

\section{Jabal Al Akhdar}

Regional KBA (IPA)

Jabal Al Akhdar dominates the Cyrenaica region in north-eastern Libya. It is a biogeographical 'island', with the Mediterranean Sea to the north and west, the Marmarica plateau to the east and the Sahara desert to the south. It rises from sea level through three levels of escarpments and plains to $882 \mathrm{~m}$. Between 100 and 140 taxa are endemic to Jabal Al Akhdar. The vegetation communities are coastal plain, coastal escarpments, central plateau and upper escarpment, and upper plateau. This KBA contains the greatest plant diversity in Libya, with $75-80 \%$ of the country's flora and a significant proportion of endemic plant species. The area is characterised by red alluvial soil (terra rossa), relatively good rainfall (up to $600 \mathrm{~mm}$ annually in certain locations), and closeness to the sea. The dominant plant species are Arbutus pavarii, Juniperus phoenicea, Olea europaea var. oleaster, Pistacia lentiscus, Phlomis floccosa and Cupressus sempervirens.

\section{Taworgha Sebkha}

Regional KBA (IPA)

Taworgha KBA is characterised by a hot spring forming a small lake. Its water runs along open canals providing wet habitats for many aquatic plant species.

\section{Jabal Nafusah}

\section{Regional KBA (IPA)}

Jabal Nafusah (the western mountain) KBA stretches for $500 \mathrm{~km}$ from the Tunisian border to the Niggaza area on the coast.

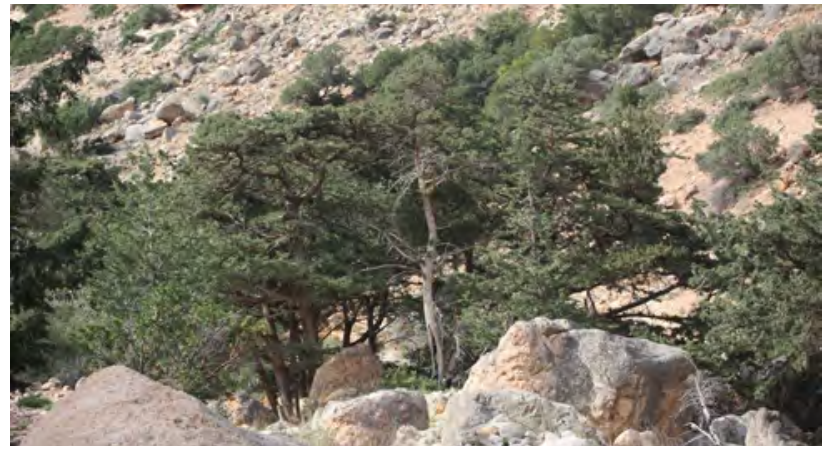

Cupressus sempervirens in Wadi Mahboul, Jabal Al Akhdar KBA, Cyrenaica region, Libya ○) Stephen Jury

\section{Description of the Libyan KBA network}

The identification of IPAs in Libya dates from 2010 (Radford et al., 2011), and there has not been any update since then, given the lack of security. During the update of the CEPF ecosystem profile in 2016, the boundaries of existing KBAs were revisited (and the current map shows the updated boundaries), but no new sites were identified for plants.

It has not been possible to assess whether regional KBAs (IPAs) are also global KBAs meeting global standards. Re-evaluating site boundaries in light of new information, field data and other existing KBAs would significantly improve proposed new boundaries.

Three regional KBA (IPAs) have been identified to date in the Mediterranean part of Libya, all of them on the coast. They include hot springs, open canals and limestone formations. The largest and most significant KBA in Libya is Jabal Al Akhdar, which contains $75 \%$ of Libya's flora. 


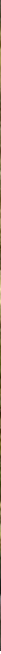

Coastline above Ras Al Hilal, Libya

\section{Main threats to the Libyan KBA network}

Given the current situation in Libya, ongoing war and conflict constitute a major threat to the KBA network. Prior to this conflict, the KBA network was mainly affected by

- Overgrazing by livestock,

- Tree cutting for wood and charcoal

- Spread of invasive species

- Unregulated development of coastal areas

- War, civil unrest and military exercises

- When the conflict subsides, it would be essential to collect new field data with the ultimate aim of reevaluating all identified KBAs and the threats affecting them.

\section{Main conservation actions recommended for the Libyan KBA network}

Given the unstable situation in many parts of Libya at the time of writing, the main obstacle to developing a comprehensive and functioning network of KBAs is the lack of security and law enforcement. If this problem is solved in the near future, there is a number of conservation actions that should be undertaken:

- Compile floristic data

- Strengthen environmental planning and management

- Develop detailed environmental impact studies 


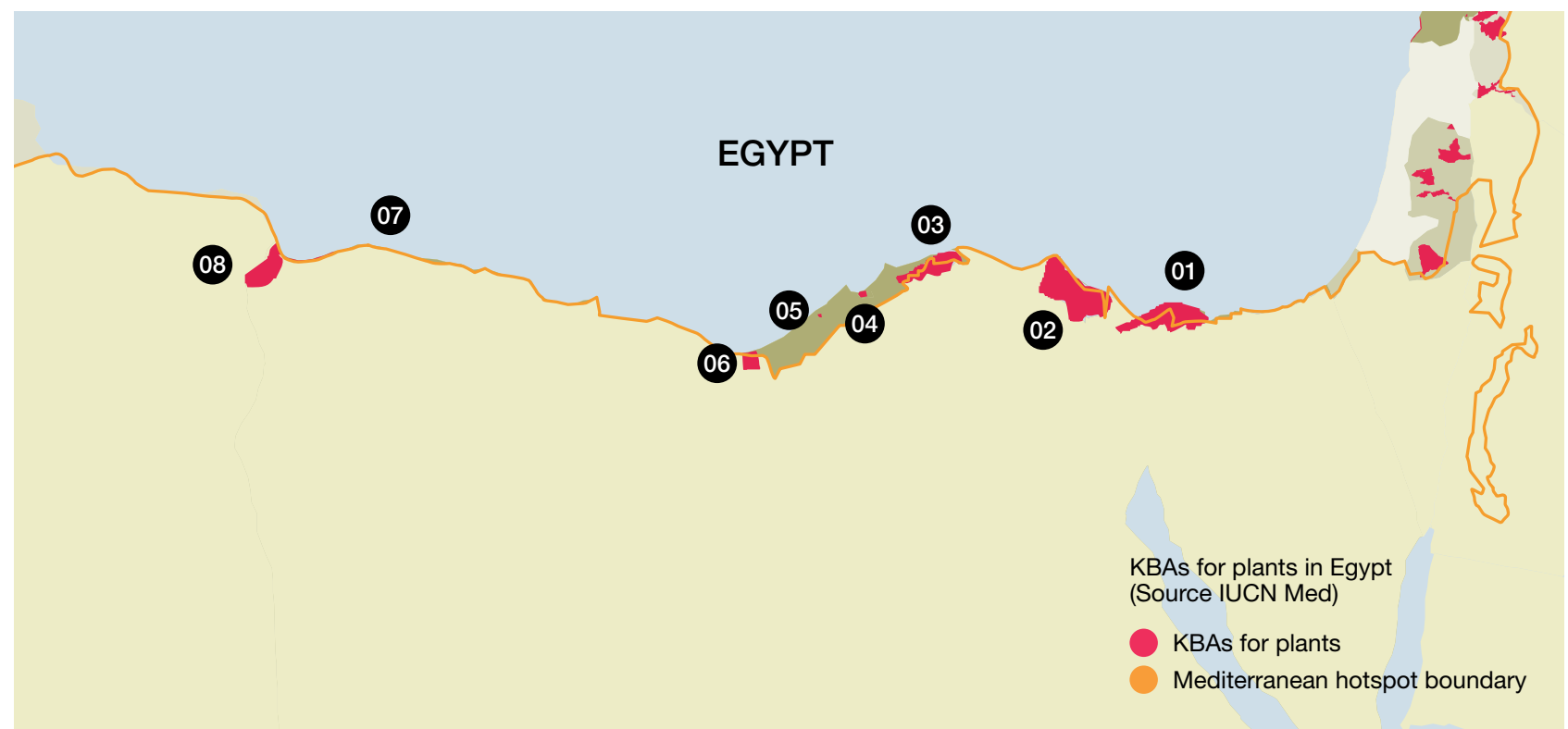

\section{EGYPT}

Authors

Kamal Shaltout

Tanta University

Karim Omar

Environmental Consultant

Contributors

Ahmed Abdallah

Taba Protected Area

Abdullah Nagy

Al-Azhar University

Ibraheim Elgamal

St Catherine Protected Area

Amir Shalof

St Catherine Protected Area

Seleim Mehana

Local Community

Mohamed Hemeid

St Catherine Protected Area

Mohamed Mahmoud

St Catherine Protected Area

Alaaeldein Ewase

St Catherine Protected Area

Ali El-Marakby

Siwa Protected Area

Tamer Saber Ismail

Omayed Biosphere Reserve

Yasser Galal

Omayed Biosphere Reserve

\section{Saad Mohammed}

Omayed Biosphere Reserve

Mostafa Fouda

Egyptian Environmental Affairs

Agency

Abdelwahab Afefe

Egyptian Environmental Affairs Agency
01 Lake Bardawil

B1 Bellevalia salah-eidii Täckh. \& Boulos

Lake Bardawil is a Ramsar site located on the Mediterranean coast of North Sinai. This lagoon is separated from the sea by a sandbar 300 to 2,000 m wide, across which two natural and two artificial openings connect the lagoon to the sea. It is the only oligotrophic hypersaline lake along the Egyptian Mediterranean coast. Part of Lake Bardawil enjoys legal protection in Zaranik Protected Area.

\section{Lake Manzala}

\section{Regional KBA (IPA)}

Lake Manzala lies in the north-eastern part of the Nile Delta between the Damietta branch and the Suez Canal. It contains a large number of islets covering some $180 \mathrm{~km}^{2}$ (15\% of the total lake area). Some islets are clayey in nature, others are sandy, while still others are composed of mollusc shells. Part of it enjoys legal protection in Ashtom El-Gamil Protected Area.

03 Lake Burullus

B1 Sonchus macrocarpus Boulos \& C.Jeffrey

Lake Burullus is a Ramsar site located in the central part of the Nile Delta shoreline. It is separated from the Mediterranean Sea by a long, curved sandbar. It is a shallow lagoon of brackish water containing some 30 islets; those near the lake-sea connection are sandy in nature, while farther from the inlet the lake bed and islets are clayey. It is a fully protected KBA.

\section{Lake Edku}

\section{Regional KBA (IPA)}

Lake Edku is situated in the north-western Nile Delta, south of Abu-Qir Bay, and has an area of $126 \mathrm{~km}^{2}$. It is a shallow brackishwater lagoon extending about $19 \mathrm{~km}$ from east to west.

\section{Lake Mariut} Regional KBA (IPA)

Lake Mariut is situated on the Mediterranean coast of Egypt behind the city of Alexandria, and has a total area of $63 \mathrm{~km}^{2}$. The lake sediments indicate that it has received both seawater and freshwater in the course of its history, as they consist of fluvial deltaic formations and brackish lagoon mud.

06 Omayed Biosphere Reserve Regional KBA (IPA)

Omayed Biosphere Reserve is located in the western Mediterranean coastal region of Egypt, $80 \mathrm{~km}$ west of Alexandria. It is an important rangeland that harbours many palatable plants such as Plantago albicans. Its landscape from north to south reflects a mosaic of different habitats from coasta dunes to inland plateau with siliceous deposits. It lies fully within a protected area.

$\underline{07}$ Western Mediterranean coastal dunes

B1 Anthemis microsperma Boiss. \& Kotschy and Pancratium arabicum Sickenb.

This KBA stretches along about $100 \mathrm{~km}$ of coastal sand dunes, which represent a disappearing landscape with special characteristics and features. A large part of these coastal dunes west of Alexandria has been destroyed over the last two decades or so by the constant, ongoing development of summer resorts. This KBA harbours many Mediterranean endemics as well as some 30 species that occur solely in Egypt.

\section{Sallum Area}

\section{Regional KBA (IPA)}

This area extends for about $120 \mathrm{~km}$ from Sallum on the Egyptian-Libyan frontier to Sidi Barrani on the Mediterranean coast. Two main types of farming are practised (rain-fed and pastoral). In rainy years, the range plants alone are sufficient to feed the livestock. It is a fully protected $\mathrm{KBA}$. 


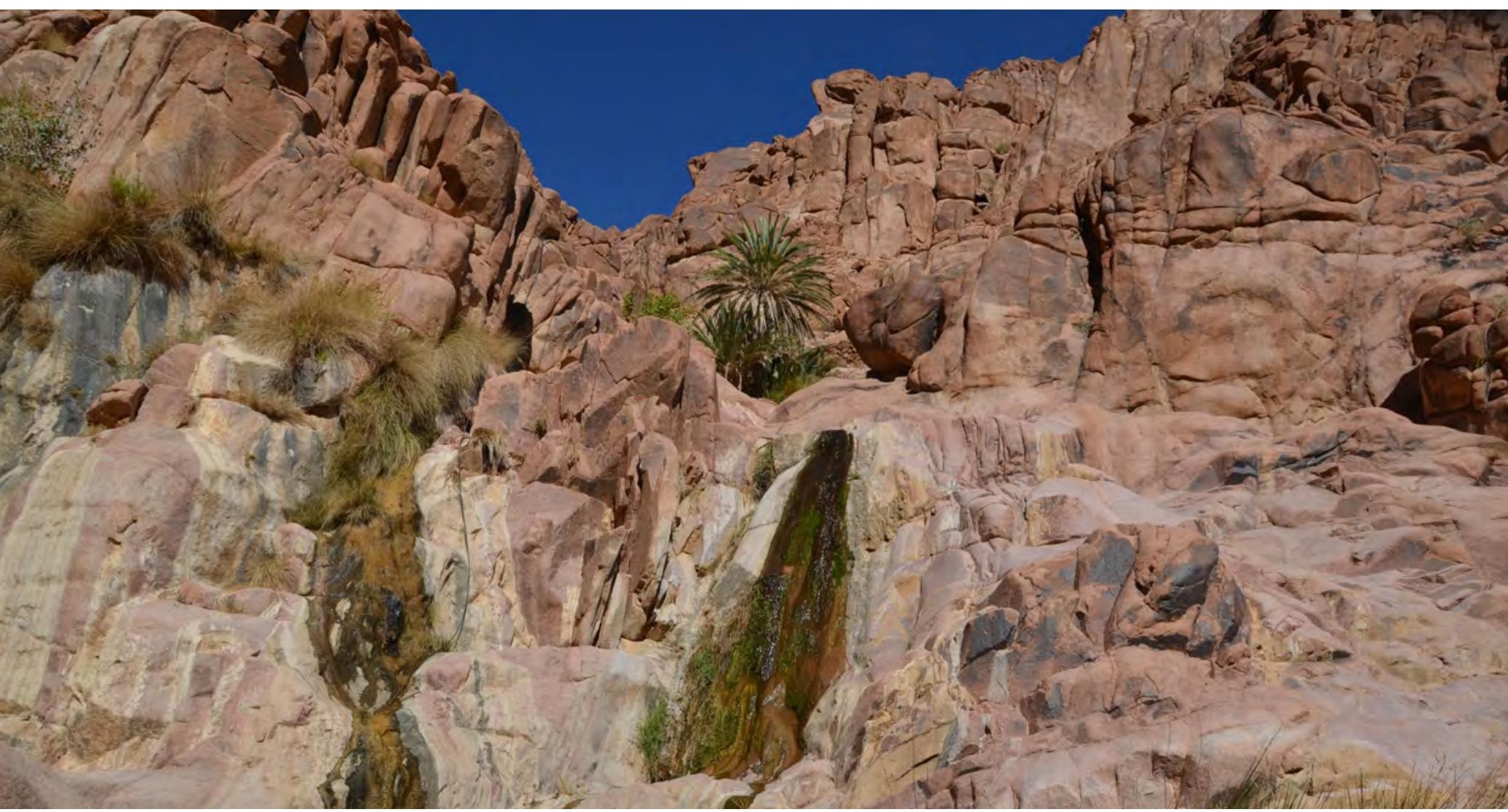

$\Delta$

St. Catherine KBA, Egypt

(c) Karim Omar

\section{Description of the Egyptian KBA network}

Initially, 20 regional KBAs (IPAs) were identified in Egypt in 2010, using criteria that measure species vulnerability (i.e. threatened species at national, regional or global scales), irreplaceability (i.e. stenoand national endemics, near-endemics- species that occurs in Egypt and another adjacent country- and Mediterranean endemics) and species richness, in addition to threatened habitats (at national and Mediterranean scales). St Catherine (south Sinai) is the KBA that has the highest number of endemic species (about 27 species $=44 \%$ of the total).

After the agreement on the KBA criteria in 2016, sites were re-evaluated against the new criteria and Mediterranean KBAs were reviewed, resulting in eight KBAs within the Mediterranean hotspot area. Four trigger species were identified to qualify three of these Mediterranean sites as global KBAs, while the other five are regional KBAs (IPAs). Most of them are lakes or are representative of coastal dune habitats. Three KBAs are included totally and two partially within Egyptian national protected areas.

\section{Main threats to the Egyptian KBA network}

- Agricultural expansion, particularly after the digging of irrigation canals and reclamation of fertile soil, leading to habitat loss

- Land degradation and desertification

- Habitats change and destruction

- Climate change

- Over use of wild plants by human and grazing animals

- Land encroachment

- Alien invasive species

- $\quad$ Fire at lakes coastal lines

- Unmanaged tourist activities

- Expansion of tourism and recreational areas

- Human intrusions and disturbance

- Recreational resorts

- Wastewater and chemicals from agriculture and industrial activities 


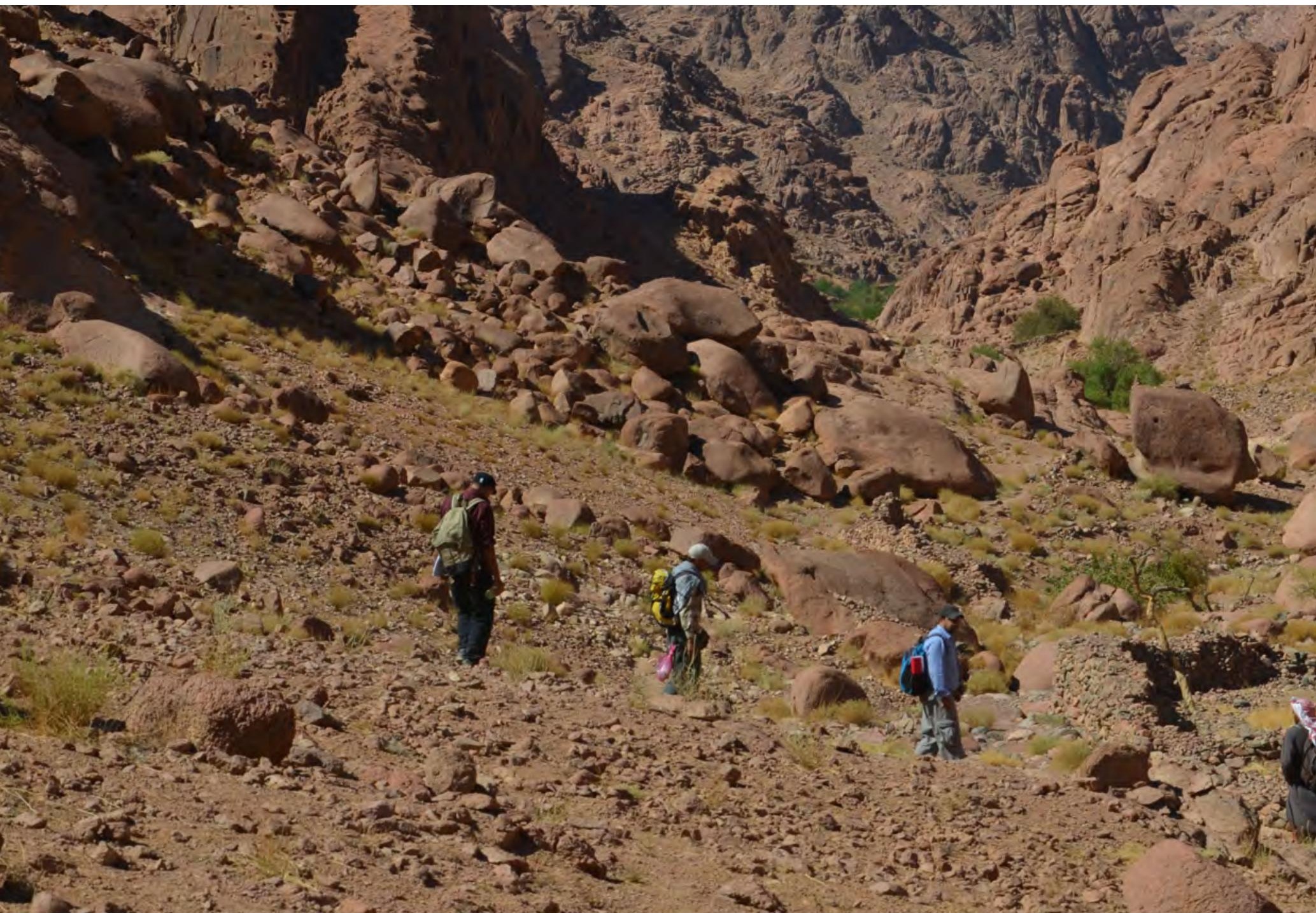

\section{Main conservation actions recommended for the Egyptian KBA network}

- Integrate the field-based knowledge derived from ecological, demographic and geographical approaches to species conservation in order to better formulate management strategies that take all the various considerations into account.

- Enforce biodiversity conservation measures in the KBAs that have management plans, such as Omayed Biosphere Reserve (OBR), Burullus and Manzala (Shaltout \& Khalil, 2005; Khalil \& Shaltout, 2006).

- Ensure the conservation of plant species by combining ex situ and in situ actions that include storing seeds in a seed bank and propagating them artificially, rehabilitating and restoring habitats and fencing enclosures on particular sites.
- Carry out a wide range of educational and awareness-raising activities in universities and research centres about the sensitivity of the threatened habitats and flora (e.g. plants in the Western Mediterranean coastal dunes such as Urginea maritima, Ononis vaginalis and Pancratium arabicum).

- Annually monitor the trends, fluctuations and probability of reduction or disappearance of plant populations and habitats.

- Zone and classify management areas within KBAs based on species frequency, status and vulnerability in different parts of the KBA. Regulate and/or restrict activities in some sensitive areas. Monitoring and conservation actions must target the core areas.

- Merge Moghra Oasis (approximately $50 \mathrm{~km}$ south of OBR) with OBR itself. Moghra Oasis could serve as an additional core area linked to OBR by an ecological corridor, or a satellite protected area on its own. It should be managed 
Reserve under the impact of habitat destruction caused by the extensive building of summer resorts, so that it was considered to be on the brink of extinction. In fact, neither of these plant species was recorded in the 2015 survey. Coastal sand dunes are the preferred habitat for $H$. sphaerocalyx, so this species may not have been found because most of its habitat had been built over.

In general, plant diversity, vegetation composition, threats, distribution, conservation and ecological status for the main plant communities in this area were identified, listed and presented to the Ministry of Environment decision makers.

\section{SAINT CATHERINE KBA}

St Catherine KBA is one of the most floristically diverse spots in the Middle East and contains 30\% of Egypt's endemic plant species. Although it lies outside the Mediterranean hotspot border (and is therefore not included on the map), the very active management and interesting conservation actions that have been taking place there in recent years could be seen as a national reference standard to be replicated in other KBAs.

To date around 1,262 plant species have been recorded in Sinai (Boulos, 1999 - 2005). A total of 472 plant species survive in St. Catherine Protected Area (Fayed \& Shaltout, 2004). Nineteen of these are endemic to Egypt, while more than 115 species have medicinal properties used in traditional therapies and remedies.

In general, restricted-range plants in this area are severely threatened by both natural (aridity and climate change leading to flooding) and human factors (overgrazing by domestic animals and feral donkeys, overcollecting, and unmanaged tourism activities). All these factors are pushing species to the brink of extinction. Endemic plants such as Rosa arabica, Anarrhinum duriminium and Bufonia multiceps are the species most adversely affected by these threats.

During the IPAMed project, the St. Catherine Protected Area team of rangers and researchers, with local community support, identified plant diversity, vegetation composition, threats, plant species distribution and the conservation status of
10 plant species (five endemics to Egypt and five near endemics- endemics to Egypt and neighbour country) : Anarrhinum duriminium, Bufonia multiceps, Euphorbia obovata, Phlomis aurea, Rosa arabica, Polygala sinaica, Nepeta septemcrenata, Salvia multicaulis, Hypericum sinaicum and Origanum syriacum.

Conservation priorities for areas and species were identified based on species distribution, population structure, and threats on species and habitats. Conservation priorities were established based on species-threat distribution dynamics; pilot areas were identified; and ex situ conservation actions for target plant species were carried out. To implement these actions for ex situ conservation practices (seed collection), researchers and protected area staff were given further training in seed collecting, cleaning and storing. The protected area staff (Ministry of Environment) and the local community were the main stakeholders involved in this action.

\section{Seed collection and storage:}

Seeds from ten plant species were collected from St. Catherine PA during the fruiting season (August - October 2017). The team did not found seeds of Euphorbia obovata and Salvia multicaulis as a result from over collection and overgrazing activities. However, we successfully collected seeds of Silene schimperiana and Thymus decussatus in addition to Anarrhinum pubescens, Bufonia multiceps, Phlomis aurea and Rosa arabica, Polygala sinaica, Nepeta septemcrenata, Hypericum sinaicum and Origanum syriacum.

- A total of 25 accessions were collected from 10 species located in 14 sites.

- A total of three accessions were collected from Bufonia multiceps, Hypericum sinaicum, Origanum syriacum, Polygala sinaica and Silene schimperiana.

- As a result from extensive threats on the study area the team has been able to collect only two accessions from Anarrhinum pubescens, Nepeta septemcrenata, Phlomis aurea, Rosa arabica and Thymus decussatus. 


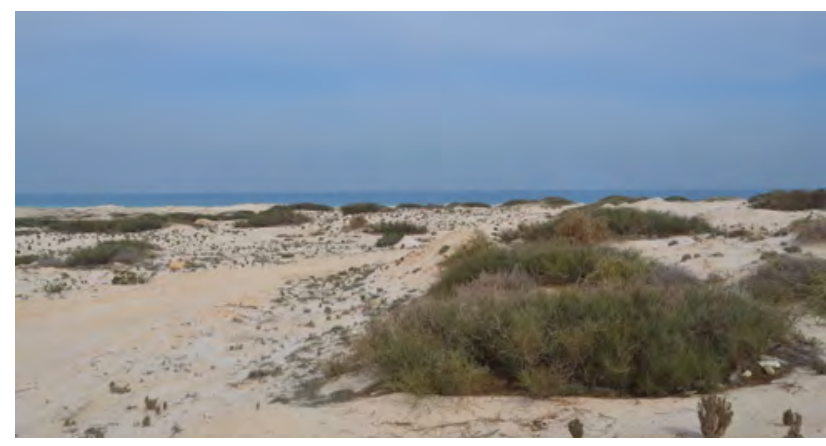

$\Delta$

El Omayed KBA landscape, Egypt () Karim Omar

- Environmental factors including edaphic and climatic features were then recorded for each accession and presented in a separate report.

- All the previous activities were undertaken with the help of the St. Catherine PA management staff and local community assited in the seed collection.

- The team were submitted the collected seeds to St. Catherine PA where they will be save and useful for future work in cultivation and research.

- After cleaning the seeds we had submitted it to St. Catherine Protected Area Management for partly storage for very near future use in germination (stored under $-15 \mathrm{C}$ ). This not long term conservation but it will help to reduce the stress caused to the populations by collecting these plants from wild.

- The seeds were then stored in St Catherine Protected Area facilities with the intention to be used in very close future for cultivation or research.

As result of the conservation actions implemented, decision makers, staff, rangers and local communities now have a better understanding of the target plant species' conservation status and are actively supporting plant conservation efforts. Conservation practices have become more focused and more effective. The level of community participation in conservation efforts has increased, and those in charge of conservation programmes have become better qualified for their work.

\section{CONCLUSIONS AND RECOMMENDATIONS}

Some recommendations regarding the threatened target plant species are summarised below (Assi, 2007; Omar et al., 2013).

- Develop a threat management plan for KBAs.

- Establish a comprehensive strategy, using a participatory approach with the local Bedouins, for dealing with possible future threats to flora like extensive use of medicinal plants and global warming.

- Strengthen cooperation between protected areas and stakeholders in planning and site management by sharing data about the areas and their importance.

- Continue and increase the emphasis on educating visitors to minimise impacts.

- KBAs need adequate funding and increasingly efficient management to reach global standards, and permanent sources of funding must be provided to modernise the scientific protection methods used.

- There are no conservation activities targeting plant communities along the Western Mediterranean shoreline, where the preasure on coastal habitats and plant communities is increasing due to the extensive building of summer resorts. It is suggested to urgently protect the remaining sites and connect them through corridors. Unless specific sites in the last remaining coastal sand dunes are declared protected areas in which human activities are banned as soon as possible, biodiversity in this habitat will be extinct within a few decades. 


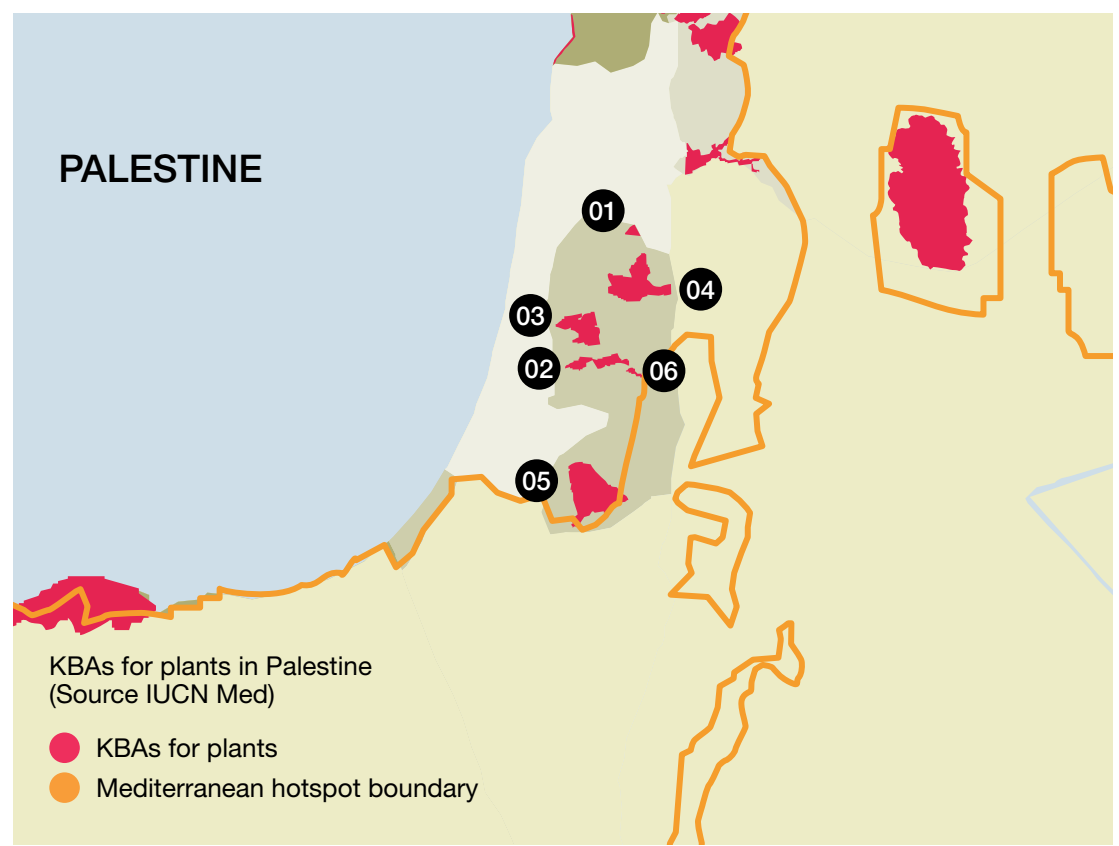

\section{PALESTINE}

\section{Author}

\section{Banan Al Sheikh}

National Agricultural Research Center, Jenin qasyunense Mouterde
01 Faqoua'-Jalboun

A1, B1 Iris haynei Baker, Allium

This area is situated in the north-eastern part of the West Bank, on the hills above the famous and most fertile meadow in the Middle East called Marj-Ibin Amer. It has a Mediterranean climate. The vegetation is open chaparral with olive groves. The most important plant species is Iris haynei, which is endemic to Palestine.

\section{Wad Elbalat- Beit Illo} B1 Atractylis comosa (Spreng.) Sieber ex Cass.

This area is situated in the Central Mountains in the middle of Palestine. It is covered by typical Mediterranean chaparral. The area is a hotspot for medicinal plants. There are many old Quercus calliprinos and Ceratonia siliqua trees close to the Qatrawan Maqam, in addition to many rare species. There are some small springs in the wadi.

03 Wad Qana - Wad Eshai'r B1 Stachys distans Benth., Allium carmeli Boiss.

This Mediterranean area lies in the mountains of central Palestine. It is a chaparral area with Pinus halepensis trees. The area constitutes a reserve for medicinal plants and some old specimens of Quercus calliprinos, Ceratonia siliqua, Crataegus azarolus var. aronia and Pistacia palaestina close to the Maqam for Sheikh
Zaid, in addition to many rare plant species. Cyperus longus and Allium carmeli are new to this KBA. There are some small springs in the wadi.

04 Yaseed-Ibzeik-Tamoun A1a, B1 Iris lortetii Boiss., Iris atrofusca Baker, Iris vartanii Foster, Cynara syriaca Boiss., Atractylis comosa (Spreng.) Sieber ex Cass., Colchicum hierosolymitanum Feinbrun

This KBA is typically Mediterranean in the west and transitional in the east. It includes chaparral, degraded chaparral, carob woodland and phrygana. The area has many rare and near-endemic species, such as Iris atrofusca, Iris lortetii, Biarum pyrami, Scutellaria tomentosa, Iris vartanii and Colchicum hierosolymitanum.

\section{Khalil Gradient}

\section{A1 Origanum dayi Post, Satureja} thymbrifolia Hedge \& Feinbrun This KBA stretches from the southern part of the Central Mountains in the West Bank to the eastern foothills at elevations from $900 \mathrm{~m}$ to $400 \mathrm{~m}$ above sea level. It extends from the Mediterranean to the Irano-Turanian phytogeographic regions. The area harbours an endemic medicinal plant Origanum dayei and near-endemics such as Caralluma europaea, Allium aschersonianum and Iris atrofusca (in restricted patches).

\section{Ain Samya- Ain Auja}

A1b, B1 Iris atrofusca Baker, Centaurea ascalonica Bornm. This KBA lies in the Irano-Turanian phytogeographic zone on the eastern slopes of the Central Mountains in Palestine. Most of its groundwater is pumped to supply the growing demand in the settlements. The landscape consists of a deep wadi with very steep rocky mountains on both sides. Its elevation ranges from $600 \mathrm{~m}$ above sea level down to $64 \mathrm{~m}$ below sea level in the lower Jordan valley (called Ghour). It is home to rare and near-endemic plant species such as Iris atrofusca, Sternbergia clausiana, Rousularia lineata and Allium rothii. 


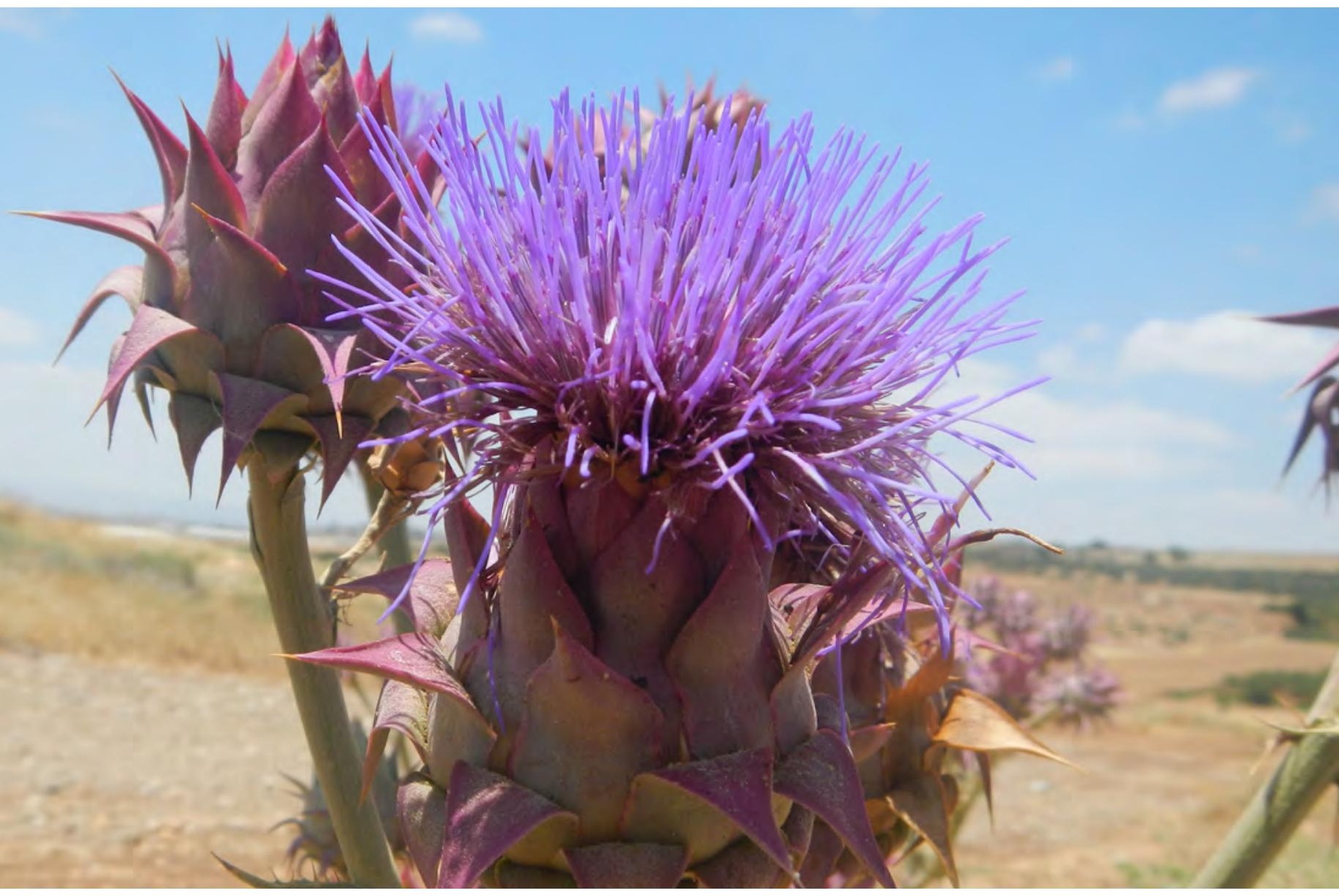

\section{Description of the Palestinian KBA network}

Initially, seven regional KBAs (IPAs) were identified in Palestine in 2010. After the agreement on the KBA criteria in 2016, the sites were re-evaluated against the new criteria. The revision resulted in a total of six KBAs for plants within the Mediterranean hotspot (all of the previously identified areas except for the extreme desert area of the Dead Sea). They are located in the Central Mountains and on their eastern slopes, in the Mediterranean and IranoTuranian floristic regions in Palestine.

The KBAs include diverse environments such as chaparral, phrygana, rocky mountains, olive groves, wet habitats (around springs), semi-desert and extreme desert. Twenty endemic and stenoendemic plant species are present in the original seven KBAs, including the endemics Iris haynei, Origanum dayei, Kickxia judaica and Centaurea ascalonica, and the stenoendemics Satureja thymbrifolia, Iris lortetii, I. atrofusca, I. vartanii, Caralluma sinaica, C. europaea, Allium ascalonicum and Allium carmeli.

Eleven trigger plant species have been identified, most of which are endemics and some are stenoendemics, for the six KBAs included within the national protected area network.
Cynara syriaca in Yaseed-Ibzeik-Tamoun KBA, Palestine (C) Banan Al Sheikh

\section{Main threats to the Palestinian KBA network}

- Agriculture intensification including groundwater extraction

- Overcollecting and collecting methods

- Urbanisation and infrastructure development

- Pollution

Severe anthropogenic effects caused by a long history of land use are now being exacerbated by urban expansion and land conversion, with the establishment, for example, of eight settlements in Wadi Qana Nature Reserve. Other human factors include military training areas, new roads, excessive groundwater abstraction, intensive agriculture and the overuse of chemical fertilisers and pesticides. Habitat quality is also being reduced by intense grazing pressure, overcollecting of medicinal plants, wildfires and land reclamation. 


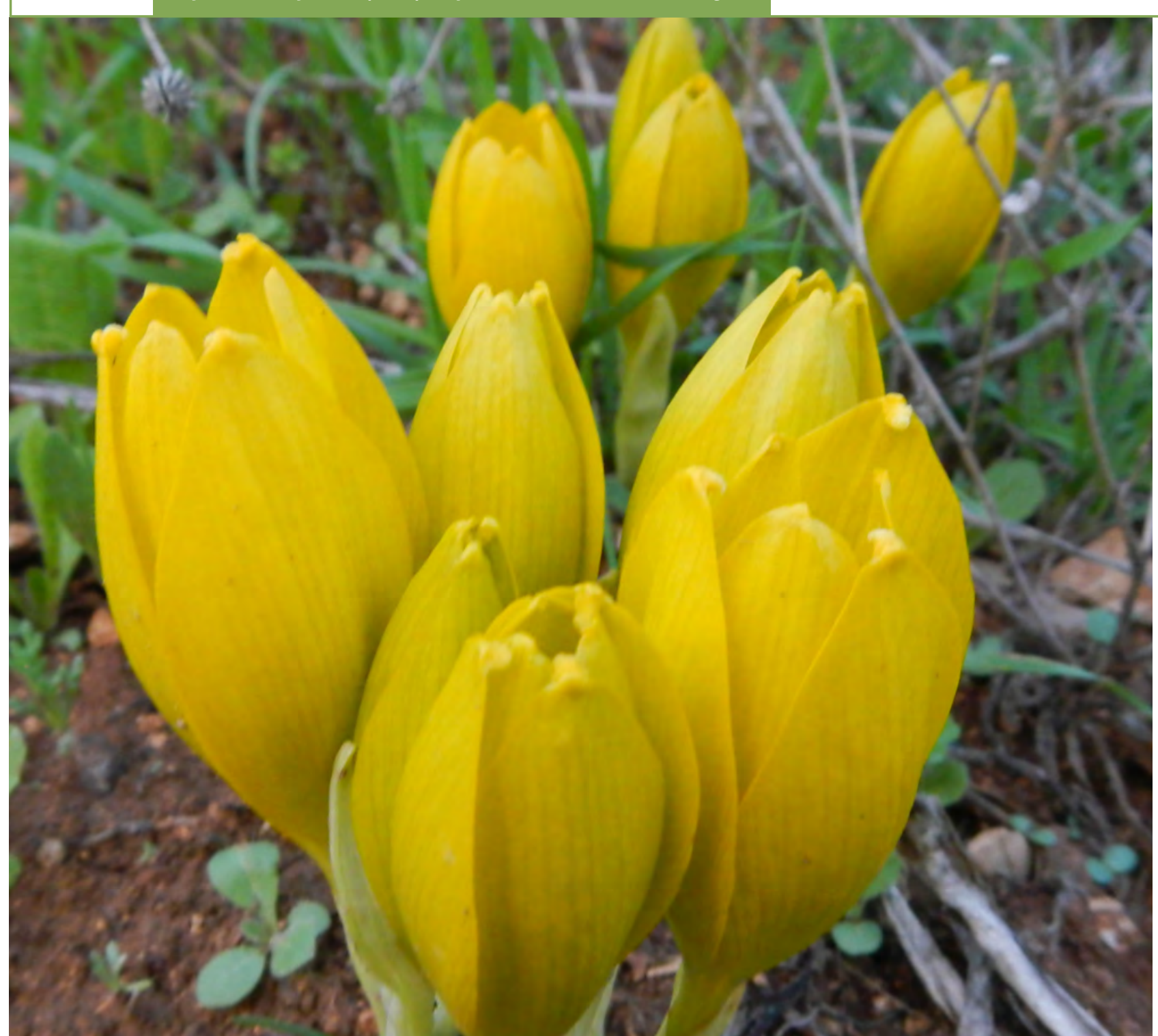

$\Delta$

Sternbergia clausiana in Ain Samya- Ain Auja KBA, on the eastern slopes of the Central Mountains of Palestine (C) Banan Al Sheikh

\section{Main conservation actions recommended for the Palestinian KBA network}

The most immediate action needed is to develop greater awareness in the community, so as to ensure in particular the sustainable harvesting of medicinal, aromatic and ornamental plants.

- Undertake the ex situ conservation of rare and threatened plant species.

- Fence off (enclose) certain areas with local community cooperation. Use modern techniques to multiply and raise seedlings for population enhancement and reintroductions.

- Implement the laws prohibiting the cutting or uprooting of certain species.

- Control grazing through management plans (e.g. with rotational grazing).

\section{Example of conservation actions}

\section{YASEED-IBZEIK-TAMOUN KBA}

This KBA has many rare and near-endemic plant species as well as remnants of ancient Ceratonia siliqua and Pistacia atlantica woodland. It harbours notable species such as Iris lortetii, Iris atrofusca, Iris vartanii, Stachys palaestina, Arum dioscoridis, Colchicum hierosolymitanum and Cynara syriaca.

The main threats are heavy grazing, unsustainable harvesting of medicinal plants, wood cutting for domestic use, land reclamation, military training, intensive agriculture and climate change.

Conservation actions being carried out in this KBA by the Forests and Rangeland Directorate include fencing, sowing forage seeds, reintroducing trees, opening firebreaks in the forest and raising awareness in the targeted local community. 
The conservation action of fencing and closing off parts of the government-owned land in this KBA for several years, in cooperation with the local community, has had a major positive impact on plant conservation. Ministry officials held meetings with shepherds, owners of neighbouring lands and the local council to explain the aim of closing off these areas and also the importance of reintroducing trees to enhance biodiversity. Rare species in the closed areas include Iris atrofusca, Delphinium peregrinum, Scutellaria tomentosa, Adonis palaestina and old Pistacia atlantica.

\section{IMPROVING KNOWLEDGE ON RARE AND}

\section{ENDEMIC TAXA: THE EXAMPLE OF PALESTINE}

For many taxa, knowledge of their current distribution is incomplete and out to date. As part of the IPA-MED project, 6 national teams conducted field inventories to improve knowledge on distribution and threats to rare, endemic and/or potentially threatened taxa.

In Palestine, these inventories were carried out in two sites, between April 2015 and October 2016:

For the KBA of Wad Quana - Wad Eshai'r, 14 taxa were searched in the field, only one could not be found (Ophrys holoserica). Data were also collected for five additional taxa. Distribution maps have been drawn up and the main threats identified.

For the KBA Yassed-Ibzeik, 13 taxa were inventoried (out of 15 taxa sought: Equisetum ramosissimum and Gundelia tournefortii have not been found). Distribution maps have been drawn up and the main threats identified.

For these two KBAs, the main threats to flora are: urbanization, over-intensive pastoralism, and excessive water withdrawals.

\section{CONCLUSIONS AND RECOMMENDATIONS}

KBAs for plants in Palestine occupy a variety of habitats and landscapes that harbour endemic, near-endemic, rare and endangered plant species. Most KBAs are on private land but some protected areas are included. The Environmental Quality Authority and the Ministry of Agriculture (Forests and Rangeland Directorate) should conduct conservation work in parts of these KBAs and put management plans in place with the cooperation of the local community. There is increasing public awareness in the local communities about the importance of biodiversity conservation, sustainability and the need to avoid uncontrolled development. This message should also be put across by the Ministry of Education in their school textbooks at various levels, and by the Ministry of Tourism. The Forests and Rangeland Directorate should collect seeds and cultivates plants of rare, threatened and medicinal species for in situ and ex situ conservation with the collaboration of the National Agricultural Research Center (NARC) botanical garden. They should produce native trees and shrubs in nurseries and reintroduce them to target sites. More fenced areas are needed to allow the original vegetation to recover, and larger areas should be sown with annual forage plant species.

Among the main challenges is the need to solve the current governance disputes, and to lead the local population to take action on the ground for protected areas and site management. The shortage of funding is also a limiting factor in the implementation of possible actions in KBAs. In addition, current environmental law needs to be properly enforced in order to strengthen their application. 


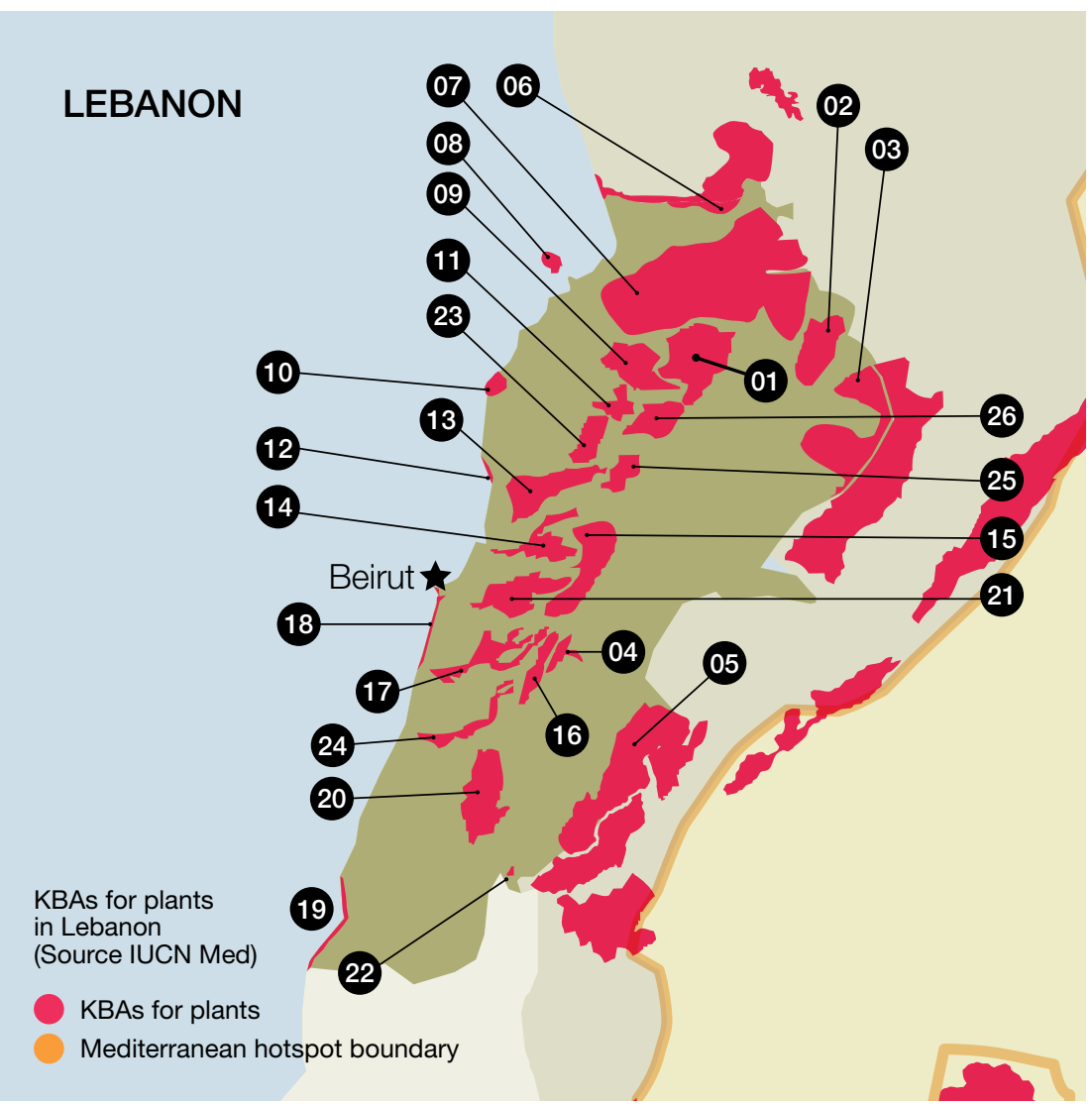

\section{LEBANON}

Authors

Hicham El Zein

American University of Beirut

Moustapha Itani

American University of Beirut

Salma N. Talhouk

American University of Beirut

Magda Bou Dagher Kharrat

Université Saint-Joseph de

Beyrouth

Mariana Yazbek

ICARDA

Mohammad S. Al-Zein

American University of Beirut

Contributors

\section{Carla Khater}

National Council for Scientific

Research - Lebanon

Jean Stephan

Lebanese University

\section{Mount Makmel}

B1 Linum carnosulum Boiss., Senecio exilis Blanche ex Boiss. = Senecio blanchei Soldano, Astragalus kurnet-es-saudae Eig., Myopordon pulchellum (Winkler \& Barbey) Wagenitz, Erigeron libanoticus Vierh.

The highest summit of Mount Lebanon Mountain range rises up to $3088 \mathrm{~m}$ and consists of limestone high mountain rocky slopes, screes, dolines and plateaux. The vegetation is dominated by dwarf spiny shrubs adapted to the harsh environment. This type of habitat has the highest level of endemism as it shelters many species endemic to Lebanon and to the Northeastern Mediterranean mountains.

\section{Hermel Plain}

B1 Astragalus trifoliolatus Boiss Located in the North of the plain of the Beqaa, Hermel plain are constituted by the riparian habitats along the sides of the river of Nahr el-Assy and by semi-arid grasslands and shrublands dominated by white wormwood (Artemisia herba-alba).

03 Aarsal - Ras Baalbek Plateaux B1 Prunus agrestis (Boiss.) Mouterde, Johrenia westii Post

These plateaux consist of semi-arid montane rocky slopes located on the western slopes of Anti-Lebanon mountain range and extend from the heights of Nahle and Aarsal to Ras Baalbek. It culminates in Talaat Moussa at $2646 \mathrm{~m}$. Several species endemic to Lebanon and Syria occur, and also shelters the most important sub-populations of Juniperus excelsa of Anti-Lebanon.

\section{Ammiq}

Regional KBA (IPA)

The KBA of Ammiq includes the eastern slopes of Jabal Barouk, which are among the most important and preserved evergreen oak woodlands of the eastern slopes of Mount Lebanon, and it also includes the wetlands of Ammiq, which are a very rare and unique habitat type in Lebanon. An important part of the Beqaa region was constituted of marshes but most of them were drained for agriculture.

05 Mount Hermon

B1 Erysimum verrucosum Boiss. \& Gaill., Ferula hermonis Boiss.

The highest summit of the Anti-Lebanon mountain range rises up to $2814 \mathrm{~m}$ and 


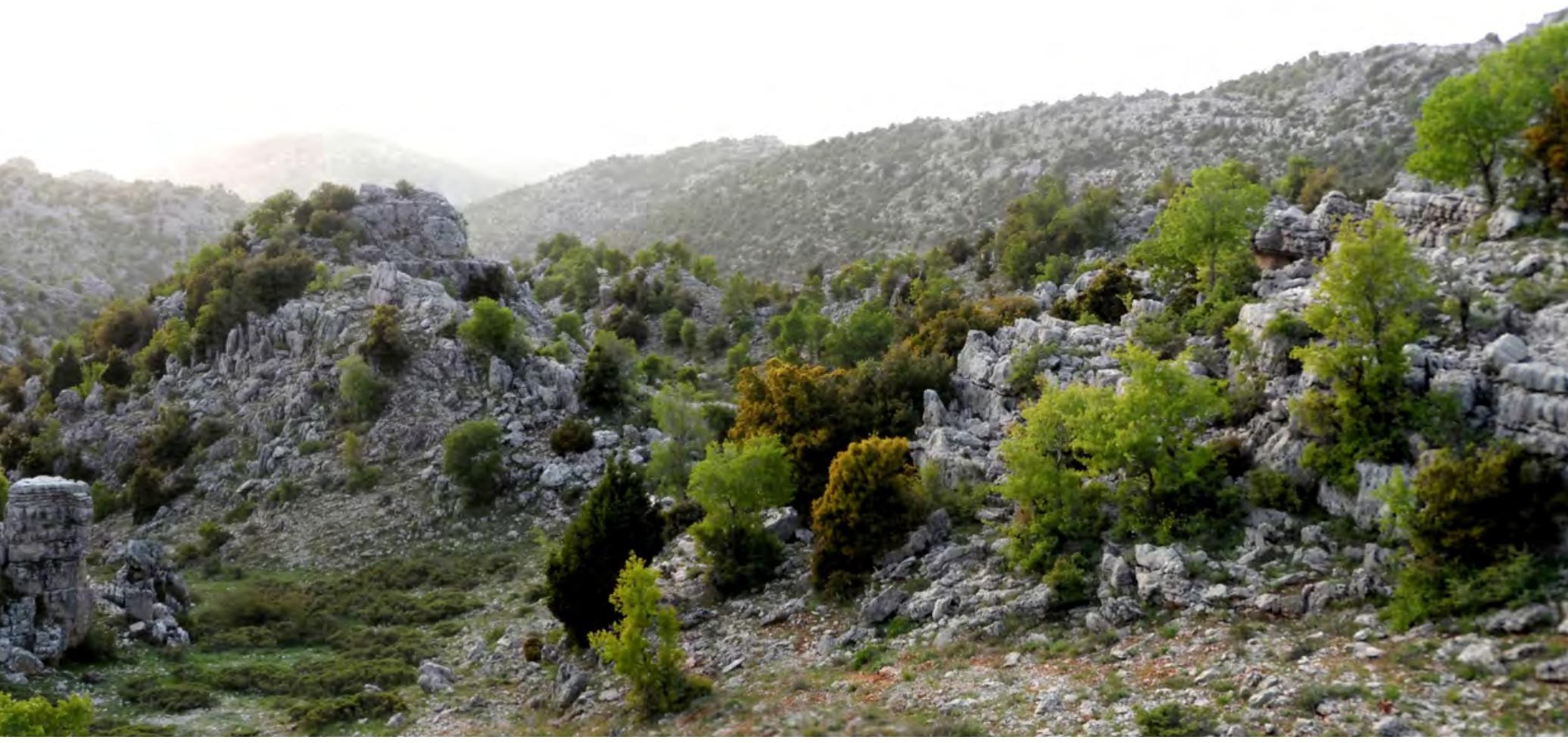

Mountain Ehmej-Jaj, Rocky high montane woodlands of oaks and junipers in Jaj (Ehmej - Jaj KBA), Lebanon

consists of limestone high mountain rocky slopes, screes and plateaux. The important amount of rainfall received creates an environment and a vegetation similar to the one found on the high plateaux of Mount Lebanon.

\section{Menjez}

B1 Isoetes libanotica Bolin, R. D.

\section{Bray and Musselman}

Riparian woodlands and low semideciduous oak woodlands occur on the slopes of Nahr el-Kabir, a river that draws the northern border between Lebanon and Syria. This KBA constitutes the most important stand of Quercus ithaburensis Decne. in Lebanon, an oak species endemic to the Eastern Mediterranean.

\section{$\underline{07}$ Akkar-Danniyeh Mountains - Hermel Plateau}

B1 Senecio mouterdei Arenes = Jacobaea mouterdei (Arènes) Greuter \& B.Nord.

This KBA is the largest of the country as the mountains of Danniyeh and Akkar are the less degraded natural landscapes of the country. It is constituted by an important diversity of well preserved habitats including perennial rivers, riparian galleries, middle montane evergreen and deciduous oak and pine forests, higher montane cedar, juniper and fir forests and rocky cliffs.

\section{Palm Islands}

\section{Regional KBA (IPA)}

Palm islands consist of three uninhabited flat rocky limestone islands, Sanani, Ramkin and Rabbits islands. Along with a diverse marine and coastal fauna, the islands shelter coastal plant communities typical of the rocky shores of the Eastern Mediterranean, which is a threatened habitat in Lebanon.

09 Bcharre-Ehden - Qadisha Valley A1a, B1 Iris cedreti Dinsm., Astragalus ehdenensis Mouterde The historical valley of Qadisha is actually composed of the two branches of Qannoubine and Qozhaya. It is among the most well preserved valleys in Lebanon, thanks to his patrimonial value and its steepness. It shelters many natural habitats such as perennial rivers, evergreen oak and pine woodlands, rocky shrublands, cliffs and small caves. The cedar woodlands and rocky cliffs of the region of Bcharre-Ehden shelter outstanding plant diversity.

\section{Ras Chekka}

\section{B1 Galium thiebautii Ehrendorfer}

Ras Chekka is composed of important coastal rocky cliffs that shelter many chasmophytes but it also constitutes of one of the only left coastal evergreen oak woodlands with rich plant diversity.
11 Tannourine Hadath ej-Jebbe B1 Chaerophyllum aurantiacum Post The upper part of Nahr el-Jaouz is one of the most preserved river valley of the country and consists of steep rocky cliffs, small caves, evergreen oak and pine forests, shrublands and riparian galleries. The larger continuous stands of cedars in Lebanon (almost $10 \mathrm{~km}^{2}$ ) occur between Tannourine and Hadath ej-Jebbe.

\section{Jbail Coast}

B1 Matthiola crassifolia Boiss. \& Gaill. The coast of Jbail, extending from the old coastal ruins to Amchit, shelters important coastal cliffs and sea rocks and constitutes the second most important habitat for the endemic Matthiola crassifolia Boiss. \& Gaill.

13 Nahr llbrahim Valley

B1 Salvia peyronii Boiss. ex Post, Cyclamen libanoticum Hildebr.

Nahr Ibrahim, also known as Wadi Janneh, is one of the most preserved valleys of the country, due to its steepness. The valley consists of steep rocky cliffs, caves, various lower and mid-montane evergreen and deciduous oak and pine forests, shrub lands and riparian gallery forests. 
14 Nahr El-Kallb Valleys

B1 Cytisus syriacus Boiss. \& Bl. Nahr El-Kalb consists of three important valleys and large watersheds that drain the underground waters of Mount Sannine. It shelters an important variety of woodlands, including lower and middle montane oak and pine forests, perennial rivers, riparian galleries, rocky cliffs and small caves.

\section{Mount Sannine and Mount Kneisse}

B1 Alchemilla diademata Rothm., Hieracium kneissaeum Mouterde, Tripleurospermum sannineum (Thieb.) Mouterde, Allium sannineum Gombault

These two mountains rise up to 2,600 meters for Sannine and up to 2,000 meters for Mount Kneisse. Sannine presents an important rocky plateau, whether Kneisse presents almost no flat areas as it is steep from both sides. Similarly to Mount Makmel, theses habitats, high mountain rocky cliffs, screes, dolines with a vegetation of dwarf spiny shrubs, have the highest rate of endemic species.

\section{Mount Barouk}

B1 Cephalaria cedrorum Mouterde Jabal Barouk culminates at $1943 \mathrm{~m}$ and has diversified and preserved montane habitats including grasslands, shrublands, rocky cliffs, and important cedar forests. It constitutes the southernmost range edge of Cedrus libani A.Rich., a tree endemic to the Northeastern Mediterranean.

\section{Nahr Ed-Damour Valleys B1 Centaurea mouterdei Wagenitz} Nahr Ed-Damour KBA consists of several watersheds and rivers mostly emerging from Chouf and Aley regions and flowing through different valleys. The steepness of the slopes of the valleys has prevented urbanisation to destroy the various natural habitats such as rocky cliffs, shrublands, forests of oak and pines, riparian woodlands and freshwater habitats.

\section{Beirut-Jiyeh Coast}

\section{B1 Matthiola crassifolia Boiss. \& Gaill.}

The Beirut-Jiyeh stretches for around 42 $\mathrm{km}$ on the shore in a reduced and narrow area. Although located into a very densely urbanised region, this coastline hosts one of the last coastal sandstone outcrops of the country which is the habitat of the endemic Matthiola crassifolia and other typical coastal species.

\section{Tyr-Naqqoura Coast \\ B1 Astragalus berytheus Boiss. \& Blanche}

The southernmost coastline of Lebanon consists of some limestone coastal cliffs in Naqqoura, along with one of the most important coastal sandy dunes hosting characteristic and well preserved vegetation in Tyr.

\section{Jabal Rihane}

\section{B1 Anthemis didymaea Mouterde}

Located on the last southern hills of Mount Lebanon, between Kfar Houne and the Litani and Zahrani rivers, Jabal Rihane hosts a variety of middle montane woodlands of evergreen oaks and pines and has an important number of species. It is also the unique locality where Inula heterolepis Boiss. can be found in the Levant.

\section{Nahr Beirut Valleys}

B1 Alkanna maleolens Bornm.

Similarly to Nahr el-Kalb Valleys, Nahr Beirut valleys are among the most important valleys of the country. The KBA consists of three important valleys and large watersheds with an important diversity of preserved woodlands and natural habitats, such as lower and middle montane forests of oak and pine, perennial and intermittent rivers, riparian galleries, rocky cliffs and small caves.

\section{Sarada}

\section{A1a Iris bismarckiana Regel}

Sarada, the smallest identified KBA, is a hill located in a region intensely cultivated in south Lebanon. The rocky grasslands and shrub lands are key habitats as they are the only place where Iris bismarckiana Regel, a species endemic to the Golan and the Galilee, can be found in Lebanon.

\section{Ehmej-Jaj}

\section{A1a, B1 Iris sofarana Foster}

Ehmej and Jaj region is located between 1200 and 2000 meters and hosts an important diversity of habitats very rich with endemic plant species. Evergreen and deciduous oak forests occur in the lower parts and rocky slopes, scattered woodlands and shrub lands are found in the upper parts. Jaj also shelters a little stand of cedars.
24 Nahr el-Awwali Valley B1 Stachys hydrophila Boiss. Nahr el-Awwali forms a long valley emerging from the Chouf region. Alike other steep valleys of the country, Nahr Awwali is a shelter for many rare species and constitutes a reference of typical and preserved natural habitats, namely pine, evergreen and deciduous oak woodlands, shrublands, cliffs and riparian woodlands.

\section{Afqa Plateau \\ B1 Arenaria libanotica Ky}

Extending between Mount Sannine and Mount Mneitre, and dominating the Nahr Ibrahim valley, the KBA consists of an important high plateau, at 1800-2000 m, hosting one of the most important subpopulation of Juniperus excelsa of the western slopes of Mount Lebanon range along with other typical high mountain plateaux vegetation, like doline and dwarf spiny shrubs.

\section{Mount Mneitre}

B1 Thesium libanoticum Ehrenb., Micromeria nummulariifolia Boiss. = Clinopodium nummulariifolium (Boiss.) Kuntze

Although understudied due to its difficulty to access, the plateaux of Mount Mneitre shows features similar to Mount Makmel and Mount Sannine, with important number of endemic species and characteristic high montane habitats types, including screes, dolines and dwarf spiny shrubs. 


\section{Description of the Lebanese KBA network}

Initially, 20 IPAs were identified in Lebanon in 2010 (Radford et al., 2011). Later, another study based on both historical and recent fieldwork data was carried out (Bou Dagher et al., 2018), which updated the IPAs. After the agreement on the KBA criteria in 2016, those sites were re-evaluated against the new criteria. Finally, a review was conducted in 2017. As a result, $26 \mathrm{KBAs}$ for plants have been identified in Lebanon, 16 of them on Mount Lebanon, located mainly on west-facing slopes and on high-mountain plateaux. The remaining KBAs for plants are found along the eastern Mediterranean coast (5), in the Beqaa valley and on part of the eastern slopes of Mount Lebanon (3), and in the Anti-Lebanon mountain range (2). With the exception of the Beirut-Jiyyeh Coast KBA, no KBAs for plants occur in dense residential and commercial areas. In addition, few KBAs occur in predominantly agricultural regions such as the Beqaa plains, south Lebanon and the plain of Akkar.

Due to the topographical complexity of the country, many different habitats occur in Lebanon and most of them are represented within these 26 KBAs. The predominant ecosystems included are steep valleys (present in eight KBAs), and rocky high-mountain plateaux, higher montane coniferous woodlands and coastal vegetation (five KBAs each). Semi-arid woodlands, shrublands and grasslands are less well-represented, as they occur in only four KBAs each.

Most of the KBAs include several kinds of ecosystems and vegetation zones along their altitudinal gradient. For instance, steep valleys are one of the most complex ecosystems as they include many types of habitat, such as perennial rivers and their riparian woodland galleries, slopes with lower evergreen woodlands, mid-montane areas with evergreen, deciduous and coniferous woodlands, and rocky cliffs.

Eighty-three species endemic to Lebanon (Mouterde, 1984) including 25 stenoendemics are included in the KBAs. The Bcharre-Ehden-Qadisha Valley KBA ranks first with 35 species endemic to Lebanon. The Sannine-Kneisse KBA ranks second with 34 species endemic to Lebanon. Mount
Makmel and Mount Barouk are joint third with 20 endemic species each. Mount Mneitre is fifth with 18 endemic species. Ehmej-Jaj, Nahr Ibrahim Valleys and Nahr el-Kalb Valleys follow with 13, 13 and 12 endemic species, respectively. Thirty-five trigger species were used to qualify 24 global KBAs.

\section{Main threats to the Lebanese KBA network}

- Urban expansion including Roads and service corridors and Dam construction

- Quarrying

- Tourism and recreational activities

- Overgrazing

- Unregulated use of biological resources such as illegal logging of conifers and wood harvesting

- Climate change

- Forest fires

- Pollution (solid waste and water pollution)

Eleven of the 26 identified KBAs for plants (42\%) are totally or partially contained within national protected areas, including three - Palm Islands, Ras Chekka and Jabal Rihane - that are totally contained. Other KBAs for plants occur in areas protected by decrees or laws that seek to conserve natural heritage sites and riparian habitats.

However, many of these areas are not effectively protected and are being systematically destroyed by urban expansion, the building of dams and other infrastructure and road development projects. This is the case for riparian areas such as Nahr el-Kalb, Nahr Ibrahim and Nahr Awwali, Nahr Damour, Nahr Beirut and Nahr el-Jawz, and natural heritage areas such as Mount Makmel and Qadisha Valley.

Depending on the location of the KBAs for plants, the main threats identified were as follows: Residential and commercial developments were major threats for $13 \mathrm{KBAs}$ located in different parts of the country. Transportation and service corridors were major threats affecting six KBAs. Quarrying, which occurs on a large scale between Akkar and 


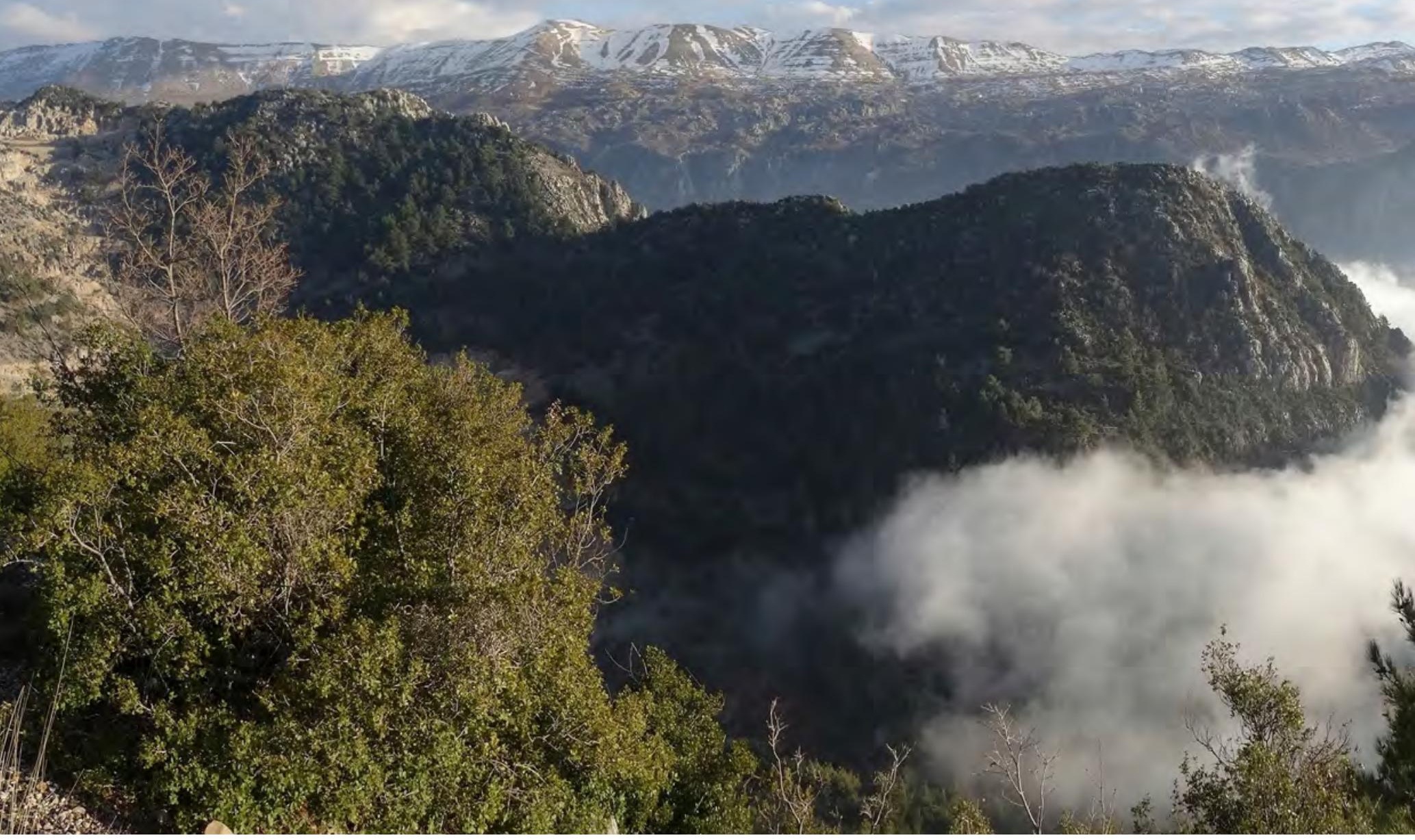

Hermel, in Aarsal and in many KBAs with sandstone bedrock, are a serious threat to KBAs located in or around these areas. Similarly, human intrusion and disturbance for the purpose of developing tourism and recreation activities are threats that mainly affect KBAs located on the coastline and at high elevations. Semi-nomadic overgrazing is a threat especially in mid- and high-elevation KBAs, and is exacerbated by the pressure of residential and commercial developments in these areas and by regional conflicts. Unregulated use of biological resources such as illegal logging of conifers and wood harvesting in the evergreen oak forests to produce charcoal are also widespread threats affecting KBAs with important woodlands. Other threats affecting particular KBAs include fires, dam construction in three of the valley KBAs, expansion of agricultural lands, and a lack of solid waste and water pollution management. Climate change, a long-term impact on KBAs, has yet to be addressed as a threat especially in high-elevation habitats.

\section{Main conservation actions recommended for the Lebanese KBA network}

Immediate conservation actions are needed in these KBAs to slow down the ongoing erosion of biodiversity and they should involve local populations through environmental awareness raising and participation. To sustain conservation actions and establish a strategy at the national level for KBAs, there should be incentives and frameworks to encourage collaboration and partnerships between the various institutions in the country. The Lebanese KBA network needs to produce the necessary public communication material to raise awareness of KBAs and to provide decision makers with the necessary tools to guide local planning. The network should identify its members' expertise and interests and develop an integrated action plan to ensure complementarity, avoid redundancy in scientific research, and optimise social participation and local planning. A 


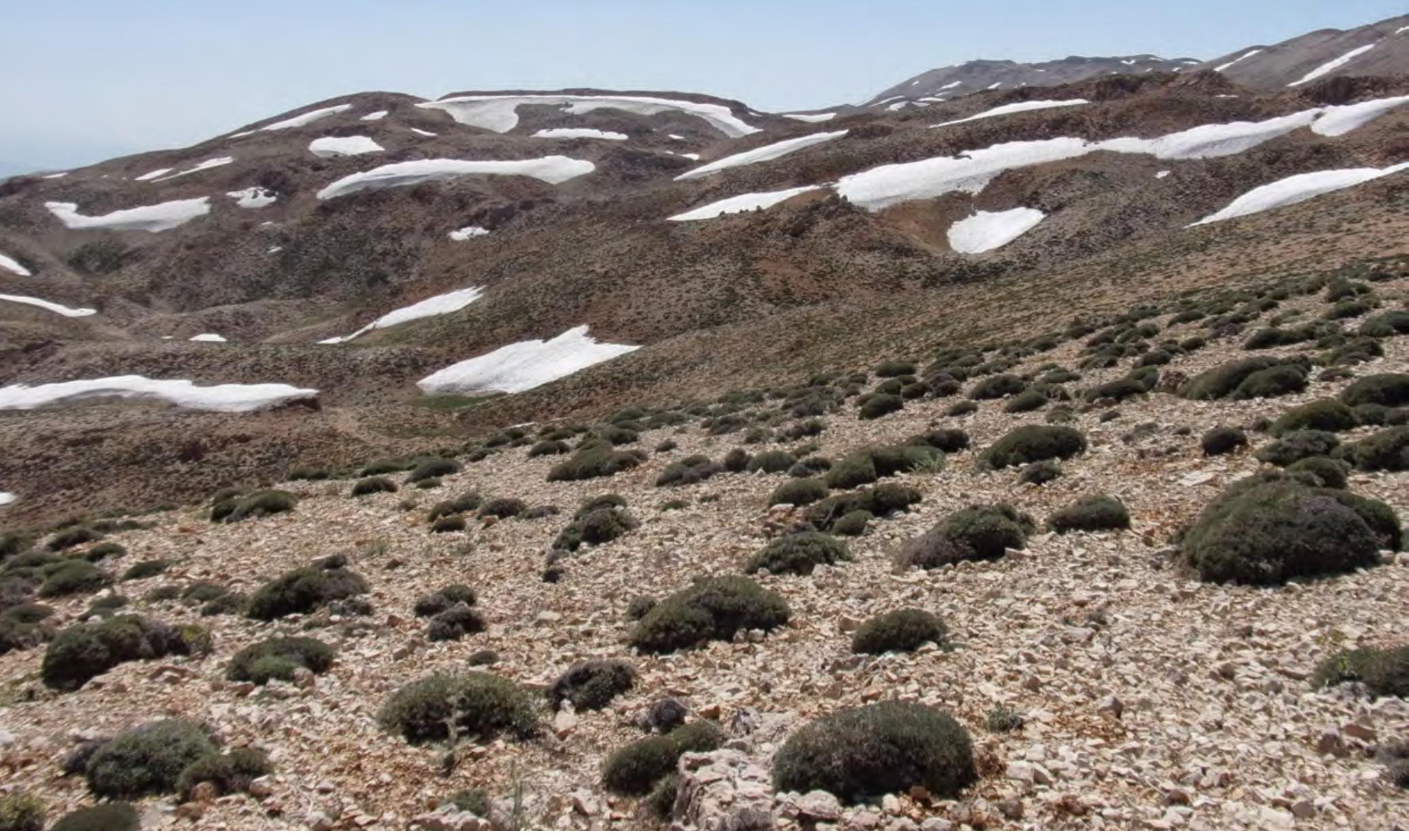

the irises occur on private lands, meetings were organised and memoranda of understanding were signed between the municipality and the private landowners allowing the municipality to prepare an impact assessment and to plan for the translocation of irises in the event that the landowners want to build on their lands.

\section{PILOT KBA: BEIRUT-JIYEH COAST KBA}

The coastal sandstone outcrops here constitute one of the last habitats of the endemic Matthiola crassifolia and other typical coastal species endemic to the Levant and Eastern Mediterranean, such as Silene chaetodonta var modesta, also found in Palestine; Artemisia monosperma, found in Palestine and Egypt; Centaurea procurrens, found in Syria and Palestine; and Campanula stellaris, found in Turkey, Syria and Palestine. Although common in other Mediterranean countries, Thymelaea hirsuta and Retama raetam have only been found in Lebanon in this coastal KBA.

The KBA is highly threatened as it occurs in a dense residential and commercial development area that is still expanding into unbuilt spaces, some of which
High mountain rocky plateaux in Mount Sannine (Sannine-Kneisse KBA), Lebanon (c) Hicham Elzein

include high-quality remnant vegetation (Hahs et al., 2009). Recently, Dalieh and Ramlet El-Bayda have been the target of such development. This has prompted local civil action in the form of protests and campaigns by the Civil Campaign to Protect the Dalieh of Raouche, and activism to protect the sandy beach of Ramlet El-Bayda. Plant conservation is used as a supportive argument in both cases, although the primary focus of both initiatives is to maintain public access to these areas. The conservation of plant diversity is likely to benefit considerably from the protection of Dalieh; at Ramlet El-Bayda, however, the plant species-poor sandy beach is the primary focus of the protection efforts, not the nearby sandstone cliffs which are significantly more diverse and represent a highly threatened habitat type in the country. Some sites in this KBA for plants are protected de facto, either due to restricted access, such as the stabilised sand dunes located within the perimeter of Rafik Hariri Beirut International airport, or due to physical inaccessibility, such as the high cliffs facing Raouche Rocks. In neither case, however, have any management strategies for plant conservation been put in place. 


\section{CONCLUSIONS AND RECOMMENDATIONS}

- National agreement: The Lebanese KBAs are composed of a mosaic of habitat types and their boundaries enclose diverse and heterogeneous landscapes. The fact that most of the plant species endemic to Lebanon were included in the KBAs delimited by CEPF in 2017 is a step forward in the identification of important sites for conservation. However, administrative borders straddled by KBAs, land ownership problems and a lack of consensus among stakeholders, remain obstacles to the emergence of lasting environmental initiatives. Consensus needs to be built in order to develop a national vision and strategy that includes incentive measures that ensure conservation through sound management and sustainable use.

- $\quad$ Protected areas: In Lebanon, almost half the KBAs for plants (42\%) are partially or totally included within a national protected area. In these KBAs, protected area management teams should develop management plans that conserve threatened target habitats and species. For KBAs that are partially included, there should be efforts to incorporate additional areas of these KBAs into the protected area system or to manage them as buffer zones. Furthermore, the ongoing national Red-Listing efforts will help management teams devise targeted management plans.

- Participatory management: KBAs that do not benefit from protection are highly threatened, especially those that do not present an attractive forested landscape, because areas protected for conservation purposes in Lebanon consist mostly of wooded areas (e.g. the western slopes of Mount Lebanon), particularly where the country's flagship species Cedrus libani grows. Still, several habitat types, such as coastal/supratidal habitats or the scrub and grasslands of the high-mountain plateaux, locally referred to as 'jurd', are of major conservation value and deserve official protection measures. In these cases, participatory approaches may be useful to achieve stakeholder consensus on a type of conservation management that is agreeable to all and can be locally enforced.

\section{Successful local case studies involving} community-led natural resource management, such as the establishment of himas (community-managed protected areas) and micro-reserves, should be well documented and shared for application throughout the country.

- Knowledge improvement: Due to a lack of security and/or accessibility, many regions of the country, especially along the borders with neighbouring countries and in other military areas or security zones, remain underexplored although they shelter important plant diversity. Botanical studies should be carried out urgently to document and inventory these areas to help in setting conservation priorities.

The widespread lack of compliance with existing laws that protect natural areas by regulating residential and commercial construction and infrastructure development needs to be addressed, not only by applying penalties, but also by offering incentives for greater compliance.

The delineation of KBAs for plants in Lebanon is an essential tool for decision makers and experts as it not only highlights and defines areas where conservation actions will be initiated, but it also serves as a guide for additional protected area designations. Nevertheless, a national consensus among experts is a necessary step for its acceptance. An example coming out of the IPAMed project is the initiative to produce a booklet on Lebanese KBAs for plants aimed at the general public and co-authored by a large number of national experts. 


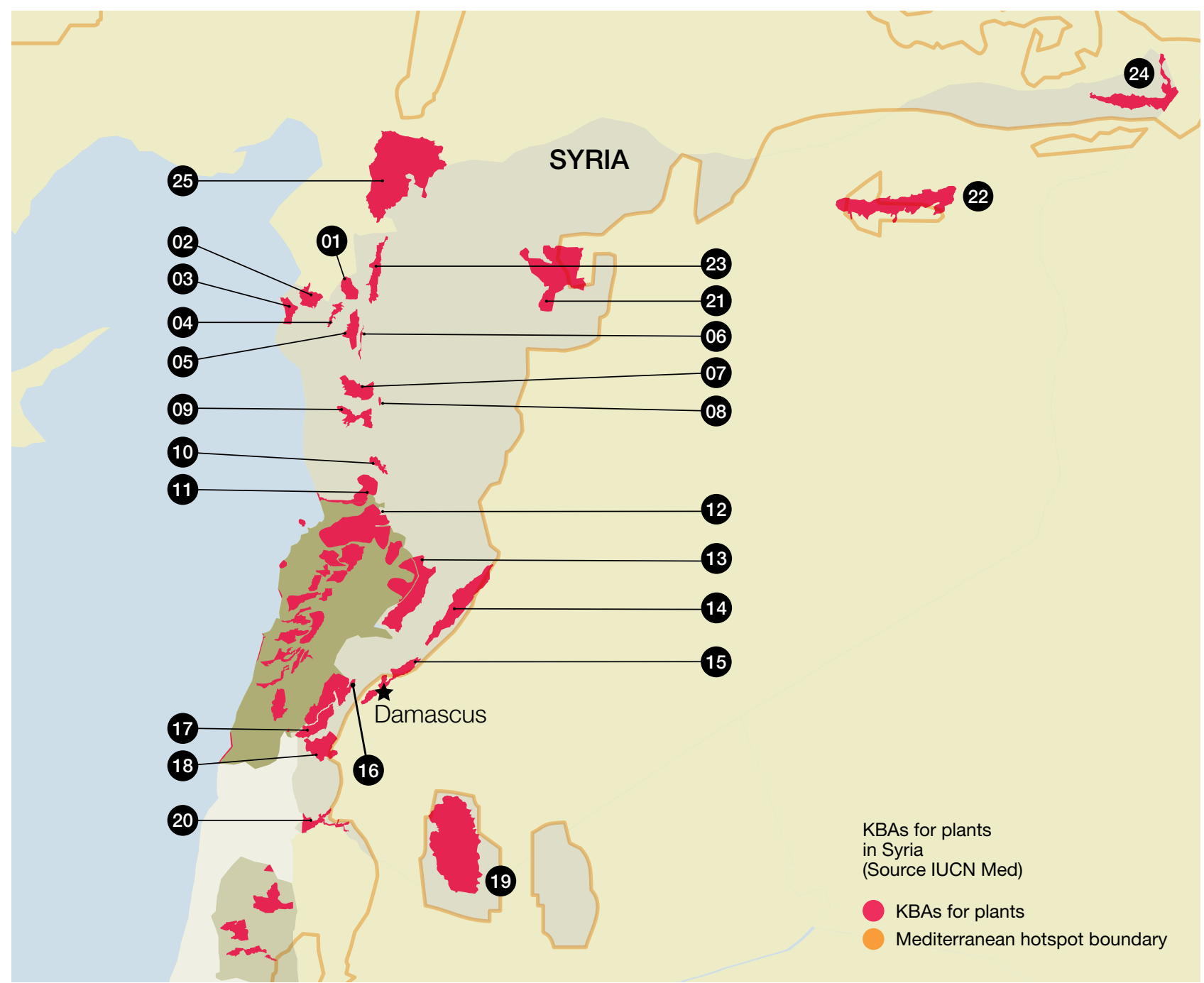

\section{SYRIA}

\section{Authors}

\section{Mwaffak Chikhali \\ ELARD-Syria}

Ali Shehadeh

Genetic Resources Section, International Center for

Agricultural Research in Dry

Areas (ICARDA)

Aroub Almasri

National Commission for

Biotechnology, Syria

Mohammad S. Al-Zein

American University of Beirut

\section{Contributors}

Sami Youssef

AMAP, Université de Montpellier

Nigel Maxted

University of Birmingham

\section{Jisr al-Shoghur}

Regional KBA (IPA)

Situated on the left bank of Orontes River, Jisr al-Shoghur KBA is the wooded hinterland of the Baer-Bassit massif. It is a slightly elevated area, its elevation ranging from 150 to $850 \mathrm{~m}$ above sea level. Humid Mediterranean bioclimatic conditions prevail in this regional KBA. the Amanus and Antioch endemics.

\section{Fronloq-Kasab}

B1 Allium calyptratum Boiss.,

Petrorhagia syriaca (Boiss.) Mouterde \& Greuter, Cytisus cassius Boiss., Ferulago amani Post

Fronloq-Kasab KBA is a mountainous region in the Baer region of Northwest Syria. Humid Mediterranean climate predominates this area, which receives an annual precipitation exceeding $1,100 \mathrm{~mm}$. This KBA constitutes the southern limit of many Euro-Siberian plant species. It also includes a large number of endemics of the coastal mountains and Amanus. Many nationally threatened species find refuge in Fronloq-Kasab, most notably Quercus infectoria subsp. veneris (A. Kern.) Meikle and and Quercus cerris L.
03 Umm al-Tuyur-Bassit

B1 Allium bassitense J. Thiébaut Umm-al-Tuyur Bassit KBA extends along the Syrian coast from Wadi Qandil River to Ras al-Bassit headland. It is characterized by green metamorphic rocks that do not occur anywhere else in the country. It is dominated by Pinus brutia Ten. woods extending all the way to the sea. A sheer rocky coast (ca. $22 \mathrm{~km}$ ), woodland hinterland towards the main LatakiaAntioch highway and a sandy beach (ca. $2 \mathrm{~km}$ ) comprise this KBA, which includes many of the endemics of Amanus and the coastal mountains, as well as many nationally rare and/or threatened species. This KBA includes one of the last remaining patches of wild olive trees (Olea europaea L.). Two marine protected areas exist within this KBA.

\section{Salma-Haffeh}

\section{Regional KBA (IPA)}

Salma-Haffeh KBA falls in the

Euromediterranean altitudinal zone of the coastal mountains, and extends ca. $15 \mathrm{~km}$ between the two towns Salma and Haffeh. The KBA is intercepted by many permanent watercourses and contains exemplars of vegetation types typical of the western 


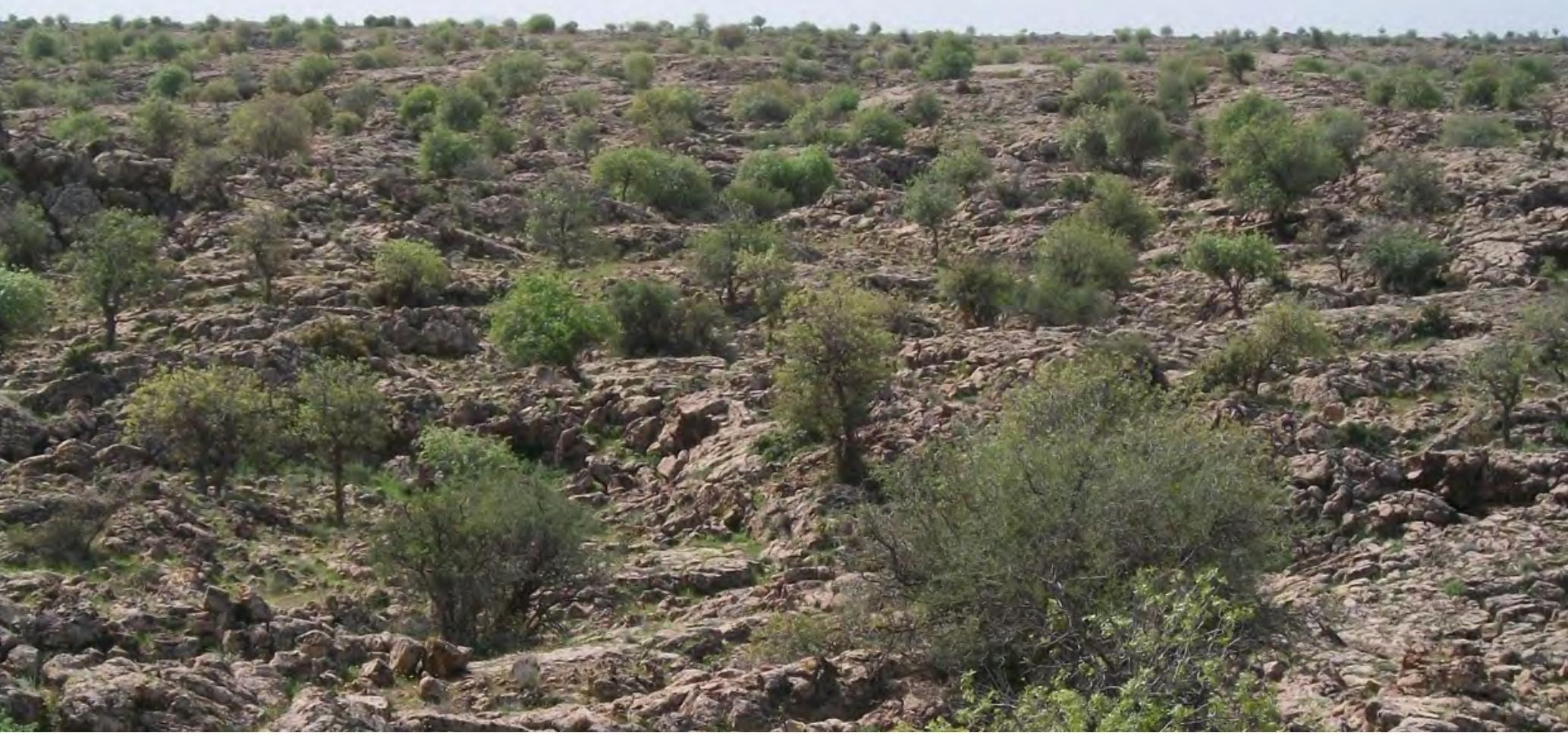

slopes of the coastal mountains. Wooded areas are dominated by Pinus brutia Ten. And Quercus coccifera L. forests, associated with Pistacia terebinthus subsp. palaestina (Boiss.) Engl. This is the only site where the nationally threatened fern, Pteris vittata L., may be found.

\section{Slenfeh-Jaubet al-Berghal}

B1 Cedrus libani A. Rich., Iris nusairiensis Mouterde, Saponaria bargyliana Gomb., Origanum bargyli Mouterde,

Slenfeh-Jaubet al-Berghal KBA extends ca. $25 \mathrm{~km}$ in the north-south direction along both sides of the crest line of the Syrian coastal mountains. In fact, this KBA covers most of the northern part of these mountains and includes their highest peak (Nabi Matta, 1,562 m above sea level). Its eastern slopes are very steep, descending to the Ghab depression, while its western slopes are less steep but intercepted by deep valleys. Around $40 \%$ of the area of this KBA is protected. This KBA is one of the best forested mountainous area in the country, its forests dominated by Abies cilicica (Antoine \& Kotschy) Carrière and Cedrus libani A. Rich. It receives the highest amount of rainfall in the country because of its direct exposure to the wet western winds. Based on its altitude, it falls between the Supramediterranean and the Oromediterranean zones.

\section{Ghab}

\section{Regional KBA (IPA)}

The Ghab depression is a flat plain in northwestern Syria that used to be transformed into a large swampy area when flooded by the Orontes River. The depression was transformed into an area of intensive agriculture through a large draining project. This KBA is therefore comprised of remnant patches that house some of the original vegetation of this swampy plain.

\section{Abu Qbeis}

\section{Regional KBA (IPA)}

Abou Qbeis KBA extends ca. 20 km east-west and $8 \mathrm{~km}$ north-south on both sides of the crest line, in the cental part of the Syrian coastal mountains. Lying in the humid Mediterranean bioclimatic zone, this $\mathrm{KBA}$ is located in the Eumediterranean, Supramediterranean and Oromediterranean zones of the mountain. This KBA was designated an Important Plant Area (IPA) based on the number of rare and threatened plant species it includes. It is also the best national site for threatened orchids. $60 \%$ of the area of this $\mathrm{KBA}$ is protected.

\section{Kanfo}

\section{Regional KBA (IPA)}

Kanfo KBA is basically the best remaining Quercus ithaburensis Decne. woodland in the country. Extending over an area of ca. $3 \mathrm{~km}^{2}$, this KBA lies at the southern end of the Ghab valley towards the northern fringes of Tar al-Ula hills. Sub-humid Mediterranean bioclimatic conditions predominate this KBA, which occurs at an average altitude of $220 \mathrm{~m}$ above sea level.

\section{Massiaf-Qadmous}

\section{Regional KBA (IPA)}

Massiaf-Qadmous KBA is located in the southern section of the Syrian coastal mountains. On its western side, it is intercepted by deep valleys with seasonal and permanent water courses. Dominated by humid and sub-humid Mediterranean bioclimatic conditions, this regional KBA contains nationally threatened
$\Delta$

Pistacia atlantica open woodland, Syria (C) Hayan Himidan

Pinus halepensis Mill. and Cupressus sempervirens L. coniferous woodlands, in addition to several coastal mountain endemics, as well as nationally threatened and rare plant species. Only about $5 \%$ of this KBA is protected.

\section{Daher al-Qseir}

B1 Iris basaltica Dinsm., Lathyrus basalticus Rech.f.

Located at the southeastern edge of the Syrian coastal mountains, Dahr al-Qseir is characterized by volcanic soil and humid Mediterranean bioclimatic conditions, a combination not found anywhere else in the country. It constitutes the southernmost limit for such species as Castanea sativa Mill. and Corylus avellana L. It also houses some of the stenoendemics of the western Homs plateau, as well as as endemics of the coastal mountains.

11 Al-Kabir al-Jonubi

B1 Isoetes libanotica Musselman,

Bolin \& R.D.Bray, Isoetes olympica A. Braun, Iris basaltica Dinsm., Lathyrus basalticus Rech.f., Arum polyphyllum Link, Pulicaria auranitica Mouterde, Cota samuelssonii (Rech. f.) Oberpr. \& Greuter, Centaurea reducta Wagenitz, Vicia kalakhensis Khattab, Maxted \& Bisby

Al-Kabir al-Janoubi river, the main coastal river of Syria, originates at the southern limits of the Syrian coastal mountains and runs through the Homs gap, demarking the Syrian-Lebanese border. Important riparian and marsh habitats located approximately $45 \mathrm{~km}$ along the Syrian 
banks of this river, comprise this KBA in Syria. Similar habitats along the Lebanese banks of this river comprise the Menjez KBA in Lebanon. This KBA includes many threatened and/or rare species. It also includes many West Homs Plateau endemics at its eastern part and Levantine coast endemics along its western part.

\section{Akkoum}

\section{Regional KBA (IPA)}

Akkoum KBA is comprised of a $10 \mathrm{~km}$ $x 4 \mathrm{~km}$ strip of low to medium elevation hills and mountains that extends into the Lebanese territories to include the extreme northeastern part of Mount Lebanon. It is dominated by Mediterranean woodlands and shrublands and include an evergreen Mediterranean forest dominated by Cupressus sempervirens L. and Juniperus excelsa M. Bieb.l ts highest point is Marmaz $(1,430 \mathrm{~m})$.

\section{Anti-Lebanon}

B1 Tulipa lownei Baker, Iris antilibanotica Dinsm., Minuartia parvulorum Rech. f., Silene schlumbergeri Boiss., Draba oxycarpa Boiss., Odontarrhena subspinosa (T. R. Dudley) Španiel \& al., Astragalus antilibani Bunge, Astragalus exiguus Post, Euphorbia antilibanotica Mouterde, Euphorbia promecocarpa Davis, Teucrium antilibanoticum Mouterde, Nepeta pabotii Mouterde, Thymus alfredae Post, Verbascum antilibanoticum Hub.-Mor., Verbascum porteri Post, Valerianella antilibanotica Rech. f., Campanula antilibanotica (P. H. Davis) Greuter \& Burdet, Phagnalon linifolium Post, Helichrysum

\section{pygmaeum Post}

Anti-Lebanon KBA is comprised of a high mountain range that extends north-east to south-west, forming the Syrian-Lebanese border. It consists mostly of an extensive highland area (ca. $2000 \mathrm{~m}$ above sea level), and includes the second highest peak in Syria (Tal'at Musa, 2,616 m). The numerous mountain peaks, steep slopes, vertical cliffs, and deep valleys provide diverse habitats for plants. The area is very rich in grasses, range species and crop wild relatives of many legumes and cereals (Triticum, Vicia, Lens, Cicer, Lathyrus). Low temperatures coupled with a long period of snow and frost allow the survival of alpine and subalpine vegetation. Being in the rainshadow of Mount Lebanon, this KBA receives modest precipitation; therefore, semiarid Mediterranean bioclimatic conditions prevail. This KBA is the most important center of endemism in Syria, with a large number of stenoendemics and three centers of endemism: Bloudan, Al Zebedani and Maloula. Around $60 \%$ of this KBA is protected.

\section{Qalamoun}

\section{B1 Allium pseudophanerantherum}

Rech. f., Iris yebrudii Dinsm. ex Chaudhary, Verbascum glanduliferum (Host) Hub.-Mor., Verbascum tropidocarpum Murb.

Qalamoun is a mountain range extending about $65 \mathrm{~km}$ from north-east to southwest, parallel to the more westerly AntiLebanon range. Being in the rainshadow of both Mount Lebanon and Anti Lebanon, it receives very low precipitation. AridMediterranean bioclimatic conditions prevail in this KBA, whichharbours a large number of national and subnational endemics and stenoendemics. Around 5\% of this KBA is protected.

\section{Qassioun}

B1 Bellevalia douinii Pabot \& Mouterde, Iris damascena Mouterde, Sedum louisii (J. Thiébaut \& Gomb.) Fröd., Onobrychis gaillardoti Boiss. Scandix damascena Bornm.

Qassioun is an elongated mountain, running at the foothills of Anti-Lebanon above Damascus from north-east to south-west. Arid Mediterranean bioclimatic conditions prevail in this KBA, which derives its importance from the relatively high number of rare, localized restricted range endemics. Some, such as the trigger species Iris damascena, may be extinct as they have not been observed for a long period of time. This may be attributed to increasing urbanization.

16 Rakhleh-Wadi al-Qarn B1 Prunus boissieri nom. nov., Ferula hermonis Boiss., Valerianella soyeri Boiss.

Rakhleh-Wadi al-Qarn is an upland area located at an elevation of 1,000-2,000 $\mathrm{m}$ on the north-eastern slopes of Mount Hermon, adjacent to the Lebanese border. Its unique position between Mount Hermon and the Anti-Lebanon Mountains contributes to the richness of its flora. Sub-humid Mediterranean bioclimatic conditions prevail in this KBA, which includes the nationally threatened oak species Quercus brantii Lindl.

\section{Hermon}

B1 Rosularia parvifolia Rech. f., Ferula hermonis Boiss., Astracantha gaillardotii (Boiss.) Podl., Linum toxicum Boiss., Euphorbia caudiculosa Boiss.

Mount Hermon, the highest mountain in Syria (ca. $2814 \mathrm{~m}$ ), constitutes the southernmost section of the Anti-Lebanon Mountains, its crestline forming the border between Syria and Lebanon. It receives abundant rainfall due to its proximity to the Galilee-Golan gap, which allows humid Mediterranean air to enter inland. Subalpine to alpine vegetation types prevail at high altitudes. Relicts of the nationally threatened oak, Quercus ithaburensis Decne. subsp. ithaburensis (=Quercus look) may be found at lower elevations.

\section{North Golan}

B1 Allium damascenum Feinbrun, Silene physalodes Boiss., Stachys paneiana Mouterde

A volcanic plateau in the northern parts of the Golan Heights in south-western Syria comprise this KBA, whose northern limits reach the foothills of Mount Hermon. Subhumid Mediterranean bioclimatic conditions prevail in this KBA, which includes relict woodlands of the nationally threatened oak, Quercus ithaburensis Decne. Many narrow endemics of the Galilee and northern Palestine reach the northern limit of their distribution in this KBA. Around 6\% of the area of this KBA is protected.

\section{Jabal al-Arab}

B1 Isoetes olympica A. Braun, Allium drusorum Feinbrun, Iris bostrensis Mouterde, Iris auranitica Dinsm., Consolida gombaultii (Thiébaut) Munz, Trifolium bonnevillei Mouterde, Trifolium salmoneum Mouterde, Vicia dionysiensis Mouterde, Prangos hermonis Boiss., Ferula armandii Mouterde, Ferulago auranitica Post, Salvia drusica Mouterde, Crataegus $\times$ sinaica Boiss.,

Jabal al-Arab, also known as Jabal al-Druze or Jabal Hauran, is an elevated convex volcanic massif extending over southern Syria. No permanent watercourses are found at this site, although many valleys (wadis), deep and short in the east and long and shallow in the west, drain the mountain. Its exposure to Mediterranean winds through the Golan Galilee gap, coupled with altitudinal factors contribute to the existence of two bioclimatic 


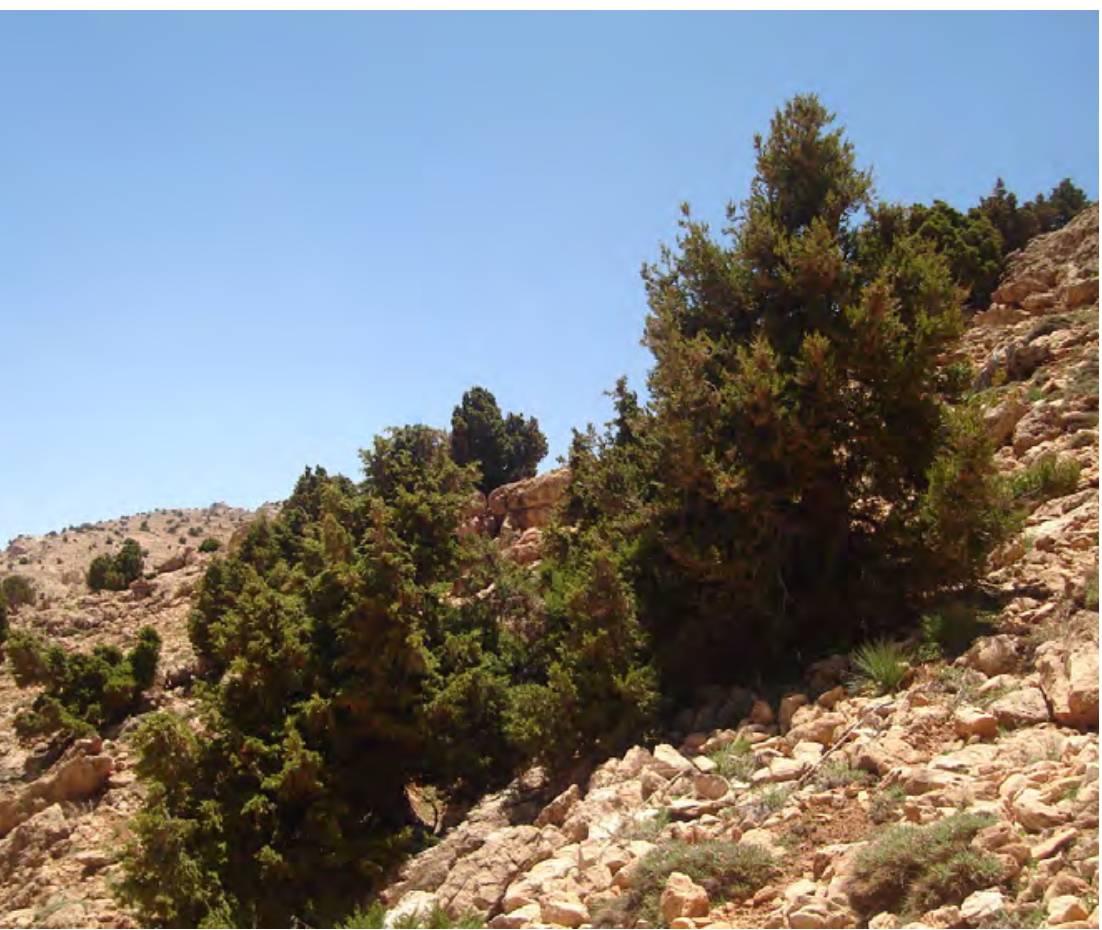

subdivisions at this IPA, the subhumid and the semiarid Mediterranean zones. A unique site for basalt habitats, this KBA includes such nationally threatened habitats as pools and basaltic rocks. The unique volcanic soil and exposure to the Mediterranean Sea are factors that make this KBA the second most important Syrian site for national and subnational endemics and stenoendemics. The area is also very rich in grasses, range species and crop wild relatives of many legumes and cereals (Triticum, Vicia, Lens, Cicer, Lathyrus). Only $2 \%$ of the area of this $\mathrm{KBA}$ is protected.

\section{Yarmuk valley}

\section{Regional KBA (IPA)}

Located in the southwestern corner of Syria, the Yarmuk valley is a deep canyon with sheer fringes. The valley is formed by the Yarmuk river, which traverses the Hauran plateau, demarking the SyrianJordanian border. Other water courses join the valley from the northern sid. The lowest part of the Yarmuk valley, where the canyon joins the Jordan valley, is below sea level. Many tropical and Saharo-Arabian plant species reach the northern limit of their distribution at this site.

\section{Hass-Jabbul}

\section{Regional KBA (IPA)}

Located in Northern Syria in the arid Mediterranean bioclimatic zone, Jabal Hass $\mathrm{KBA}$ is an elevated plateau surrounding Jabbul Lake from the western and southern sides and housing some endemics of the Aleppo region. The lake, occupying a closed depression (40 km x $10 \mathrm{~km}$ ), is shallow (60 to $160 \mathrm{~cm}$ in depth) and saline to brackish. Declared a protected wetland, Lake Jabbul is an important RAMSAR site in the Middle East. Industrial waste water and irrigation drainage has rendered the water of this lake rather fresh.

\section{Jabal Abdul Aziz}

B1 Michauxia nuda A. DC., Linum chaborasicum Mouterde

Lying between the arid and semiarid Mediterranean bioclimatic zones, Jabal Abdul Aziz KBA is an elongated mountain range in the Jezira steppes with some localized endemics along with other endemics to Upper Jezira. The predominant vegetation type is the open shrubby woodland dominated by Pistacia atlantica Desf. and Pistacia khinjuk Stocks.

\section{Jabal al Wastani}

B1 Iris alcarea Dinsm., Astracantha griseosericea (Eig) Greuter, Teucrium haradjanii Briq. ex Rech. f.

Jabal al Wastani KBA is an elongated north-south mountainous chain extending over a distance of $45 \mathrm{~km}$, with an average width of $5 \mathrm{~km}$, and culminating at Hanash (847 $\mathrm{m}$ above sea level). This mountain is characterized by sheer and steep eastern slopes, descending towards Rouj plain, and gentler slopes descending towards bioclimatic zone predominates in this area. Euromediterranean woodlands dominated by Quercus coccifera L. prevail. The area is rich in grasses, range species and crop wild relatives of of many legumes and cereals (endemics belonging to the genera Triticum, Vicia, Lens, Cicer, Lathyrus). Noteworthy wild relatives of Lathyrus are Lathyrus digitatus (M. Bieb.) Fiori and Lathyrus ciliolatus Sam. ex Rech.f.

\section{Karatchok-Tigris}

B1 Senecio delbesianus Arènes and Echinops descendens Hand.-Mazz. Orontes River. The semi-arid Mediterranean
Juniperus, Anti-Lebanon KBA, Lebanon

(C) Hayan Himidan
This KBA, located in an area that has been subjected to intensive agriculture since the 1960s, represents the last remaining natural land in Upper Jezira. It is comprised of a $16 \mathrm{~km}$ long northwest to southeast mountain of low elevation, touching the Iraqi border at its southern end. Tigris River, with its unique habitats at the national level, is part of this KBA. Its flora has strong Irano-Taurainan affinity, with a number of Upper Jezira, Mesopotamian, and south Turkey endemics located within its limits. The area is very rich in grasses, range species, and crop wild relatives of many legumes and cereals (endemics belonging to the genera Triticum, Vicia, Lens, Cicer, Lathyrus). Crop wild relatives found in this KBA include Vicia tigridis Mouterde and Triticum monococcum L. ssp. aegilopoides (Link) Thell.

\section{Kurd Dağ}

B1 Astracantha darmikii (Mouterde) Podl., Cicer bijugum Rech. f., Vicia qatmensis Gomb., Iris calcarea Dinsm.

Kurd Dağ is a moderately elevated calcareous mountain massif occupying the north-western corner of Syria. Extending $50 \mathrm{~km}$ from northeast to southwest, this mountainous area, with well preserved vegetation, stretches more or less as a parallel ridge to Amanus Mountains in Hatay Province, Turkey, and constitutes the southernmost continuation of Taurus Mountains. Its highest point is Kutchuk Darmik at 1230 m. Sub-humid to semi-arid Mediterranean bioclimatic conditions prevail at this site. Botanically, it is a center of endemism for the Northern Levant (along with adjacent Gaziantep province, Turkey), with a relatively large number of Southern Turkish/ Northern Syrian plant endemics. It is very rich in grasses, range species and crop wild relatives of many legumes and cereals (endemics belonging to the genera Triticum, Vicia, Lens, Cicer and Lathyrus). There are ongoing concerns about extraction of minerals and the potential construction of a dam at this site. The site has no legal protection and no management plan. 


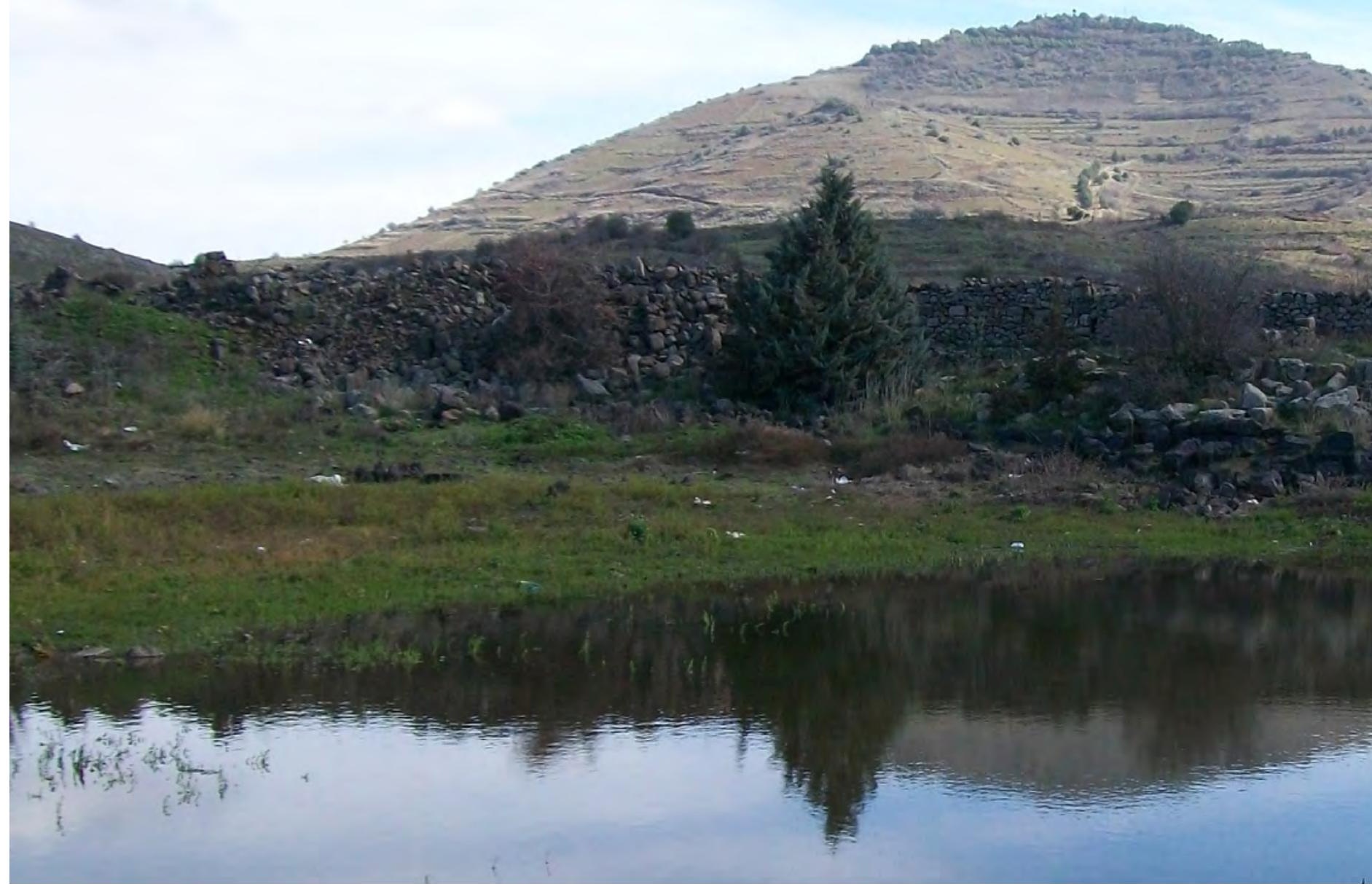

\section{Description of the Syrian KBA network}

The identification of IPAs in Syria dates back to 2010 (Radford et al., 2011), when a national coordinating organization, Syrian Society for the Conservation of Wild Life (SSCW), prepared the first report on IPAs based on a rapid assessment. In that report, 33 IPAs were identified at the national level, 25 of which fall within the boundaries of the Mediterranean Biodiversity Hotspot. Since then, there has been no effort to update this report given the situation of the country. During the update of the CEPF Mediterranean Biodiversity Hotspot ecosystem profile in 2016, the boundaries of some existing IPAs, all of which are regional KBAs, were revisited (updated boundaries in map), but no new KBAs were identified based on plant species.

More recently, we assessed all these regional KBAs based on existing data and expert opinion. Of the 25 regional KBAs, 16 qualified as global KBAs. More than 70 trigger species, all restricted range endemics, and many of which are stenoendemics were used to designate these global KBAs. Many of the global KBAs are located in the humid Mediterranean (Umm al-Tuyur-Bassit and SlenfehJaubet al-Berghal for example), sub-humid Mediterranean (Karatchok-Tigris for example) and semi-arid (Anti-Lebanon, Akkoum and Hermon for example) bioclimatic zones. The predominant ecosystems in these identified global KBAs include coastal mountains (Fronloq-Kasab for example), riparian habitats (Al-Kabir al-Jonubi and Ghab for example) and Eumediterranean shrubs on calcerous rocks (Daher al-Qseir for example). Protected areas partly cover more than $10 \mathrm{KBAs}$. The most urbanized of the KBAs is Salma-Haffeh, while the most agricultural is Ghab and Al-Kabir Al-Janoubi.

The number of plant species endemic to Syria is 243 (ca. 9\% of the Syrian flora) according to Mouterde (1966-1983). The Fourth National Report on Biodiversity in the Syrian Arab Republic (2009) refers to 207 endemic plant species. The plant families with the largest number of endemic species include Fabaceae, Asteraceae, Lamiaceae, Lilliaceae sensu latu, and Iridaceae. The genera with the highest percentage of endemism include Iris (Iridaceae), Astragalus (Fabaceae), Centaurea (Asteraceae), Allium (Alliaceae), and Verbascum (Scrophulariaceae). A revision of the flora of Syria is necessary for determining the exact number of endemic plant species in the country. 
Jabal AI Arab KBA, centre of endemism for Syria (C) Hayan Himidan

\section{Main threats to the Syrian KBA network}

Given the current situation in Syria, ongoing war and conflict constitute a major threat to the KBA network. Prior to this conflict, the KBA network was highly threatened by

- Unsustainable collection of herbs and medicinal plants,

- Deforestation, including collection of wood for fuel

- Extraction of minerals, including quarries

- Overgrazing, agricultural intensification, fires, and water extraction and drainage.

When the conflict subsides, it would be essential to collect new field data with the ultimate aim reevaluating all identified KBAs and the threats affecting them.

\section{Main conservation actions recommended for the Syrian KBA network}

Immediate intervention would be needed at the level of all identified KBAs as soon as the ongoing conflict subsides. Rehabilitation of degraded or destroyed habitats, particularly those falling within identified KBAs, should be undertaken. A national network of KBAs should be set up and new protected areas should be delineated and declared particularly in global KBAs. Management plans for currently designated protected areas that lack such plans should be developed and implemented, with emphasis on those protected areas that fall within the boundaries of identified KBAs.

The government should support and fund scientific research in the area of biodiversity conservation, with emphasis on trigger species, and ecosytems that fall within global KBAs. The government should also support regional collaboration in the area of biodiversity conservation and hold bilateral meetings with stakeholders (local communities, non-governmental organizations, etc.)

Deepening and strengthening environmental education, and increasing public awareness regarding biodiversity and its sustainable use and conservation would also be essential. 


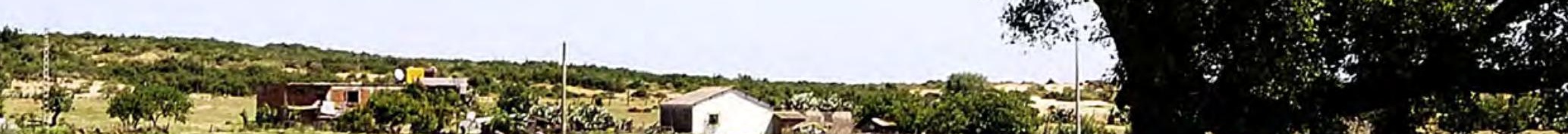

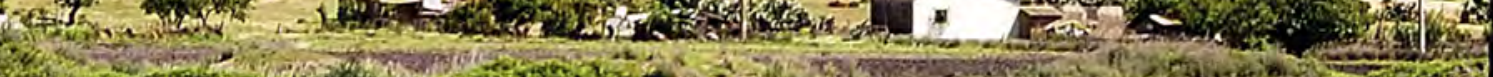

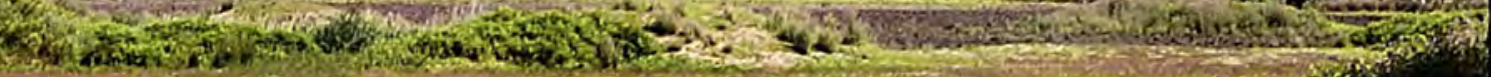

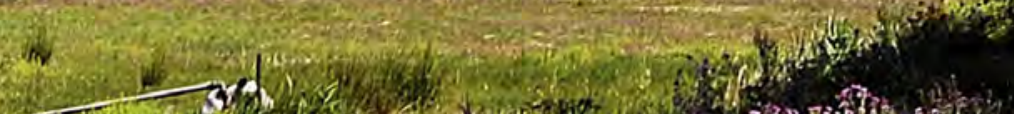

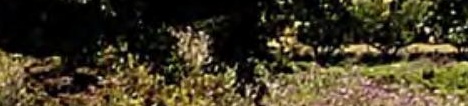

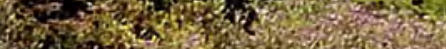

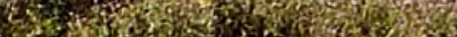

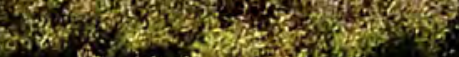
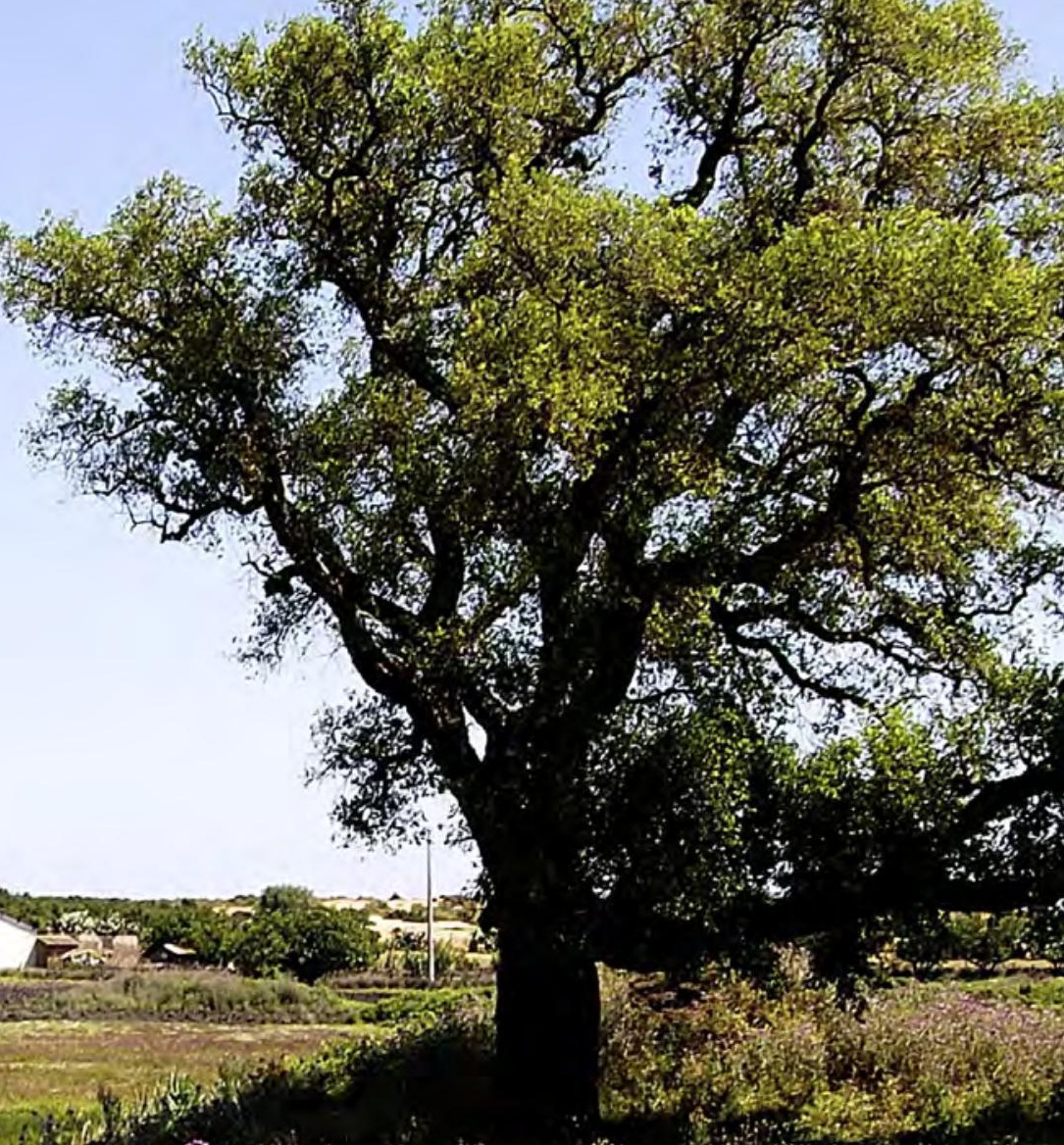

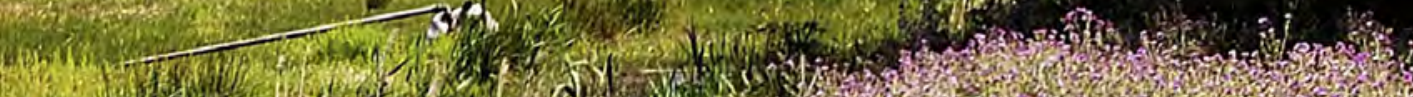

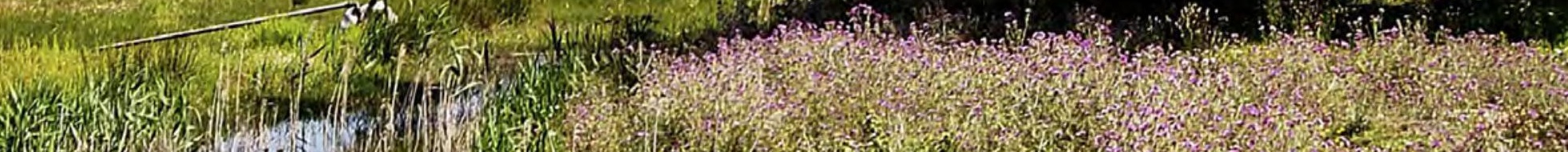

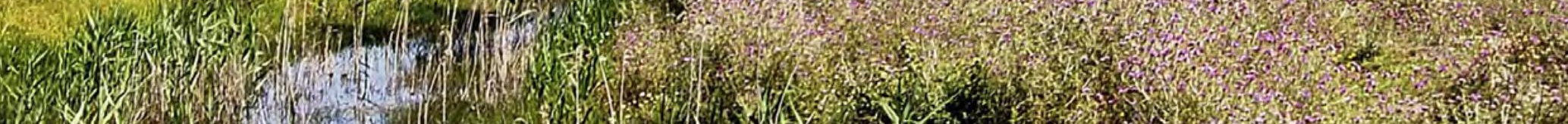

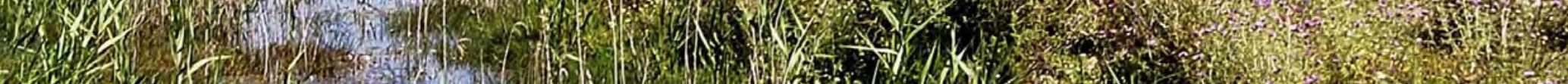
1. 2. 6.

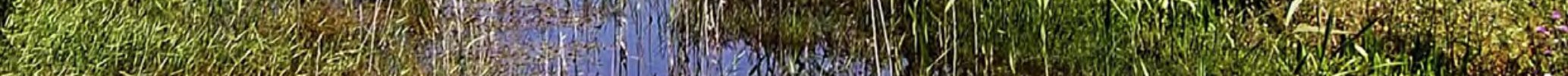
-7.20 (2) th

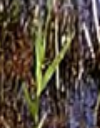




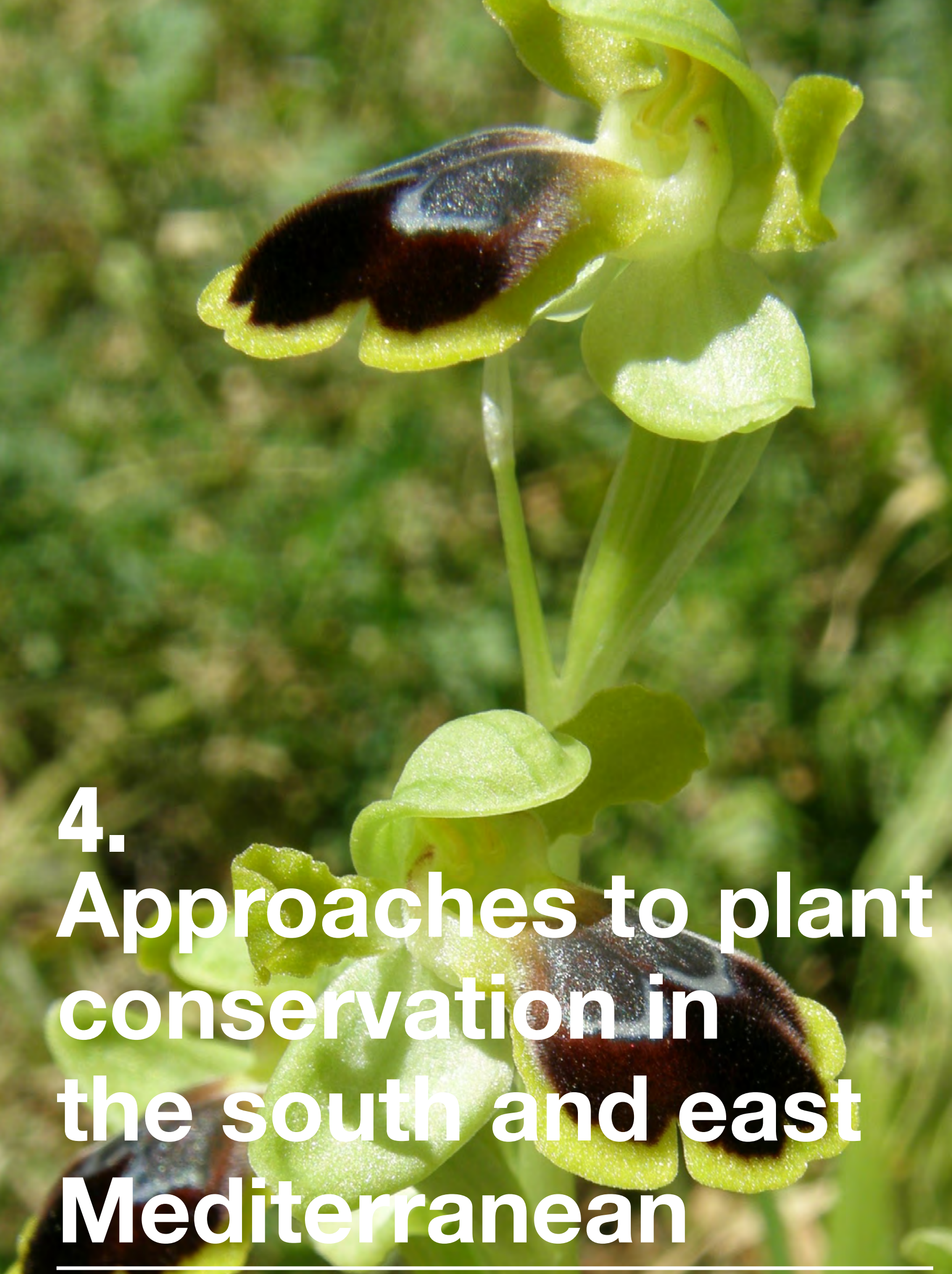

Chapter coordinator: Prof. Vernon Heywood 


\subsection{Introduction}

The countries of North Africa and the Middle East, bordering the eastern and southern shores of the Mediterranean, lie between Europe, Africa and Asia and are biogeographically highly complex. The plant life of these countries is generally less rich floristically than that of the countries on the northern shores - although still with some 2,000 singlecountry endemic species - and is less well studied (See Chapter 1). As noted elsewhere, these regions contain important centres of plant diversity (Davis et al., 1994; Médail \& Quézel, 1997, 1999), Vavilov centres of crop diversity (Vavilov 1926) and numerous IPAs (Radford et al., 2011), which have been updated as KBAs in Chapter 3. The eastern Mediterranean/ Middle East is a major centre of crop diversity and home to many crop wild relatives (Heywood \& Zohary, 1995; Kell et al., 2008; Zohary et al., 2012; Vincent et al., 2013), as well as some iconic tree species such as the Atlantic and Lebanon cedars.

Most southern Mediterranean forests are endangered to some degree. In the Maghreb, the situation is critical for the fir forests of Abies marocana (Talassemtane, in the Rif, Morocco) and A. numidica (Babor, Algeria), as well as populations of Pinus nigra subsp. mauritanica, Cupressus atlantica, Betula pendula subsp. fontqueri, Olea marocana, Laurus azorica, Quercus afares and Q. faginea subsp. tlemcenensis, and even some Argania spinosa, Cedrus atlantica, Tetraclinis articulata and Juniperus thurifera forests (Quézel \& Barbero, 1990; Quézel, 1991). In the eastern Mediterranean, the application of stricter forestry management (especially in Turkey) and the participation of local inhabitants in the benefits of exploitation have left forests in a better state of conservation (Quézel \& Barbero, 1990), although certain plant communities deserve careful monitoring, such as: Abies nordmanniana subsp. equitrojani, Quercus aucheri, Liquidambar orientalis and Fagus orientalis forests in Turkey and Cedrus brevifolia and Quercus alnifolia stands in Cyprus.

\section{Conservations needs and approaches}

Although a national system of protected areas is generally recognised as the underpinning of plant conservation, the protection afforded to threatened species by such areas alone is seldom sufficient and needs to be complemented by other actions both in situ and ex situ. This approach, known as integrated or complementary conservation, involves both area-based and species-based actions and requires close cooperation between different agencies as well the involvement of local communities. An example is the Egyptian Environmental Affairs Agency (EEAA) Saint Catherine Protectorate Development project 'Botanical Conservation Measures and Ecological Monitoring Program.'. The protected area contains some 500 plant species, 30 of which are endemic to Egypt, and conservation activities have been ongoing there since the 1990s. Recent extensive studies on its threatened species have led to proposals to integrate the knowledge derived from ecological, demographic and geographical approaches in formulating management strategies. An urgent need is to conserve the high-priority species Rosa arabica and Salvia multicaulis through both in situ and ex situ actions, including habitat restoration, fenced enclosures, species augmentation, recovery and reintroduction, as well as a wide range of educational and awareness activities (Omar, 2017).

The effectiveness of protected areas in contributing to biodiversity conservation depends largely on how well they are designed, managed, maintained and protected, and on a comprehensive inventory of the species they contain so that necessary actions are taken to protect taxa of special concern (Iriondo et al., 2008; Heywood 2017).

At species level, both ex situ and in situ conservation actions are needed. But before these are initiated, it is important to undertake as full an assessment as possible of the distribution, 
ecology, demography, genetic variation, variability and reproductive biology of the candidate species for conservation. Often known as ecogeographic surveys, these assessments involve both desktop studies of the literature and field work (Maxted et al., 1995; Castañeda Álvarez et al., 2011). Often now ecogeographic surveys are linked to a gap analysis, which compares the plant diversity in nature with the diversity being conserved either in situ or ex situ to identify the 'gap' as components of future conservation action (Maxted et al., 2012). Then a full threat assessment of the target species is needed to ensure that the necessary steps can be taken to eliminate, manage or contain these threats. Such an assessment is needed in addition to the IUCN Red List categories of threat assessment (if available) which indicate the species' likely extinction risk, and any national or local threat status assessment.

The next stage is to decide, in the light of the previous information, the conservation priority for each candidate species and its conservation needs. For many species, constant vigilance or monitoring of its status is all that will be needed. For others some degree of conservation action or management intervention may be needed, ranging from fencing, habitat management, habitat weeding or control of invasive species, to a full-scale recovery programme and action plan (Heywood, 2014, 2015; Heywood et al., 2018) often involving population augmentation, or a reintroduction programme when the species has disappeared from all or part of its natural range (Maschinski et al., 2012).

While the aim should be to plan the most effective conservation action possible, often there will be a trade-off between what is ideal and what is possible with the resources available. Viewed pragmatically, some conservation action is better than none, although it has to be recognised that failure to undertake all the actions considered necessary to prevent the further deterioration of threatened species/populations will store up problems for the future, at which time even more drastic actions may be needed to save the species from extinction (Heywood et al., 2018).

Ideally, the conservation of target species should take place within formally established protected areas and most known recovery plans are for

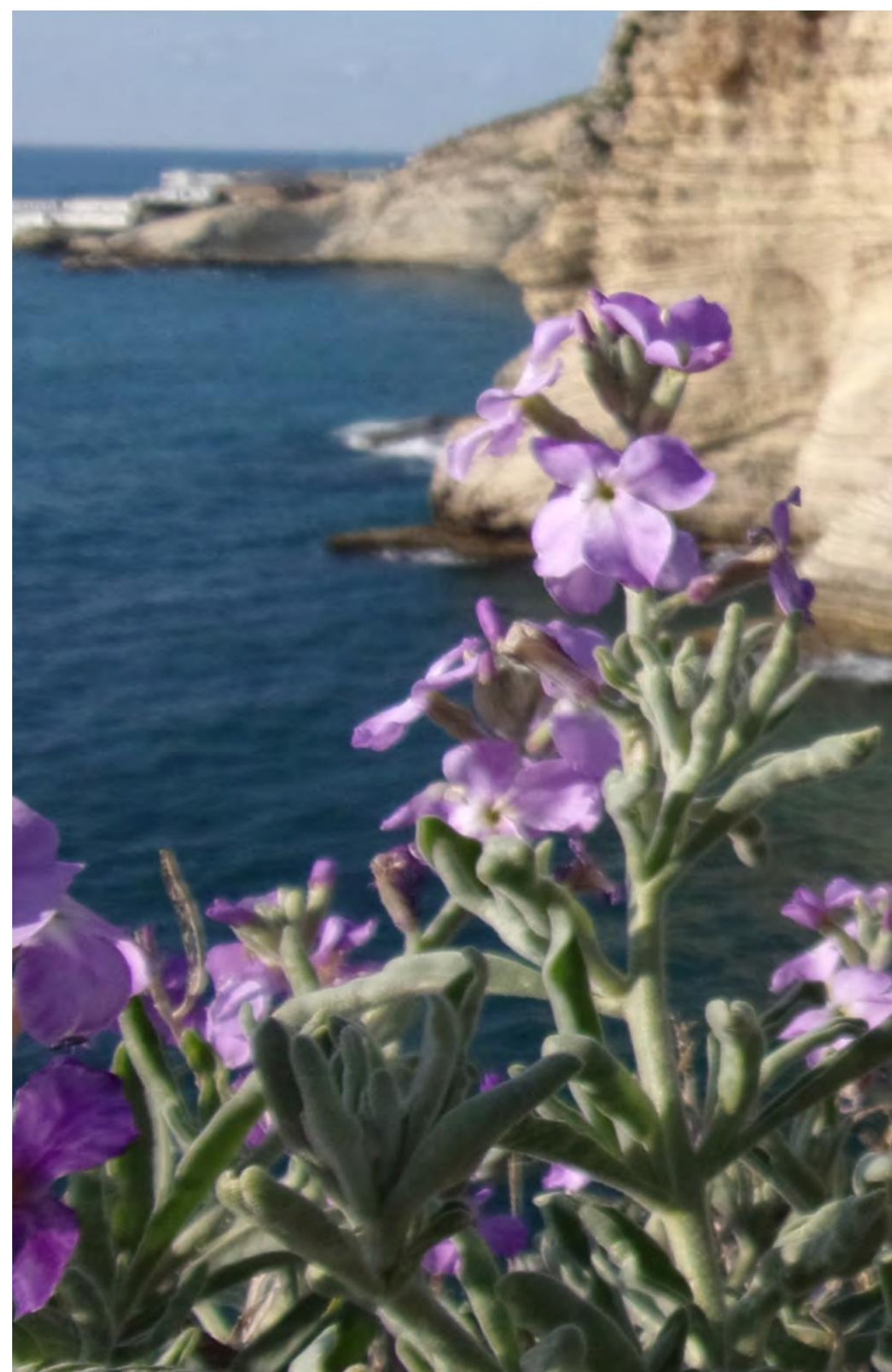

species that occur in such areas. However, the majority of threatened species occur outside protected areas and conservation actions for such species can be carried out in a variety of ways. These usually rely on agreements being made with landowners to maintain populations in a prescribed manner or through conservation easements and environmental stewardships. Details of such schemes are given in Hunter \& Heywood (2011: chapter 11). These schemes are usually dependent on the cooperation and participation of the local community. Little is known of the long-term effectiveness of such approaches. Although these less formal mechanisms cannot replace the longer-term security provided by formal nationally designated protected areas, they can be a useful complement to full protected area site designation.

Ex situ conservation in seed banks, pollen banks, field gene banks, botanic garden living collections, and tissue/cell culture laboratories for short-, 


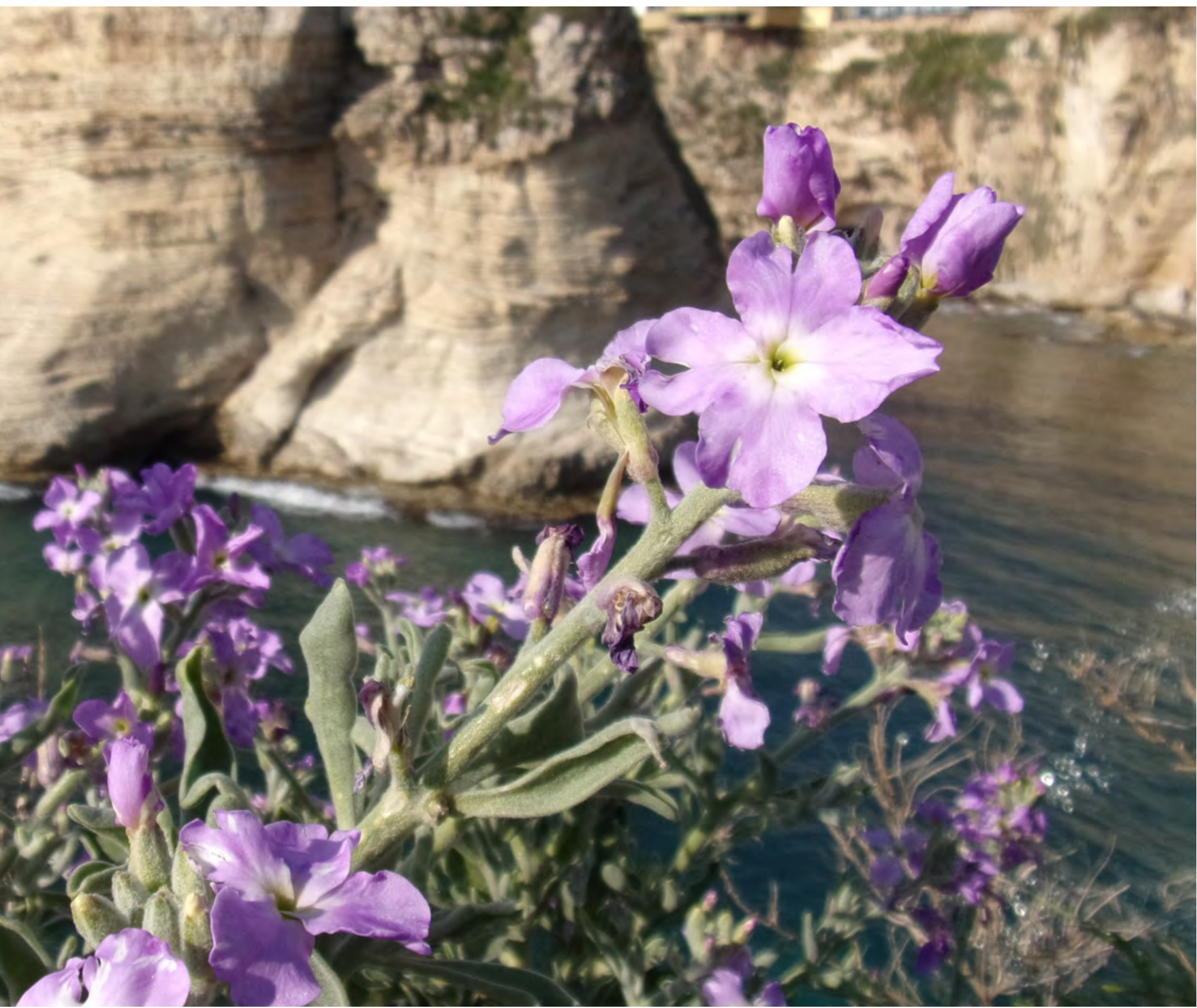

medium- or long-term storage of germplasm is needed to support in situ actions such as population augmentation in recovery programmes and species reintroduction and ecological restoration. For these purposes, such ex situ conservation collections should aim to capture the genetic diversity of the target species and hold or produce, through multiplication, sufficient material for their effective implementation. In addition, seed banks are needed for long-term storage of large numbers of species, or even whole floras, as an insurance policy against the loss of species or populations in the wild and, in the case of agricultural gene banks, to conserve samples of wild relatives, landraces and cultivars of crop plants for use in breeding programmes.

In addition to the above conservation activities, novel approaches that bridge the gap between in situ and ex situ conservation are being developed, such as inter situs and quasi in situ conservation, some of which have been pioneered in the region.
$\Delta$

Matthiola crassifolia is a steno-endemic of the coast of Lebanon. Beirut-Jiyeh and Jbeil areas constitute its only habitats. Thanks to the presence of coastal cliffs and to its capacity to settle in mineral substrate, the species survives despite the very disturbed and densely urbanised environment (Beirut-Jiyeh KBA)

(C) Hicham Elzein

Monitoring plays a key role in biodiversity conservation and provision should be made for it in conservation projects. It may be used for recording: changes to population/species abundance; trends in population size and structure, so as to assess the health and viability of the population both before and after any management intervention; changes in genetic diversity; predator numbers, to assess the effectiveness of control programmes; the spread or control of invasive species to assess their impact on the species populations and the habitat or area as a whole; and changes in vegetation cover or soil condition, to assess the state of target species' habitat. With appropriate guidance, local people can participate in monitoring activities. 


\subsection{Policy guidance}

\section{Author: Vernon Heywood \\ University of Reading}

The global mandate for plant conservation derives from the Convention on Biological Diversity (CBD). The objectives of the CBD are the conservation of biological diversity, the sustainable use of its components, and the fair and equitable sharing of the benefits arising from commercial and other utilisation of genetic resources. The agreement covers all ecosystems, species, and genetic resources. The CBD is an outline treaty and its implementation is guided by a series of decisions made by the Parties to the Convention. Specifically for plants, the CBD's Global Strategy for Plant Conservation (GSPC) contains a series of time-limited targets. Those that address the conservation of ecosystems and species in the current version (2011-2020) are: Target 4 (ecosystem conservation), Target 5 (protecting important areas for plant diversity), Target 6 (conservation within production areas) and Targets 7 and 8 (species-level conservation). For species-level conservation, the key targets are: Target 7: "At least $75 \%$ of known threatened plant species conserved in situ" and Target 8: "At least $75 \%$ of threatened plant species in ex situ collections, preferably in the country of origin, and at least $20 \%$ available for recovery and restoration programmes" and for socio-economically important plants, "Target 9: 70 per cent of the genetic diversity of crops including their wild relatives and other socio-economically valuable plant species conserved, while respecting, preserving and maintaining associated indigenous and local knowledge". In addition, the CBD has adopted a revised Strategic Plan for Biodiversity, including 20 Aichi Biodiversity Targets for the period 2011-2020, Target 12 being "By 2020 the extinction of known threatened species has been prevented and their conservation status, particularly of those most in decline, has been improved and sustained". Moreover, Goal C of the Strategic Plan is to "Improve the status of biodiversity by safeguarding ecosystems, species and genetic diversity", which would be achieved in part through species and habitat recovery actions.

The Convention on International Trade in Endangered Species of Wild Fauna and Flora
(CITES) aims to ensure that international trade in specimens of wild animals and plants does not threaten their survival. Through its three appendices (lists of species afforded different levels or types of protection from overexploitation), the Convention accords degrees of protection to more than 30,000 plant and animal species. Decisions regarding plants are proposed by its Plants Committee. Illegal overharvesting of plants, such as medicinal and aromatic species, that affects their survival is a major concern in the Mediterranean region and in the target countries in particular.

For species of agricultural importance, the International Treaty on Plant Genetic Resources for Food and Agriculture provides a mandate. Its objectives are the conservation and sustainable use of plant genetic resources for food and agriculture and the fair and equitable sharing of the benefits arising out of their use, in harmony with the Convention on Biological Diversity, for sustainable agriculture and food security. In addition policy guidance is provided by the Second Global Plan of Action (GPA) for Plant Genetic Resources for Food and Agriculture, and by the Second Report on the State of the World's Plant Genetic Resources for Food and Agriculture (FAO, 2010) which includes detailed information on their state of diversity, in situ management, ex situ management, national programmes, training needs and legislation.

Other plant biodiversity-related treaties are:

Convention on Wetlands (popularly known as the Ramsar Convention), which provides the framework for national action and international cooperation for the conservation and wise use of wetlands and their resources.

World Heritage Convention (WHC), whose primary mission is to identify and conserve the world's cultural and natural heritage by drawing up a list of sites whose outstanding values should be preserved for all humanity, and to ensure their protection through closer cooperation among nations. A number of these sites are of importance for their cultural landscapes and biodiversity and/or agrobiodiversity.

International Plant Protection Convention (IPPC), which aims to protect world plant resources, 


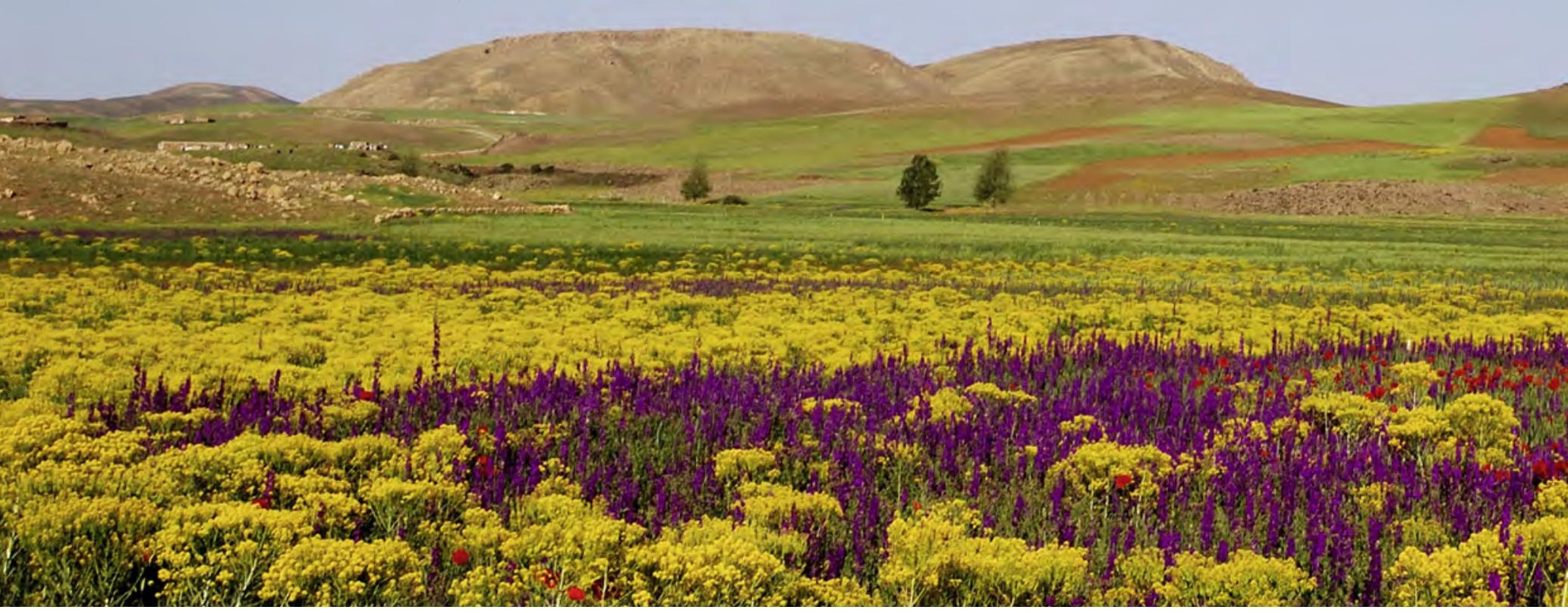

$\boldsymbol{\Delta}$

Landscape of the Middle Atlas, Morocco (c) WWF

including cultivated and wild plants, by preventing the introduction and spread of plant pests and promoting appropriate measures for their control.

An intergovernmental regional agreement that includes several of the target counties is the Revised African Convention on the Conservation of Nature and Natural Resources, which urges its Contracting States to adopt the necessary measures to ensure conservation, utilisation and development of soil, water, flora and fauna in accordance with scientific principles, with due regard to the best interests of the people.

At a national level, every country has to prepare a Biodiversity Strategy and Action Plan as required under the CBD and also to submit National Reports that provide information on the state of their implementation of CBD policies. Each country also has as its own conservation policy and priorities adopted by the ministries and agencies concerned, and its own legislative arrangements that deal with plant conservation. These include the creation of national parks and other kinds of protected areas, as well as the development of a threat assessment system and categories for species, which may adopt the IUCN categories of threat or set its own criteria to reflect national conservation priorities. A national Red List or Red Book may be prepared. Some countries also prepare a national conservation action plan in addition to that required under the CBD and develop their own conservation legislation to be taken into account when considering any conservation action.

It needs to be stressed that designating IBAs and KBAs is not a conservation action unless it leads to site protection and species-targeted actions. Likewise, gazetting a protected area does not necessarily lead to more than passive conservation of the ecosystems and biodiversity it contains unless it is effectively protected and staffed and a management plan that includes biodiversity conservation among its goals is prepared and implemented. Similarly, Red Listing is not in itself an act of conservation but an indication of likelihood of extinction, which may be used as a priority determining mechanism for conservation action. Most Red Listed species do not have a conservation/ recovery action plan.

At a Mediterranean level, no overall or regional plant conservation strategy exists, although various 
Prunus ursina in Horsh Ehden Nature Reserve, and Pistacia khinjuk in Abdel Aziz PA in Syria; endemic species such as Argania spinosa, Olea maroccana and Dracaena draco subsp. ajgal in Morocco; and other species of high conservation value such as Tetraclinis articulata and Laurus azorica in Morocco and Retama raetam in Dana BR in Jordan. The existing network of PAs in Lebanon does not fully represent the country's key ecological features (El-Hajj et al., 2016), and this also applies to other target countries. Insufficient emphasis on biodiversity in their management plans limits their effectiveness in conserving plant diversity.
The protection of nationally designated sites is the responsibility of the competent national authorities or is subject to collaborative management, as is the case of more than $50 \%$ of the protected sites in Morocco (WDPA, November 2017). In the new millennium, initiatives to shift area-based in situ conservation approaches from strict protection to participatory management with various levels of stakeholder involvement have been partly dependent on the existing dynamics of governance vs local communities. Those initiatives were undertaken either by government-appointed committees, as in the case of Lebanon and Jordan,

Table 4.1. Categories and distribution of protected areas in the east and south Mediterranean (WDPA, November 2017; Ramsar country profiles. IDS = Internationally Designated Sites).

\begin{tabular}{|c|c|c|c|c|}
\hline Country & Number & Area $\left(\mathrm{km}^{2}\right)$ & IUCN cat. & Contribution to plant species conservation \\
\hline \multicolumn{5}{|l|}{ Algeria } \\
\hline Nature Reserves & 5 & 403 & la & \multirow{4}{*}{$\begin{array}{r}\text { Abies numidica, Cupressus dupreziana, Olea euorpea } \\
\text { subsp.laperrinei, Paeonia algeriensis, Myrtus nivelle } \\
\text { subsp. nivelleii, Mesembryanthemum cryptanthum, } \\
\text { Pseuderucaria clavata, Acacia nilotica subsp. tomentosa, } \\
\text { Bupleurum plantagineum, Euphorbia dendroïdes, } \\
\text { Lithospermum rosmarinifolium. }\end{array}$} \\
\hline Cultural Parks & 2 & 177,970 & II & \\
\hline National Parks & 9 & 1,897 & II & \\
\hline IDS & 59 & $3,136,512$ & NR & \\
\hline Total & 78 & & & \\
\hline \multicolumn{5}{|l|}{ Egypt } \\
\hline Protected Areas & 8 & 58,789 & NR & \multirow{8}{*}{$\begin{array}{r}\text { Artemisia monosperma, Hammada elegans, H. scorpia, } \\
\text { Suaeda pruinosa, Salsola tetrandra, Glinus lotoides, } \\
\text { Salsola baryosma, Acacia ehrenbergiana, A. raddiana, A. } \\
\text { tortilis, Balanites egyptiaca, Salvadora persica }\end{array}$} \\
\hline Multiple Use Areas & 11 & 28,235 & $\mathrm{VI}$ & \\
\hline National Parks & 3 & 56,932 & III & \\
\hline Natural Monuments & 2 & 5,810 & III & \\
\hline $\begin{array}{l}\text { Nature Conservation } \\
\text { Reserves }\end{array}$ & 2 & 930 & IV & \\
\hline Protected Landscapes & 3 & 5,810 & V & \\
\hline Strict Nature Reserves & 5 & 63 & la & \\
\hline IDS & 6 & 28,713 & NR & \\
\hline Total & 50 & & & \\
\hline \multicolumn{5}{|l|}{ Lebanon } \\
\hline Nature Reserves & 15 & 241 & NR & \multirow{6}{*}{$\begin{array}{r}\text { Cedrus libani, Abies cilicica, Quercus cerris, Q. } \\
\text { cedrorum, Malus trilobata, Pyrus syriaca, P. ursina, Iris } \\
\text { sofarana, Origanum libanoticum, O. ehrenbergii }\end{array}$} \\
\hline National Parks & 4 & 350 & II & \\
\hline $\begin{array}{l}\text { Private Protected } \\
\text { Areas }\end{array}$ & 2 & 4 & NR & \\
\hline Forest Reserves & 4 & $>6.6$ & NR & \\
\hline Protected Forests & 1 & 0.102 & NR & \\
\hline IDS & 10 & 212 & NR & \\
\hline Total & 34 & & & \\
\hline
\end{tabular}


or by groups of community representatives as in Morocco and Tunisia. In Morocco, the shift in governance structure and management ensured the sustainability of the sites by promoting local entrepreneurship in the ecotourism and hospitality sectors as well as artisanal products. Successful showcase examples can be found in most of the target countries, such as Al-Shouf Nature Reserve in Lebanon, Dana Biosphere Reserve in Jordan, Jebel Bouhedma in Tunisia and Arganeraie Biosphere Reserve in Morocco (UNESCO-MAB, 2013; MALE, 2016; DLDPN, n.d.; Al Rfoue, 2017).

\section{International sites}

The region has many internationally designated sites (IDS). It is worth noting that many IDSs also have a national designation in terms of in situ habitat protection. Other than being sites for migratory bird species, they are home to a large range of plant species of high conservation value. The region contains 144 Ramsar sites, $81 \%$ of which are located in southern Mediterranean countries, with the highest numbers in Algeria and Tunisia. Other categories of conservation sites of international importance are the UNESCO Biosphere Reserves

\section{Country Number Area $\left(\mathrm{km}^{2}\right)$ IUCN cat. Contribution to plant species conservation}

\begin{tabular}{|c|c|c|c|c|}
\hline \multicolumn{5}{|l|}{ Libya } \\
\hline National Parks & 4 & 4,470 & II & \multirow{4}{*}{$\begin{array}{r}\text { Cyclamen rohlfsianum, Arbutus pavarii, Ferula } \\
\text { marmarica, Crocus boulosii, Allium ruhmerianum, Poa } \\
\text { vaginata, Orchis cyrenaica. }\end{array}$} \\
\hline Nature Reserves & 4 & 1,029 & IV & \\
\hline Protected Areas & 14 & 901 & IV & \\
\hline IDS & 2 & 0.83 & NR & \\
\hline Total & 24 & & & \\
\hline \multicolumn{5}{|l|}{ Morocco } \\
\hline $\begin{array}{l}\text { Sites of Biological and } \\
\text { Ecological Interest }\end{array}$ & 71 & 11,905 & NR & \multirow{6}{*}{$\begin{array}{r}\text { Abies pinsapo subsp. maroccana, Cedrus atlantica, } \\
\text { Tetraclinis articulata, Juniperus thurifera, Argania } \\
\text { spinosa, Olea maroccana, Dracaena draco subsp. } \\
\text { ajgal, Tetraclinis articulata, Laurus azorica, Retama } \\
\text { dasycarparaetam }\end{array}$} \\
\hline Biological Reserves & 1 & 70 & NR & \\
\hline National Parks & 11 & 28,348 & II & \\
\hline Natural Parks & 19 & 4,630 & $\mathrm{VI}$ & \\
\hline Nature Reserves & 9 & 1,045 & IV & \\
\hline IDS & 28 & 121,232 & NR & \\
\hline Total & $325^{1}$ & & & \\
\hline \multicolumn{5}{|l|}{ Syria } \\
\hline Nature Reserves & 1 & 220 & NR & \multirow{3}{*}{$\begin{array}{r}\text { Alnus. orientalis, Celtis tournefortii, Asterolinon linum- } \\
\text { stellatum, Pistacia khinjuk, Prunus microcarpa, Paeonia } \\
\text { mascula }\end{array}$} \\
\hline Protected Areas & 13 & 38 & NR & \\
\hline IDS & 2 & 120 & NR & \\
\hline Total & 19 & & & \\
\hline \multicolumn{5}{|l|}{ Tunisia } \\
\hline National Parks & 18 & 5,587 & II & \multirow{4}{*}{$\begin{array}{r}\text { Acacia raddiana, Cenchrus ciliaris, Digitaria nodosa, } \\
\text { Rhanterium suaveolens, Artemisia herba-alba, } \\
\text { Arthrophytum scoparium }\end{array}$} \\
\hline Nature Reserves & 31 & 816 & NR & \\
\hline Wetlands & 46 & 8,214 & NR & \\
\hline IDS & 48 & 8,668 & NR & \\
\hline Total & 147 & & & \\
\hline \multicolumn{5}{|l|}{ State of Palestine } \\
\hline Protected Areas & 15 & 198,471 & I, III, IV & \multirow{2}{*}{$\begin{array}{r}\text { Delphinium ithaburense, Tulipa agenensis, Iris atrofusca, } \\
\text { I. vartanii, I. Iortetii, Grewia villosa }\end{array}$} \\
\hline IDS & 13 & 560 & IBAs & \\
\hline
\end{tabular}

${ }^{1} 55 \%$ of the total protected sites have not yet been designated. 


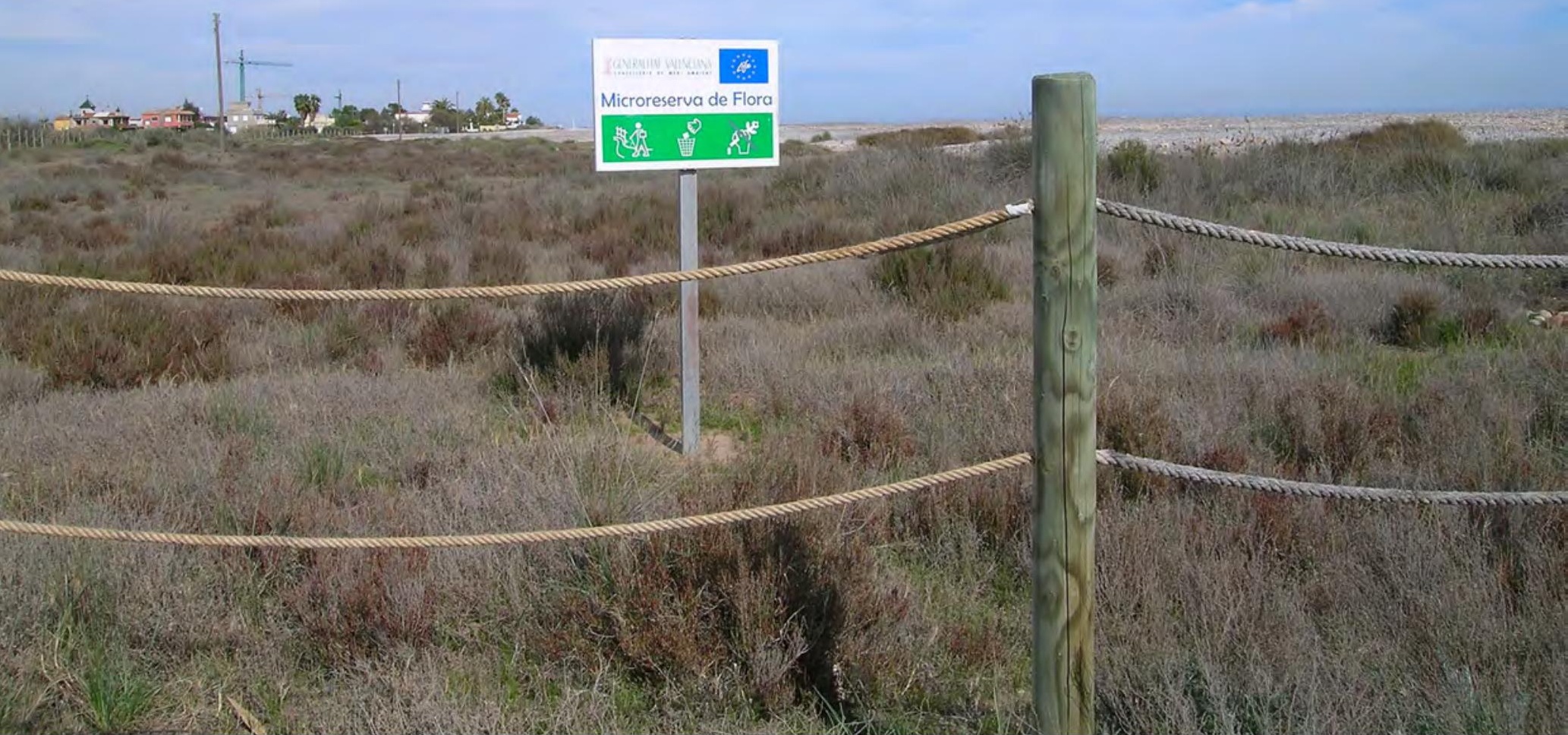

\section{$\Delta$}

Platja de Moncofa

Moncofa, Province of Castellón, Valencian Community, Spain (C) Emilio Laguna

and UNESCO Global Geoparks, which are recognised as hotspots for biological, cultural and socio-economic diversity. They embrace a diverse array of habitats representing all terrestrial, marine and coastal ecosystems, where flora and fauna thrive. Both categories align biodiversity conservation with development through the creation of partnerships between people and nature.

The only Global Geopark in the Mediterranean region is M'Goun in Morocco, but currently there are 79 Biosphere Reserves in 15 countries in the Mediterranean Basin, 20 of which are in Levantine and North African countries. They include a network of ecosystems representing all the ecological features of the region. In Morocco, the Arganeraie Biosphere Reserve covers over 2,560,000 ha and includes open forests of the commercially important argan tree (Argania spinosa). In Lebanon, the Jabal Moussa and Al-Shouf Biosphere Reserves, covering 6,500 ha and 50,000 ha respectively, host a mix of eastern Mediterranean forests with important species such as Origanum libanoticum, Salvia peyronii, Paeonia kesrouanensis and Pentapera sicula var. libanotica, among others. In Jordan, Dana Biosphere Reserve, covering 30,000 km², features arid ecosystem and rangeland-adapted species such as Juniperus phoenica, Pistacia atlantica, Retama raetam, Acacia tortilis, Haloxylon persicum and Panicum turgidum, and endemic and rare species such as Micromeria danaensis, Rubia danaensis and Silene danaensis. In Tunisia, Jebel Bouhedma features temperate grassland covering 16,988 ha and protects Acacia raddiana forests - relicts of pre-Saharan savannah - with their assemblage of important plant species. In Egypt, Wadi Allaqi contributes to the protection of desert plants such as Salsola baryosma, Acacia ehrenbergiana, Balanitesa egyptiaca, Salvadora persica and Acacia tortilis subsp. raddiana. In Algeria, the Tassili N'Ajjer hosts Olea europaea subsp. laperrinei and Myrtus nivellei. The first Intercontinental Biosphere Reserve, the IBR of the Mediterranean, connects part of the Tingitane Peninsula in Morocco with southern Andalusia in the Iberian Peninsula and features an interconnected mix of habitats. In Syria, Lajat Biosphere Reserve, covering 12,038 ha, contributes to the conservation of agricultural crops such as barley, date palm, fig, garlic, grape, olive, onion, pomegranate and wheat in its transition zone, as is the case of BRs in other countries of the region. 
The importance of both Biosphere Reserves and Global Geoparks for in situ habitat conservation lies in their multiple roles: as observatories for assessing ecosystem vulnerability and resilience and the adaptation of plants to climate change; as living seed and gene banks in the region; and as learning grounds for pioneering showcases of good practice in conservation, ecological restoration and sustainable management of biodiversity. Both categories can give an extra impetus to scientists and practitioners in the region to help boost ecosystem resilience and ensure the survival of plant and animal communities in the south and east Mediterranean (Sattout, 2017).

\section{State of in situ habitat conservation}

To date, in situ habitat protection has played an important role in the conservation of plant diversity. However, the region's diversity in administrative frameworks, land tenure systems and governance influences the success of the conservation undertaken: some countries have flaws in their governance and management systems which hinder progress, whether in the direct protection of species or the management of activities arising from conservation (such as community development and ecotourism).

One factor that is having an increasing influence on the success of plant protection is the decentralisation of in situ habitat protection from the national competent authority to local government. For example, in Lebanon the municipalities are taking on conservation and management schemes in view of the benefits that the resulting influx of domestic and international tourists could bring to their communities. With decentralisation comes a proliferation of new, local-level labels for in situ conservation areas, which helps buy-in by local government.

With the promotion of international and domestic tourism associated with the area-based conservation emerging in the region comes the improvement of local infrastructure. This has empowered local communities, especially women, in some countries such as Jordan, Lebanon and Morocco. However, increasing ecotourism makes it necessary to measure its ecological footprint. For the resulting monitoring programmes and research

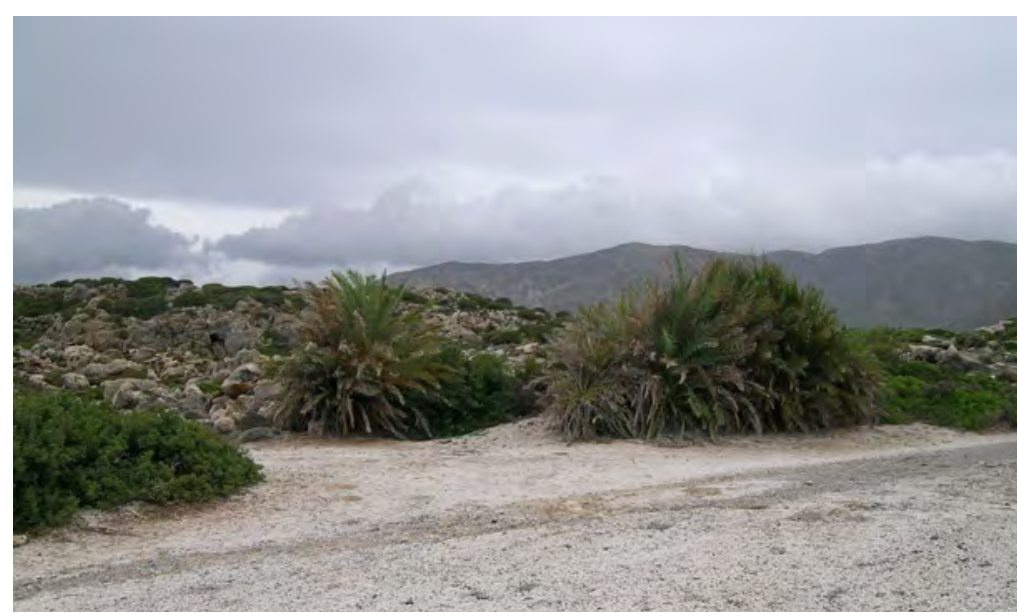

\section{$\Delta$}

Relict palm communities of Phoenix theophrastii near Chryssoskalitissa Monastery, Elafonissi, Chania Prefecture, Crete.

(c) Emilio Laguna

to be cost effective, they need to focus on the lowest possible number of indicator species, such as endemic, keystone or umbrella species.

\section{Future leadership of area conservation}

In this fast-changing world, new insights into the role of in situ habitat conservation and the importance of local and regional habitat inter-connectedness are needed for the whole region. It is almost 10 years since the last assessment of area conservation in the region (Chape et al., 2008), and protection and managerial skills have been upgraded through learning by doing and through technology transfer and cooperation throughout the past four decades. Leadership in conservation and management varies not only between adjacent countries at regional level but also at national level. Politically driven leadership, or private leadership supported by a strong national and international network, has been remarkably successful both in attracting international and private funds and in popularising the sites and reaching out to the public.

The evolution of conservation and management plans has resulted in the improvement of most management schemes, as in the case of the Biosphere Reserves of Dana in Jordan, Al-Shouf in Lebanon, Arganeraie in Morocco and Djurjura and Taza-Jijel in Algeria. The UNESCO Man and Biosphere (MAB) programme has succeeded in strengthening the social capital of the reserves while 


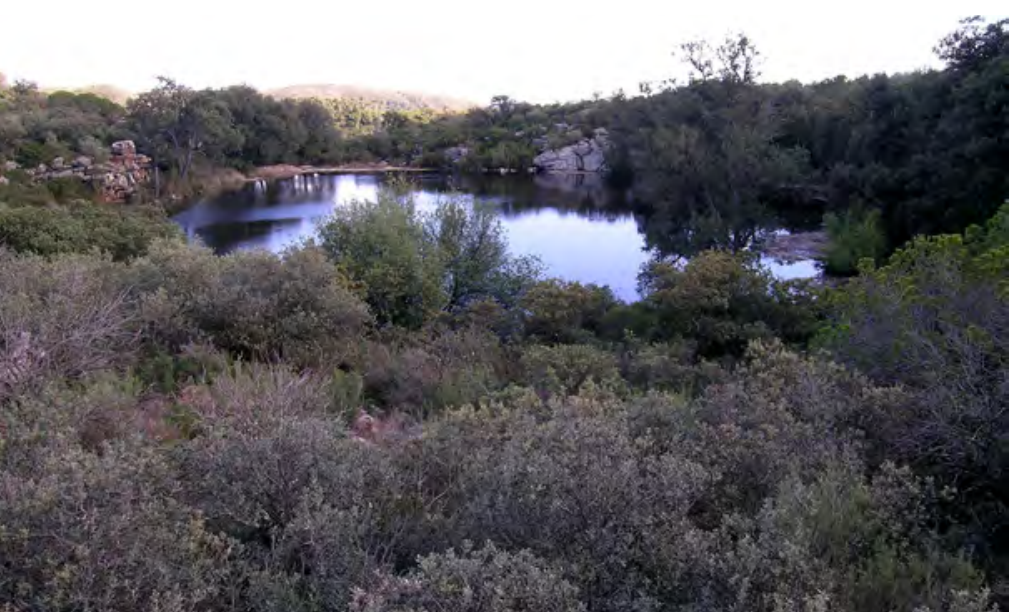

ensuring an enabling environment for community members, especially women and young people, who have been introduced to new skills to revive old traditions and crafts (UNESCO, Periodic Evaluation reports). Protection at habitat level in the region, especially on IDS, represents good practice in biodiversity conservation and in ecosystem restoration and management, and promises to become better adapted to those ends in the local context in the coming decades. For example, the MAB programme strategy (2015-2025) and its associated Lima action plan (2016-2025) introduce effective periodic reviews which should ensure that members of the World Network of Biosphere Reserves adhere to certain standards for plant species conservation and ecosystem restoration (UNESCO, 2017). On another note, the IDS aim to indirectly transform the social fabric of communities living near and at some distance from those areas so that they become partners in the implementation of conservation and management schemes. All this depends on the country's preparedness and the willingness of local authorities and civil societies to take part in the management schemes.

In conclusion, the region's aspirations towards effective management of plant diversity at the habitat level are promising. Nevertheless, the implementation tools and mechanisms still lack some rigour and require joint collaborative efforts at national and regional levels. In situ habitat conservation 'labels' are many and redundant, which is a drain on resources. What is needed at this moment in time is to pool efforts and channel conservation leadership in order to direct all resources and capacities towards a new vision. Mainstreaming conservation efforts to involve local authorities through decentralisation is a good approach, as has been the case in many countries in the region. Efforts can be sustained because of the income generated through ecotourism. On another note, in order to improve the effectiveness of in situ plant conservation, there is a need to better integrate plant conservation strategies
Balsa de la Dehesa

Soneja, Province of Castellón, Valencian Community, Spain (C) Emilio Laguna

within national policies and to put them on the agenda of today's growing approaches to inclusive planning aimed at successful implementation of the Sustainable Development Goals 2030 among Multilateral Environmental Agreement (Biodiversity cluster and Chemical cluster). There needs to be a system to evaluate the effectiveness of habitat management at national level by governments where plant diversity conservation is one of the main criteria, while also learning from the evaluation procedure adopted by UNESCO Global Geoparks, among others, which could be a model for PA governance.

\section{Recommended reading}

López, A. and Correas E. (2003). Assessment and Opportunities of Mediterranean Networks and Action Plans for the Management of Protected Areas. Gland, Switzerland and Cambridge, UK: IUCN.

Vogiatzakis, N., Mannion, A.M. and Griffiths, G.H. (2006). 'Mediterranean ecosystems: problems and tools for conservation'. Progress in Physical Geography 30(2): 175-200. 


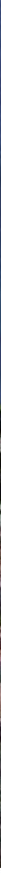

\subsubsection{Plant micro-reserves in the Mediterranean area}

\section{Author: Emilio Laguna}

Centre per a la Investigació i Experimentació Forestal (CIEF). Generalitat Valenciana, Spain

\section{Collaborators}

\section{Costas Thanos}

Faculty of Biology, National and Kapodistrian

University of Athens, Greece

\section{Christine Fournaraki}

CIHEAM Mediterranean Agronomic Institute of Chania (MAICh), Chania, Crete, Greece

\section{Costas Kadis}

Frederick University, Nicosia, Cyprus

\section{Magda Bou Dagher Kharrat}

Department of Life and Earth Science, Université Saint-Joseph de Beyrouth, Lebanon

Conservation of very small but species-rich sites is often seen as a problem as there are usually few options for their protection (see discussion in Heywood, 1999). In many countries, the complexity of declaring protected natural spaces means that small sites may be ignored, because their protection would require a considerable bureaucratic effort for a small area or for only one or a few plant species.

A valid alternative for protecting these small localities is the creation of plant micro-reserves (PMRs), a model that has been adapted to comply with the specific legal requirements of different countries. PMRs have been proposed as a useful
$\Delta$

Cabo Cervera (province of Alicante, Spain) hosts one of the best known populations of Helianthemum caput-felis

(C) Emilio Laguna

and successful option for the in situ conservation of microhabitats and small sites rich in threatened flora (Akeroyd, 1998; Raeymaekers, 2000; Heywood \& Dulloo, 2005; Dulloo et al., 2008; Silva et al., 2008, 2009; Heywood, 2014, 2016). The idea of creating PMRs is not new; Gómez-Campo (1981) formulated the concept of mini-reserves but in relation to very few sites that required an extremely high level of protection (Gómez-Campo \& Herranz, 1993).

In the early 1990s, when the idea of creating a network of PMRs in the Valencian Community (Spain) was proposed, two suggestions were made to facilitate their implementation: 1) the sites should be managed as a network, considerably reducing the need for a large team of officers and technicians to manage a long list of PMRs; and 2) a 'light' legal model was required, suitable for the conservation and management of public lands. This model was devised because the majority of the areas of high botanical value in the Valencian Community were on public land managed by the Valencian regional government (Laguna, 1995, 2001). There were also some on private land whose owners might be interested in conservation provided two conditions were met: 1) the land should not be expropriated; and 2) the landowners would remain in charge of the site's management, if possible with financial support from the regional government. Based on these 
ideas, the plant micro-reserve legal protection model (Laguna, 1995) was established in 1994 and the process of selecting suitable areas began, in order to establish a network representative of the diversity and uniqueness of Valencian habitats (Laguna et al., 2004) with special emphasis on endemic, rare or threatened plants (Laguna, 1999, 2001; Laguna et al., 2004; Serra et al., 2004; Fos et al., 2014).

The first Valencian PMRs were declared in 1998. By 2017, the Valencian network had 300 legally protected PMRs, totalling 2,291 hectares. The network has populations of 1,940 species, including 311 Spanish endemics, 66 of which are exclusive Valencian endemics (Laguna et al., 2016; Fos et al., 2017). As PMRs can receive increased funding for conservation, the network is the target of numerous projects to improve the populations and habitats of threatened species, including the three species that have a legally approved regional recovery plan: Cistus heterophyllus subsp. carthaginensis, Silene hifacensis and Limonium perplexum.

The creation of the Valencian PMR network was initially funded by the European Union's LIFE programme, which subsequently helped develop projects in other European regions for site selection and/or the creation of PMR networks. These projects have been described by Kadis et al. (2013). In Greece, seven PMRs have been established in western Crete to protect populations of six species covered by Annexes II and IV of the European Union's Habitats Directive (Androcymbium rechingeri, Anthemis glaberrima, Bupleurum kakiskalae, Cephalanthera cucullata, Hypericum aciferum and Nepeta sphaciotica), as well as the EU's priority habitat of Phoenix theophrasti palm groves in Crete (Thanos et al., 2006, 2007; Kargiolaki et al., 2007; Kadis et al., 2013).

The model proposed for Crete, unlike that of the Valencian Community, is to protect a smaller number of PMRs that are more intensively studied and monitored. Using the same model, a micro-reserve network to conserve species and habitats under the Habitats Directive was established in Cyprus (Kadis et al., 2010) which has effectively protected sites for four species (Arabis kennedyae, Astragalus macrocarpus subsp. lefkarensis, Centaurea akamantis and Ophrys kotschii) and selected examples of Quercus alnifolia and Cedrus brevifolia forests (Kadis et al., 2013). In addition, there are proposals to conserve plants unique to the Green Line in Cyprus by using PMRs (Kadis et al., 2010).

In the eastern Mediterranean, micro-reserves have recently been set up in Lebanon in a programme developed by Université Saint-Joseph de Beyrouth in the framework of a Partnership Fund (CEPF) programme. Three PMRs protect endangered endemic or rare species: Iris sofarana subsp. kasruwana in Ehmej, Iris bismarckiana in Sarada and Drosera rotundifolia in Baskinta. In Lebanon the concept had to be adapted to fit the different land ownership types: private, public and waqf (lands belonging to religious communities) (Bou Dagher Kharrat et al., 2016; Hurrell, 2014).

In addition to these PMRs that have been created, Kadis et al. (2013) mention proposals for PMRs in other Mediterranean areas and thematic projects such as that of the University of Mansoura (Egypt) to create a network of micro-reserves for aromatic and medicinal plants that can supply seeds for cultivation by the Bedouin communities of $\mathrm{St}$ Catherine Protectorate in the Sinai peninsula - a project unfortunately interrupted due to the unstable social situation in the country.

PMRs are designated to protect both species in situ and habitats; they are particularly appropriate for microhabitats where many endangered, rare or endemic species grow together (e.g. Mediterranean temporary ponds with Isoëto-Nanojuncetea communities; and active calcareous springs covered by bryo-pteridophytic bioconcrescent formations (tufa), with Cratoneurion commutati communities). PMRs have not only proved useful for the conservation of unique populations of endemic and threatened species (Laguna, 2004 and 2007, Kell et al., 2008b), but above all they have also been, optimal sites for the development of scientific and educational projects, and environmental education activities in particular (Kadis et al., 2013). In many cases, PMRs highlight the value of unusual small-scale features (plants, landscapes, symbolic sites, etc.), leading local authorities and NGOs to become more involved in their promotion and conservation. They serve, therefore, as a good example of 'thinking globally and acting locally', the basis of sustainability in the use of the planet's ecosystems. 



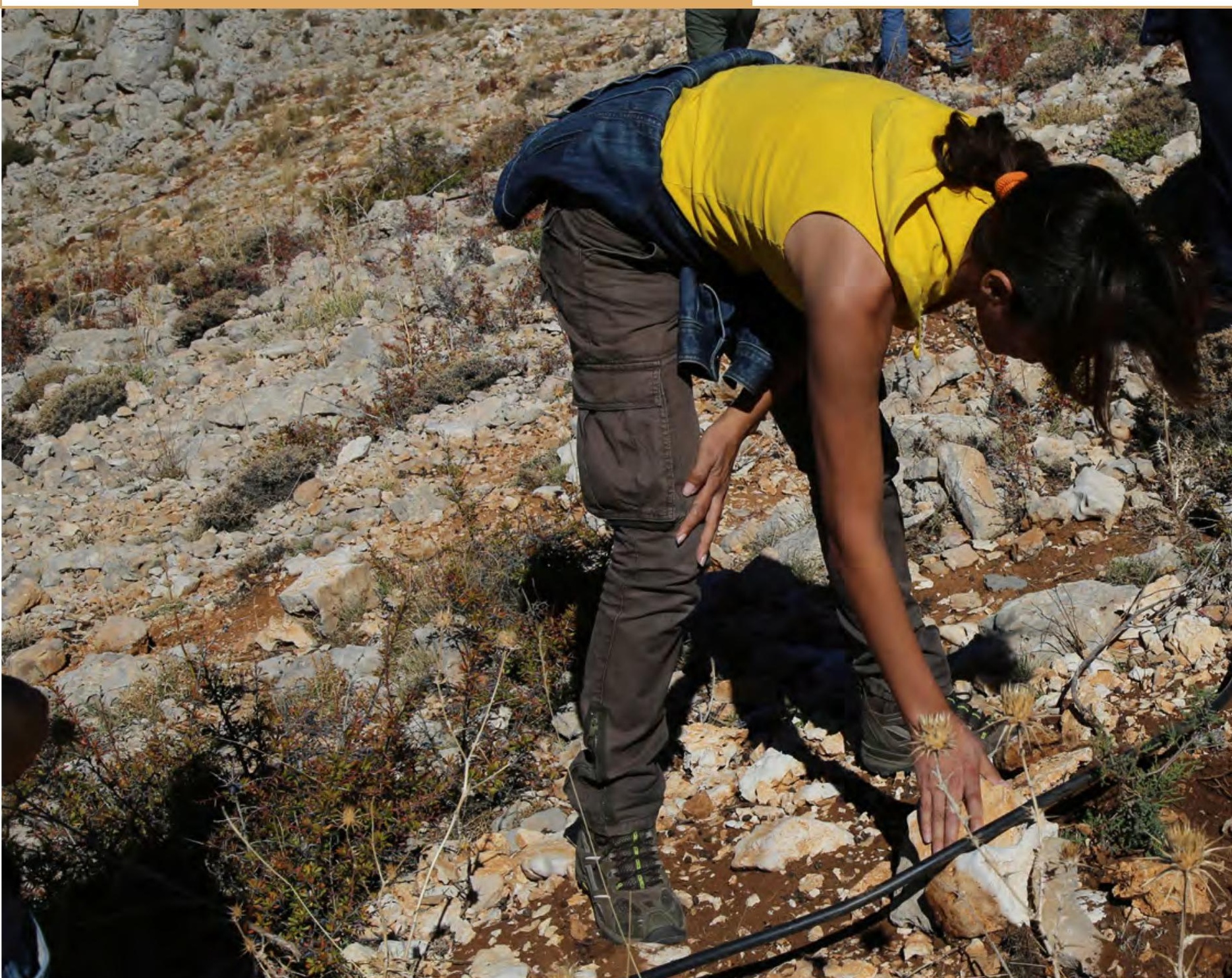

$\boldsymbol{\Delta}$

Monitoring the restoration activities of the EcoplantMed project, implemented in Kfardebian (Lebanon) by the scientific staff of Saint Joseph University, Beirut. The original ecosystem was mainly restored by planting the original flora, principally composed by Cedrus libani A.Rich. and Juniperus excelsa M.Bieb

(C) Gianluigi Bacchetta

Indeed, the species' population(s) will continue to decline, unless habitat loss is the primary threat, and even then continued management may be needed to ensure their survival (Heywood, 2016).

While the importance of in situ measures is widely recognised, they have yet to be implemented to any great extent in the south and east Mediterranean. Although numerous species have been identified as in need of conservation, few attempts have been made to carry out the necessary conservation or recovery actions. This is an instance of how good intentions are seldom put into practice.

Each country in the region needs to undertake a programme to assess and conserve threatened and other priority species. This should involve assessing and monitoring the status of the target species; surveying their distribution, ecology, demography and reproductive biology; conducting a detailed analysis of the threats to the populations and their habitats; deciding on the nature of the conservation or recovery actions needed in both the short and the long term; and preparing a strategy and action plan and an implementation schedule for each species.

Before a species can be conserved effectively, its range must be mapped and its existing populations surveyed so that its conservation status can be accurately determined. Its threat status needs to be confirmed as early as possible if conservation actions are not to come too late (Volis, 2016). Information on the geographical distribution of a rare species is usually scarce, and making accurate distribution maps for endangered and rare species is difficult as it often requires intensive surveys.

Detailed assessments of a rare species' distribution and demography require an understanding of the factors that restrict its range. A rare species - generally one with a small range and/or low abundance - may occupy (micro)habitats that are themselves limited in extent, or they may have a 


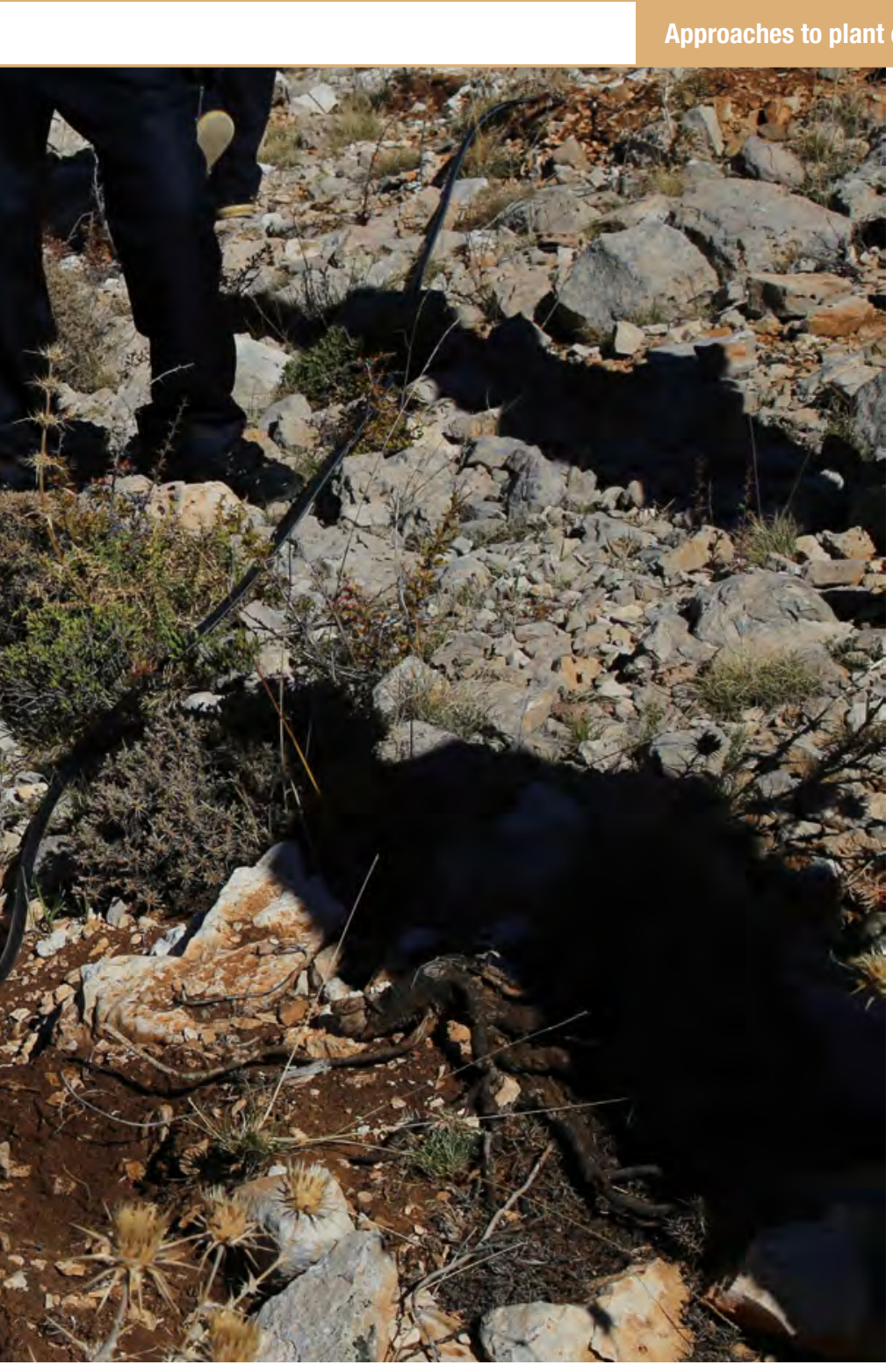

narrower range of values along one or more niche axes than more common species (Maschinski et al., 2012). This has implications for the design of the distribution survey and the resulting reserve, as well as for the selection of suitable reintroduction or translocation sites.

A species' distribution and intraspecific variation depends to a great extent on the variety of environmental and ecological conditions within its range. Hence there is a need to determine the soils, elevations, climatic conditions (including microand meso-climates) and vegetation types of the locations where it is found, and how these factors interact with the biology of the species in question.

The population assessment also has to take account of intraspecific variation in the plant's ecology and genetics. To encapsulate the role of this variation in an evolutionary context, Ryder (1986) defined 'evolutionary significant units' as "subsets of the more inclusive entity species, which possess genetic attributes significant for the present and future generations of the species in question", subsets that should be defined on the basis of the congruence between different types of information, such as ecological, genetic and physiological data.

Niche-based modelling can be an effective method of locating further individuals and populations of rare species, especially in cases where little is known of their abundance and distribution (Guisan et al., 2006). When iteratively alternated with field sampling it is a cost-efficient approach to the mapping of rare species (e.g. Fois et al., 2015).

The monitoring of threatened plant populations both before and after recovery actions faces two main practical difficulties: the need to maintain a sustained monitoring effort year after year in order to ensure the collection of relevant time series, and the need to obtain data that are sufficiently precise to reveal significant changes in biodiversity across space and time. Overcoming these constraints often requires considerable financial and human resources that may exceed the amount available (Fenu et al., 2015).

The following are examples of conservation actions currently being undertaken in the east and south Mediterranean.

In Imegdale KBA (Morocco), the Global Diversity Foundation is implementing plant enrichment measures. After building community nurseries to cultivate threatened, endemic and useful species, plants will be put back into the wild in collaboration with the Forest Department. Nursery grown material of these species will also be distributed to local people for planting on their private terraces, so as to relieve the pressure on the wild population and curb overcollecting.

In Egypt, a botanical conservation programme was set up in St Catherine KBA between 1998 and 2003. The scheme included establishing 48 permanent enclosures ranging in area from $7 \mathrm{~m} 2$ (Wadi ElArbain enclosure 1) to $300 \mathrm{~m} 2$ (Wadi Zaghra) to protect, manage and monitor the endemic and threatened plant species in this protected area so that natural evolutionary processes could be maintained (Omar, 2014). With support from other schemes, such as the Conservation Leadership Programme's Rosa arabica project (http://www. conservationleadershipprogramme.org/project/ ecological-and-conservation-assessment-of-rosa- 
arabica-in-st-katherine-egypt/), the fenced-off areas are still being monitored.

Also, as noted above, during the IPAMed project St Catherine Protected Area rangers and a research team with local community support documented plant diversity, vegetation composition, threats, plant species distribution and conservation status for 10 plant species with restricted distributions: Anarrhinum duriminium, Bufonia multiceps, Euphorbia obovata, Phlomis aurea, Rosa arabica, Polygala sinaica, Nepeta septemcrenata, Salvia multicaulis, Hypericum sinaicum and Origanum syriacum.

Further in situ conservation measures, such as population augmentation, fencing and invasive plant eradication, have recently been implemented in several Mediterranean countries, such as Cyprus, Lebanon (Tyre Nature Reserve) and Italy (Sicily and Sardinia), under the CARE-MEDIFLORA project (http://www.care-mediflora.eu/), supported by the MAVA Foundation.

Recognition of the threats posed by invasive alien species (IAS) is a relatively recent development in the Mediterranean region as a whole, but the eradication of invasive plants has now become one of the most common management actions throughout the region. Considerable experience has been accumulated, with a total of 33 invasive plant eradication and control actions recorded in the area by 2013: 16 in Spain, 7 in Italy, 7 in France, 1 in Malta and 2 in the southern Mediterranean (Brunel et al., 2013). More recently, further eradication programmes have been implemented in other Mediterranean territories, such as Sardinia (Acunto et al., 2017) and the Pontine Archipelago in the Tyrrhenian Sea (Celesti-Grapow et al., 2017). However, compared to the real need, the number of activities has been quite limited, notably in the east and south, and the measures already taken are still too recent for their effectiveness to have been properly assessed.

Attempts have been made to establish in situ genetic conservation of crop wild relatives in the south and east Mediterranean region, most notably via the 'Conservation and Sustainable Use of Dryland Agrobiodiversity in Jordan, Lebanon, Syria and the Palestinian Authority' project led by ICARDA and funded by the Global Environment Facility (Amri and
Damania, 2013). Little is now known of the Syrian sites due to the current conflict in Syria, but two genetic reserves established by the project in SaleRsheida (to conserve wild wheat Triticum dicoccoides and wild barley Hordeum spp. - Al-Atawneh et al., 2008) and Wadi Sair (to conserve forage legumes, fruit trees and vegetable wild relatives - Al-Atawneh et al., 2013) are still actively managed.

\section{Recommended reading}

Guidance on species recovery, reintroductions and translocations can be found in:

Heywood, V. Shaw, K., Harvey-Brown, Y. and Smith, P. (Eds.). (2018). BGCl and IABG's Species Recovery Manual. Richmond, United Kingdom: Botanic Gardens Conservation International.

Heywood, V.H. (2014). 'An overview of in situ conservation of plant species in the Mediterranean'. Flora Medit. 24:5-24.

Heywood, V.H. and Dulloo, M.E. (2005). In situ conservation of wild plant species: $A$ critical global review of good practices. IPGRI Technical Bulletin No. 11. Rome: FAO and IPGRI.

Rossi, G., Amosso, C., Orsenigo, S. and Abeli, T. (2013). 'Linee guida per la traslocazione di specie vegetali spontanee'. Quaderni Conservazione della Natura 38. Rome: Istituto Superiore per la Protezione e la Ricerca Ambientale (ISPRA) 


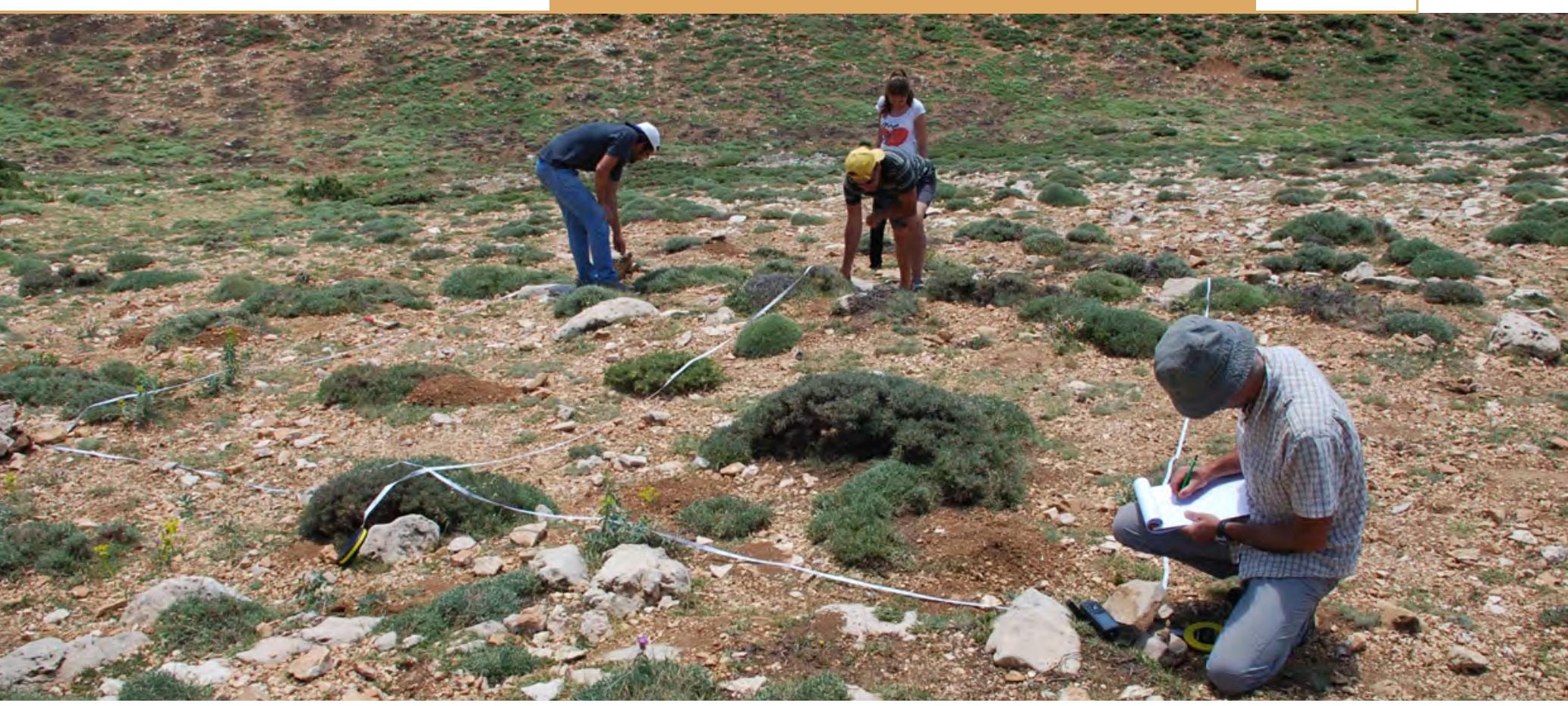

\subsection{Species reintroduction programmes}

Author

Magda Bou Dagher Kharrat

Department of Life and Earth Science, Université Saint-Joseph de Beyrouth, Lebanon

Reintroduction is the deliberate movement (translocation) of individuals of a species to parts of its natural indigenous range from which it has been lost with the aim of establishing a new, viable, selfsustaining population. It is often undertaken when species recovery is not possible.

IUCN has published guidelines to help practitioners (IUCN, 2013). Detailed guidelines have also been prepared by the US Center for Plant Conservation.

Comprehensive reviews and reports on reintroductions to guide plant conservationists are the best way to understand failures and improve the overall success of reintroduction efforts (Godefroid et al., 2011; Dalrymple et al., 2012; Guerrant, 2012; Liu et al., 2015). In the Mediterranean region, examples of documented successful introductions are few and far between (Dominione et al., 2005; Heywood, 2014) and almost unknown in the Levant and North Africa. One known reintroduction is of the Critically Endangered Iris sofarana subsp. kasruwana, rhizomes of which were translocated successfully in Ehmej, Lebanon (Bou Dagher Kharrat et al., 2016).

Reintroduction is considered successful when flowering, fruiting and recruitment take place spontaneously several years after reintroduction. The parameters influencing successful establishment are the type of propagules, their age (Godefroid et al., 2011), the soil microbiota, breeding system, type of
$\Delta$

Kfardebian, Lebanon. Assessing plant-plant interactions (competition and facilitation) in cushion-like plants to be used as potential nurse plants for newly planted tree seedlings.

c) M. Bou Dagher Kharrat

pollination vector, type of seed dispersal and seed viability (IUCN, 2013), genetic diversity (Hackney \& MacGraw, 2001), and direct protection of the reintroduction site (Fenu et al., 2016).

As part of their commitments to the CBD to meet the GSPC and Aichi targets by conserving threatened species, southern Mediterranean countries are undertaking some species reintroductions. However, almost all of them lack national regulations on plant reintroductions. We therefore recommend establishing national offices and databases, like the one developed by the Italian Botanical Society (Rossi \& Bonomi, 2009; Rossi et al., 2013), to coordinate and support threatened plant reintroduction projects, including conservation translocations, when requested by botanists and wildlife managers.

\section{Recommended reading}

Maschinski, J., Albrecht, M.A., Monks, L. and Haskins, K.E. (2012) 'Center for Plant Conservation best reintroduction practice guidelines'. In: J. Maschinski and K.E. Haskins (eds) Plant Reintroduction in a Changing Climate: Promises and Perils, pp. 277-306. Washington: Island Press.

Maschinski, J. and Albrecht, M.A. (2017). 'Center for Plant Conservation's Best Practice Guidelines for the reintroduction of rare plants'. Plant Diversity 39(6):390-395. 


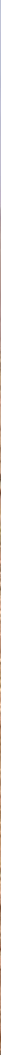

\subsection{Genetic conservation of crop will relatives}

\section{Authors}

\section{Nigel Maxted, Joana Magos Brehm and Shelagh Kell}

School of Biosciences, University of Birmingham

Crop wild relatives (CWR) are wild plant species that include important and novel sources of traits for crop improvement, given their genetically close relationship to crops (Tanksley \& McCouch, 1997; Maxted et al., 2006). They have been used increasingly since the early 20th century, for example to confer resistance to pests and diseases, improve tolerance to environmental conditions such as extreme temperatures, drought and flooding, and to improve nutrition, flavour, colour, texture and handling qualities (see Hajjar \& Hodgkin, 2007; Maxted \& Kell, 2009, for reviews). CWR diversity thus constitutes a critical plant genetic resource that can help ensure food, nutrition and economic security (Maxted et al., 2011).

The Mediterranean region is particularly important for its diversity of wild relatives, having more CWR than any other global region, with 262 of the global priority 1,667 CWR taxa representing 173 crop complexes (Vincent et al., 2013). Many of these have significant known economic value derived from their existing use for crop improvement and those that have not yet been utilized have potential value
Wild pear Pyrus pyraster growing in Wadi Sair, Palestinian Territories. (C) Nigel Maxted

as gene donors in the future, particularly as plant breeders seek greater diversity to adapt crops to our changing climate. In the eastern Mediterranean and North Africa, these include CWR of wheat (Triticum aestivum), barley (Hordeum vulgare), oat (Avena sativa), chick pea (Cicer arietinum), lentil (Lens culinaris), pea (Pisum sativum), faba bean (Vicia faba), lucerne (Medicago sativa), white clover (Trifolium repens), grape (Vitis vinifera), fig (Ficus carica), olive (Olea europaea), almond (Prunus dulcis) and pistachio (Pistacia vera), as well as the minor crops flax (Linum usitatissimum), melon (Cucumis melo), lettuce (Lactuca sativa) and sage (Salvia officinalis) (Heywood \& Zohary, 1995; Kell et al., 2008a).

Mediterranean CWR diversity, despite its obvious economic value, is threatened and under-conserved. A recent review of CWR ex situ holdings by Castañeda et al. (2016) found that CWR taxa represent $10.5 \%$ of total ex situ holdings, about a third of CWR taxa are unconserved (no accessions in gene banks), about a third are poorly conserved $(<10$ accessions), and $72 \%$ are a high priority for further collection. The situation for in situ CWR conservation is even less satisfactory: although many CWR are found in existing protected areas they are not being actively monitored and managed, while the handful 


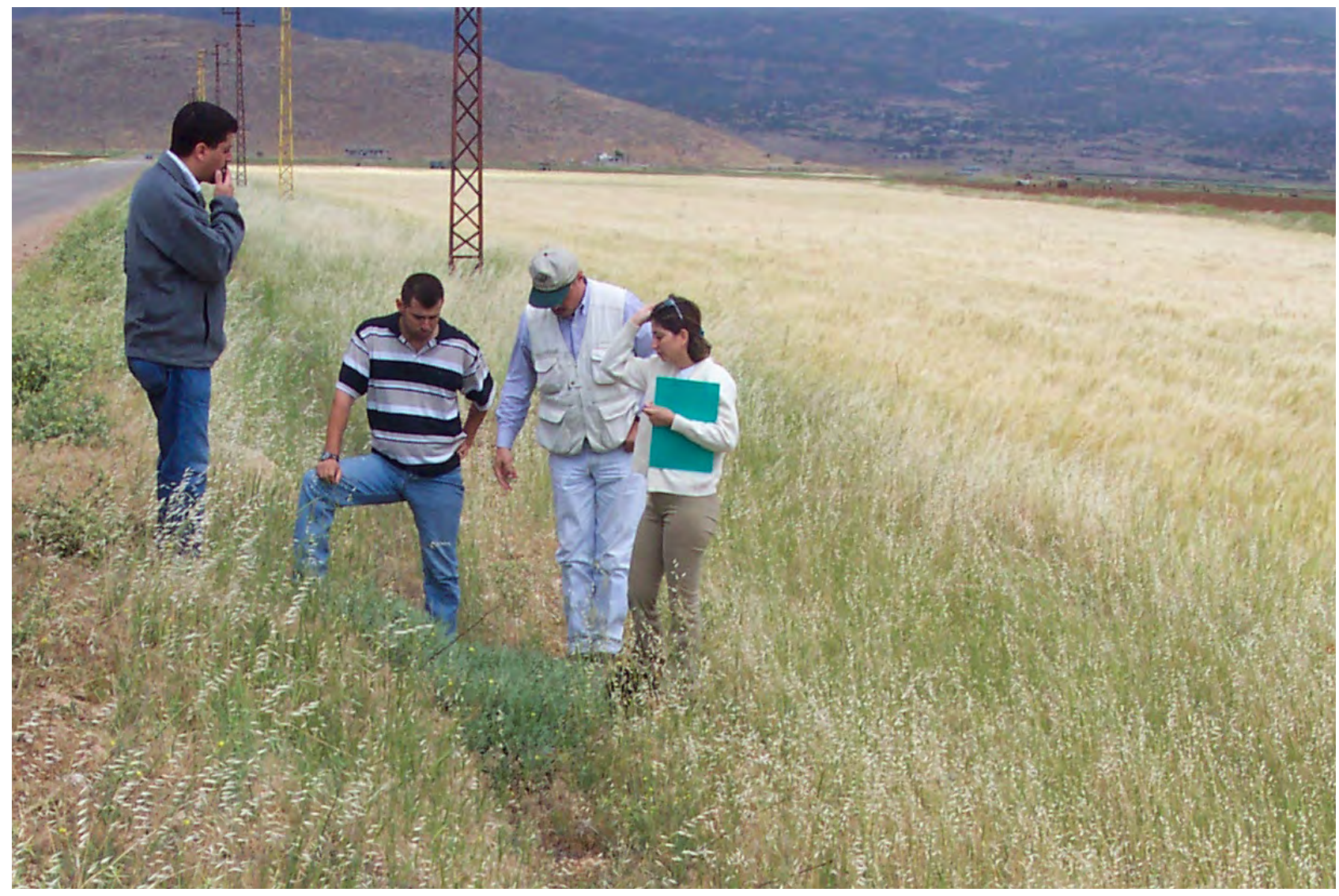

$\Delta$

Informal in situ genetic reserve conservation along roadside, Upper Beqaa Valley, Lebanon.

() Nigel Maxted

of CWR populations that are actively managed (e.g. Triticum spp. in Israel and Triticum and Hordeum spp. in the Palestinian Territories) are not managed to the conservation standards proposed by Iriondo et al. (2012). A summary of CWR in situ conservation actions in the eastern Mediterranean/Middle East is given by Heywood (2008).

Although systematic CWR conservation does not yet exist in the Mediterranean region, progress towards this goal has begun: notably, Castañeda et al. (2016) identified the region as the first global priority for ex situ CWR conservation and the Global Trust (Dempewolf et al., 2013) is currently actively collecting and storing ex situ germplasm from the region. Progress with active in situ conservation has been slower, but the ECPGR Wild Species Conservation in Genetic Reserves Working Group (http://www.ecpgr.cgiar.org/working-groups/wildspecies-conservation// has received a series of EU-funded grants to focus on improving CWR in situ conservation. These culminated in a proposed concept for CWR in situ conservation in Europe and the Mediterranean (Maxted et al., 2015) and funding to implement the concept is now in place via the recent EU-funded project 'Farmer's Pride' (http://www.ecpgr.cgiar.org/working-groups/wildspecies-conservation/ and http://farmerspride. eu/), which started on 1st November 2017. This has the explicit objective that by 2020 it will have established a network of in situ stakeholders and CWR populations across the region to actively promote in situ CWR conservation. Therefore, we hope that by 2020 systematic CWR conservation in the Mediterranean region will be closer to reality and the availability of that diversity for crop improvement enhanced for future food, nutrition and economic security.

\section{Recommended reading}

Hunter, D. and Heywood, V. (eds) (2011) 'Crop Wild Relatives. A Manual of In Situ Conservation'. London: Earthscan

Maxted, N., Ford-Lloyd, B.V., Kell, S.P., Iriondo, J., Dulloo, E. and Turok, J. (eds) (2008) 'Crop Wild Relative Conservation and Use'. CAB International, Wallingford, UK.

Magos Brehm J, Kell S, Thormann I, Gaisberger H, Dulloo E and Maxted N (2017) Interactive Toolkit for Crop Wild Relative Conservation Planning version 1.0. University of Birmingham, Birmingham, UK and Bioversity International, Rome, Italy. Available at: http://www. cropwildrelatives.org/conservation-toolkit. 


\subsection{Ex situ conservation of Mediterranean vascular flora}

\section{Authors}

\section{Marco Porceddu}

Centre for the Conservation of Biodiversity (CCB), University of Cagliari, Italy

\section{Gianluigi Bacchetta}

Centre for the Conservation of Biodiversity (CCB), University of Cagliari, Italy

Ex situ conservation acts as a back-up for certain fields of plant diversity, generally through the maintenance of clonal material in field gene banks and in vitro banks, certain trees in conservation stands, and many seed-bearing species in botanic gardens and/or in conventional and cryogenic seed banks (Li \& Pritchard, 2009). The term gene bank therefore includes various forms of ex situ conservation; there are seed banks sensu stricto that store conserve desiccation-tolerant orthodox seeds; in vitro conservation/cryopreservation gene banks, which are particularly important for the conservation of recalcitrant seeds; and field gene banks aimed at the conservation of perennial plants producing very few or no seeds at all, plants with a long-life cycle, and vegetatively propagated species. Several seed banks adopt a two-tier seed storage system, comprising a base collection, defined as a set of accessions preserved for long-term conservation (seeds preferably stored at close to $-20^{\circ} \mathrm{C}$ with $3-8 \%$ internal seed moisture content), and an active collection formed of accessions preserved for medium-term conservation, which can be made available for seed germination experiments, multiplication, population augmentation in species recovery projects, indices seminum and/or other uses.

Until recently, most seed banks were agricultural, focusing almost exclusively on plant varieties of agricultural interest and their wild relatives. For this reason, the largest percentage of accessions in seed banks worldwide is of cultivars and landraces of agronomically important species. ICARDA maintains an important gene bank for such taxa. Although officially based in Aleppo, Syria, ICARDA's sites in Rabat, Morocco, and Turbol, Lebanon, have become its primary seed storage and research centres since the Aleppo hub was seized by an Islamist rebel group in September

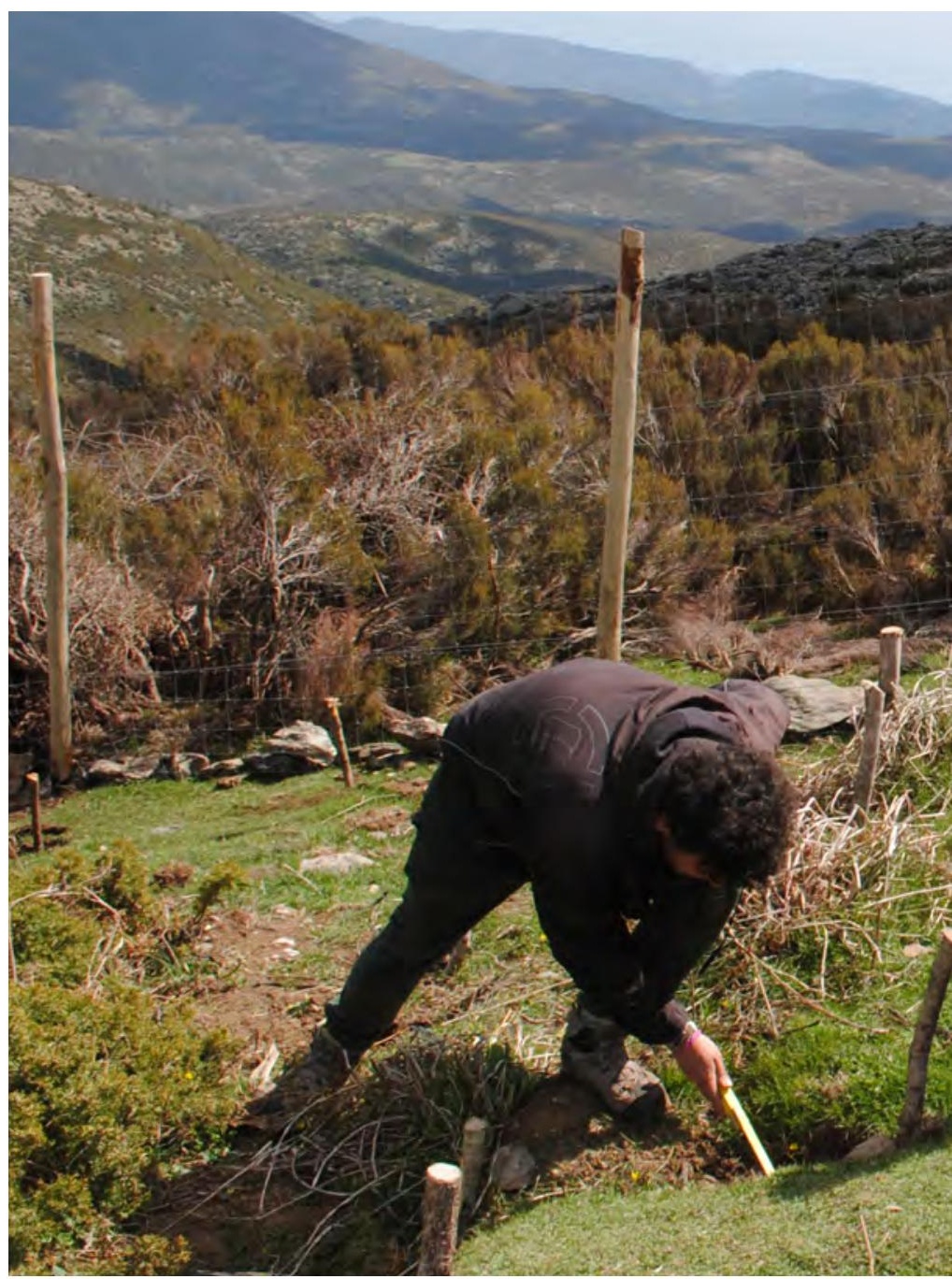

2015. It holds accessions of crop landraces and wild relatives, especially of barley, faba bean, durum wheat, chickpeas and lentils. The Aleppo gene bank contained over 32,000 accession of crop wild relatives (www.genesys-pgr.org), some of which were duplicated outside of Syria but not all.

Today, several gene banks in the Mediterranean are involved in preserving the wild, autochthonous flora of the region, such as the UPM Seed Bank of Madrid, Spain (considered the pioneer seed bank for wild plant species: Gómez-Campo, 1997), the Sardinian Germplasm Bank (BG-SAR; Porceddu et al., 2017), the seed bank of CIHEAM Mediterranean Agronomic Institute of Chania (MAICh) in Greece, the bank of Conservatoire botanique national méditerranéen de Porquerolles in France, the Jouzour Loubnan Seed Bank in Lebanon and the seed bank at INRGREF in Tunisia. Botanic gardens have also developed seed banks for ex situ conservation of wild species in many Mediterranean countries. At a global level, the Royal Botanic Garden Kew's Millennium Seed Bank is considered the leader in the ex situ conservation of wild threatened and potentially useful plant species, primarily of arid zones. 
may include plant reintroduction and population augmentation programmes (Fenu et al., 2015) as well as ecological restoration activities that contribute to the conservation of the plant species themselves and their genetic diversity.

It is vital to maintain the activities of existing networks of scientific institutions and germplasm banks, and also to create new ones at different levels of sophistication, so as to ensure collaboration and/or knowledge exchange between members in different countries. For example, since 2005 the Italian Network of Germplasm Banks for the Ex situ Conservation of Native Flora (RIBES), which brings together 17 Italian seed banks, has provided a national framework for conserving the seeds of rare and endangered species as well as endemic crop wild relatives (http://www. reteribes.it/). Similarly, at European level, the European Native Seed Conservation Network (ENSCONET) coordinates native seed plant conservation within Europe, and the institutions within the network collaborate to preserve seeds for the future, exchanging experiences, protocols and facilities (http://ensconet.maich.gr/). Starting in 2004, the international projects GENMEDOC and SEMCLIMED (Interreg IIIB MEDOCC) laid the foundations for a plant conservation network at Mediterranean level; subsequently, in 2010, 13 members founded the Network of Mediterranean Plant Conservation Centres (GENMEDA; http: $\backslash \backslash$ genmeda.net), which currently has 18 members. Its objectives are to 1) reinforce and enhance the effectiveness of plant conservation, 2) promote and develop actions for environmental education and dissemination in order to increase public awareness concerning biodiversity conservation, 3) draw up joint initiatives and projects to further scientific and technical knowledge of the conservation and/ or management of plant genetic materials, and 4) support decision-making processes relating to plant biodiversity conservation policies in the Mediterranean region.

Thanks to the exchange of knowledge and the experience accumulated, network members have taken part in several international Mediterranean projects since 2011, such as 'Ensuring the survival of endangered plants in the Mediterranean' (funded by the MAVA Foundation; http://medislandplant. maich.gr), 'ECOlogical use of native PLANTs

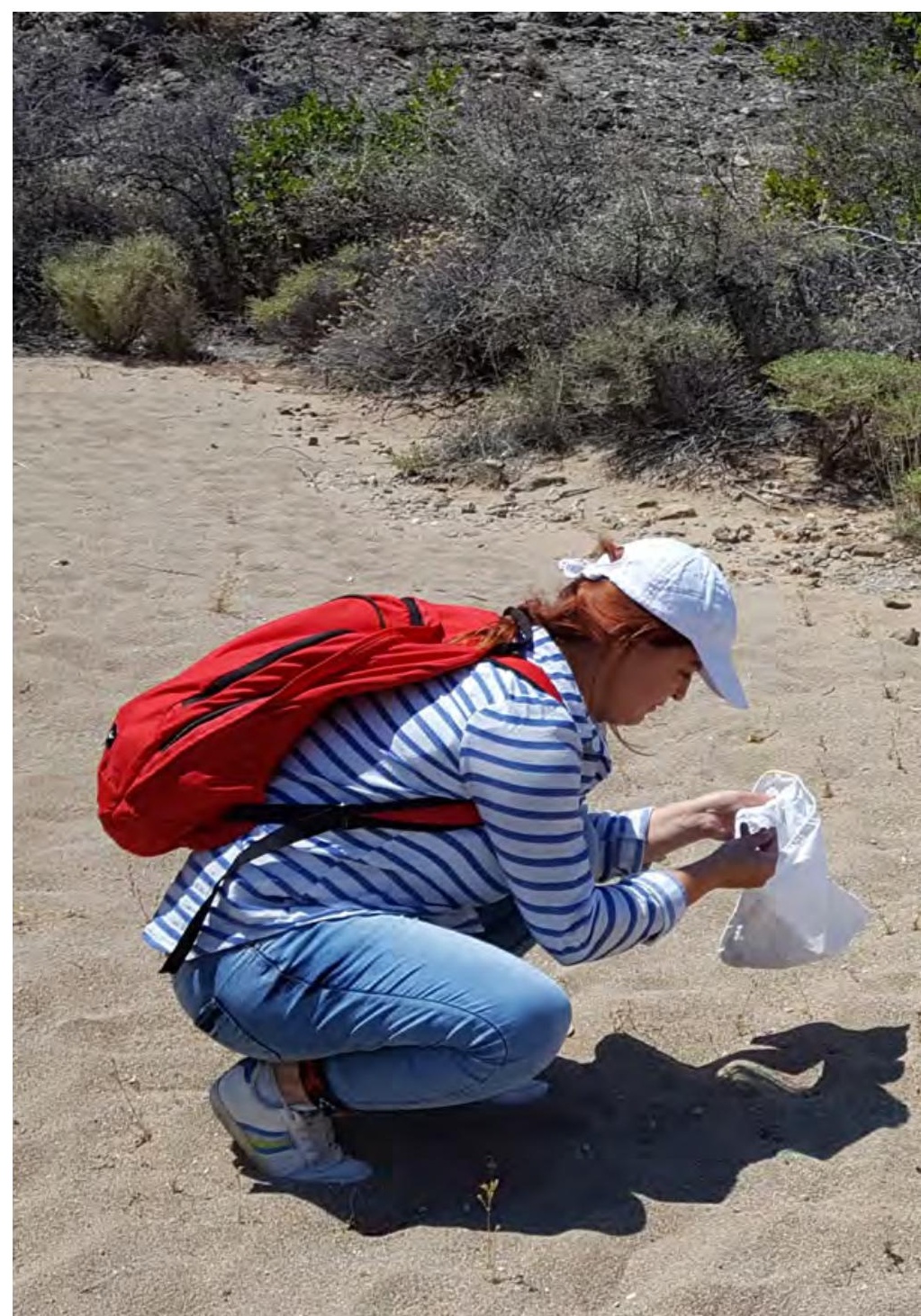

$\Delta$

Seed collecting in Crete (c) MAICh

for environmental restoration and sustainable development in the MEDiterranean region' (ECOPLANTMED; http://www.ecoplantmed.eu) and 'Conservation Actions for Threatened Mediterranean Island Flora: ex situ and in situ joint actions' (CAREMEDIFLORA; http://www.care-mediflora.eu).

The CARE-MEDIFLORA project, active since 2016, is led by seven institutions from six Mediterranean islands (Balearic Islands, Corsica, Sardinia, Sicily, Crete and Cyprus) and the IUCN/SSC Mediterranean Plant Specialist Group. The project strategy is mainly based on using ex situ activities to improve the in situ conservation of threatened plant species. Through the use of germplasm and knowhow of ex situ conservation techniques are applied to germplasm of selected species with a view to using it directly or for raising material in cultivation for carrying out field interventions, resulting in effective in situ conservation of those species. 


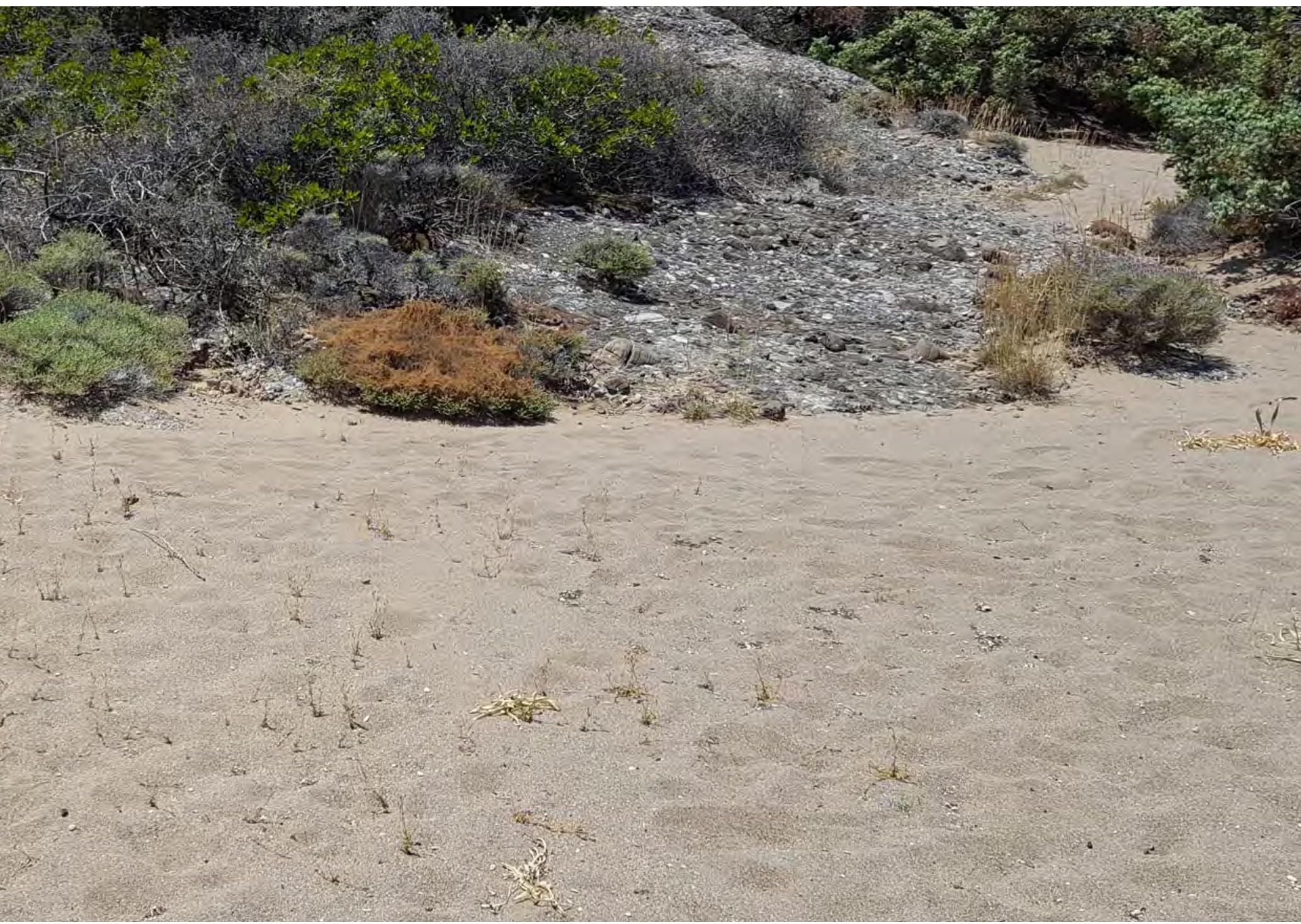

The ECOPLANTMED project was a joint Mediterranean initiative based on collaboration among seed banks, research institutes and institutions dealing with native plant conservation and management. Important project outcomes include publication of the Manual for the propagation of selected Mediterranean native plant species (Ballesteros et al., 2015), the Guide of good restoration practices in Mediterranean habitats (Marzo et al., 2015) and the 'Results of Project germination experiments' (technical report ECOPLANTMED, 2015), as well as the restoration of 13 hectares in Tunisia and Lebanon and the creation of a new Germplasm Bank in Tunisia.

The current situation, ex situ plant conservation in particular the number of species successfully conserved, international collaboration between institutions, the work done by existing and new networks and the development of new ex situ (and in situ) conservation projects - has laid the foundations for developing common plant conservation strategies and has shown the effectiveness of such measures for the protection of the Mediterranean flora.

\section{Recommended reading}

Bacchetta G., Fenu G., Mattana E., Piotto B. and Virevaire M. (eds) (2006) 'Manuale per la raccolta, studio, conservazione e gestione ex situ del germoplasma'. Manuali e Linee guida APAT 37/2006. Roma: APAT.

Bacchetta G., Bueno Sánchez A., Fenu G., Jiménez-Alfaro B., Mattana E., Piotto B. and Virevaire M. (eds) (2008'. 'Conservación ex situ de plantas silvestres'. Principado de Asturias/ La Caixa.

Guerrant, E.O., Havens, K. and Maunder. M. (eds) (2004) 'Ex Situ Plant Conservation. Supporting species survival in the wild'. Island Press: Washington. 


\subsection{Ancillary botanic garden}

\section{Authors}

\section{Salma Talhouk}

American University of Beirut

Yaser Abunnasr

American University of Beirut

\section{Alan Forrest}

Royal Botanic Gardens, Edinburgh

Centre for Middle Eastern Plants

\section{Tony Miller}

Royal Botanic Gardens, Edinburgh

\section{Centre for Middle Eastern Plants}

The Arab League countries, with a total of 33 botanic gardens, have the lowest number of gardens per total area and the lowest number per capita out of many countries and regions of comparable size and population (Talhouk et al., 2014). In our response to these findings, we have investigated ways to broaden society's participation in the establishment of botanic gardens as venues for conservation, education and outreach. Using Lebanon as a case study, we proposed the recognition of a new category of botanic gardens which are better aligned with local expectations, cultural perceptions and real estate realities. We call these 'ancillary botanic gardens' (ABG) (Talhouk et al., 2014). Ancillary botanic gardens are secondary on a spatial level in that they are established in the periphery of sites already assigned a primary purpose, such as archaeological sites, educational facilities, religious land holdings, private institutions and touristic sites; all are characterised by having unbuilt land or green spaces that support the primary site function. At the social level, ABGs are grounded in grassroots knowledge and rely on using local names for effective local communication and engagement, both of which are fundamental in developing the necessary enthusiasm for plant conservation and for facilitating the link between plants and people. They are planned and managed by local citizens, their establishment is negotiated and regulated between local groups and primary site function owners, and their mandates, defined by immediate stakeholders, are flexible rather than prescriptive. In Figure 4.1 we show archaeological sites throughout Lebanon with potential to establish ABGs. The purpose is to guide the sustainable preservation of archaeological and historical sites in Lebanon by

\section{LEBANON}

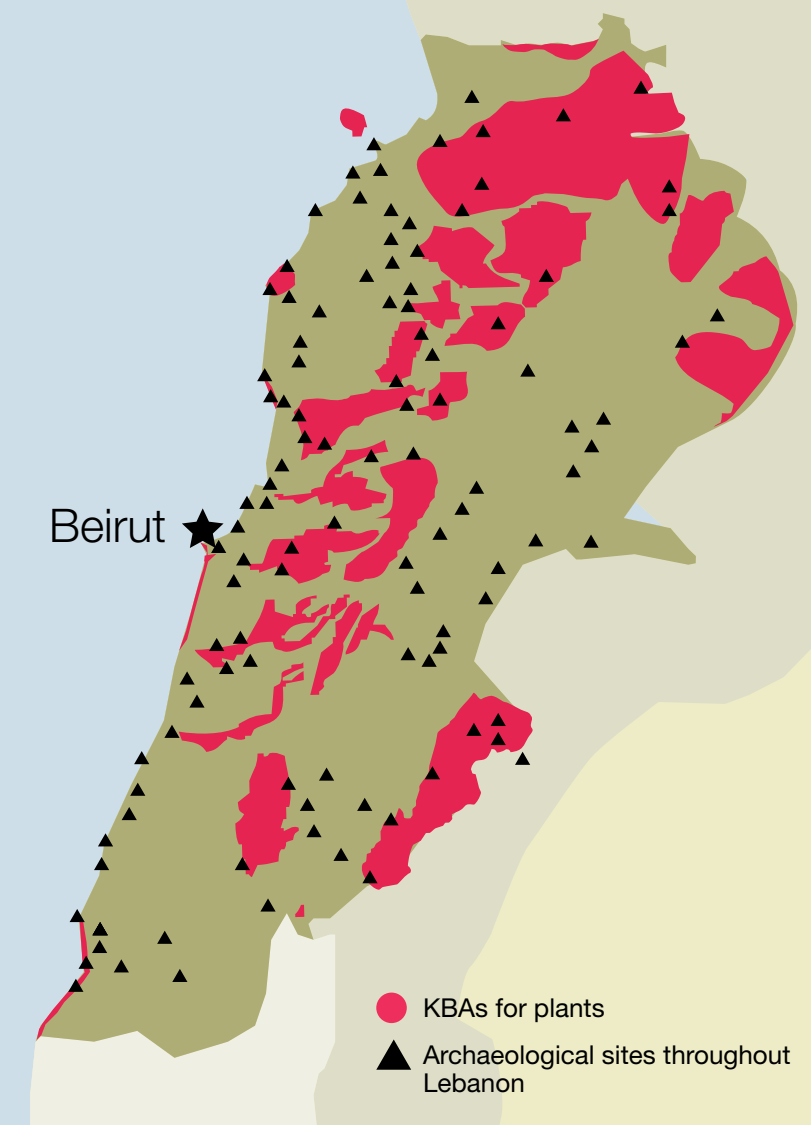

Archaeological sites throughout Lebanon.

Source "National physical master plan of the lebanese territory" (CDR, 2005).

producing site-specific vegetation management methods, developing landscape design guidelines, and engaging local communities for better site enjoyment and biodiversity conservation. On archaeological sites suitable for ABG establishment, a community-based strategy is planned to conduct participatory design and planning of ABGs. Training botanical 'guides', organising plant educational activities and conducting citizen science research to engage local residents in vegetation monitoring and/or management are included in this strategy. There are an estimated 350 archaeological sites in the country, 200 of which are excavated. The sites, which vary in size from 3 to 25 hectares, are largely protected and while major sites are managed, smaller ones are left unmanaged. Establishment of $A B G$ in strategic locations of conservation interest is a multifunctional strategy that meets multiple aims, including reconnecting with cultural and natural heritage, preserving local knowledge of plants, empowering communities with respect to the land ethic, conserving natural and cultural heritage, and monitoring short- and long-term impacts on plant diversity. 


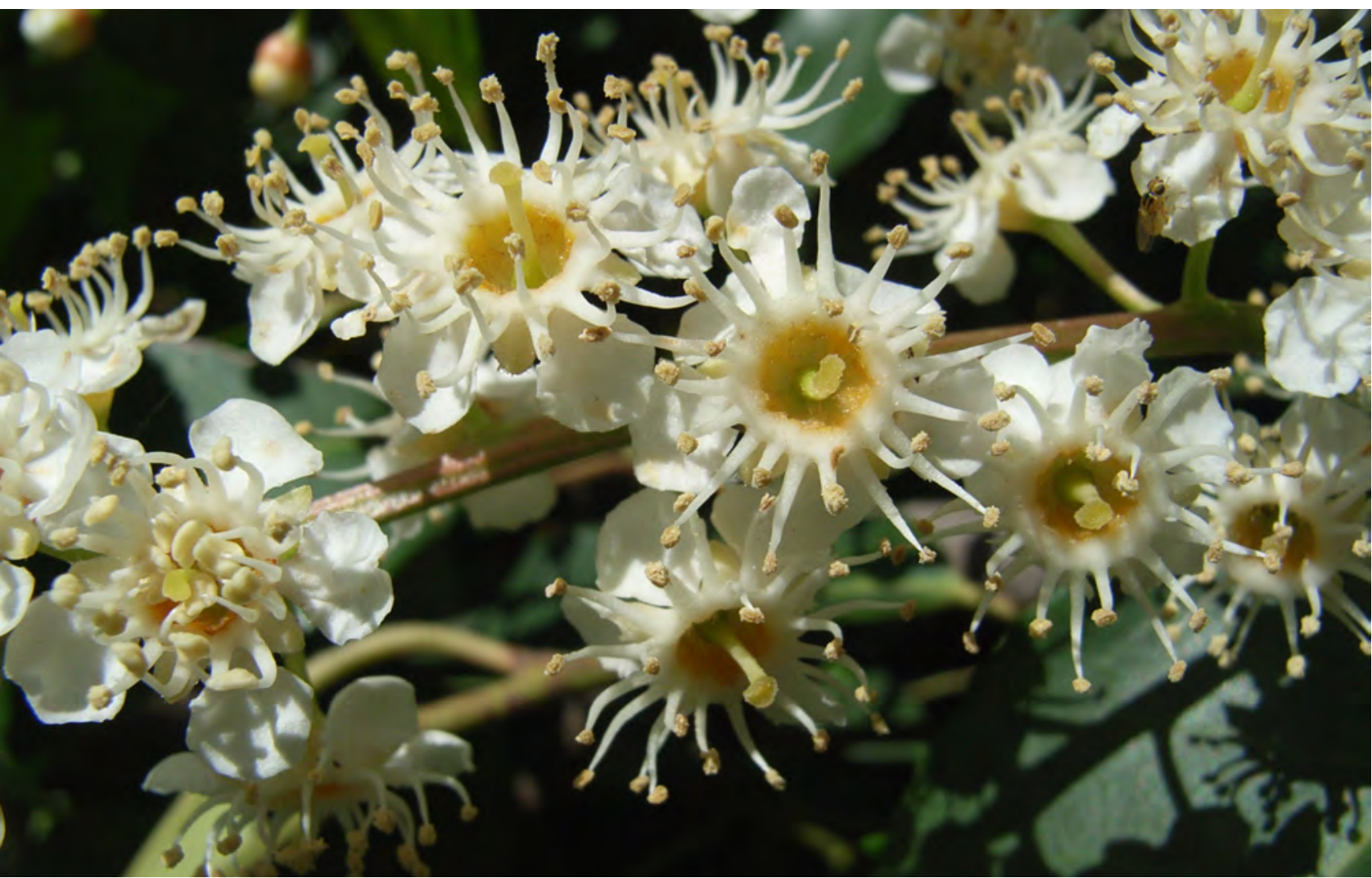

$\Delta$

\subsection{Community and participatory approaches}

Authors

Vernon Heywood

University of Reading

\section{Elsa Sattout}

UNESCO Regional Office for Sciences in the Arab States, Cairo, Egypt, and Cluster Office for Egypt, Sudan and Libya

The need to involve local communities in the management of their environment and resources is now part of mainstream conservation practice. There are numerous examples of such participatory approaches in the eastern Mediterranean and North African countries, which have complex systems of land ownership and traditional lifestyles that are closely linked to knowledge and use of the local plant resources. Communities in these countries can therefore play an important role in conserving plant diversity. As general rule, local people should be involved in conservation actions that directly or indirectly affect them, such as the planning and management of a protected area and species recovery planning. They may also actively participate, for example, by assisting in the management and monitoring of habitats and species.

An example of traditional community-based conservation is the hema system, which originated in the Arab and Islamic worlds where resources Prunus lusitanica, Zerkat, Morocco
(c) Helios Sainz

were meant to be equitably shared by local communities. Those practices lasted for 1,400 years in the northern Arabian Peninsula, ensuring that all members of society were included through consultation with a view to achieving sustainable resource use and the improvement of local livelihoods. It provided a way for communities to adapt to the carrying capacities of their lands to ensure the resilience of ecosystems (Kilani et al., 2007). The hema system was successfully revived in the late 1990s in Lebanon with the establishment of the hemas of Ebl es Saqi, Kfarzabad and Qleile. Traditional conservation practices under the revived system brought back the community-based management model for rangelands and agricultural lands in Lebanon (Sattout, 2014). In Syria, traditional forms of protection include range reserves (Mahmeya) which are still to be found in steppe areas although much less frequent than 50 years ago (Barkoudah, 1998). In the agro-pastoral system practised by the Ait Ikis community in the Moroccan High Atlas, the village assembly manages the rangelands so as to respect the carrying capacity of land and conserve plant species. Another example from Morocco is the agdal system, which over time has demonstrated the proactive conservation of certain plant species, such as Juniperus oxycedrus (Dominguez, 2014). It is worth noting that, as these cases reveal, complete success remains dependent on local governance. 


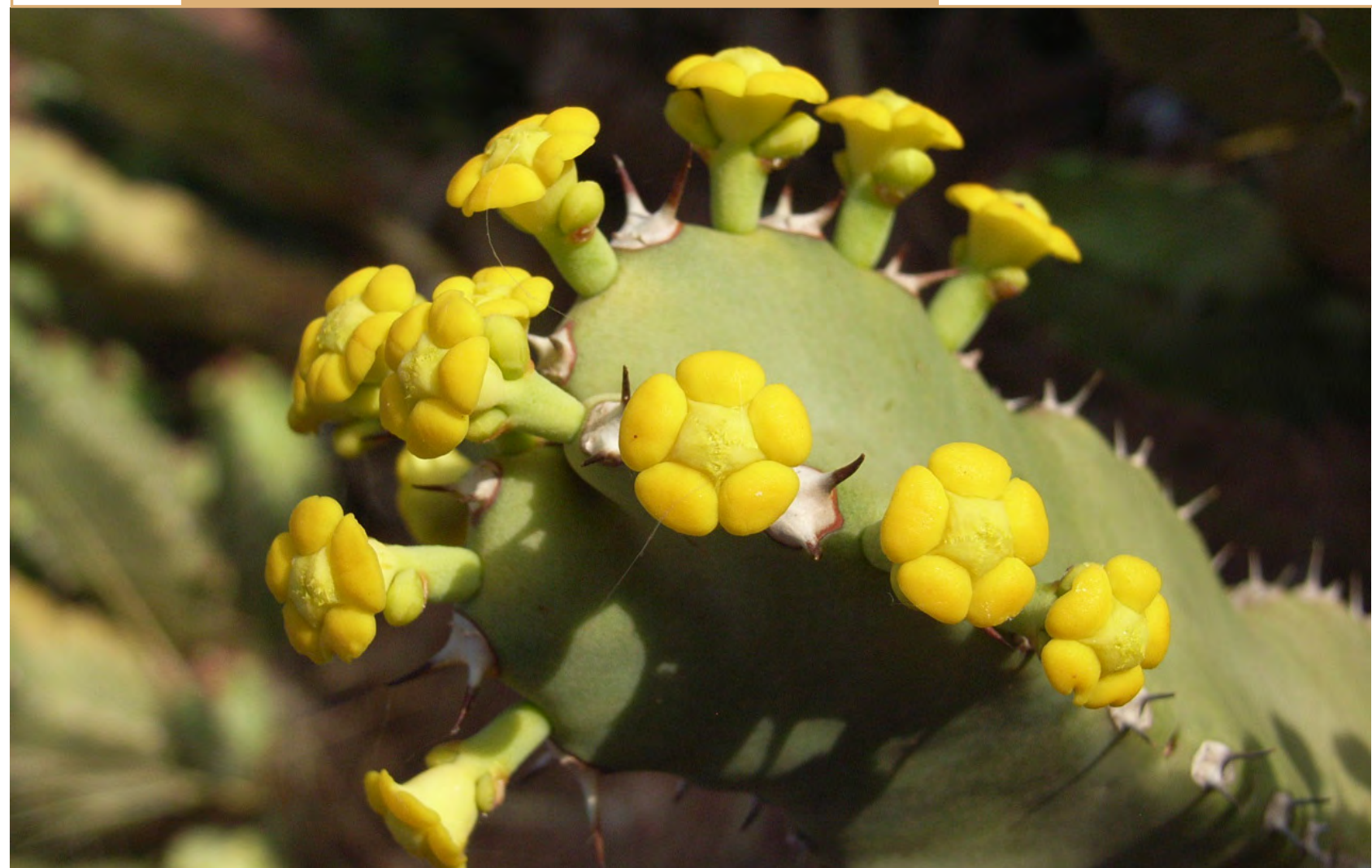

$\Delta$

Participatory mapping of Lebanon

\section{Authors}

Salma N. Talhouk, Lama Y. Tawk, Syrine Abi Kheir, Ramzi Malti, Moustapha Itani, and Wassim Kays

American University of Beirut.

The project facilitates the formation of local committees of volunteers, representing public and private sectors, which meet regularly over a period of four months and consult with knowledgeable members of the community.

The outcomes of the village committees' efforts include: community-generated information about the village natural landmarks. In 2011 the Nature Conservation Center at the American University of Beirut (AUB NCC) launched a participatory mapping project entitled 'Biodiversity Village Award' (Baldati Bi'ati). The project aims to explore the prospects for decentralised nature conservation efforts in Lebanon. The methodology consists of a combination of conventional and unconventional participatory approaches that seek to encourage communities to adopt a holistic consideration of their natural heritage (Tawk, 2014), a georeferenced database of these landmarks, a contextualisation of these landmarks through a narrated village map that reflects local interest and knowledge, a list of trees and wild edible plants of the village, and a short list of future conservation activities based on existing capacity and consensus. To date 100 village maps have been completed throughout Lebanon. The AUB NCC is
Euphorbia resinifera, Ouaouizarht, Morocco (c) Helios Sainz

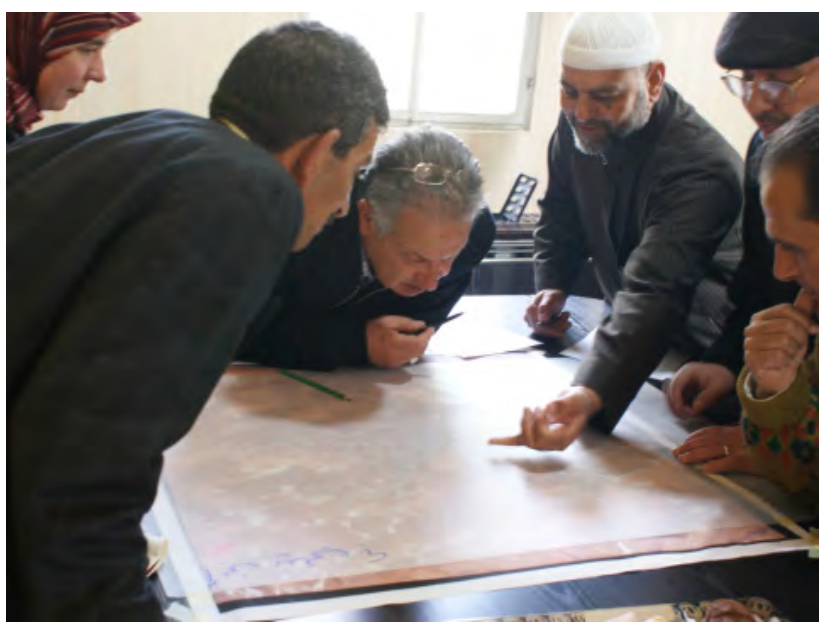

$\Delta$

Participatory Mapping of Lebanon (c) Salma Talhouk

a digital platform and phone application under the name Daskara.

The study demonstrates that scientists can play a pivotal role in development by providing an academic platform using resourceful methodologies to decentralise the process of conservation towards more community-based schemes that empower local residents to adopt meaningful conservation practices on their own initiative.

Further info https://www.daskaraapp.com/ 


\section{Studying ecosystems with the involvement of local communities: A conservation programme case study in Morocco}

\section{Authors}

\section{Ugo D'Ambrosio, Hassan Rankou, Emily Caruso, Gary Martin}

Global Diversity Foundation

Throughout most of 2016 and 2017, the Ethnobiology Programme team of the Global Diversity Foundation, in collaboration with the Moroccan Biodiversity and Livelihoods Association and the communes of Ait M'hamed and Imegdal (High Atlas, Morocco), carried out a detailed survey documenting cultural practices for conservation (CPCs) and ethnobotanical knowledge in these regions. By using a community-based and participatory approach and developing an operational definition of 'cultural practices of conservation' during the research, this project aimed to document how local people perceive these practices and indigenous knowledge to have changed in recent years and what they see as the drivers of this change.

Data were collected from inhabitants of the rural communes of Ait M'hamed and Imegdale mostly through structured interviews designed during workshops with local community researchers. Complementary data, essential to contextualise and flesh out the responses from structured interviews, were collected through participant observation and open-ended, unstructured and informal interviews conducted by the GDF-MBLA team during field visits. Over $20 \mathrm{CPCs}$ and over 1,000 ethnobotanical uses were described by informants during the research. Cultural practices of conservation were etically organised into seven broad, interconnected domains: fencing and soil management, agriculture, pastoralism, water management, cooperation, food, and ceremonies, which represent aspects of the more complex local agro-ecological system. Although documented as separate entities, these agro-ecological practices cannot be understood in isolation from each other; they all contribute to the High Atlas biodiversity patterns and to livelihoods.

One of the main conclusions that emerged in the early stages of the research is that the complex, long-standing systems of natural and cultural landscape management in the High Atlas by Amazigh communities at intercommunal, intracommunal and household levels must be understood as socio-environmentally resilient, economically viable and enriching approaches to land use, which should be reinvigorated with the active participation of local stakeholders. High Atlas biocultural systems and resources could thus be used at a regional scale as a model for developing local conservation and development programmes that target specific conditions, while enriching biodiversity and the practices associated with it. Ultimately, effective conservation can only be achieved with the long-term participation and understanding of communities.

\section{Link: https://www.global-diversity.org/ working-at-the-intersection-of-local- livelihoods-and-biodiversity-conservation-in-the- moroccan-high-atlas}

Another example of involving the local population in conservation and development actions is the collaboration agreement between IUCN-Med and the Tunisian Direction Générale des Forêts to improve protected area governance and more specifically to evaluate and test the co-management initiatives introduced in Zaghouan and El Feija National Parks in Tunisia. The project 'Participatory governance as an instrument for the management of natural resources in Tunisia' has two objectives: 1) To improve the protection and conservation status of Tunisian protected areas through the implementation of innovative models of participatory governance; and 2) To improve local livelihoods and diversify income opportunities for the communities living in the surroundings of protected areas

Link: https://www.iucn.org/regions/mediterranean/ projects/current-projects/participatory-governanceinstrument-management-natural-resources-tunisia 


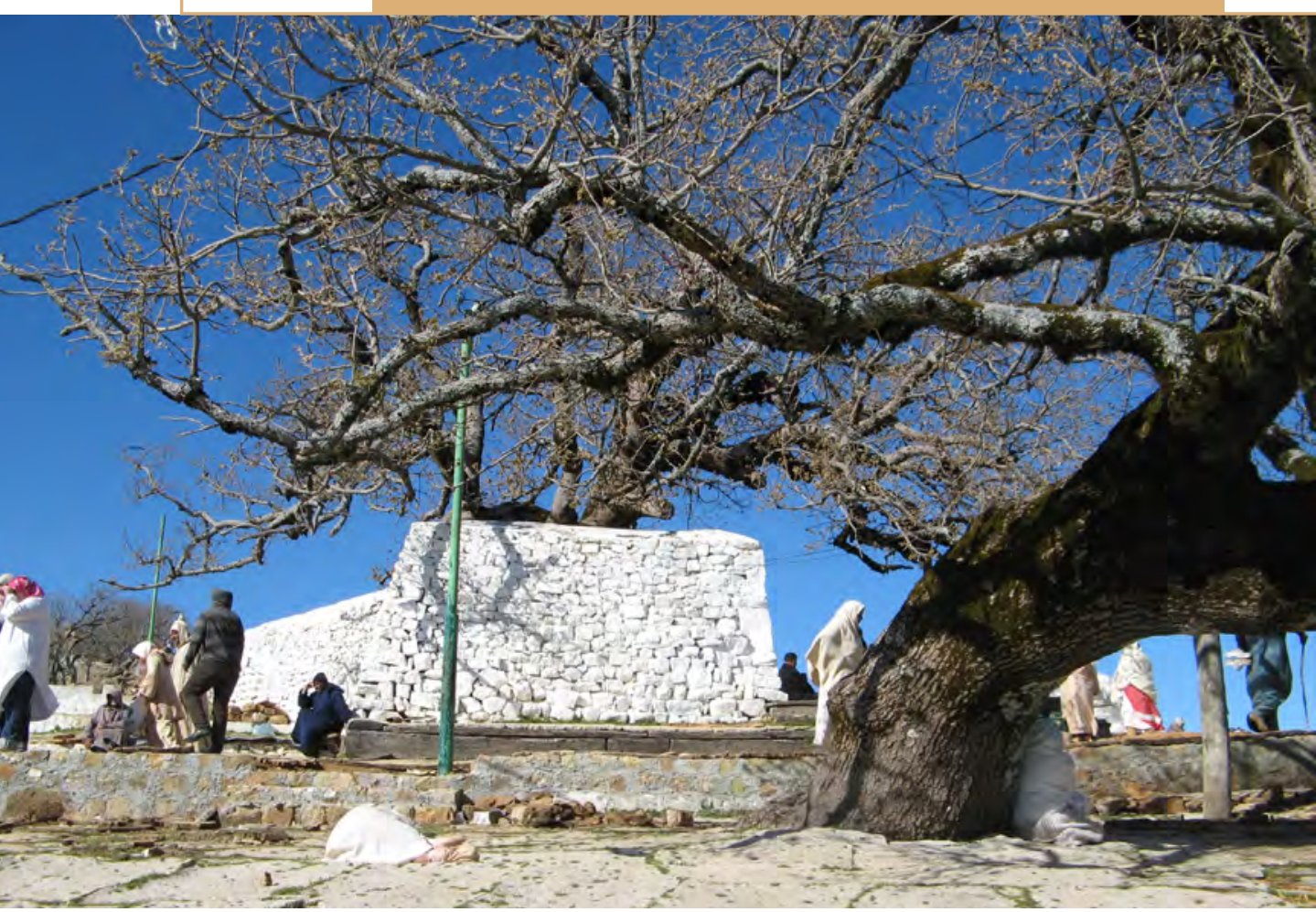

Sacred Pyrenean-oak trees (Quercus pyrenaica Willd.). Moulay Abdessalam sanctuary. Larache Province, Morocco.

(c) Lahcen Tahiqui

Traditional protected patches of Mediterranean forests

\section{Author}

\section{Lahcen Taiqui}

Université Abdelmalek Essaâdi, Tétouan, Morocco

Mazar (plural mazarat), ribat or khaloa (Arabic), amrabd (Amazigh) and site maraboutique (French) are generic names used to designate sacred sites in North Africa. The origins of mazarat seem to be related to pre-Islamic forms of nature conservation that were later recognised and developed in line with the approach adopted by Sufism (the mystical path in Islam). They embody the character and identity of North African landscapes. There are two kinds of mazarat: (a) important places associated with the sanctity of great individuals, often linked to centres of activity of Sufi brotherhoods (zaouia), and (b) old rural cemeteries and small sanctuaries of anonymous saints representing a community level of 'nature worship' closely linked to the agricultural calendar. The second category consists of sacred forest patches, sheltering relict elements of high cultural and ecological value. Such patches are common in all rural landscapes of the region and tend to be more densely concentrated near human settlements and along ancient trade routes and borders between tribal territories. In north-western Morocco, most traditional villages (douars) have one or several mazarat nearby, resulting in a density of 3 sites $/ 10 \mathrm{~km}^{2}$.

Mazarat are very useful for studies of bioclimatology and phytosociology in the region. Although they are often limited to small fragments, natural patches of mazarat play important roles in biodiversity conservation and the provision of many ecosystem services. They are the only remaining reservoirs and refugia of threatened biological diversity within seriously degraded landscapes. In addition to protecting biodiversity, rare species and genetic resources, some mazarat also function as stepping stones for mobile organisms or as home islands for metapopulations. Mazarat usually contain a mosaic of heterogeneous vegetation types in an area of less than 5 ha. Some types of endemic forest communities nowadays exist almost exclusively in mazarat, e.g. kermes oak and wild olive forests. Biodiversity studies have demonstrated that plant richness can be much higher there than in cultivated areas in agricultural landscapes. This richness includes a large proportion of vulnerable species sensitive to grazing. Trees, shrubs, herbs and vines can attain extraordinary growth and exceptional abundance in forested mazarat. Many plants that are shrubs in most Mediterranean forests, such as Arbutus unedo, Phillyrea latifolia and Chamaerops humilis, can reach the height and spread of trees in mazarat. Well-conserved sites often have closed, impenetrable vegetation due to plant density and a tangle of lianas from the ground to the canopy.

For centuries mazarat have been areas conserved by the local community through their religious beliefs without physical fences. Some outstanding landscapes have special religious protection, such as Jabal La'lâm in Morocco, in the core area of the Mediterranean Intercontinental Biosphere Reserve, which was declared a hurm (inviolable place) by royal decree of King al-Mansûr five centuries ago. Many other mazarat are included within National Parks (IUCN category V) but without recognition or special protection measures from the authorities. 


\subsection{Habitat restoration}

\section{Authors}

\section{Antoni Marzo}

Centre per a la Investigació i Experimentació Forestal (CIEF), Generalitat Valenciana, Spain

\section{Emilio Laguna}

Centre per a la Investigació i Experimentació

Forestal (CIEF), Generalitat Valenciana, Spain

\section{Magda Bou Dagher Kharrat}

Department of Life and Earth Science, Université

Saint-Joseph de Beyrouth, Lebanon

\section{Ramy Charbel Sakr}

Department of Life and Earth Science, Université

Saint-Joseph de Beyrouth, Lebanon

The conservation of KBAs for plants, IPAs and other relevant sites for wild plants includes habitat restoration action, a fast-developing discipline in terms of global knowledge and experience. In recent years there has been increasing convergence between the concepts of habitat restoration and ecological restoration, especially in the case of fragile habitats or where such restoration aims at conserving important species - especially those that are rare, endemic or threatened. According to the International Primer on Ecological Restoration (SER, 2004), "ecological restoration is the process of assisting the recovery of an ecosystem that has been degraded, damaged or destroyed". Based on the premise that IPAs should already have or should achieve the status of Protected Areas, ecological restoration work has to be developed carefully due to legal and technical limitations (Keenleyside et al., 2012). In addition, some of the species to be used may be threatened or rare plants that require very specific biotic and abiotic conditions (Kell \& al., 2008b).

The countries of the Mediterranean Basin have accumulated considerable experience of forest restoration, mainly through classical reforestation techniques. IUCN and the World Resources Institute (WRI) have produced the Restoration Opportunities Assessment Methodology (ROAM), which "provides a flexible and affordable framework for countries to rapidly identify and analyse areas that are primed for forest landscape restoration and to identify specific priority areas at a national or sub-national level" (IUCN \& WRI, 2014). In recent decades there have been numerous cases of non-forest habitat restoration. Although the pioneering work was done in more economically developed countries (examples in van Andel \& Aronson, 2012; Laguna et al., 2003; Silva et al., 2008, 2009), other countries have gradually been adopting ecological restoration techniques, and their use will undoubtedly become widespread in the near future. To facilitate this, technical platforms should be created for the exchange of scientific knowledge and technical experience - if possible, a Mediterranean alliance for ecological restoration should be set up.

Ecological restoration is now becoming common practice (examples in Heywood \& Dulloo, 2005; Silva et al., 2009; Heywood, 2014), and restoration techniques are complemented by a significant input of sound scientific knowledge (Nunes et al., 2016). In parallel, the foundations of ecological restoration in the Mediterranean region have been strengthened with experience, incorporating aspects ranging from the choice of species (Ferrer-Gallego, 2007) to the integration of human activities within the landscape (Vogiatzakis et al., 2006).

The in situ conservation of Mediterranean species and habitats, including their improvement through ecological restoration, is still subject to many uncertainties and numerous problems needs to be solved (Heywood, 2016). Of these, despite the growing volume of experimental results, the restoration of highly arid habitats probably remains the greatest technical challenge (see Bainbridge, 2007; Cortina et al., 2011), one that affects the countries in the south and east of the Mediterranean Basin most of all. Projects focusing on these countries have been carried out under international cooperation programmes, such as the Interreg SEMCLIMED and GENMEDOC projects, and the more recent ENPI CBC-MED ECOPLANTMED, co-financed by the European Commission, as well as CARE-MEDIFLORA, funded by the MAVA Foundation. The ECOPLANTMED project has published a guide on good practice in ecological restoration in the Mediterranean (Marzo et al., 2015), which includes examples of completed and ongoing work on two pilot sites in Tunisia and Lebanon; it also describes the Mediterranean Quarry Rehabilitation project sponsored by Holcim Lebanon, in Chekka, Lebanon, and the project for Integrated Management of the Mid-Atlas Forests in Morocco. 


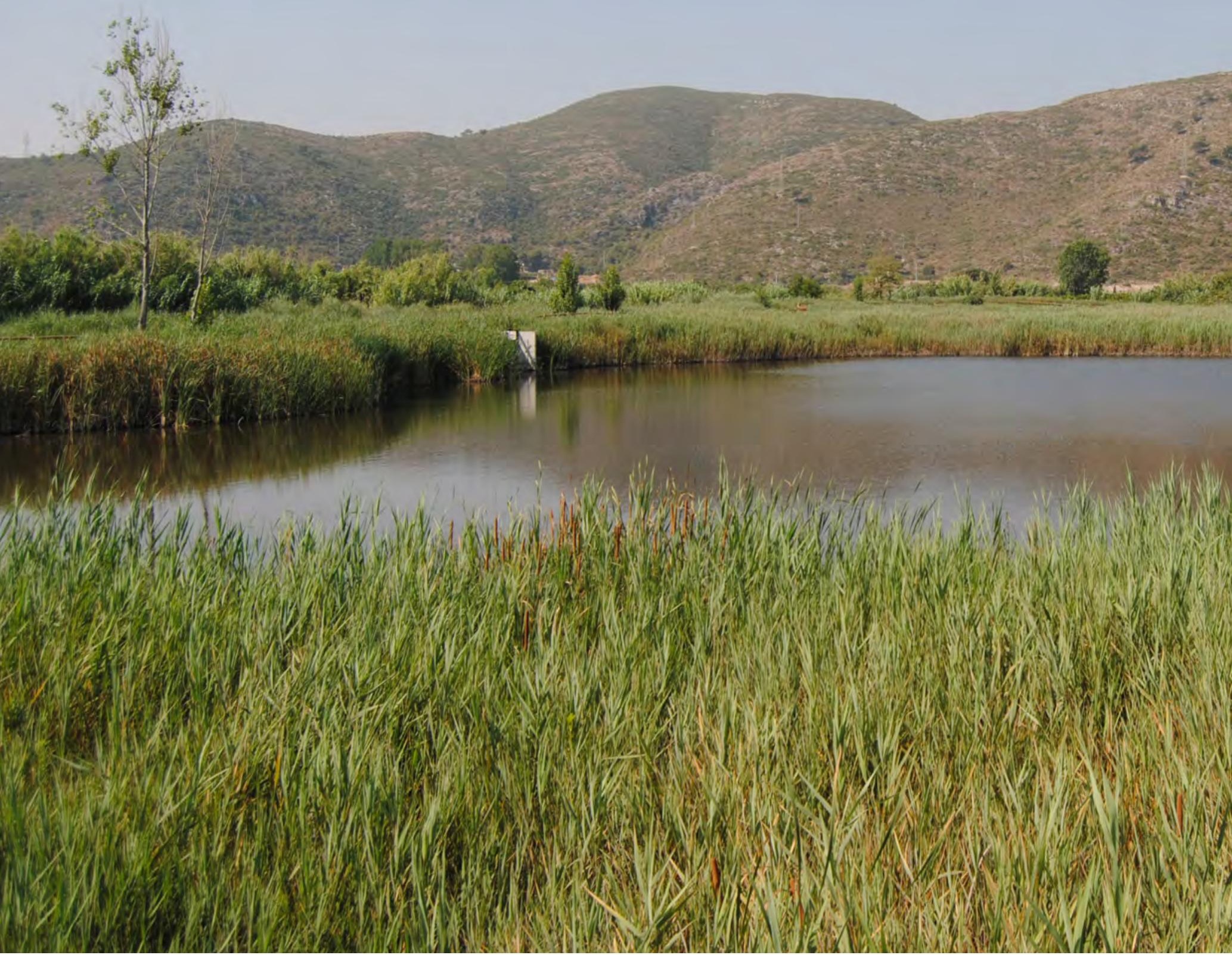

$\Delta$

Long-term restored wetlands in Marjal dels Borrons (Valencia, Spain), located on former sites of Eucalyptus spp. plantations.

(C) Emilio Laguna

Finally, it should be borne in mind that issues often forgotten in technical restoration work, such as public acceptance and social integration, or the conservation of crop wild relatives, together with new challenges arising from globalisation and climate change, including the increase in invasive species, for example, will have a much more serious impact in Mediterranean countries in the future (Heywood, 2011; Hunter \& Heywood, 2011; Hunter et al., 2012; Brunel et al., 2013). A new scenario will be created in which it is necessary to continually reevaluate the lessons learned from the past, and to embark upon a strategy of adaptive management of ecological restoration practices.

\section{Recommended reading}

Marzo, A., Herreros, R. and Zreik C. (eds) (2015). Guide of Good Restoration Practices for Mediterranean Habitats. ECOPLANTMED, ENPI, CBC-MED.

IUCN and WRI (2014). 'A guide to the Restoration Opportunities Assessment Methodology (ROAM): Assessing forest landscape restoration opportunities at the national or sub-national level'. Working Paper (Road-test edition). Gland, Switzerland: IUCN. $125 \mathrm{pp}$. 


\subsection{Conclusions and recommendations}

Although considerable advances have been made in some areas and in some of the countries concerned and some innovative approaches have been introduced, the conservation of the rich plant diversity in the east and south Mediterranean remains a major challenge. The detailed work on IPAs and KBAs and in Red Listing has provided an important basis for setting conservarion priorities and now the need is to move on to implementing effective conservation, both area-based and species-based, on the ground. There are still serious gaps in the coverage and ecological representativeness of protected areas and the level of protection and management is not always adequate. Too little focus has been given in protected areas management plans to actions directed at the conservation of threatened and endemic species that occur in these areas. In addition, the conservation needs of the large number of threatened species that occur outside protected areas should be addressed as a matter of urgency.

Only a small percentage of threatened species have been the subject of recovery actions and it is recommended that a strategic plan should be drawn up to address this key issue for both the south and the east Mediterranean areas. In addition, each country should identify the target species in need of conservation action and prepare a strategy and action plan for this purpose. Likewise, only a small number of reintroductions have been carried out or are planned and there are few examples of ecological restoration.

Progress has been made in ex situ conservation but is hindered by the lack of facilities such as gene banks, botanic gardens and nurseries.

It is still uncertain what impact the loss of the ICARDA gene bank at Tel Hadya, Syria will have on the conservation of wild species of agricultural importance. The recently EU-funded project 'Farmer's Pride' (http://farmerspride.eu/) intends to establish a network of in situ conserved crop wild relative populations across the region, if successful it will be the first network of its kind globally and a significant step forward in plant genetic conservation in the south and east Mediterranean. It will help secure this critical resource for crop improvement, nutrition and economic security. However, given the recent partial, and as yet unquantified, loss of the ICARDA ex situ collection of crop wild relative diversity in Syria, it will be important this in situ resource is backed-up in the now decentralised ICARDA gene bank.

There is an urgent need for the training of more specialists in conservation biology and conservation practice.

Much more cooperation between institutions in the European Mediterranean and those in the south and east would help address these problems. Those cooperative projects that have been carried show how successful such actions can be. 


\section{Way forward}

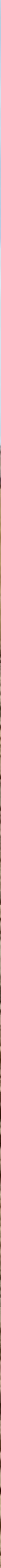




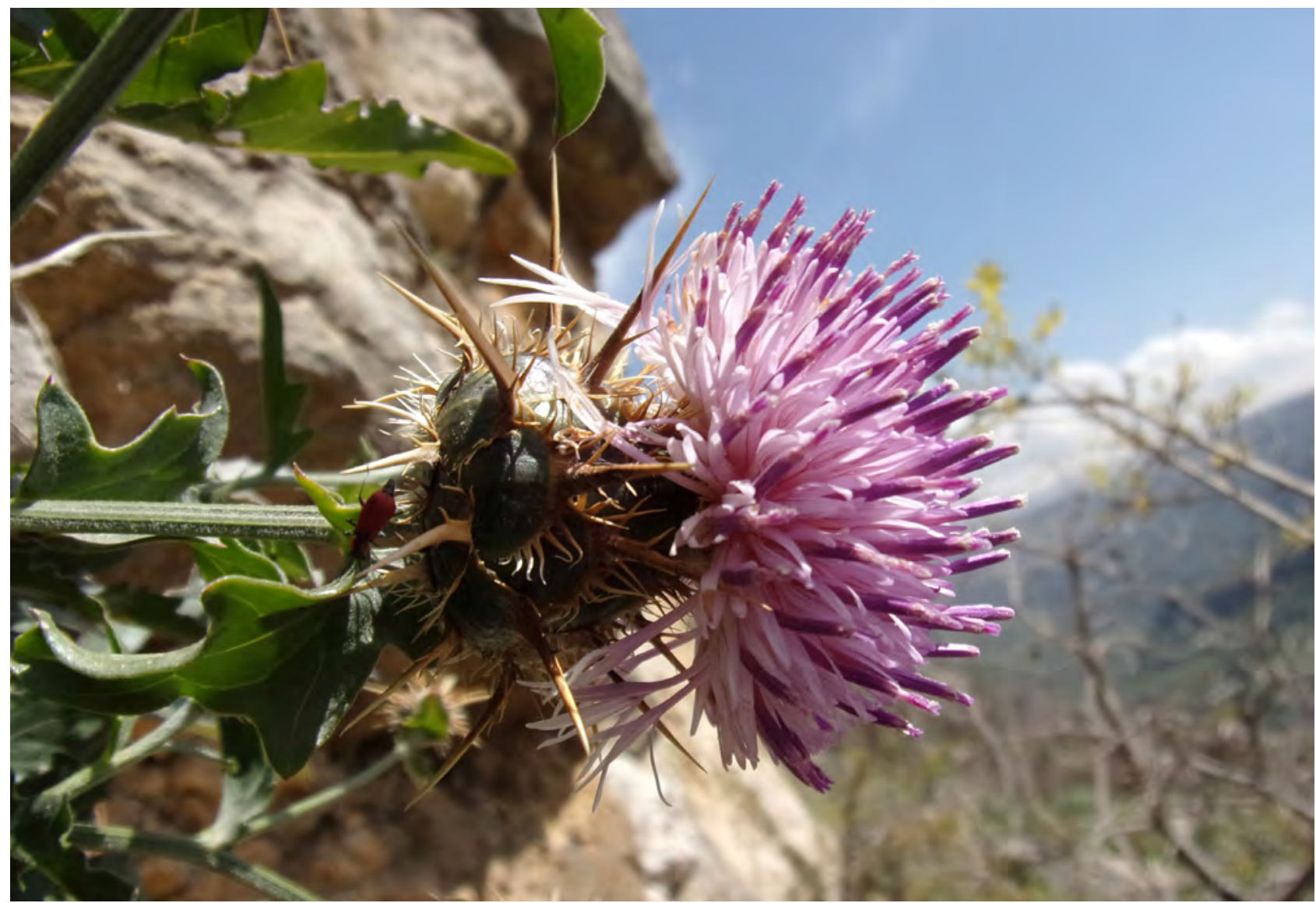

\section{$\Delta$}

Centaurea mouterdei is endemic to rocky cliffs in steep valleys of Mount Lebanon, especially in Damour Valley. It often grows in localities difficult to access.

(c) Hicham Elzein

\section{Recommendations}

The continual decline of plant diversity in the south and east Mediterranean is not only a regional but a worldwide phenomenon. Regional and national conservation programmes and strategies increasingly recognized the need to include specific, actions plans and programmes addressing the specific plant conservation to halt biodiversity loss.

Considerable advances have been made in plant conservation during the last 20 -years but it is abundantly clear that the 2020 targets set by the CBD will not be met. We are conscious of the fact that the impact of conservation actions in slowing the rate of decline of plant diversity is still moderate and that we need to redouble our efforts to avoid further serious losses. In particular, the situation in the east and south Mediterranean is troubling due to a lack of resources such as environment agencies, gene banks, botanic gardens and a shortage of appropriately trained specialists. Although much planning and preparatory work has been done, action on the ground is still too limited to be effective in slowing the rate of loss of threatened species and habitats.

\section{We need to move on urgently from a phase of planning to one of implementation.}

It is evident that we live in growingly connected society and this is also affecting the plant conservation community. This is leading to increasingly connected networks of botanists and practitioners, jointly implementing conservation programmes, and producing very fruitful exchanges between scientist and site managers. For example the Mediterranean Plant Conservation Week gathers scientist, practitioners, site managers and community members. It is essential that this networking leads to much greater cooperation between institutions and practitioners in the European and in the south and east parts of the Mediterranean region.

The combination of threats contributing to plant diversity decline is often complex, as we can see analysing the information contained in the Red List of Threatened Species and in detailed threat analyses undertaken as part of species recovery programmes. The answer for a multi-faced pressure may address the conservation of plants from a multiple set of angles including: 


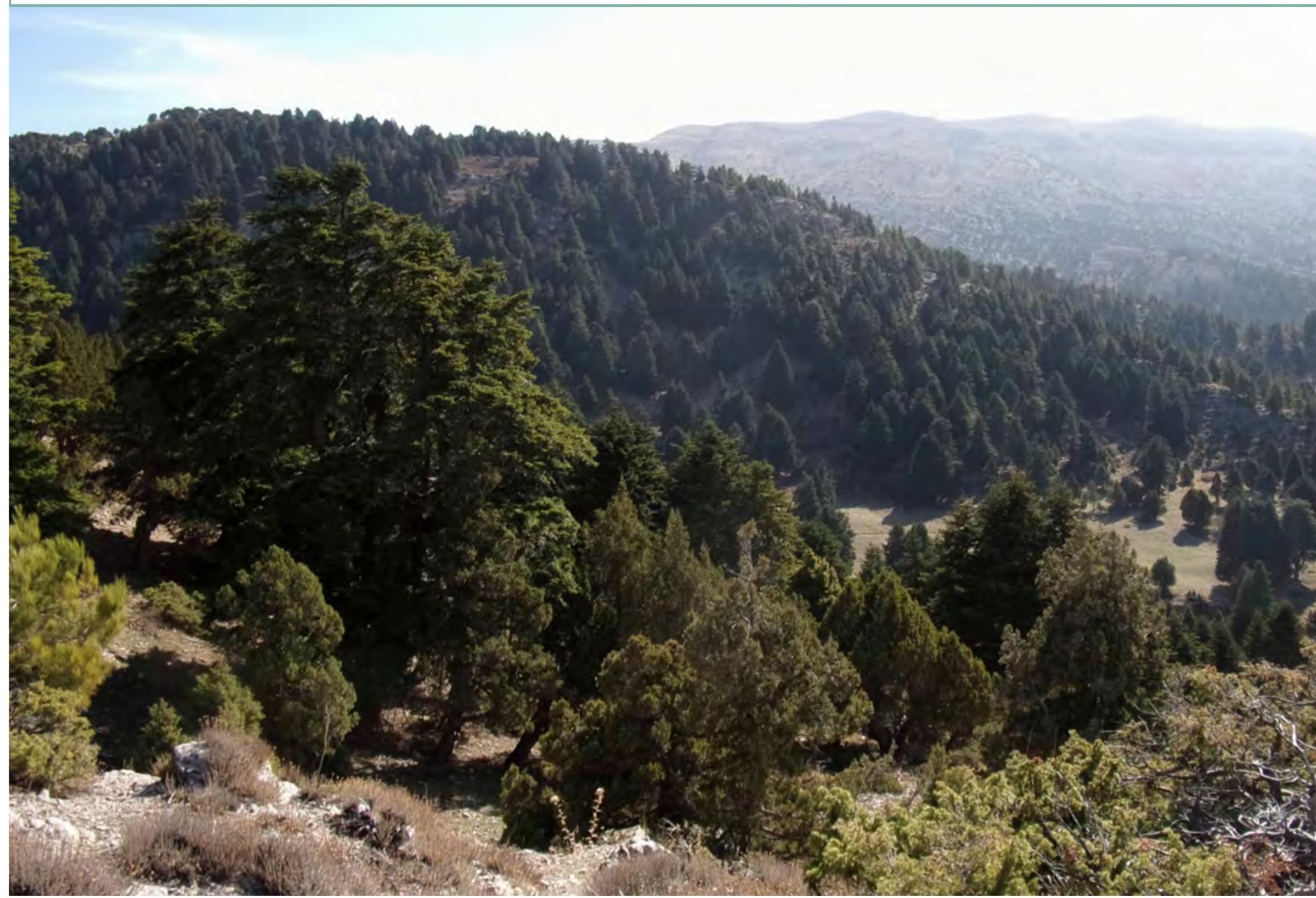

\section{A. At the policy level:}

a. Strengthen efforts to mainstream biodiversity at all levels in national planning including national commitments towards the achievement of international biodiversity-related conventions and agreements including CBD, CITES and the ITPGRFA.

b. Complete and update Red lists of Threatened Species which provide a useful source of information on the extinction risk of species, threats and trends that can be used to support definition of national and regional strategies.

c. Reinforce the national Protected Area Systems, ensure their effective management and include the conservation of threatened plant diversity in their management plans and undertake gap analyses to ensure that they provide a better coverage of the different ecosystems in the region and the increased inclusion of threatened plant species.

d. Reinforce the application of KBAs standards, understanding the information provided by Key Biodiversity Areas as useful mean to identify priority sites for conservation at national regional and global level. e. Cooperate with FAO and other agencies in the conservation of important centres of crop plant origin and diversification and recognize the importance of conserving the large number of Crop Wild Relatives that grow in the region.

f. Recognize the importance of other area-based conservation measures (OEABCMs) and community/participatory conservation.

g. Update national Biodversity Strategies and Action Plans, develop National Strategies for threatened species recovery, conservation of crop wild relatives and other economically important species and control and management of Invasive Alien Species. 


\section{Annex 1: References}

Academy of Scientific Research and Technology - Egyptian Environmental Affairs Agency (ASRTEEAA) (2016). Conservation and Sustainable Use of Medicinal Plants in Egypt: National Surveys. Vols 1-5. Cairo, Egypt: Printshop of Al-Ahram on behalf of ASRT and EEAA.

Acunto, S., Bacchetta, G., Bordigoni, A., Cadoni, N., Cinti, M.F., Navarro, M.D., Frau, F., Lentini, L., Liggi, M.G., Masala, V., Meloni, F., Pinna, R., Podda, L. and Sanna, A. (2017). 'The LIFE+ project "RES MARIS-Recovering Endangered habitatS in the Capo Carbonara MARIne area, Sardinia": first results'. Plant Sociology 54:85-95. https://doi. org/10.7338/pls2017541S1/11

Akeroyd, J. (1998). 'Micro-reserves "capture" Valencia's rare plants'. Plant Talk 14:20-23

Ahmed, D.A.A. (2009). 'Current Situation of the Flora and Vegetation of the Western Mediterranean Desert of Egypt'. PhD thesis. Tanta, Egypt: Faculty of Science, Tanta University.

Alcaraz, C. and Santa, S. (1968). Flore des sahels, des basses plaines, des plateaux et des sebkhas de l'Oranie septentrionale.

Al-Atwaneh, N., Amri, A. and Maxted, N. (2013). 'Wadi Sair genetic reserve management plan in Palestine'. In: N. Amri and A. Damania (eds) Proceedings of the International Conference on Promoting Community-driven In Situ Conservation of Dryland Agrobiodiversity. ICARDA, Aleppo, Syria, 18-21 April 2005, pp.329-340. Beirut, Lebanon: International Center for Agricultural Research in the Dry Areas (ICARDA).

Al-Atawneh, N., Amri, A., Assi, R. and Maxted, N. (2008). 'Management plans for promoting in situ conservation of local agrobiodiversity in the West Asia centre of plant diversity'. In: N. Maxted, S.P. Kell, B.V. Ford-Lloyd, E. Dulloo and J. Iriondo (eds) Crop Wild Relative Conservation and Use, pp.340363. Wallingford, UK: CAB International.
Al-Holani, A. (2000). 'The biodiversity of Iris genre in Syria'. MSc dissertation. Damascus: University of Damascus, Faculty of Agriculture (in Arabic).

Al-Oudat, M. and Qadir, M. (2011). The halophytic flora of Syria. Aleppo, Syria: International Center for Agricultural Research in the Dry Areas.

Al-Rfou', A. (2015). Dana Biosphere Reserve. Al Jubeiha, Jordan: The Royal Society for the Conservation of Nature.

Al-Sheikh, B., Salman, J. Masalha, J., Salem, K., Ron, M. and Shmida, A. (2000). Preliminary Checklist and Ecological Data-Base of Plants of the West Bank. Abu Deis, Palestine: Al-Quds University.

Ali, S.I., Jafri, S.M.H. and El Gadi, A. (eds) (19761989). Flora of Libya. Tripoli, Libya: Al Faateh University.

Ammar, E.E. (2015). Current situation of Agrobiodiversity in Nile Delta. MSc dissertation. Tanta, Egypt: Faculty of Science, Tanta University.

Amigues, S. (2010). Théophraste : Recherches sur les plantes: A l'origine de la botanique. Paris, France: Belin.

Amri, A. and Damania, A. (2013). Proceedings of the International Conference on Promoting Communitydriven Conservation and Sustainable Use of Dryland Agrobiodiversity. ICARDA, Aleppo, Syria, 18-21 April 2005. Beirut, Lebanon: International Center for Agricultural Research in the Dry Areas (ICARDA).

Assi, R. (2007). 'MP Threat Analysis and Threat Reduction Assessment Report'. Conservation and sustainable use of medicinal plants in arid and semi-arid ecosystems project, 61pp.

Bacchetta, G., Bueno Sánchez, A., Fenu, G., Jiménez-Alfaro, B., Mattana, E., Piotto, B. and Virevaire, M. (eds) (2008). Conservación ex situ de plantas silvestres. Gijón, Spain: Jardín Botánico Atlántico, Principado de Asturias / La Caixa. 
Bacchetta, G., Fenu, G., Mattana, E., Piotto, B. and Virevaire, M. (eds) (2006). Manuale per la raccolta, studio, conservazione e gestione ex situ del germoplasma. Rome, Itay: Agenzia per la Protezione dell'Ambiente e per i servizi Tecnici (APAT), 244pp.

Bainbridge, D.A. (2007). Guide for Desert and Dryland Restoration. New hope for arid lands. Washington, DC, USA: Island Press.

Ballesteros, D., Meloni, F. and Bacchetta, G. (eds) (2015). Manual for the propagation of selected Mediterranean native plant species. Ecoplantmed, ENPI, CBC-MED.

Barkoudah, Y. (1998). 'Country profile: Syrian Arab Republic (Syria)'. In: V.H. Heywood and M. Skoula (eds) Wild food and non-food plants: information networking. Proceedings of the second Medusa regional workshop on 'Wild food and non-food plants: information networking' held on 1-3 May 1997 at Port el Kantaoui, Tunisia (Cahiers Options Méditerranéennes, Vol.38), pp.275-294. Paris, France: CIHEAM.

Battandier, J. and Trabut, L. (1905). Flore analytique et synoptique de l'Algérie et de la Tunisie. Alger, Algeria : Vve. Girault.

Blondel, J., Aronson, J., Bodiou, J.-Y. and Boeuf, G. (2010). The Mediterranean Region. Biological Diversity in Space and Time. 2nd Edition. Oxford, UK: Oxford University Press.

Boissier, E. (1867-1888). Flora Orientalis. Vols 1-5 and Supplement. Geneva, Switzerland.

Bou Dagher-Kharrat, M., El Zein, H. and Rouhan, G. (2018). 'Setting conservation priorities for Lebanese flora - Identification of important plant areas'. Journal for Nature Conservation 43:85-94. https:// doi.org/10.1016/j.jnc.2017.11.004

Bou Dagher-Kharrat, M., El Zein, H., Waked, H., Jardak, R. and Kahale, R. (2016). 'Setting conservation priorities is a priority: case of Lebanese flora', paper delivered at the 1st Mediterranean Plant Conservation Week on 'Building a regional network to conserve plants and cultural diversity', Ulcinj, Montenegro, 24-29 October 2016.
Boulos, L. (2009). Flora of Egypt Checklist. Revised Annotated Edition. Cairo, Egypt: Al-Hadara Publishing.

Boulos, L. (1999-2005). Flora of Egypt. 4 Volumes. Cairo, Egypt: Al-Hadara Publishing.

Breasted, J.H. (1916). Ancient times, a history of the early world: An introduction to the study of ancient history and the career of early man. Boston, USA: Ginn and Co.

Brullo, S. and Furnari, F. (1990). 'La vegetazione costiera della Cirenaica'. Boll. Acc. Gioenia Sci. Nat. 21(334):37-117

Brunel, S., Brundu, G. and Fried, G. (2013). 'Eradication and control of invasive alien plants in the Mediterranean Basin: towards better coordination to enhance existing initiatives'. EPPO Bulletin 43:290-308. https://doi.org/10.1111/ epp.12041

Castañeda-Álvarez, N.P., Khoury, C.K., Achicanoy, H.A., Bernau, V. Dempewolf, H., Eastwood, R.J., Guarino, L., Harker, R.H., Jarvis, A., Maxted, N., Müller, J.V., Ramirez-Villegas, J., Sosa, C.C., Struik, P.C., Vincent, H. and Toll, J. (2016). 'Global conservation priorities for crop wild relatives'. Nature Plants 2, article 16022. https://doi. org/10.1038/nplants.2016.22

Castañeda Álvarez, N.P., Vincent, H.A., Kell, S.P., Eastwood, R.J. and Maxted, N. (2011). 'Ecogeographic surveys'. In: L. Guarino, V. Ramanatha Rao and E. Goldberg (eds), Collecting Plant Genetic Diversity: Technical Guidelines, 2011 update. Rome, Italy: Bioversity International.

Celesti-Grapow, L., Abbate, G., Baccetti, N., Capizzi, D., Carli, E., Copiz, R., Frondoni, F., Giunti, M., Gotti, C., Iberite, M., Monaco, A., Petrassi, F., Raganella Pelliccioni, E., Romano, A., Sozio, G., Sposimo, P., Tilia, A. and Blasi, C. (2017). 'Control of invasive species for the conservation of biodiversity in Mediterranean islands. The LIFE PonDerat project in the Pontine Archipelago, Italy'. Plant Biosystems 151:795-799. https://doi.org/10.1080/11263504.20 17.1353553 
Chaieb, M. and Boukhris, M. (1998). Flore succincte et illustrée des zones arides et sahariennes de Tunisie. Tunis, Tunisia : L’Or du Temps.

Chape, S., Spalding, M. and Jenkins, M. (eds) (2008). The World's Protected Areas: Status, values, and prospects in the twenty-first century. Berkeley, USA: University of California Press and UNEP World Conservation Monitoring Centre.

Charco, J. (2001). Guía de los árboles y arbustos del Norte de África. Madrid, España: Cultura Hispánica.

Chikhali, M. (2001). 'Endemism in natural vegetation: lack of interest in the Arabic-speaking world' [in Arabic]. Science \& Technology Magazine (Kuwait) 90:38-41.

Chikhali, M. (2000). 'Ecology and Vegetation of south-east Syria (Jabal El-Arab)', PhD thesis, Stuttgart, Germany: University of Hohenheim.

Chikhali, M. (1994). ('Tulipa species in Syria and using plant tissue culture to propagate Tulipa montana Lindly' [in Arabic]). MSc dissertation. Damascus, Syria: Faculty of Science, Damascus University. 121pp.

Collenot, A., Dubuis, A. and Faurel, L. (1960). 'Note sur la flore du Tassili N'Ajjer'. Bull. Soc. Hist. Nat. Afrique N. 51:233-254.

Cortina, J., Amat, B., Castillo, V., Fuentes, D., Maestre, F.T., Padilla, F.M. and Rojo, L. (2011). 'The restoration of vegetation cover in the semi-arid Iberian southeast'. Journal of Arid Environments 75:1377-1384. https://doi.org/10.1016/j. jaridenv.2011.08.003

Council for Development and Reconstruction (CDR) (2005). National physical master plan of the Lebanese territory. Lebanon: Council for Development and Reconstruction.

Critical Ecosystem Partnership Fund (CEPF) (2017). Ecosystem Profile: Mediterranean Basin Biodiversity Hotspot. Critical Ecosystem Partnership Fund .

Cuénod, A., Pottier-Alapetite, G. and Labbe, A. (1954). Flore analytique et synoptique de la Tunisie : Cryptogames Vasculaires, Gymnospermes et Monocotylédones. Tunis, Tunisia: Office de l'expérimentation et de la vulgarisation agricoles de Tunisie.

Dalrymple, S.A., Banks, E., Stewart, G.B. and Pullin, A.S. (2012). 'A meta-analysis of threatened plant reintroductions from across the globe'. In: J. Maschinski and E.H. Haskins (eds) Plant Reintroduction in a Changing Climate: Promises and Perils, pp.31-50. Washington, D.C., USA: Island Press. https://doi.org/10.5822/978-1-61091-1832_3

Daoud-Bouattour, A., Muller, S.D., Ferchichi-Ben Jamaa, H., Ghrabi-Gammar, Z., Rhazi, L., Gammar, A.M., Karray. M.R., Soulié-Märsche, I., Zouaïdia, H., de Bélair, G., Grillas, P. and Limam-Ben Saad, S. (2009). 'Recent discovery of the small pillwort (Pilularia minuta Durieu, Marsileaceae) in Tunisia: hope for an endangered emblematic species of Mediterranean temporary pools?' Comptes Rendus Biologies 332:886-897. https://doi.org/10.1016/j. crvi.2009.07.004

Daoud-Bouattour, A., Ghrabi-Gammar, Z. and Limam-Ben Saad, S. (2007). Guide illustré des plantes du Parc National de l'Ichkeul. Ariana, Tunisie : Bureau d'Etudes Eco-Ressources International (ERI), 167pp.

Davis, P.H. (ed.) (1965-1988). Flora of Turkey and the East Aegean Islands. 10 Volumes. Edinburgh: Edinburgh University Press.

Davis, S.D., Heywood, V.H. and Hamilton, A.C. (eds) (1994). Europe, Africa, south West Asia and the Middle East. Volume 1, Centres of plant diversity. A guide and strategy for their conservation. Cambridge UK: WWF and IUCN.

Debeaux, M.O. (1894). Flore de la Kabylie du Djurdjura. Paris : Paul Klincksieck, Librairie des Sciences Naturelles. 468pp.

Dempewolf, H., Eastwood, R.J., Guarino, L., Khoury, C.K., Müller, J.V. and Toll, J. (2013). 'Adapting Agriculture to Climate Change: A Global Initiative to Collect, Conserve, and Use Crop Wild Relatives'. Agroecology and Sustainable Food Systems 38:369-377. https://doi.org/10.1080/21683565.201 3.870629 
Direction de la Lutte Contre la Désertification et la Protection de la Nature (DLDPN) (n.d.) Rapport d'Evaluation Décennale de la Réserve de Biosphère Arganeraie. Rabat, Marocco: Haut Commissariat aux Eaux et Forêts et à la Lutte Contre la Désertification.

Dobignard, A. and Chatelain, C. (2010-2013). Index synonymique de la flore d'Afrique du Nord. 5 tomes. Geneva, Switzerland: Éditions des Conservatoire et Jardin Botaniques.

Domínguez, P. (2014). 'Current situation and future patrimonializing perspectives for the governance of agro-pastoral resources in the Ait Ikis transhumants of the High Atlas'. In: P. Herrera, J. Davies and P. Manzano Baena (eds), The Governance of Rangelands: Collective Action for Sustainable Pastoralism, pp.126-144. Abingdon, UK: Routledge.

Dominione, V., Rossi, G., Foggi, B. and Parolo, G. (2005). 'Verso un archivio Nazionale degli interventi di reintroduzione delle piante minacciate della flora spontanea italiana: prima realizzazione di un sito web'. Inform. Bot. Ital. 27:130-131.

Dulloo, M.E., Labokas, J., Iriondo, J.M., Maxted, N., Lane, A., Laguna, E., Jarvis, A. and Kell, S.P. (2008). 'Genetic reserve location and design'. In: J.M. Iriondo, N. Maxted and M.E. Dulloo (eds) Conserving Plant Genetic Diversity in Protected Areas. Population management of Crop Wild Relatives, pp.23-64. Wallingford, UK: CABI. https:// doi.org/10.1079/9781845932824.0023

Durand, E. and Barratte, G. (1910). Flora Libycae prodromus ou Catalogue raisonné des plantes de Tripolitaine. Geneva, Switzerland.

ECOPLANTMED (2015). Results of Project Germination Experiments. ENPI CBC MEDProgramme.

Eken, G., Bennun, L., Brooks, T.M., Darwall, W., Fishpool, L.D.C., Foster, M., Knox, D., Langhammer, P., Matiku, P., Radford, E., Salaman, P., Sechrest, W., Smith, M.L., Spector, S. and Tordoff, A. (2004). 'Key biodiversity areas as site conservation targets'. BioScience 54:1110-1118. https://doi. org/10.1641/0006-3568(2004)054[1110:KBAASC]2. 0.CO;2
El-Hadidi, M.N. and Hosni, H. (2002). Flora Aegyptiaca: Volume 1. Cairo, Egypt: The Palm Press.

El-Hadidi, M.N. and Hosni, H. (2000). 'Conservation and Threats'. In: El Hadidi, M.N. (ed.), Flora Aegyptiaca, Volume 1(1), pp.105-150. Cairo, Egypt: The Palm Press.

El-Hajj, R., Khater, C., Véla, E., Khalife, A. and Tatoi, T. (2016). 'Pertinence of protected areas networks in biodiversity conservation strategies: insights from an eastern Mediterranean context. Pertinence des réseaux d'aires protégées dans les stratégies de conservation de la biodiversité: perspective méditerranéenne orientale'. Ecologia Mediterranea 42:5-19.

El-Saadawi, W. and Shabbara, H. (2007). 'Hepatics of Egypt: An annotated checklist'. Taeckholmia 27:133-147.

El-Saadawi, W., Shabbara, H., Refai, M.S. and Abou-Salama, U.Y. (2003). 'Mosses of different phytogeographical territories of Egypt'. Bocconea 16(1):133-146.

Erdag, A. and Kürschner, H. (2017). Türkiye Bitkileri Listesi (List of Turkey's plants). Istanbul, Turkey: ANG Vakfı.

Fayed, A. and Shaltout, K. (2004). Conservation and sustainable use of Medicinal plants in arid and semi-arid eco-systems project, Egypt (GEF, UNDP) (project no: 12347/12348), Flora of Saint Katherine protectorate, final report. And Floristic Survey of the Mountainous Southern Sinai: Saint Katherine Protectorate, final report. Cairo, Egypt.

Fennane, M. (2017c). Eléments pour un Livre rouge de la flore vasculaire du Maroc. Fasc. 4. Basellaceae-Buxaceae (version 1, octobre 2017). Edit. Tela-Botanica. Licence CC-BY NC ND.

Fennane, M. (2017b). Eléments pour un Livre rouge de la flore vasculaire du Maroc. Fasc. 3. Asteraceae (version 1, avril 2017). Edit. Tela-Botanica. Licence CC-BY NC ND. 
Fennane, M. (2017a). Eléments pour un Livre rouge de la flore vasculaire du Maroc. Fasc. 2. Gymnospermae, Dicotyledonae (AcanthaceaeAristolochiaceae) (version 1, janvier 2017). Edit. Tela-Botanica. Licence CC-BY NC ND.

Fennane, M. (2016). Eléments pour un Livre rouge de la flore vasculaire du Maroc. Fasc. 1. Pteridophyta (version 1, nov. 2016). Edit. TelaBotanica. Licence CC-BY NC ND.

Fennane, M. (2004). Propositions de Zones Importantes pour les Plantes au Maroc (ZIP Maroc). https://cmsdata.iucn.org/downloads/ipas_proposal_ morocco.pdf.

Fennane, M. and Ibn Tattou, M. (2012). 'Statistiques et commentaires sur l'inventaire actuel de la flore vasculaire du Maroc'. Bulletin de l'Institut Scientifique, Rabat, section Sciences de la Vie 34:1-9.

Fennane, M. and Ibn Tattou, M. (2005-2008). Flore vasculaire du Maroc, inventaire et chorologie, Tomes 1 et 2. Rabat, Marocco: Institut Scientifique.

Fennane, M. and Ibn Tattou, M. (1998). 'Catalogues des plantes vasculaires rares, menacées ou endémiques du Maroc'. Bocconea 8:5-343.

Fennane, M., Ibn Tattou, M., Mathez, J., Ouyahya, A. and El Oualidi, J. (1999). 'Flore Pratique du Maroc, volume 1'. Trav. Inst. Sci. 36, 560 pp.

Fennane, M., Ibn Tattou, M., Ouyahya, A. and El Oualidi, J. (2007). 'Flore Pratique du Maroc, volume 2'. Trav. Inst. Sci. 38: I-XI; 636pp.

Fennane, M., Ibn Tattou, M. and El Oulaidi, J. (2014). 'Flore pratique du Maroc, volume 3'. Trav. Inst. Sci. 40: I-XI; 793pp.

Fenu, G., Cogoni, D. and Bacchetta, G. (2016). 'The role of fencing in the success of threatened plant species translocation'. Plant Ecology 217(2):207217. https://doi.org/10.1007/s11258-015-0517-1

Fenu, G., Fois, M., Cogoni, D., Porceddu, M., Pinna, M.S., Cuena Lombraña, A., Nebot, A., Sulis, E., Picciau, R., Santo, A., Murru, V., Orrù, M. and Bacchetta, G. (2015). The Aichi Biodiversity Target
12 at regional level: an achievable goal? Biodiversity 16:120-135. https://doi.org/10.1080/14888386.201 5.1062423

Ferchichi-Ben Jamaa, H., Muller, S.D., DaoudBouattour, A., Ghrabi-Gammar, Z., Rhazi, L., Soulié-Märsche, I., Ouali, M. and Ben Saad-Limam, S. (2010). 'Structures de végétation et conservation des zones humides temporaires méditerranéennes : la région des Mogods (Tunisie septentrionale)'. Comptes Rendus Biologies, 333:265-279. https:// doi.org/10.1016/j.crvi.2009.12.014

Ferrer-Gallego, P.P. (ed.) (2007). Base estructural de un Hábitat: principios para su definición y diagnosis. Valencia, España: Conselleria de Medio Ambiente, Agua, Urbanismo y Vivienda. Generalitat Valenciana.

Fois, M., Fenu, G., Lombrana, A.C., Cogoni, D. and Bacchetta, G. (2015). 'A practical method to speed up the discovery of unknown populations using Species Distribution Models'. Journal for Nature Conservation 24:42-48. https://doi.org/10.1016/j. jnc.2015.02.001

Food and Agriculture Organization of the United Nations (FAO (In press). State of Mediterranean Forests 2018. Rome, Italy: FAO.

Food and Agriculture Organization of the United Nations (FAO) (2018). The second report on the state of the world's plant genetic resources for food and agriculture. Rome, Italy: Commission on Genetic Resources for Food and Agriculture.

Food and Agriculture Organization of the United Nations (FAO) (2014). Genebank Standards for Plant Genetic Resources for Food and Agriculture. Revised edition. Rome, Italy: FAO.

Fos, S., Laguna, E., Jiménez, J. and GómezSerrano, M.A. (2018). 'Plant micro-reserves in Valencia (E. Spain): A model to preserve threatened flora in China?'. Plant Diversity 39: 383-389.

Fos, S., Laguna, E. and Jiménez, J. (2014). 'Plant micro-reserves in the Valencian Region (E of Spain): Are we achieving the expected results? Passive conservation of relevant plant species'. Flora Mediterranea 24:153-162. https://doi.org/10.1016/j. pld.2017.10.002 
Fragman, O., Plitman, U., Heller, D. and Shmida, A. (1999). Checklist and Ecological Data-base of Israel and its Surroundings. Jerusalem, Israel: Israel Nature \& National Parks.

García, N., Cuttelod, A. and Malak, D.A. (2010). The status and distribution of freshwater biodiversity in Northern Africa. Gland, Switzerland: IUCN.

Gawhari, A.M., Jury, S.L. and Culham, A. (2018). 'Towards an updated checklist of the Libyan flora'. Phytotaxa 338(1):1-16.

Gay, H. (1889). 'Florule de Blida'. Revue de botanique. Bulletin mensuel Soc. Bot. de France 8:87-155.

Ghazal, A. (2008). 'Landscape ecological, phytosociological and geobotanical study of eumediterranean in west of Syria'. PhD thesis. Stuttgart, Germany: University of Hohenheim.

Ghrabi-Gammar, Z., Muller, S.D., Rouissi, M., Ben Haj Jilani, I., Rhazi, L., De Bélair, G., Ben Saad-Limam, S. and Daoud-Bouattour, A. (2017). 'Rumex tunetanus (Polygonaceae): rediscovery of an endangered Tunisian endemic'. Phytotaxa 296(2):118-130. https://doi.org/10.11646/ phytotaxa.296.2.2

Godefroid, S., Piazza, C., Rossi, G., Buoard, S., Stevens, A.-D., Aguraiuja, R., Cowell, C., Weekley, C.W., Vogg, G. Iriondo, J.M., Johnson, I., Dixon, B., Gordon, D., Magnanon, S., Valentin, B., Bjuereke, K., Koopman, R., Vicens, M., Virevaire, M., Vanderborght, T. (2011). 'How successful are plant species reintroductions?' Biol. Conserv. 144:672682. https://doi.org/10.1016/j.biocon.2010.10.003

Gómez-Campo, C. (1981). 'Conservación de recursos genéticos'. In: J.L. Ramos (ed.), Tratado del Medio Natural, vol. II: 97-124. Madrid, Spain: Universidad Politécnica de Madrid.

Gómez-Campo, C. and Herranz, J.M. (1993). 'Conservation of Iberian endemic plants: the botanical reserve of La Encantada (Villarobledo, Albacete, Spain)'. Biological Conservation 64:155160. https://doi.org/10.1016/0006-3207(93)90652-H
Greuter, W. (1991). 'Botanical diversity, endemism, rarity and extinction in the Mediterranean area : an analysis based on the published volumes of MedChecklist'. Bot. Chron. 10:63-79.

Greuter, W., Burdet, H.M. and Long, G. (1984-2008). Med-Checklist. Volumes 1 (1984), 2 (2008), 3 (1986), 4 (1989). Geneva, Switzerland: Conservatoire et Jardin botaniques de la Ville de Genève.

Guerrant, E.O., Jr. (2012). 'Characterizing two decades of rare plant reintroductions'. In: J. Maschinski and K.E. Haskins (eds), Plant Reintroduction in a Changing Climate: Promises and Perils, pp.9-29. Washington, D.C., USA: Island Press. https://doi.org/10.5822/978-1-61091-1832_2

Guisan, A., Broennimann, O., Engler, R., Vust, M., Yoccoz, N.G., Lehmann, A. and Zimmermann, N.E. (2006). 'Using niche-based models to improve the sampling of rare species'. Conservation Biology 20:501-511. https://doi.org/10.1111/j.15231739.2006.00354.x

Güner, A., Aslan, S., Ekim, T., Vural, M. and Babaç, M.T. (eds) (2012). Türkiye Bitkileri Listesi (Damarlı Bitkiler) (List of Turkey's Plants - Vascular plants). Istanbul, Turkey: Nezahat Gökyiğit Botanic Garden and Flora Research Society Publishing.

Güner, A. and Ekim, T. (2014). Resimli Türkiye Florası. (Illustrated Flora of Turkey). Volume 1. Istanbul, Turkey: Türkiye İş Bankası Kültür Yayınları.

Güner, A., Kandemir, A., Menemen, Y., Yıldırım, H., Aslan, S., Ekşi, G., Güner, I. and Çimen, A.Ö. (eds) (2018). Resimli Türkiye Florası (Illustrated Flora of Turkey). Volume 2. Istanbul, Turkey: ANG Vakfı Nezahat Gökyiğit Botanik Bahçesi Yayınları.

Haber, R.M. and Semaan-Haber, M. (2009). Orchids of Lebanon. Beirut, Lebanon: Terre du Liban.

Hackney, E.E. and McGraw, J.B. (2001). 'Experimental demonstration of an Allee effect in American ginseng'. Conservation Biology 15:129-36. https://doi.org/10.1111/j.15231739.2001.98546.x 
Hahs, A.K., McDonnell, M.J., McCarthy, M.A., Vesk, P.A., Corlett, R.T., Norton, B.A. and Williams, N.S.G. (2009). 'A global synthesis of plant extinction rates in urban areas'. Ecology Letters 12(11):1165-1173. https://doi.org/10.1111/j.1461-0248.2009.01372.x

Hajjar, R. and Hodgkin, T. (2007). 'The use of wild relatives in crop improvement: a survey of developments over the last 20 years'. Euphytica 156:1-13. https://doi.org/10.1007/s10681-0079363-0

Harlan, J.R. (1998). Distribution of agricultural origins: a global perspective. In: A.B. Damnaia, J. Valkoun, G. Wilcox and C.O. Qualset (eds), The origins of agriculture and crop domestication, pp.1-4. Aleppo, Syria: ICARDA.

Heywood, V.H. (2017). Plant conservation in the Anthropocene - Challenges and future prospects‘. Plant Diversity 39:314-330. https://doi. org/10.1016/j.pld.2017.10.004

Heywood, V.H. (2016). 'In situ conservation of plant species - an unattainable goal?' Israel Journal of Plant Sciences 63:211-231.

Heywood, V.H. (2015). 'In situ conservation of plant species - an unattainable goal?' Israel Journal of Plant Sciences. https://doi.org/10.1080/07929978.2 015.1035605

Heywood, V.H. (2014). 'An overview of in situ conservation of plant species in the Mediterranean. Flora Mediterranea 24:5-24 https://doi.org/10.7320/ FIMedit24.005.

Heywood, V.H. (2011a). 'An outline of the impacts of climate change on endangered species in the Mediterranean region'. II Naturalista Siciliano 35:107-119.

Heywood, V.H. (2011b). 'The impacts of global change on plant life in the Mediterranean and the spread of invasive species'. In: S. Brunel, A. Uludag, E. Fernández-Galiano and G. Brundu (eds), Proceedings 2nd International Workshop on Invasive Plants in the Mediterranean Type Regions of the World 2010-08-02/06, Trabzon, Turkey, pp.48-634.
Heywood, V.H. (2002). 'The future of floristics in the Mediterranean region', Israel Journal of Plant Sciences 50 (suppl.1):5-13. https://doi.org/10.1560/ W2X3-XK8G-YCYW-54YG

Heywood, V.H. (1999). 'Is the conservation of vegetation fragments and their biodiversity worth the effort?' In: E. Maltby, M. Holdgate, M. Acreman, and A.G. Weir (eds) Ecosystem Management: Questions for science and society, pp.65-76. London, UK: Royal Holloway Institute for Environmental Research, 1998.

Heywood, V.H. (1998). 'The Mediterranean region a major centre of plant diversity'. In: V.H. Heywood (ed.), Wild food and non-food plants: information networking. Proceedings of the second Medusa regional workshop on 'Wild food and non-food plants information networking'. Cahiers Options Méditerranéennes 3:5-15.

Heywood, V.H., Shaw, K., Harvey-Brown, Y. and Smith, P. (eds) (2018). BGCI and IABG's Species Recovery Manual. Richmond, United Kingdom: Botanic Gardens Conservation International.

Heywood, V.H. and Dulloo, M.E. (2005). In situ conservation of wild plant species. A critical global review of good practices. IPGRI Technical Bulletin $\mathrm{n}^{\circ}$ 11. Rome, Italy: International Plant Genetic Resources Institute.

Heywood, V.H. and Zohary, D. (1995). A catalogue of the wild relatives of cultivated plants native to Europe. Palermo, Italy: Council of Europe and Orto Botanico di Palermo, Regione Siciliana, Assesorato Agricoltora e Foreste.

Hunter, D. and Heywood, V.H. (2011). Crop Wild Relatives: A Manual for in situ Conservation. London, UK and Washington D.C., USA: Earthscan.

Hurrell, S. (2014). 'Growing hope for plants in Lebanon'. BirdLife Middle East, News. http://www. birdlife.org/middle-east/news/growing-hope-plantslebanon.

Ibrahim, K., Hosni, H. and Peterson, P. (2016). Grasses of Egypt. Smithsonian Contribution to Botany No. 103. 201pp. https://doi.org/10.5479/ si. 19382812.103 
IPCC (2013). The Fifth Assessment Report of the United Nations Intergovernmental Panel on Climate Change. Geneva, Switzerland: IPCC. 151pp.

Iriondo, J.M., Maxted, N., Kell, S.P., Ford-Lloyd, B.V., Lara-Romero, C., Labokas, J. and Magos Brehm, J. (2012). 'Quality standards for genetic reserve conservation of crop wild relatives'. In: $\mathrm{N}$. Maxted, M.E. Dulloo, B.V. Ford-Lloyd, L. Frese, J.M. Iriondo and M.A.A. Pinheiro de Carvalho (eds) Agrobiodiversity Conservation: Securing the Diversity of Crop Wild Relatives and Landraces, pp.72-77. Wallingford, UK: CAB International. https://doi.org/10.1079/9781845938512.0072

Iriondo, J.M., Maxted, N. and Dulloo, M.E. (eds) (2008). Conserving Plant Diversity in Protected Areas. Wallingford, UK: CAB International.

International Seed Testing Association (ISTA) (2017). International Rules for Seed Testing. Bassersdorf, Switzerland: International Seed Testing Association.

Issaoui, A., Kallala, A., Neffati, M. and Akrimi, N. (1996). Plantes naturelles du Sud tunisien. Tunis, Tunisia : La Page infographique.

International Union for Conservation of Nature (IUCN) (2016). A Global Standard for the Identification of Key Biodiversity Areas, Version 1.0. Gland, Switzerland: IUCN. https://portals.iucn.org/ library/node/46259

International Union for Conservation of Nature (IUCN) (2013). Guidelines for Reintroductions and Other Conservation Translocations, Version 1.0. Gland, Switzerland: IUCN Species Survival Commission. https://portals.iucn.org/library/ node/10386

International Union for Conservation of Nature / Species Survival Commission (IUCN/SSC) (2012a). Guidelines for Application of IUCN Red List Criteria at Regional and National Levels, Version 4.0. Gland, Switzerland and Cambridge, UK: IUCN. ii + 41pp. https://portals.iucn.org/library/node/10336

International Union for Conservation of Nature / Species Survival Commission (IUCN/SSC) (2012b). IUCN Red List Categories and Criteria, Version 3.1. Second edition. Gland, Switzerland and Cambridge,
UK: IUCN. Iv + 32pp. https://portals.iucn.org/library/ node/10315

Julien, A. (1894). Flore de la région de Constantine. Constantine, Algeria: Louis Marle. 332pp.

Jury, S.L., Rutherford, R.W., Rejdali, M., Rankou, $\mathrm{H}$. and El Atechi, T. (2008). The vascular flora of Oukaïmeden, in the Moroccan High Atlas. http://bibdigital.rjb.csic.es/PDF/Jury_Vasc_Fl Oukaimeden_Ed2_2008.pdf. Accessed on 8 August 2018.

Kadis, C., Thanos, C. and Laguna, E. (eds) (2013). Plant micro-reserves: From theory to practice. Experiences gained from EU LIFE and other related projects. Athens, Greece: Utopia Publishing. 194pp.

Kadis, C., Pantazi, C., Tsintides, C.T., Christodoulou, C., Thanos, C.A, Georghiou, K., Kounnamas, C., Constantinou, C., Andreou, M. and Eliades, N.G. (2010). 'Establishment of a Plant Micro-reserve Network in Cyprus for the Conservation of Priority Species and Habitats'. In: D. Sanchez Bengoa and D. Powell (eds), Conference Proceedings, 1st International Bi-communal Conference held in Cyprus on Biodiversity: 'TOP Biodiversity', Threats, Opportunities and Paces for Biodiversity, Larnaca, Cyprus, June 3-4, 2010, pp.113-120. Larnaca, Cyprus: Intercollege-Larnaca.

Kargiolaki, H., Thanos, C.A., Fournaraki, C., Maria, E.A. and Karpathaki, H. (2007). 'Plant MicroReserves (A Pilot Project Implemented In Western Crete) and Samaria Biosphere Reserve'. In: Priorities for Conservation of Biodiversity in Biosphere Reserves in Changing Conditions, Proceedings from the International Conference, MAB UNESCO, 2-6 June 2007, Stará Lesná, Slovakia, pp.17-23. Bratislava, Slovakia: Institute of Landscape Ecology, Slovak National Committee for UNESCO MAB Programme, Slovak Academy of Sciences.

Karzon, S. (2010). Report on Natural Resource Conservation and Management project in NE Syria (Jabal Abdel Aziz - Hassakeh). Damascus, Syria: Ministry of State for Environmental Affairs. 
Kassas, M. (ed). (2002). Management Plan for Omayed Protected Area. Cairo, Egypt: MedWetCoast, Global Environment Facility and Egyptian Environmental Affairs Agency. 130pp.

Keenleyside, K.A., Dudley, N., Cairns, S., Hall, C.M. and Stolton, S. (2012). Ecological Restoration for Protected Areas: Principles, Guidelines and Best Practices. Gland, Switzerland: IUCN. x + 120pp. https://portals.iucn.org/library/node/10205

Kell, S.P., Knüpffer, H., Jury, S.L., Ford-Lloyd, B.V. and Maxted, N. (2008a). 'Crops and wild relatives of the Euro-Mediterranean region: making and using a conservation catalogue'. In: N. Maxted, B.V. FordLloyd, S.P. Kell, J. Iriondo, E. Dulloo and J. Turok (eds), Crop Wild Relative Conservation and Use, pp.69-109. Wallingford, UK: CABI.

Kell, S.P., Laguna, E., Iriondo, J.M. and Dulloo, M.E. (2008b). 'Population and habitat recovery techniques for the in situ conservation of plant genetic diversity'. In: Iriondo, J.M., Maxted, N. and Dulloo, M.E. (eds): Conserving Plant Genetic Diversity in Protected Areas. Population management of Crop Wild Relatives, pp.124-168. Wallingford, UK: CABI. https://doi. org/10.1079/9781845932824.0124

Khalil, M.T. and Shaltout, K.H. (2006). Lake Bardawil: Zaranik Protected Area. Publication of National Biodiversity Unit No. 15. Cairo, Egypt: Egyptian Environmental Affairs Agency (EEAA). 599pp.

Kilani, H., Serhal, A. and Llewellyn, O. (2007). AlHima: A way of life. Amman, Jordan: IUCN West Asia Regional Office, and Beirut, Lebanon: SPNL.

Laguna, E. (2007). 'The network of plant microreseves, consolidated experience from the Valencian Community (Spain)'. Ensconews 2:12-13.

Laguna, E. (2004). 'The plant micro-reserve initiative in the Valencian Community (Spain) and its use to conserve populations of crop wild relatives'. Crop Wild Relative, 2:10-13.

Laguna, E. (2001). The micro-reserves as a tool for conservation of threatened plants in Europe. Nature and Environment series $n^{\circ} 121$. Strasbourg, France: Council of Europe.
Laguna, E. (1999). 'The plant micro-reserves programme in the region of Valencia, Spain'. In: $\mathrm{H}$. Synge and J. Akeroyd (eds), Proceedings Planta Europa 1998, Second European Conference on the Conservation of Wild Plants, pp.181-185. Uppsala, Sweden: The Swedish Threatened Species Unit, and London, UK: Plantlife.

Laguna, E. (1995). 'Microrreservas de flora: un nuevo modelo de conservación en la Comunidad Valenciana. Quercus 118:22-26.

Laguna, E., Fos, S., Jiménez, J. and Volis, S. (2016). 'Role of micro-reserves in conservation of endemic, rare and endangered plants of the Valencian region (Eastern Spain)'. Israel Journal of Plant Sciences 63:320-332. https://doi.org/10.1080/07929978.201 6.1256131

Laguna, E., Deltoro, V.I., Pérez-Botella, J., PérezRovira, P., Serra, L., Olivares, A. and Fabregat, C. (2004). 'The role of small reserves in plant conservation in a region of high diversity in Eastern Spain'. Biological Conservation 119:421-426. https://doi.org/10.1016/j.biocon.2004.01.001

Laguna, E., Deltoro, V., Fos, S., Pérez-Rovira, P., Ballester, G., Olivares, A., Serra, L. and Pérez Botella, J. (2003). Priority habitats in the Valencian Community (Spain): their faunistic and botanical values [CD-ROM]. Valencia, Spain: Conselleria de Territori i Habitatge, Generalitat Valenciana. 223pp.

Lansdown, R.V., Houri, A., Kavak, S., MachakaHouri, N. and Smith, K.G. (2014). 'Freshwater plants'. In: K.G. Smith, V. Barrios, W.R.T. Darwall and C. Numa (eds) The status and distribution of freshwater biodiversity in the Eastern Mediterranean pp. 70-88. Cambridge, UK, Malaga, Spain and Gland, Switzerland: IUCN. https://portals.iucn.org/ library/node/44937

Le Floc'h, E., Boulos, L. and Véla, E. (2010). Catalogue synonymique commenté de la Flore de Tunisie. Édition 2. Tunis, Tunisie : Ministère de l'Environnement et du Développement durable. 500pp.

Leredde, C. (1957). Etude écologique et phytosociologique du Tassili n'Ajjer. Alger, Algérie: Inst. Rech. Sah. 455pp. 
Li, D.Z. and Pritchard, H.W. (2009). 'The science and economics of ex situ plant conservation'. Trends in Plant Science 14:614-621. https://doi.org/10.1016/j. tplants.2009.09.005

Liu, H., Ren, H., Liu, Q., Wen, X., Maunder, M. and Gao, J. (2015). 'Translocation of threatened plants as a conservation measure in China'. Conservation Biology 29(6):1537-1551. https://doi.org/10.1111/ cobi.12585

Maginnis, S., Laestadius, L., Verdone, M., DeWitt, S., Saint-Laurent, C., Rietbergen-McCracken, J., Shaw, D.M.P. (2014). A guide to the Restoration Opportunities Assessment Methodology (ROAM): Assessing forest landscape restoration opportunities at the national or sub-national level. Working Paper (Road-test edition). Gland, Switzerland: IUCN. https://portals.iucn.org/library/node/44852

Magos Brehm J, Saifan S, Taifour H, Abu Laila K, Al-Assaf A, Al-Oqlah A, Al-Sheyab F, Bani-Hani R, Ghazanfar S, Haddad N, Shibli R, Abu Taleb T, bint Ali B and Maxted N (2016) Crop wild relatives, a priority in Jordan? - Developing a national strategy for the conservation of plant diversity in Jordan using a participatory approach. In: Maxted N, Dulloo ME and Ford-Lloyd BV (eds) Enhancing Crop Genepool Use: Capturing Wild Relative and Landrace Diversity for Crop Improvement. CAB International, Wallingford, UK. pp. 172-188

Maire, R. (1952-1987). Flore de l'Afrique du Nord. Vol. I à Vol. XVI. Paris, France : Editions Lechevallier.

Maire, R. and Wilczek, E. (1936). 'Florule des lles Habibas'. Bull. Soc. Hist. Nat. Afr. Nord 26:64-72.

Makhoul, E. (2012). Les Astragales: A la Découverte de la Flore Libanaise. Presses de l'Université SaintJoseph. $144 \mathrm{pp}$.

Martin, R., Véla, E. and Ouni, R. (2015). 'Orchidées de Tunisie'. Bulletin de la Société Botanique du Centre-Ouest (France) Numéro spécial 44 : 0-163.

Marzo, A., Herreros, R. and Zreik, C. (eds) (2015). Guide of Good Restoration Practices for Mediterranean Habitats. Ecoplantmed, ENPI, CBCMED.
Maschinski, J., Falk, D.A., Wright, S.J., Possley, J., Roncal, J. and Wendelberger, K.S. (2012). 'Optimal locations for plant reintroductions in a changing world'. In: J. Maschinski and K.E. Haskins (eds), Plant reintroduction in a changing climate: Promises and perils, pp.109-130. Washington, D.C., USA: Island Press. https://doi.org/10.5822/978-1-61091183-2_7

Maxted, N., Avagyan, A., Frese, L., Iriondo, J.M., Magos Brehm, J., Singer, A. and Kell, S.P. (2015). ECPGR Concept for in situ conservation of crop wild relatives in Europe. Rome, Italy: Wild Species Conservation in Genetic Reserves Working Group, European Cooperative Programme for Plant Genetic Resources.

Maxted, N., Castañeda Álvarez, N.P., Vincent, H.A. and Magos Brehm, J. (2012). 'Gap analysis: a tool for genetic conservation'. In: L. Guarino, V. Ramanatha Rao and E. Goldberg (eds), Collecting Plant Genetic Diversity: Technical Guidelines. 2011 update. Rome, Italy: Bioversity International.

Maxted, N., Kell, S.P. and Magos Brehm, J. (2011). Options to Promote Food Security: On-Farm Management and In situ Conservation of Plant Resources for Food and Agriculture. FAO CGRFA Background Study Paper no. 51. Rome, Italy: FAO.

Maxted, N. and Kell, S. (2009). Establishment of a Network for the In situ Conservation of Crop Wild Relatives: Status and Needs. Rome, Italy: Commission on Genetic Resources for Food and Agriculture, FAO.

Maxted, N., Ford-Lloyd, B.V., Jury, S., Kell, S.P. and Scholten, M.A. (2006). 'Towards a definition of a crop wild relative'. Biodiversity and Conservation, 15(8):2673-2685. https://doi.org/10.1007/s10531005-5409-6

Maxted, N., van Slageren, M.W. and Rihan, J.R. (1995). 'Ecogeographic surveys'. In: L. Guarino, V. Ramanatha Rao and R. Reid (eds), Collecting Plant Genetic Diversity, Technical Guidelines, pp.255-285. Wallingford, UK: CABI.

Médail, F., Pasta, S. and Chaieb, M. (2015). Flore et végétation des îles et îlots satellites de l'archipel des Kerkennah (Tunisie orientale). Bilan de la biodiversité 
végétale terrestre, impacts environnementaux et recommandations de gestion. Note naturaliste PIM. Aix-en-Provence, France : Initiative PIM. 66pp.

Médail, F. and Quézel, P. (1999). 'Biodiversity hotspots in the Mediterranean basin: setting global conservation priorities'. Conservation Biology 13:1510-13. https://doi.org/10.1046/j.15231739.1999.98467.x

Médail, F. and Quézel, P. (1997). 'Hot-spots analysis for conservation diversity in the Mediterranean Basin'. Annals of the Missouri Botanical Garden 84:112-127. https://doi.org/10.2307/2399957

Ministère des Affaires Locales et de I'Environnement (MALE) (2016). Rapport sur le suivi des recommandations relatives aux examens périodiques adoptés par le Conseil International de Coordination du Programme MAB. Tunis, Tunisie : Direction Générale de l'Environnement et de la Qualité de la Vie.

Ministry of State for Environmental Affairs, Biodiversity Unit (2001). Biodiversity atlas of Syria - National Country Study of Biological Diversity in Syrian Arab Republic. Damascus, Syria: Ministry of State for Environmental Affairs, Biodiversity Unit.

Mittermeier, R.A., Robles Gil, P., Hoffman, M., Pilgrim, J., Brooks, T., Mittermeier, C.G., Lamoreux, J. and da Fonseca, G.A.B. (2005). Hotspots Revisited: Earth's Biologically Richest and Most Endangered Terrestrial Ecoregions. Chicago, USA: University of Chicago Press.

Mittermeier, R.A., Robles Gil, P., Hoffman, M., Pilgrim, J., Brooks, T., Mittermeier, C.G., Lamoreux, J. and da Fonseca, G.A.B. (2004). Hotspots Revisited. Mexico City, Mexico: CEMEX.

Mouterde, P. (1966-1983). Nouvelle flore du Liban et de la Syrie. 3 Tomes + Atlas. Beirut, Lebanon: Dar EI Mashreq.

Muñoz-Rodríguez, P., Draper Munt, D. and Moreno Saiz, J.C. (2016). 'Global strategy for plant conservation: inadequate in situ conservation of threatened flora in Spain'. Israel Journal of Plant Sciences 63:297-308.
Nunes, A., Oliveira, G., Mexia, T., Valdecantos, A., Zucca, C., Costantin, E.A.C., Abraham, E.M., Kyriazopoulos, A.P., Salah, A., Prasse, R., Correia, O., Milliken, S., Kotzen, B. and Branquinho, C. (2016). 'Ecological restoration across the Mediterranean Basin as viewed by practitioners'. Science of the Total Environment 566-567:722-732. https://doi.org/10.1016/j.scitotenv.2016.05.136

Omar, K.A. (2017). Ex situ conservation activities in St. Catherine IPA, Egypt 2017.

Omar, K.A. (2014). 'Evaluating the effectiveness of in-situ conservation on some endemic plant species in south Sinai, Egypt'. American Journal of Life Sciences, 2:164-175. https://doi.org/10.11648/j. ajls.20140203.16

Omar, K.A., Khafagi, O. and Elkholy, M.A. (2013). Geomatics and plant conservation: GIS for best conservation planning. Lambert Academic Publishing.

Ozenda, P. (1991). Flore et végétation du Sahara. 3ème édition. Paris, France : CNRS. 662pp.

Pampanini, R. (1930). Prodromo della flora Cirenaica. Forlì, Italy: Ministerio delle Colonie.

Piazza, C., Hugot, L., Richard, F. and Schatz, B. (2011). 'In situ conservation operations in Corsica, 1987-2004: assessing the balance and drawing'. Ecologia Mediterranea 37:7-16.

Post, G.E. (1932-1933). Flora of Syria, Palestine and Sinai. Beirut, Lebanon: Faculty of Arts and Sciences, American University of Beirut.

Pottier-Alapetite, G. (1979). Flore de la Tunisie : Angiospermes Dicotyledones, Tome I : Apétales -Dialypétales. Tunis, Tunisie : Ministère de l'Enseignement Supérieur et de la Recherche Scientifique et le Ministère de l'Agriculture. 654pp.

Pottier-Alapetite, G. (1981). Flore de la Tunisie : Angiospermes Dicotyledones. Tome II: Gamopétales. Tunis, Tunisie : Ministère de I'Enseignement Supérieur et de la Recherche Scientifique et le Ministère de l'Agriculture. 535pp. 
Quézel, P. (1991). 'Structures de végétation et flore en Afrique du Nord: leurs incidences sur les problèmes de conservation'. In: M. Rejdali and V.H. Heywood (eds), Conservation des Ressources Végétales, pp.19-33. Rabat, Marocco: Actes Editions.

Quézel, P. (1954). Contribution à l'étude de la flore et de la végétation du Hoggar. Travaux Inst. Rech. Sahara. Alger, Algérie : Imp. Imbert. 164pp.

Quézel, P. and Médail, F. (1995). 'La région circum-méditerranéenne, centre mondial majeur de biodiversité végétale'. In : Actes des 6èmes Rencontres de l'Agence Régionale pour l'Environnement Provence-Alpes-Côte d'Azur. - Colloque Scientifique International "Bio'Mes», pp.152-160. Gap, France: Agence Régionale pour l'Environnement Provence-Alpes-Côte d'Azur.

Quézel, P. and Barbero, M. (1990). 'Les forêts méditerranéennes. Problèmes posés par leur signification historique, écologique et leur conservation'. Acta Bot. Malacitana 15:145-178.

Quézel, P. and Bounaga, D. (1975). 'Aperçu sur la connaissance actuelle de la flore d'Algérie et de Tunisie'. In : Centre National de la Recherche Scientifique, La flore du bassin méditerranéen, pp.125-130. Paris, France: CNRS.

Quézel, P. and Santa, S. (1962-1963). Nouvelle Flore de l'Algérie et des régions désertiques méridionales. 2 tomes. Paris, France: CNRS. 1170pp.

Radford, E.A., Catullo, G. and Montmollin, B. de. (eds). (2011). Important Plant Areas of the south and east Mediterranean region : priority sites for conservation. Gland, Switzerland and Malaga, Spain: IUCN. viii + 108pp.

Rankou, H., Culham, A., Jury, S.L. and Christenhusz, M.J.M. (2013). 'The endemic flora of Morocco'. Phytotaxa 78:1-69.

Rankou, H., Culham, A., Taleb, M.S., Ouhammou, A., Martin, G. and Jury, S.L. (2015). 'Conservation assessments and Red Listing of the endemic Moroccan flora (monocotyledons)'. Botanical Journal of the Linnean Society 177:504-575.
Raeymaekers, G. (2000). 'Plant conservation. In the beginning of a new era?' Natura 2000 12:8-10.

Ryder, O.A. (1986). 'Species conservation and systematics: the dilemma of subspecies'. Trends in Ecology and Evolution 1:9-10.

Society for Ecological Restoration (SER) (2004). The SER International Primer on Ecological Restoration. Tucson, USA: Society for Ecological Restoration International, Science and Policy Working Group.

Serra, L., Pérez-Rovira, P., Deltoro, V.I., Fabregat, C., Laguna, E. and Pérez-Botella, J. (2004). 'Distribution, status and conservation of rare relict plant species in the Valencian Community'. Bocconea 16:857-863.

Rossi, G. and Bonomi, C. (2007). 'A review of plant reintroduction practice', paper delivered at the 5th European Conference on the Conservation of wild plants in Europe 'Working together for plants', Cluj-Napoca. www.societabotanicaitaliana.it/ uploaded/370.pdf. [Accessed June 2009].

Rouissi, M., Muller, S.D., Ben Haj Jilani, I., GhrabiGammar, Z., Rhazi, L., Paradis, L., Bottollier-Curtet, M., Gerbaud, E. and Daoud-Bouattour, A. (2016). 'Conservation issues of an exceptional freshwater Mediterranean wetland in northwest Tunisia:

Garâa Sejenane'. Revue d'Ecologie (Terre et Vie), 71(3):222-238.

Santa, S. (1949). 'Catalogue des plantes de l'Algérie occidentale et du Maroc oriental'. Bulletin de la Société de géographie et d'archéologie d'Oran 72(226).

Sattout, E. (2014). 'Rangeland management in Lebanon: Cases from Northern Lebanon and Bekaa'. In: P. Herrera, J. Davies and P. Manzano Baena (eds), The Governance of Rangelands: Collective Action for Sustainable Pastoralism, pp. 145-155. Abingdon, UK: Routledge.

Sattout, E., Sulayem, M.S.A. and Spalding, M. (2008). 'North Africa and the Middle East'. In: S. Chape, M. Spalding and M. Jenkins (eds), The World's Protected Areas: Status, values, and prospects in the twenty-first century, pp.258-267. 
Berkeley, USA: University of California Press and UNEP World Conservation Monitoring Centre.

Shaltout, S.K.H. (2014). 'Ecological Study of the Alien Species in the Egyptian Flora'. M.Sc dissertation. Tanta, Egypt: Faculty of Science, Tanta University. $191 \mathrm{pp}$.

Sattout, E. (2017). 'UNESCO Biosphere Reserves and Global Geoparks: hubs for seed preservation in arid ecosystems', paper presented at the International Symposium on Native Seeds in Restoration of Dryland Ecosystems. Kuwait Institute for Scientific Research (KISR) and International Network for Seed-based Restoration (INSR). Kuwait city, November 20-23, 2017.

Shaltout, K.H. and Eid, E.M. (2017). National Progress Towards Targets of the Global Strategy for Plant Conservation. Saarbrücken, Germany: Lambert Academic Publishing.

Shaltout, K.H. and Khalil, M.T. (2005). Lake Burullus: Burullus Protected Area. Publication of National Biodiversity Unit No. 13. Cairo, Egypt: Egyptian Environmental Affairs Agency (EEAA). 578pp.

Shaltout, K.H., Sharaf El-Din, A. and Ahmed, D.A. (2010). Plant life in the Nile Delta. Tanta, Egypt: Tanta University Press.

Silva, J., Toland, J., Jones, W., Elridge, J., Hudson, T., Thorpe, E. and O'Hara, E. (2009). Protecting Europe's Nature: Learning from LIFE Nature conservation best practices. Brussels, Belgium: European Commission.

Silva, J., Toland, J., Jones, W., Elridge, J., Thorpe, E., Campbell, M. and O'Hara, E. (2008). LIFE and endangered plants. Conserving Europe's threatened flora. Brussels, Belgium: European Commission.

Talhouk, S.N., Abunnasr, Y., Hall, M., Miller, T. and Seif, A. (2014). 'Ancillary botanic gardens in Lebanon - Empowering local contributions to plant conservation'. Sibbaldia: The Journal of Botanic Garden Horticulture 12:111-129.

Tanksley, S.D. and McCouch, S.R. (1997). 'Seed banks and molecular maps: unlocking genetic potential from the wild'. Science

\section{7(5329):1063-1066. https://doi.org/10.1126/} science.277.5329.1063

Tawk, L. (2014). 'Defining environmental and cultural landmarks in Lebanese villages through an integrated public participation GIS method'. MSc dissertation. Beirut, Lebanon: American University of Beirut.

Thanos, C.A., Fournaraki, C., Georghiou, K., Dimopoulos, P. and Bergmeier, E. (2007). 'The establishment, monitoring and management of a pilot network of micro-reserves in Western Crete for the conservation of European threatened plants (CRETAPLANT Project, EU-LIFE)'. In: D. Rockich, G. Moss, C. Yates, K. Dixon and J. Stevens (eds) Proceedings, MEDECOS XI Conference, Perth, Australia, pp.249-250. Perth, Australia: Botanic Gardens and Parks Authority, Kings Park and Botanic Garden.

Thanos, C.A., Fournaraki, C. and Gotsiou, P. (2006). Plant micro-reserves. Knowledge, protection, preservation. Endangered, rare and endemic plants in Crete. Chania, Greece: NKUA, MAICh and the Forest Directorate of Chania.

Thiébault, S. and Moatti, J.-P. (eds) (2016). 'The Mediterranean region under climate change : a scientific update'. Marseille, France: IRD ; AllEnvi, 736 p. (Synthèses). COP. Convention des Parties de la convention Cadre des Nations Unies sur le Changement climatique, 22., Marrakech (MAR), 2016/11/7-18.

Tohmé, G. and Tohmé, H. (2014). Illustrated flora of Lebanon. 2nd edition. Beirut, Lebanon: Lebanese National Council for Scientific Research.

United Nations Educational, Scientific and Cultural Organization, Man and Biosphere Programme (UNESCO-MAB) (2013). Formulaire de l'examen périodique de la réserve de biosphère intercontinentale de la Méditerranée 2006-2016. Rabat, Morocco: Ministère de l'Agriculture, de la Pêche Maritime, du Développement Rural et des Eaux et Forêts et Haut Commissariat aux Eaux et Forêts et à la Lutte Contre la Désertification. 
Valdés, B., Rejdali, M., Achhal El Kadmiri, A., Jury, S.L. and Montserrat, J.M. (2002). Catalogue des plantes vasculaires du nord du Maroc incluant des clés d'identification. Volumes 1 and 2. Madrid, Spain: Consejo Superior de Investigaciones Científicas.

Van Andel, J. and Aronson, J. (eds) (2012). Restoration Ecology: The New Frontier. 2nd Edition. Oxford, UK: Blackwell Publishing. https://doi. org/10.1002/9781118223130

Vavilov, N. (1926). 'The centers of origin of cultivated plants'. Applied Botany and Plant Breeding 16(2):248.

Véla, E., Benhouhou, S., Yahi, N. and Gil, T. (2016). 'Inventorying and delimitation of Algerian IPAs, ongoing research'. Paper presented at the 1st Mediterranean Plant Conservation Week, IUCNPlantLife, Ulcinj, Montenegro, 24-29 October 2016.

Véla, E. and Viglione, J. (2015). 'Recent inputs to the Lebanese Orchid flora and a proposal of a national checklist for Orchidaceae family'. Acta Botanica Gallica - Botany Letters 162(4):271-285. https://doi. org/10.1080/12538078.2015.1105148

Vincent, H., Wiersema, J., Dobbie, S., Kell, S.P., Fielder, H., Castãneda Alvarez, N.P., Guarino, L., Eastwood, R., Le冈n, B. and Maxted, N. (2013). 'A prioritised crop wild relative inventory as a first step to help underpin global food security'. Biol Conserv 167:265-275.

Vogiatzakis, I.N., Griffiths, G.H., Melis, M.T, Marini, A. and Careddu, M.D. (2006). 'Landscape typology in the Mediterranean context: A tool for habitat restoration'. Journal of Mediterranean Ecology 7:23-30.

Volis, S. (2016). 'Species-targeted plant conservation: time for conceptual integration'. Israel Journal of Plant Sciences 63:232-249.

World Database on Protected Areas (WDPA). https://www.iucn.org/theme/protected-areas/ourwork/quality-and-effectiveness/world-databaseprotected-areas-wdpa.
Yahi, N., Benhouhou, S., Rebbas, K., Véla, E. and Beghami, Y. (2016). Flore endémique : inventaire et perspectives de conservation. ZIP Gouraya et Chélia-Aurès. Rapport final IPAMed projet. 22pp.

Yahi, N., Véla, E., Benhouhou, S., Belair, G. de and Gharzouli, R. (2012). 'Identifying Important Plants Areas (Key Biodiversity Areas for Plants) in northern Algeria'. Journal of Threatened Taxa 4(8):2753-2765. https://doi.org/10.11609/JoTT.02998.2753-65

Zohary, M. (1966-1972). Flora Palaestina. Volumes 1-2. Jerusalem, Israel: The Israel Academy of Sciences and Humanities.

Zohary, D., Hopf, M. and Weiss, E. (2012). Domestication of plants in the Old World: the origin and spread of cultivated plants in west Asia, Europe and the Mediterranean Basin. Oxford, UK: Oxford University Press. https://doi.org/10.1093/acprof:oso bl/9780199549061.001.0001 


\section{Annex 2: KBA criteria and thresholds}

Summary of KBA criteria and thresholds extracted from Global Standards for the Identification of Key Biodiversity Areas Version 1.0 (IUCN, 2016)

\begin{tabular}{|c|c|c|c|}
\hline A. Threatened Biodiversity & Biodiversity element at site & $\begin{array}{l}\% \text { global pop. } \\
\text { size/extent }\end{array}$ & $\mathbf{R U}^{1}$ \\
\hline \multirow[t]{5}{*}{ A1. Threatened species } & (a) CR or EN species & $\geq 0.5 \%$ & $\geq 5$ \\
\hline & (b) VU species & $\geq 1 \%$ & $\geq 10$ \\
\hline & $\begin{array}{l}\text { (c) CR or EN species Threatened only due to population } \\
\text { size reduction in the past or present }\end{array}$ & $\geq 0.1 \%$ & $\geq 5$ \\
\hline & $\begin{array}{l}\text { (d) } V U \text { species Threatened only due to population size } \\
\text { reduction in the past or present }\end{array}$ & $\geq 0.2 \%$ & $\geq 10$ \\
\hline & (e) CR or EN species & $\begin{array}{l}\text { Entire global } \\
\text { population size }\end{array}$ & $2.5 \%$ \\
\hline \multirow[t]{2}{*}{ A2: Threatened ecosystem types } & (a) CR or EN ecosystem type & $\geq 5 \%$ & \\
\hline & (b) VU ecosystem type & $\geq 10 \%$ & \\
\hline $\begin{array}{l}\text { B. Geographically restricted } \\
\text { biodiversity }\end{array}$ & Biodiversity element at site & $\begin{array}{l}\% \text { global pop. } \\
\text { size/extent }\end{array}$ & RU \\
\hline $\begin{array}{l}\text { B1: Individual geographically } \\
\text { restricted species }\end{array}$ & Any species & $\geq 10 \%$ & $\geq 10$ \\
\hline $\begin{array}{l}\text { B2: Co-occurring geographically } \\
\text { restricted species }\end{array}$ & $\begin{array}{l}\text { Restricted-range species: } \geq 2 \text { species OR } 0.02 \% \text { of total } \\
\text { number of species in taxonomic group, whichever is larger }\end{array}$ & $\geq 1 \%$ & \\
\hline \multirow[t]{2}{*}{$\begin{array}{l}\text { B3: Geographically restricted } \\
\text { assemblages }\end{array}$} & $\begin{array}{l}\text { (a) } \geq 5 \text { ecoregion-restricted species }{ }^{2} \text { OR } 10 \% \text { of the species } \\
\text { restricted to the ecoregion, whichever is larger }\end{array}$ & $\geq 0.5 \%$ & \\
\hline & $\begin{array}{l}\text { (b) } \geq 5 \text { bioregion-restricted species }{ }^{2} \text { OR } 30 \% \text { of the } \\
\text { bioregion-restricted species known from the country, }\end{array}$ & & $\geq 5$ \\
\hline
\end{tabular}
bioregion-restricted species known from the country, whichever is larger

(c) Part of the globally most important $5 \%$ of occupied habitat of each of $\geq 5$ species within a taxonomic group

B4: Geographically restricted ecosystem types

\begin{tabular}{ll}
\hline C. Ecological integrity & Biodiversity element at site \\
\hline Wholly intact ecological communities
\end{tabular}

D. Biological processes

\section{D1: Demographic aggregations}

\section{Biodiversity element at site}

(a) Species aggregation during one or more key stages of its life cycle

(b) Among the largest 10 aggregations known for the species

\begin{tabular}{|c|c|c|c|}
\hline D2: Ecological refugia & $\begin{array}{l}\text { Species aggregations during periods of past, current or } \\
\text { future environmental stress }\end{array}$ & $\geq 10 \%$ & \\
\hline D3: Recruitment sources & $\begin{array}{l}\text { Propagules, larvae or juveniles maintaining high proportion } \\
\text { of global population size }\end{array}$ & $\geq 10 \%{ }^{3}$ & \\
\hline \multirow[t]{2}{*}{$\begin{array}{l}\text { E. Irreplaceability through } \\
\text { quantitative analysis }\end{array}$} & Biodiversity element at site & Irrepl. score & RU \\
\hline & $\begin{array}{l}\text { Site has high irreplaceability measured by quantitative } \\
\text { spatial analysis }\end{array}$ & $\begin{array}{l}\geq 0.90 \text { on } \\
0-1 \text { scale }\end{array}$ & $\begin{array}{r}\geq 10 \text { (or } \\
\geq 5 \text { for } \\
\text { EN/CR } \\
\mathrm{sp} \text { ) }\end{array}$ \\
\hline
\end{tabular}

\footnotetext{
${ }^{(1)} \mathrm{RU}=$ reproductive units; ${ }^{(2)}$ within a taxonomic group; ${ }^{(3)}$ refers to global population size rather than immature individuals produced.
} 


\section{IUCN}

INTERNATIONAL UNION FOR CONSERVATION OF NATURE

IUCN Centre for Mediterranean

Cooperation

Calle Marie Curie, 22

29590 Campanillas

Malaga, Spain

Tel. : +34 952028430

Fax: +34 952028145

Email: uicnmed@iucn.org

www.iucn.org/resources/publications

www.iucn.org/mediterranean

Core support for the IUCN Centre for Mediterranean Cooperation is provided by:

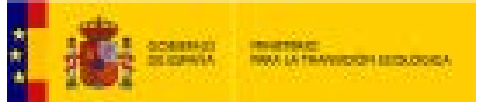

